\title{
Research, Monitoring, and Evaluation for the Federal Columbia River Estuary Program
}

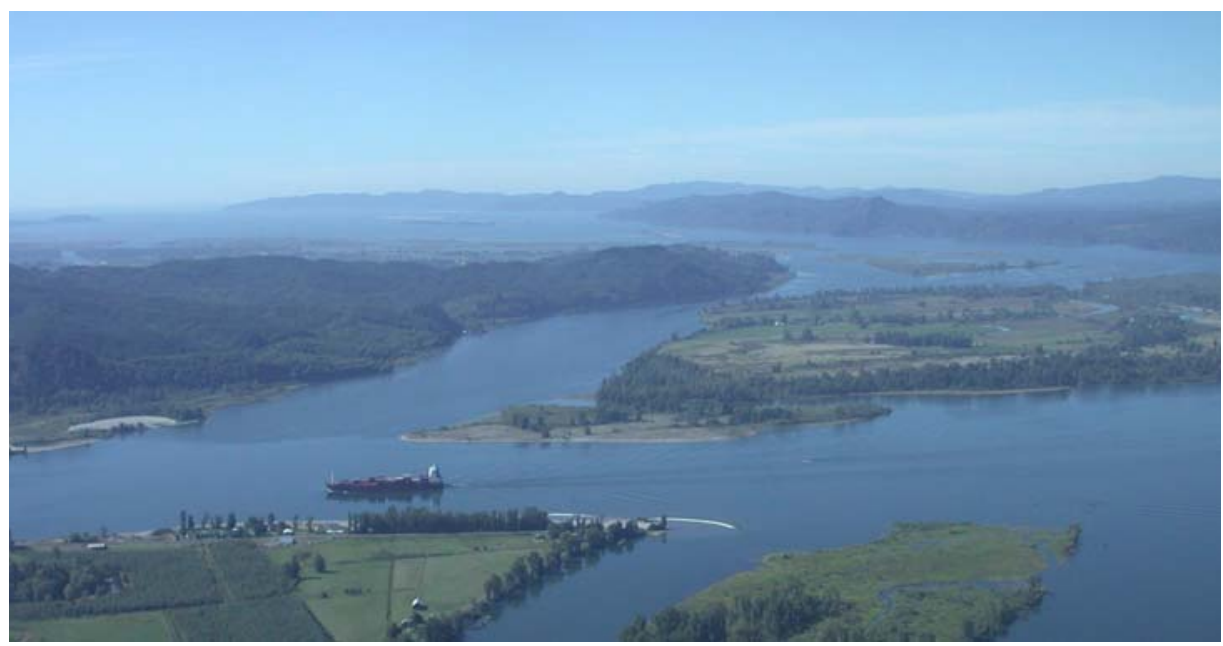

January 31, 2008

Prepared for the Bonneville Power Administration by the Pacific Northwest National Laboratory under a Related Services Agreement with the U.S. Department of Energy Contract DE-AC05-76RL01830 in conjunction with NOAA Fisheries and the U.S. Army Corps of Engineers, Portland District with the collaboration of the Lower Columbia River Estuary Partnership
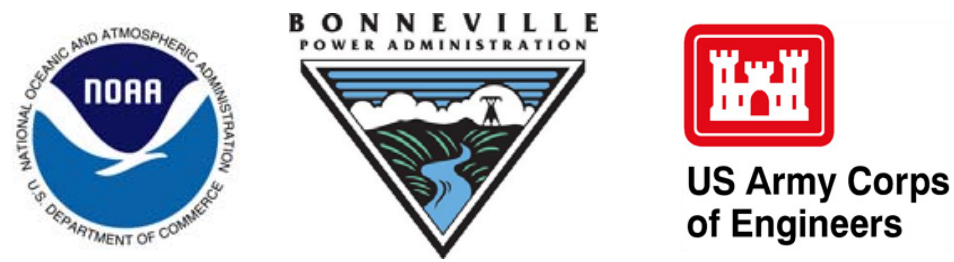
of Engineers 


\section{DISCLAIMER}

This report was prepared as an account of work sponsored by an agency of the United States Government. Neither the United States Government nor any agency thereof, nor Battelle Memorial Institute, nor any of their employees, makes any warranty, express or implied, or assumes any legal liability or responsibility for the accuracy, completeness, or usefulness of any information, apparatus, product, or process disclosed, or represents that its use would not infringe privately owned rights. Reference herein to any specific commercial product, process, or service by trade name, trademark, manufacturer, or otherwise does not necessarily constitute or imply its endorsement, recommendation, or favoring by the United States Government or any agency thereof, or Battelle Memorial Institute. The views and opinions of authors expressed herein do not necessarily state or reflect those of the United States Government or any agency thereof.

PACIFIC NORTHWEST NATIONAL LABORATORY

operated by BATTELLE for the

UNITED STATES DEPARTMENT OF ENERGY

under Contract DE-AC06-76RL01830

Cover Photo: View of the Columbia River estuary looking downstream with Tenasillahe Island on the right. 
PNNL-17300

\title{
Research, Monitoring, and Evaluation for the Federal Columbia River Estuary Program
}

\author{
Gary E. Johnson ${ }^{1}$ \\ Heida L. Diefenderfer ${ }^{1}$ \\ Blaine D. Ebberts ${ }^{2}$ \\ Cathy Tortorici ${ }^{3}$ \\ Tracey Yerxa ${ }^{4}$ \\ Jill Leary ${ }^{5}$ \\ John R. Skalski ${ }^{6}$
}

January 31, 2008

Prepared for the Bonneville Power Administration

by the Pacific Northwest National Laboratory

under a Related Services Agreement with the U.S. Department of Energy Contract DE-AC05-76RL01830

in conjunction with NOAA Fisheries and

the U.S. Army Corps of Engineers, Portland District

with the collaboration of the Lower Columbia River Estuary Partnership

1 Pacific Northwest National Laboratory

${ }^{2}$ U.S. Army Corps of Engineers Portland District

${ }^{3}$ NOAA Fisheries

4 Bonneville Power Administration

${ }^{5}$ Lower Columbia River Estuary Partnership

${ }^{6}$ University of Washington 



\section{Summary}

The purpose of this document is to describe research, monitoring, and evaluation (RME) for the Federal Columbia River Estuary Program, hereafter called "the Estuary Program." The intent of this RME effort is to provide data and information to evaluate progress toward meeting program goals and objectives and support decision making in the Estuary Program. The goal of the Estuary Program is to understand, conserve, and restore the estuary ecosystem to improve the performance ${ }^{\text {a }}$ of listed salmonid populations. The Estuary Program has five general objectives, designed to fulfill the program goal, as follows.

1. Understand the primary stressors affecting ecosystem controlling factors, such as ocean conditions and invasive species.

2. Conserve and restore factors controlling ecosystem structures and processes, such as hydrodynamics and water quality.

3. Increase the quantity and quality of ecosystem structures, i.e., habitats, juvenile salmonids use during migration through the estuary.

4. Maintain the food web to benefit salmonid performance.

5. Improve salmonid performance in terms of life history diversity, foraging success, growth, and survival.

The goal of estuary RME is to provide pertinent and timely research and monitoring information to planners, implementers, and managers of the Estuary Program. The goal leads to three primary management questions pertaining to the main focus of the Estuary Program: estuary habitat conservation and restoration. 1) Are the estuary habitat actions achieving the expected biological and environmental performance targets? 2) Are the offsite habitat actions in the estuary improving juvenile salmonid performance and which actions are most effective at addressing the limiting factors preventing achievement of habitat, fish, or wildlife performance objectives? 3) What are the limiting factors or threats in the estuary/ocean preventing the achievement of desired habitat or fish performance objectives?

Performance measures for the estuary are monitored indicators that reflect the status of habitat conditions and fish performance, e.g., habitat connectivity, survival, and life history diversity. Performance measures also pertain to implementation and compliance. Such measures are part of the monitoring, research, and action plans in this estuary RME document. Performance targets specific to the estuary were not included in the 2007 draft Biological Opinion.

To address the estuary RME goal and management questions, estuary RME has the following objectives and associated sub-objectives:

${ }^{\text {a }}$ Salmonid performance means life history diversity, foraging success, spatial structure, and growth (Bottom et al. 2005). 


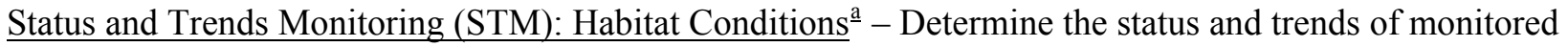
indicators for estuary/ocean conditions that are ecologically significant to listed salmonids in the lower river, estuary, plume, and nearshore ocean.

STM 1. Map bathymetry and topography of the estuary as needed for RME.

STM 2. Establish a hierarchical habitat classification system based on hydrogeomorphology, groundtruth it with vegetation cover monitoring data, and map existing habitats.

STM 3. Develop an index of habitat connectivity and apply it to each of the eight reaches of the study area.

STM 4. Monitor habitat conditions periodically, including water surface elevation, vegetation cover, plant community structure, substrate characteristics, dissolved oxygen, temperature, conductivity, and primary and secondary production at representative locations in the estuary and plume.

Status and Trends Monitoring: Juvenile Salmonid Performance - Determine the status and trends of monitored indicators for juvenile salmonid performance in the estuary and plume.

STM 5. Evaluate migration charcateristics, including juvenile salmonid abundance, residence times, growth rates, diets, and prey resources at representative locations in the estuary and plume to understand habitat usage and relative ecological importance of various habitats to juvenile salmonids.

STM 6. Monitor and evaluate juvenile salmonid survival from Bonneville Dam through the estuary into the plume.

STM 7. Develop an index and monitor and evaluate life history diversity of juvenile salmonid populations at representative locations in the estuary.

STM 8. Monitor and evaluate temporal and spatial species composition, abundance, and foraging rates of juvenile salmonid predators at representative locations in the estuary and plume.

$\underline{\text { Action Effectiveness Research (AER) }}{ }^{\underline{b}}$-- Using a representative set of projects, monitor and evaluate the effects of habitat restoration actions in the estuary.

AER 1. Develop a limited number of reference sites for typical habitats, e.g., tidal swamp, marsh, island, and tributary delta, to use in action effectiveness evaluations.

AER 2. Evaluate the effects of selected individual habitat restoration actions at project sites relative to reference sites and evaluate post-restoration trajectories based on project-specific goals and objectives. ("Effectiveness Monitoring")

AER 3. Develop and implement a methodology to estimate the cumulative effects of habitat conservation and restoration projects in terms of cause-and-effect relationships between ecosystem

${ }^{a}$ Status and trends monitoring is defined as census or statistically designed monitoring of fish or wildlife populations and/or environmental conditions (i.e., watershed conditions) to assess the current status (at a particular time) or trend (over time) (BPA 2005).

${ }^{\mathrm{b}}$ Action effectiveness research is defined as research to determine the effects of an action or suite of actions on fish survival, productivity, and/or habitat conditions. This is a manipulative experiment that statistically assesses the effect of a treatment (action) condition relative to a control or reference condition (BPA 2005). 
controlling factors, structures, and processes affecting salmon habitats and performance. ("Validation Mon.")

Critical Uncertainties Research (CUR) ${ }^{a}$ - Investigate critical uncertainties in the state-of-the-science in the estuary, plume, and nearshore ocean that are pivotal to understanding estuary/ocean effects on juvenile salmonid performance.

CUR 1. Continue work to define the ecological importance of the tidal freshwater, estuary, plume and nearshore ocean environments to the viability and recovery of listed salmonid populations in the Columbia Basin.

CUR 2. Continue work to define the causal mechanisms and migration/behavior characteristics affecting survival of juvenile salmon during their first weeks in the ocean.

CUR 3. Investigate the importance of the early life history of salmon populations in tidal freshwater of the lower Columbia River.

CUR 4. Investigate the effects of hatchery fish on wild (naturally produced) fish in the estuary.

CUR 5. Understand the wetting and drying of the floodplain habitats caused by complex hydrodynamic interactions of tides, mainstem and tributary flows, and the effect of the FCRPS on river conditions.

Implementation and Compliance Monitoring (ICM) - Assess whether projects are being implemented as planned and measure the amount of estuary habitat being conserved and restored annually.

ICM 1. Determine whether restoration projects were carried out as planned, i.e., whether specified project criteria were met ("Implementation Monitoring").

ICM 2. Total the amount of estuary habitat conserved and restored annually by habitat type.

Synthesis and Evaluation (SE) -- Synthesize data from Objectives 1-5 and evaluate the Estuary Program within an adaptive management framework.

SE 1. Upload, compile, manage, and disseminate project-level data at the Estuary Program level.

SE 2. Synthesize the data and periodically report it to the region.

SE 3. Use the synthesized data to evaluate the Estuary Program and refine the estuary RME effort as necessary.

To design and implement the estuary RME, this document contains a monitoring plan for the status and trends monitoring and action effectiveness research objectives, a research plan for the critical uncertainties research objectives, and an action plan for the implementation/compliance and synthesis and evaluation objectives. Status and trends monitoring is important because it will reveal whether CRE ecosystem features that support salmonids are improving, staying the same, or degrading. Action effectiveness research in the CRE is important because it will show the ecological results from the

${ }^{a}$ Uncertainties research is defined as research to resolve scientific uncertainties regarding the relationships between fish and wildlife health, population performance, habitat conditions, life history, and/or genetic conditions. Uncertainties research referenced herein requires resolution in order to successfully implement the Estuary Program. 
primary management action in the $\mathrm{CRE}$ - habitat conservation and restoration - and provide feedback to managers for the next generation habitat projects. Knowledge developed from status and trends monitoring and action effectiveness research, when integrated with scientific findings from critical uncertainties research, will help guide management actions on the estuary.

The monitoring plan uses a framework that provides the scientific basis for status and trends monitoring in the CRE. The overall objective of STM is to measure monitored indicators that are ecologically significant to listed salmonids in the lower river, estuary, plume, and nearshore ocean. The specific STM objectives deal with ecosystem controlling factors, structures, and salmonid performance. The Columbia River Estuary Conceptual Model forms a basis for the selection of monitored indicators for each objective. A rotational split panel sampling design is recommended. Data collection methods, the spatial and temporal scale of monitoring, and example protocols are provided in an appendix.

In the monitoring plan, the overall purpose of action effectiveness research is to use quantitative studies to demonstrate how habitat restoration actions affect factors controlling ecosystem structures and processes at site and landscape scales and, in turn, juvenile salmonid performance. The specific AER objectives address effectiveness and validation monitoring. (Implementation monitoring is covered in the action plan.) A control chart method based on data from a suite of reference and restoration sites is recommended for effectiveness monitoring, and a meta-analysis method is recommended for validation monitoring. To efficiently assess the effectiveness of habitat restoration actions on the Columbia River estuary and to meet the AER objectives, pertinent elements of the datasets developed through status and trends monitoring, implementation and compliance monitoring, and restoration project-specific monitoring will need to be analyzed, synthesized, and evaluated. A network of reference sites will be crucial to this effort. Data collection methods for action effectiveness, as well as the spatial and temporal scale of monitoring and example protocols are provided in an appendix.

The research plan's overall objective is to investigate critical uncertainties in the state-of-the-science in the estuary, plume, and nearshore ocean that are pivotal to understanding estuary/ocean effects on fish performance. The necessary focus is on management questions and RME objectives. Specific uncertainties pertain to the ecological importance of the CRE to salmonids, causal mechanisms affecting survival, early life history in tidal freshwater, effects of hatchery fish on wild fish in the estuary, and effects of FCRPS regulation and other factors on wetting and drying of floodplain habitats. As shown in the Columbia River Estuary Conceptual Model, many of the monitored indicators for research are ecosystem processes and linkages between these and ecosystem structures and salmonid performance. Results from uncertainties research will reduce risk during management decision making for the CRE.

The estuary RME action plan responds to project- and program-levels needs. The action plan identifies what needs to be done to implement estuary RME. While it is beyond the scope of this document to designate responsible agencies, we do provide a definitive list of actions to prioritize the research and monitoring activities in the CRE. The intent is to coordinate estuary RME implementation across multiple entities whose projects provide data pertinent to estuary RME objectives. Coverage of many of the estuary RME objectives is ongoing. 
For the estuary RME objectives not currently being addressed by an existing project, the estuary/ocean subgroup recommends modifications to existing projects or formation of new projects as follows: 1) Develop an index of habitat connectivity and apply it to each of the eight reaches of the study area. 2) Develop an index and monitor and evaluate life history diversity of salmonid populations at representative locations in the estuary. 3) Investigate effects of hatchery fish on wild (naturally produced) fish in the estuary.

At the program-level, the action plan includes the following recommendations. Coordination and Implementation - 1) Establish an estuary RME coordination committee that includes the Action Agencies, NMFS, the Estuary Partnership, and other entities charged with research and monitoring in the estuary. 2) Develop a statement of roles and responsibilities of each agency and entity working on RME in the estuary. In addition, consider establishing a memorandum of understanding between the key parties regarding the roles and responsibilities, governance structure, and organization of the estuary RME effort. 3) Use contractual mechanisms when possible to require that a) performance criteria be developed in the planning phase of each habitat restoration project; $b$ ) post-restoration monitoring of performance indicators be conducted; and c) data resulting from action effectiveness and status and trends monitoring be compiled and reported to standards appropriate for estuary-wide analyses. d) Coordinate with other basin-wide RME groups, other federal monitoring programs, interested parties, and state and local monitoring efforts. Continue to integrate estuary RME with the Pacific Northwest Aquatic Monitoring Partnership with representation at PNAMP meetings to describe and report estuary RME activities and participation in the estuary group for PNAMP.

Data Management, Analysis, and Dissemination - 1) Develop estuary RME data specifications to support a coordinated data management system. 2) Adopt standardized methods for status and trends monitoring to allow comparisons through time for given monitored attributes. 3) Adopt standardized methods for action effectiveness research to allow comparisons across projects and to address the cumulative effects of projects. 4) Build a data center to house results from status and trends monitoring and action effectiveness research. 5) Establish an estuary RME data center -- a central, web-accessible repository for estuary data, and a publicly accessible homepage with links to a networked system of databases. Specifically, this system should be linked to basin-wide RME data to facilitate basin-wide evaluations. 6) Maintain a project inventory database for restoration projects in the Estuary Program.

Information Reporting - 1) Convene biennial estuary RME workshops to present new data, evaluate the conduct of the estuary RME effort, exchange information, and provide input to the coordinating committee. 2) Write a biennial estuary RME report - this estuary RME report series would summarize data and provide adaptive management recommendations at the program level for submittal to the Action Agencies, estuary restoration project leaders, and other related entities (e.g., PNAMP). 3) Establish procedures that link decision makers and data managers to the coordinating committee in a manner consistent with basin-wide adaptive management. 4) Develop web-based information portals.

Implementation and Compliance Monitoring - 1) Determine whether restoration projects were carried out as planned, i.e., whether specified project criteria were met ("Implementation Monitoring"). BPA's 
project management system, Pisces, and similar NMFS and USACE systems could be applied here. 2) Total the amount of estuary habitat conserved and restored annually, by habitat type.

Synthesis and Evaluation -- 1) Upload, compile, manage, and disseminate project-level data at the estuary RME program level. 2) Synthesize the data and periodically report it to the region. 3) Use the synthesized data to evaluate the Estuary Program and refine estuary RME as necessary.

In conclusion, the estuary RME effort is designed to meet the research and monitoring needs of the Estuary Program using an adaptive management process. Estuary RME's success and usefulness will depend on the actual conduct of adaptive management, as embodied in the objectives, implementation, data, reporting, and synthesis, evaluation, and decision making described herein. 


\section{Preface}

This effort, funded by the Bonneville Power Administration (BPA), is being conducted by the Pacific Northwest National Laboratory (PNNL) with cooperation from the BPA, the Portland District U.S. Army Corps of Engineers (USACE), and the National Oceanic and Atmospheric Administration (NOAA). Technical assistance is provided by the Lower Columbia River Estuary Partnership and the University of Washington Columbia Basin Research Center. The purpose of the project (BPA Project No. 2002-077) is to coordinate and facilitate activities of the estuary/ocean subgroup for research, monitoring, and evaluation (RME) established in response to the 2000 and 2004 Federal Columbia River Power System (FCRPS) Biological Opinions. The estuary/ocean subgroup ${ }^{\mathrm{a}}$ is tasked by NOAA Fisheries and the Action Agencies (BPA and USACE) with developing and implementing research, monitoring, and evaluation for the Columbia River estuary, including the lower 146 miles of river below Bonneville Dam and the plume in the nearshore ocean, to support the Federal Columbia River Estuary Program, also referred to as the Estuary Program. The estuary/ocean subgroup functions under the auspices of the basin-wide RME planning process to implement federal RME in the estuary. The estuary RME described herein is the result of the estuary/ocean subgroup's efforts to date.

For the purposes of the Estuary Program, the estuary/ocean subgroup examined a variety of goals for the estuary identified in federal, state, and local programs, and developed a goal statement and objectives for Columbia River estuary habitat restoration to support endangered and threatened salmonid populations. The resulting goal statement is congruent with existing goals of other programs in the estuary. The goal of the Estuary Program is to understand, conserve, and restore the estuary ecosystem to improve the performance of listed salmonid populations.

Estuary RME differs in some respects from other basin-wide RME efforts, e.g., tributary habitat RME, because of the physical and biological nature of estuarine ecosystems. As well, the state of the science relative to ecosystem processes and functions affecting salmon in the Columbia River estuary is not as advanced as it is in the tributaries. Likewise, significantly less effort has been made to date to improve habitat conditions and monitor in the estuary than has been made at the mainstem dams and in upstream tributaries. Accordingly, estuary RME involves research to address uncertainties, as well as monitoring of the status and trends of ecosystem features and the effectiveness of management actions. As the results of this effort are evaluated within an adaptive management framework, the specific activities for implementing estuary RME will be examined and decisions made on revisions.

During the estuary/ocean RME subgroup process, which started in 2002, scientists from PNNL drafted sections of the estuary RME document, which were then reviewed by staff from the BPA Fish and Wildlife Division, USACE Portland District Environmental Planning Division, the Lower Columbia River Estuary Partnership, NOAA Fisheries Habitat Conservation Division, and other regional scientists.

a The Estuary/Ocean Subgroup for Federal RME is comprised of members from BPA, USACE, Estuary Partnership, NOAA Fisheries, and PNNL. 
The September 2003 and August 2004 versions of the estuary RME document released regionally were reviewed by B. Sutherland, S. Waste, and the Independent Scientific Review Panel (ISRP) (ISAB/ISRP 2004-01 and ISRP 2004-16, respectively). In addition, the Estuary Partnership's Science Work Group, Northwest Power and Conservation Council (NPCC) staff, state and tribal fisheries management agencies, and interested parties had the opportunity to review the August 2004 version. The comments resulting from this review process are reflected in the May 2006 version of estuary RME, which was in turn reviewed by regional scientists (M. Burlin, L. Caton, A. Giorgi, T. Hillman, C. Paulsen, R. Scranton, S. Simenstad, and R. Thom). Modifications based on these comments were incorporated into the current version of the estuary RME document (January 2008).

This January 2008 regional release also contains new material regarding goals, objectives, the conceptual ecosystem model, monitored indicators, method and protocols, and specific implementation recommendations. We incorporated new knowledge gained from ongoing research by BPA, the Estuary Partnership, NOAA Fisheries, Oregon State University (OSU), PNNL, USACE, University of Washington (UW), and others. We also completely reorganized the document to streamline the main body while maintaining important supporting material in appendices. The EOS reviewed this document. It is anticipated that the estuary RME document will be updated in the future as new information and experience are gained. Finally, it is important to recognize the following points:

1. The BPA, NOAA Fisheries, and USACE are not obligated to fund elements included in this estuary RME document.

2. Funding of actions recommended in this document will be determined in processes elsewhere, such as the USACE Anadromous Fish Evaluation Program and the NPCC Fish and Wildlife Program. One purpose here is to provide a framework that the funding agencies and project entities can use to coordinate activities and make decisions about scopes of work.

3. This document focuses on listed salmon species, although its ecosystem-based approach necessarily serves other species as well. Research, monitoring, and evaluation for salmon are best undertaken within the context of other biota and physical processes using an ecosystem perspective.

4. Major habitat areas that are not addressed in this document, or in other RME documents for the Columbia Basin, are the nearshore ocean along the continental shelf to Alaska and the open ocean salmonid habitats in the Gulf of Alaska. These areas may also contribute substantially to stockspecific survival of salmon and steelhead.

For more information about the estuary RME document, please contact Gary E. Johnson (503-4177567, gary.johnson@pnl.gov). 


\section{Acknowledgments}

Many people have contributed to this document as it has evolved over the years. We gratefully acknowledge:

- BioAnalysts, Inc. - Al Giorgi and Tracy Hillman

- Bonneville Power Administration - Jim Geiselman, Nicole Ricci, Alan Ruger, and Jessica Wilcox

- Corps of Engineers - Taunja Berquam, Eric Braun, Kim Larson, and Bob Willis

- Independent Consultant - Earl Dawley

- Independent Scientific Advisory Board

- Independent Scientific Review Panel

- Lower Columbia River Estuary Partnership - Scott McEwen

- NOAA Fisheries - Ed Casillas

- Pacific Northwest National Laboratory - Dennis Dauble, Dick Ecker, Jan Slater, Kathryn Sobocinski, Ron Thom, and Greg Williams

- Portland State University - Curt Peterson

- Reviewers - Larry Caton (Oregon DEQ), Al Giorgi and Tracy Hillman (BioAnalysts, Inc.), Si Simenstad (University of Washington), Charlie Paulsen (Paulsen Environmental Research), Bruce Sutherland (retired-Oregon Department of Environmental Quality), and Steve Waste (Northwest Power and Conservation Council). 
Research, Monitoring, and Evaluation for the Federal Columbia River Estuary Program 


\section{Contents}

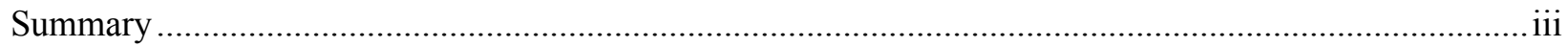

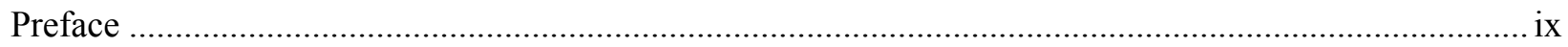

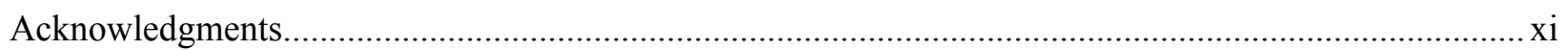

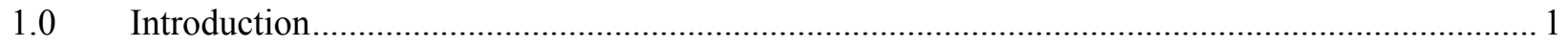

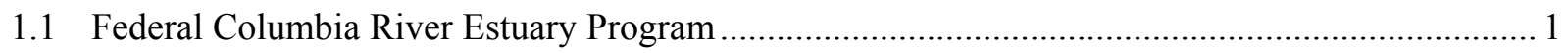

1.2 Estuary RME Goal, Management Questions, Objectives, and Actions ....................................... 3

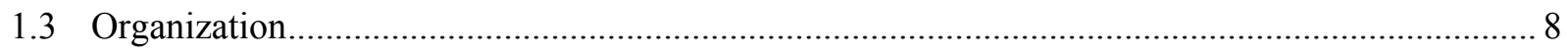

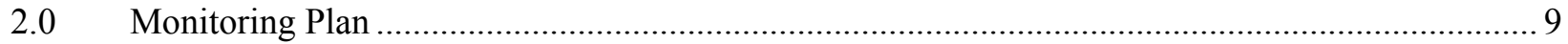

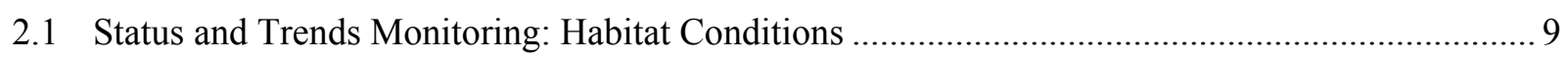

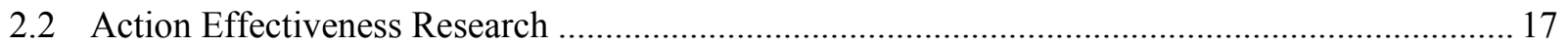

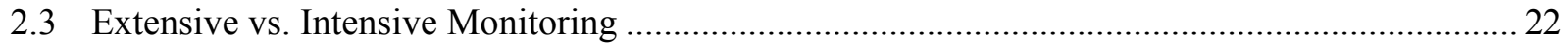

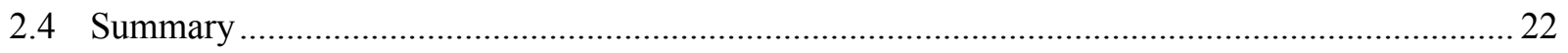

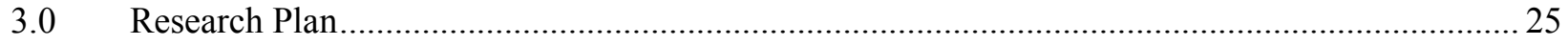

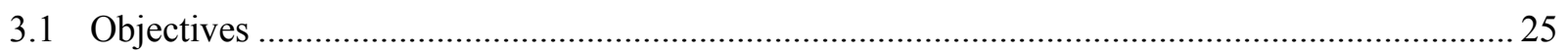

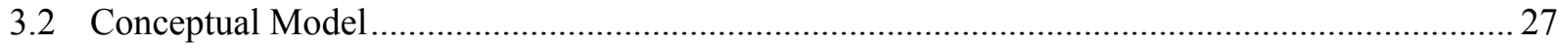

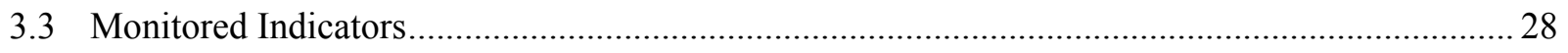

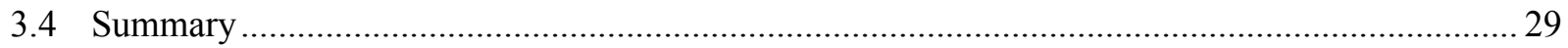

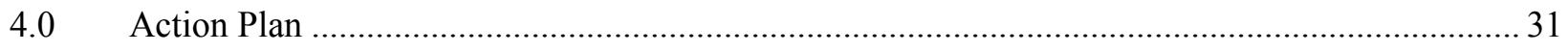

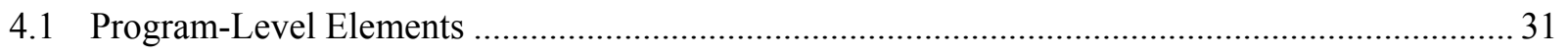

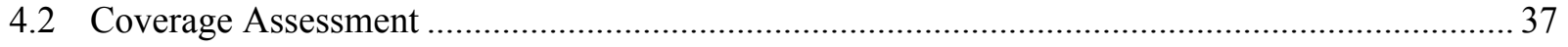

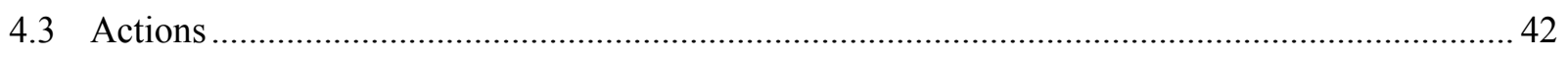

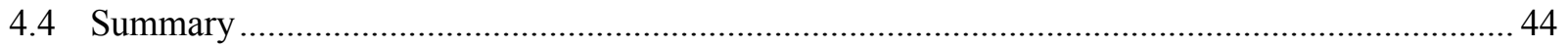

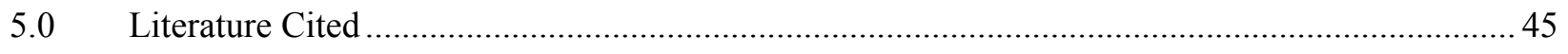

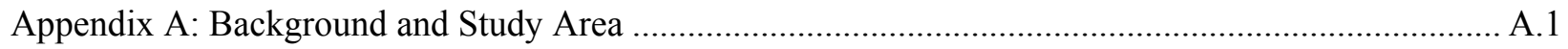

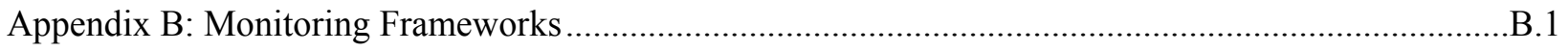

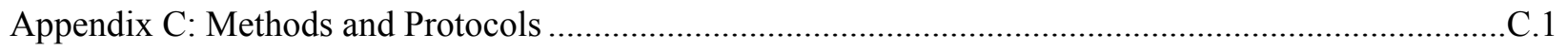

Appendix D: Abbreviations, Acronyms, and Glossary .................................................................. D.1 


\section{Figures}

Figure 1. Columbia River Estuary from Bonneville Dam to Pacific Ocean, including the Plume 2

Figure 2. Estuary Program Goal and Objectives and Estuary RME Goal, Management Questions, and Objectives

Figure 3. Map of the Lower Columbia River and Estuary Showing Hydrogeomorphic Reaches..... 11

Figure 4. Rotational Split-Panel Design. Here, one panel of sites is monitored annually because of strategic, biological, or social importance

Figure 5. Conceptual Framework for Monitoring Restoration Effectiveness Using Only Reference Sites as a Target for Recovery.....

Figure 6. Illustration of Using Control Chart Methods to Monitor Recovery Success 20

Figure 7. Columbia River Estuary Conceptual Model Applied to Estuary Uncertainties Research 27

Figure 8. Schematic of an Adaptive Management Process for Estuary RME 32

Figure A.1. Schematic of RME Development for the Estuary Program. A.2

Figure A.2. Basic Elements of the Columbia River Estuary Conceptual Model. A.3

Figure A.3. Image of the Estuary Study Area

Figure A.4. Relationship of Estuary RME to Drivers, Technical Guidance, Regional Planning Processes, Primary Funding Sources, and Estuary RME Project Areas...

Figure B.1. Columbia River Estuary Conceptual Model Applied to Estuary RME Status and Trends Monitoring

Figure B.2. Relationship between Geographic Scale of the Monitoring Program, the Indicators Measured, and Associated Sampling Techniques.

Figure B.3.a-f. Six Alternative Sampling Designs.

Figure B.4. Columbia River Estuary Conceptual Model Applied to Estuary RME Action Effectiveness Research.

Figure B.5. Habitat Capacity, Opportunity, and Realized Function as Depicted in the Columbia River Estuary Conceptual Model

Figure B.6. Conceptual Framework for Evaluating Restoration Effectiveness.

Figure B.7. Conceptual Framework for Monitoring Restoration Effectiveness Using Only Reference Sites as a Target For Recovery.

Figure B.8. Illustration of Using Control Chart Methods to Monitor Recovery Success. 
Figure B.9. Graphical Representation of Before-After Response to Restoration at Replicate Restoration-Reference Sites used in Regional Assessment.

Figure B.10. Hypothetical Relationships between the Magnitude of Environmental Response and Size Of The Restoration Area

Figure B.11. Hypothetical Relationship between Numbers of Restoration Projects in a Cluster and Mean Responses.

Figure B.12a-b. Hypothetical Relationship between Temporal Patterns of Site Response to One (A) and More (B) Interventions at Nearby Restoration Sites.

\section{Tables}

Table 1. Monitoring Guidance for Status and Trends Monitoring.

Table 2. Core Biological and Physical Indicators Recommended for Action Effectiveness

Monitoring of Habitat Restoration Projects in the Estuary .................................................... 18

Table 3. Monitored Indicators for Uncertainties Research in Estuary RME .......................................28

Table 4. Ongoing Monitoring Programs Applicable to Estuary RME (August 2007 status) ................... 38

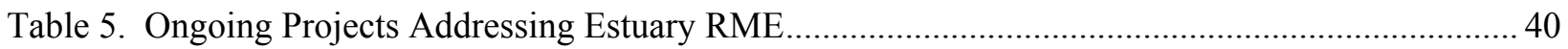

Table A.1. Technical Recovery Team, Evolutionarily Significant Unit, and Endangered Species Act (ESA) Status of Listed Salmonids

Table B.1. Monitored Indicators for Status and Trends Monitoring in Estuary RME.

Table B.2. Optimal Fraction of Monitoring Sites to Retain from One Year to the Next in a Rotational Sampling Design for Status and Trends Monitoring.

Table B.3. Definitions of Habitat Capacity, Habitat Opportunity, and Realized Function.

Table B.4. Monitored Indicators and the Action Effectiveness Research

Table C.1. Methods to Measure the Monitored Indicators. 
Research, Monitoring, and Evaluation for the Federal Columbia River Estuary Program 


\subsection{Introduction}

The purpose of this document is to describe research, monitoring, and evaluation (RME) for the Federal Columbia River Estuary Program, hereafter called "the Estuary Program." The intent of this RME effort is to provide data and information to evaluate progress toward meeting program goals and objectives and to support decision making in the Estuary Program. Inclusion in this document, however, does not imply a commitment or obligation to funding from the Bonneville Power Administration, NOAA Fisheries, the U.S. Army Corps of Engineers, or any other entity.

\subsection{Federal Columbia River Estuary Program}

The Estuary Program, which was established in response to the 2000 Biological Opinion (National Marine Fisheries Service [NMFS] 2000) on operation of the Federal Columbia River Power System, consists of projects to conserve and restore estuarine habitats and associated research and monitoring to evaluate this effort. The program, described by Berquam et al. (2003), is coordinated with other federal, state, and tribal agencies and non-governmental organizations with responsibilities for stewardship in the Columbia River estuary ${ }^{\mathrm{a}}$ (Figure 1). The goal of the program is as follows:

Estuary Program Goal: Understand, conserve, and restore the estuary ecosystem to improve the performance $^{\mathrm{b}}$ of listed salmonid populations.

The Estuary Program goal is congruent with existing regional and national goals for estuarine protection and restoration (e.g., EPA 2004; LCREP 1999) and the Northwest Power and Conservation Council's Fish and Wildlife Program (NPCC 2000), as well as the intent of earlier Biological Opinions (NMFS 2000, 2004) and the recent Biological Assessment (Action Agencies 2007) and draft Biological Opinion (NMFS 2007) on operation of the FCRPS. The Estuary Program goal relies on the best available science to support estuary management actions directed to attaining the goal. This science emphasizes population performance and the importance of life history diversity and spatial distribution (Bottom et al. 2005; Fresh et al. 2005). The goal also implicitly incorporates survival as an indicator of population performance, as does federal research, monitoring, and evaluation for the tributaries and hydrosystem (RME Plan 2003).

${ }^{a}$ For the purposes of the estuary RME, the Columbia River estuary is defined as the tidally influenced portion of the river and its tributaries from Bonneville Dam to and including the plume. Lower Columbia River tributary watersheds, such as the Cowlitz and Lewis rivers, and the Willamette River upstream of the Multnomah Channel, are not part of the estuary RME study area.

${ }^{\mathrm{b}}$ Salmonid performance means life history diversity, foraging success, spatial structure, and growth (Bottom et al. 2005). 


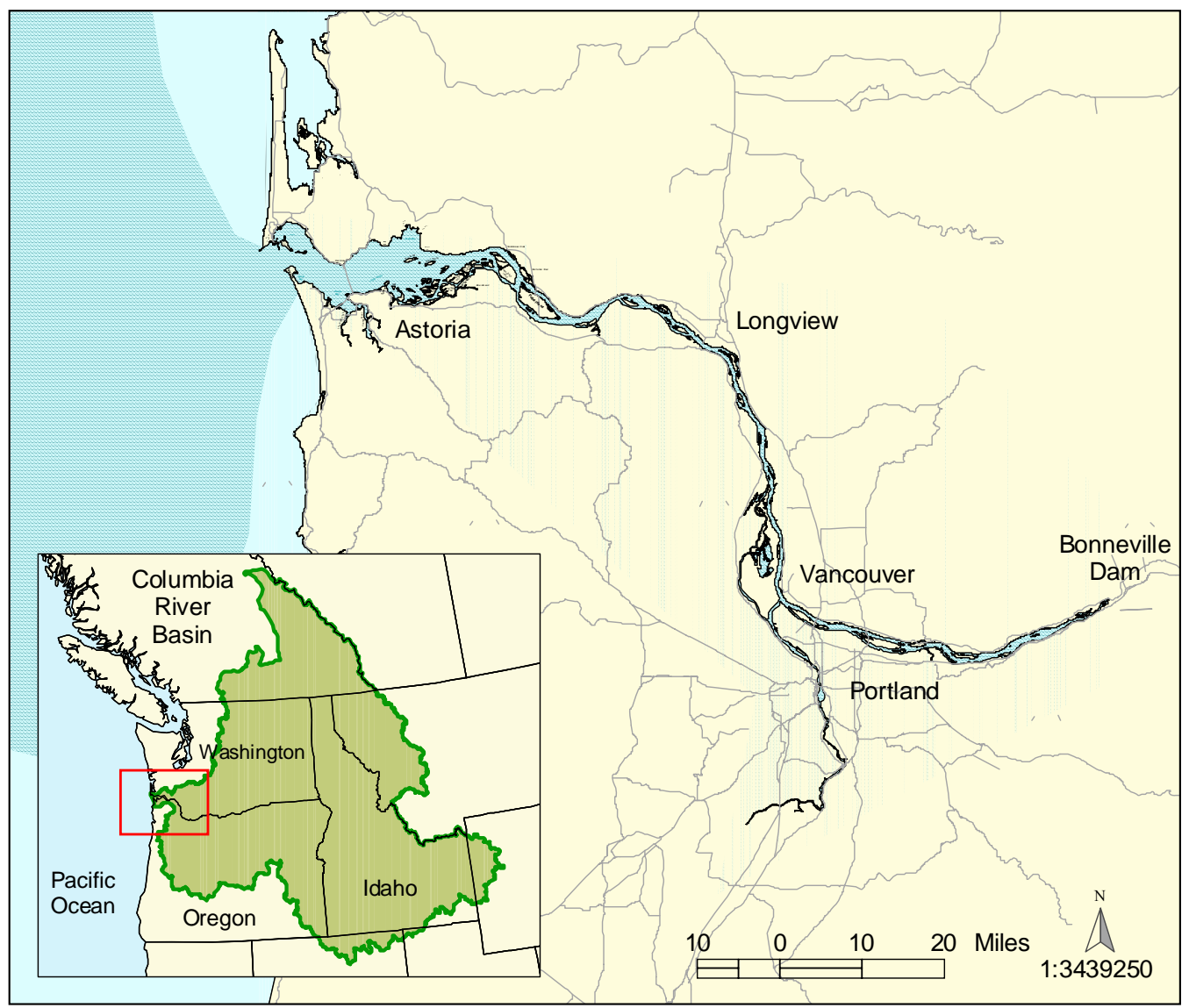

Figure 1. Columbia River Estuary from Bonneville Dam to Pacific Ocean, including the Plume. The inset shows the location of the Columbia River estuary relative to the Columbia basin.

The Estuary Program has five general objectives, designed to fulfill the program goal, as follows.

1. Understand the primary stressors affecting ecosystem controlling factors, such as ocean conditions and invasive species.

Stressors are forces external to the geographic area of the Columbia River estuary or anthropogenic actions within the estuary that directly influence the controlling factors in the estuary ecosystem. The stressors include watershed condition, flow regulation, diking, dredging, invasive species, ocean conditions, and regional climate change. Understanding the stressors affecting the estuary ecosystem will allow managers to make informed decisions for the federal Estuary Program.

2. Conserve and restore factors controlling ecosystem structures and processes, such as hydrodynamics and water quality.

Conserving and restoring controlling factors of ecosystem structures and processes is fundamental to the ecosystem-basis of the Estuary Program. The ecosystem-basis is derived from the conceptual model for the Columbia River estuary developed by Thom et al. (2004). For example, water quality is a controlling factor that can affect salmonid performance (Arkoosh et al. 1998). 
3. Increase the quantity and quality of ecosystem structures, i.e., habitats juvenile salmonids use during migration through the estuary.

Ecosystem structures, such as forested wetlands, emergent marshes, and mud/sand flats, affect salmonid performance through ecosystem processes that provide food, refuge, and other habitat functions. The quantity of ecosystem structures important to salmonids has been decreased over time by dikes disconnecting them from the mainstem estuary. The quality of these habitats refers to their capacity to support juvenile salmonids.

4. Maintain the food web to benefit salmonid performance.

The estuarine food web process supports salmonids (Simenstad et al. 1990a) and affects juvenile salmonid survival (Roby et al. 2003). The food web includes prey produced in estuarine wetlands that salmonids eat as well as predators that eat salmonids. As such, the food web is inexorably linked to juvenile salmonid performance.

5. Improve salmonid performance in terms of life history diversity, foraging success, growth, and survival.

Performance is an indicator of the state of anadromous salmonid populations. Performance can be defined by growth, foraging success, spatial structure, and life history diversity (Bottom et al. 2005). Fresh et al. (2005) state that the latter two elements are an "especially critical portion of the role of the estuary." In the estuary, performance will be assessed by monitored indicators for juvenile salmon life history diversity, spatial and temporal distribution, foraging success, growth, and survival.

In conclusion, progress toward meeting the goals and objectives of the Federal Columbia River Estuary Program, and decision making within it, will be addressed by a specially designed research, monitoring, and evaluation effort. The purpose of this document is to describe RME for the Estuary Program.

\subsection{Estuary RME Goal, Management Questions, Objectives, and Actions}

The goal of estuary/ocean $\mathrm{RME}^{\mathrm{a}}$ is as follows:

Estuary RME Goal: Provide pertinent and timely research and monitoring information to planners, implementers, and managers of the Estuary Program designed to improve the performance of listed salmonid populations.

Estuary RME is part of a larger, basin-wide effort. Since the 2000 and 2004 Biological Opinions on FCRPS operations were issued, the Action Agencies have worked with NMFS and federal, state, and tribal fisheries management agencies to develop a comprehensive RME plan for the Columbia River basin

\footnotetext{
${ }^{\text {a }}$ For brevity, the term estuary/ocean RME is shortened to estuary RME in the remainder of the document, i.e.,
} estuary RME includes the ocean. 
(called the "basin-wide plan"; referenced as "RME Plan 2003"). In the basin-wide plan, RME activities are focused on the 12 salmon evolutionarily significant units listed under the Endangered Species Act (Appendix A, Table A1). Using a hierarchical context of the ecosystems, subbasins, and habitats supporting these species, the basin-wide plan encompasses RME activities in all Columbia River basin habitats used by juvenile and adult life stages of salmon: natal streams and tributaries, the mainstem, and the estuary including the Columbia River plume. This framework has been carried forward into the 2007 Biological Assessment (Action Agencies 2007) and is included in the 2007 draft Biological Opinion (NMFS 2007).

The following are the primary management questions with respect to estuary habitat actions, as stated in the 2007 Biological Assessment (Action Agencies 2007). These management questions are consistent with those identified by the Pacific Northwest Aquatic Monitoring Partnership for estuaries (PNAMP 2007). The RME objectives and sub-objectives described in this section are focused on providing information needed to answer these questions to support ongoing management decisions.

- Are the estuary habitat actions achieving the expected biological and environmental performance targets?

This management question primarily concerns status and trends monitoring, in combination with action effectiveness research. Status monitoring is the "measurement of environmental characteristics over an extended period of time to determine status or trends in some aspect of environmental quality" (from Suter 1993, cited in Noon 2003). Status monitoring can describe differences in values of given monitored indicators among locations at a given moment in time (snapshot) or changes in their values across time at a given location (trend).

- Are the habitat actions in the estuary improving juvenile salmonid performance and which actions are most effective at addressing the limiting factors (see next question) preventing achievement of habitat, fish, or wildlife performance objectives?

This management question concerns action effectiveness evaluation. Action effectiveness evaluation determines the physical, biological, and ecological effects of management actions relative to project and program objectives. The conclusions generated from action effectiveness evaluation will inform decision making in the adaptive management process for the federal estuary restoration effort as a whole.

- What are the limiting factors or threats in the estuary/ocean preventing the achievement of desired habitat or fish performance objectives?

This management question concerns critical uncertainties research. The resolution of uncertainties in the existing estuary/ocean knowledge base is required for implementation of appropriate management actions as well as associated status and trends monitoring and action effectiveness evaluation. "Uncertainties" are those currently unavailable, scientifically based, conclusions that managers require for informed, effective decision making. 
Performance measures for the estuary are monitored indicators that reflect the status of habitat conditions and fish performance, e.g., habitat connectivity, reach survival, and life history diversity. Performance measures also pertain to implementation and compliance. Such measures are part of the monitoring, research, and action plans (Sections 2, 3, and 4, respectively). Performance targets specific to the estuary were not included in the 2007 draft Biological Opinion (NMFS 2007).

To address the management questions, estuary RME has six overall objectives (indicated by shading in the box below) based on key RME concepts from the basin-wide RME effort, supplemental information from BPA (2005), and guidance from NPCC (2006a). Additionally, Johnson et al. (2004) provided an annotated bibliography of monitoring plans, strategies, protocols, and guidance documents relevant to estuary RME. The estuary RME objectives and associated sub-objectives are as follows.

\section{Estuary RME Objectives and Sub-Objectives:}

1. Status and Trends Monitoring: Habitat Conditions ${ }^{\mathrm{a}}$ - Determine the status and trends of monitored indicators for estuary/ocean conditions that are ecologically significant to listed salmonids in the lower river, estuary, plume, and nearshore ocean.

STM 1. Map bathymetry and topography of the estuary as needed for RME.

STM 2. Establish a hierarchical habitat classification system based on hydrogeomorphology, ground-truth it with vegetation cover monitoring data, and map existing habitats.

STM 3. Develop an index of habitat connectivity and apply it to each of the eight reaches of the study area.

STM 4. Monitor habitat conditions periodically, including water surface elevation, vegetation cover, plant community structure, substrate characteristics, dissolved oxygen, temperature, conductivity, and primary and secondary production at representative locations in the estuary and plume.

2. Status and Trends Monitoring: Juvenile Salmonid Performance - Determine the status and trends of monitored indicators for juvenile salmonid performance in the estuary and plume.

STM 5. Evaluate migration charcateristics, including juvenile salmonid abundance, residence times, growth rates, diets, and prey resources at representative locations in the estuary and plume to understand habitat usage and relative ecological importance of various habitats to juvenile salmonids.

STM 6. Monitor and evaluate juvenile salmonid survival from Bonneville Dam through the estuary into the plume.

STM 7. Develop an index and monitor and evaluate life history diversity of juvenile salmonid populations at representative locations in the estuary.

STM 8. Monitor and evaluate temporal and spatial species composition, abundance, and foraging rates of juvenile salmonid predators at representative locations in the estuary and plume.

\footnotetext{
${ }^{a}$ Status and trends monitoring is defined as census or statistically designed monitoring of fish or wildlife populations and/or environmental conditions (i.e., watershed conditions) to assess the current status (at a particular time) or trend (over time) (BPA 2005).
} 
$\underline{\text { 3. Action Effectiveness Research }}^{\mathrm{a}}$-- Using a representative set of projects, monitor and evaluate the effects of habitat restoration actions in the estuary.

AER 1. Develop a limited number of reference sites for typical habitats, e.g., tidal swamp, marsh, island, and tributary delta, to use in action effectiveness evaluations.

AER 2. Evaluate the effects of selected individual habitat restoration actions at project sites relative to reference sites and evaluate post-restoration trajectories based on project-specific goals and objectives. ("Effectiveness Monitoring")

AER 3. Develop and implement a methodology to estimate the cumulative effects of habitat conservation and restoration projects in terms of cause-and-effect relationships between ecosystem controlling factors, structures, and processes affecting salmon habitats and performance. ("Validation Mon.")

$\underline{4 . ~ C r i t i c a l ~ U n c e r t a i n t i e s ~ R e s e a r c h ~}^{\mathrm{b}}$ - Investigate critical uncertainties in the state-of-the-science in the estuary, plume, and nearshore ocean that are pivotal to understanding estuary/ocean effects on juvenile salmonid performance.

CUR 1. Continue work to define the ecological importance of the tidal freshwater, estuary, plume and nearshore ocean environments to the viability and recovery of listed salmonid populations in the Columbia Basin.

CUR 2. Continue work to define the causal mechanisms and migration/behavior characteristics affecting survival of juvenile salmon during their first weeks in the ocean.

CUR 3. Investigate the importance of early life history of salmon populations in tidal freshwater of the lower Columbia River.

CUR 4. Investigate the effects of hatchery fish on wild (naturally produced) fish in the estuary.

CUR 5. Understand the wetting and drying of the floodplain habitats caused by complex hydrodynamic interactions of tides, mainstem and tributary flows, and the effect of the FCRPS on river conditions.

5. Implementation and Compliance Monitoring - Assess whether projects are being implemented as planned and measure the amount of estuary habitat being conserved and restored annually.

ICM 1. Determine whether restoration projects were carried out as planned, i.e., whether specified project criteria were met ("Implementation Monitoring").

ICM 2. Total the amount of estuary habitat conserved and restored annually by habitat type.

6. Synthesis and Evaluation -- Synthesize data from Objectives 1-5 and evaluate the Estuary Program within an adaptive management framework.

Cont'

${ }^{a}$ Action effectiveness research is defined as research to determine the effects of an action or suite of actions on fish survival, productivity, and/or habitat conditions. This is a manipulative experiment that statistically assesses the effect of a treatment (action) condition relative to a control or reference condition (BPA 2005).

${ }^{\mathrm{b}}$ Uncertainties research is defined as research to resolve scientific uncertainties regarding the relationships between fish and wildlife health, population performance, habitat conditions, life history, and/or genetic conditions. Uncertainties research referenced herein requires resolution in order to implement the Estuary Program. 
SE 1. Upload, compile, manage, and disseminate project-level data at the Estuary Program level.

SE 2. Synthesize the data and periodically report it to the region.

SE 3. Use the synthesized data to evaluate the Estuary Program and refine the estuary RME effort as necessary.

The Estuary Program goal and objectives drive the estuary RME goal, management questions, and objectives (Figure 2). The estuary RME objectives incorporate guidance from the 2007 Biological Assessment, the 2007 draft Biological Opinion, the federal RME plan and guidance document, and other regional restoration and monitoring planning documents, as well as literature from estuarine restoration and fisheries science.

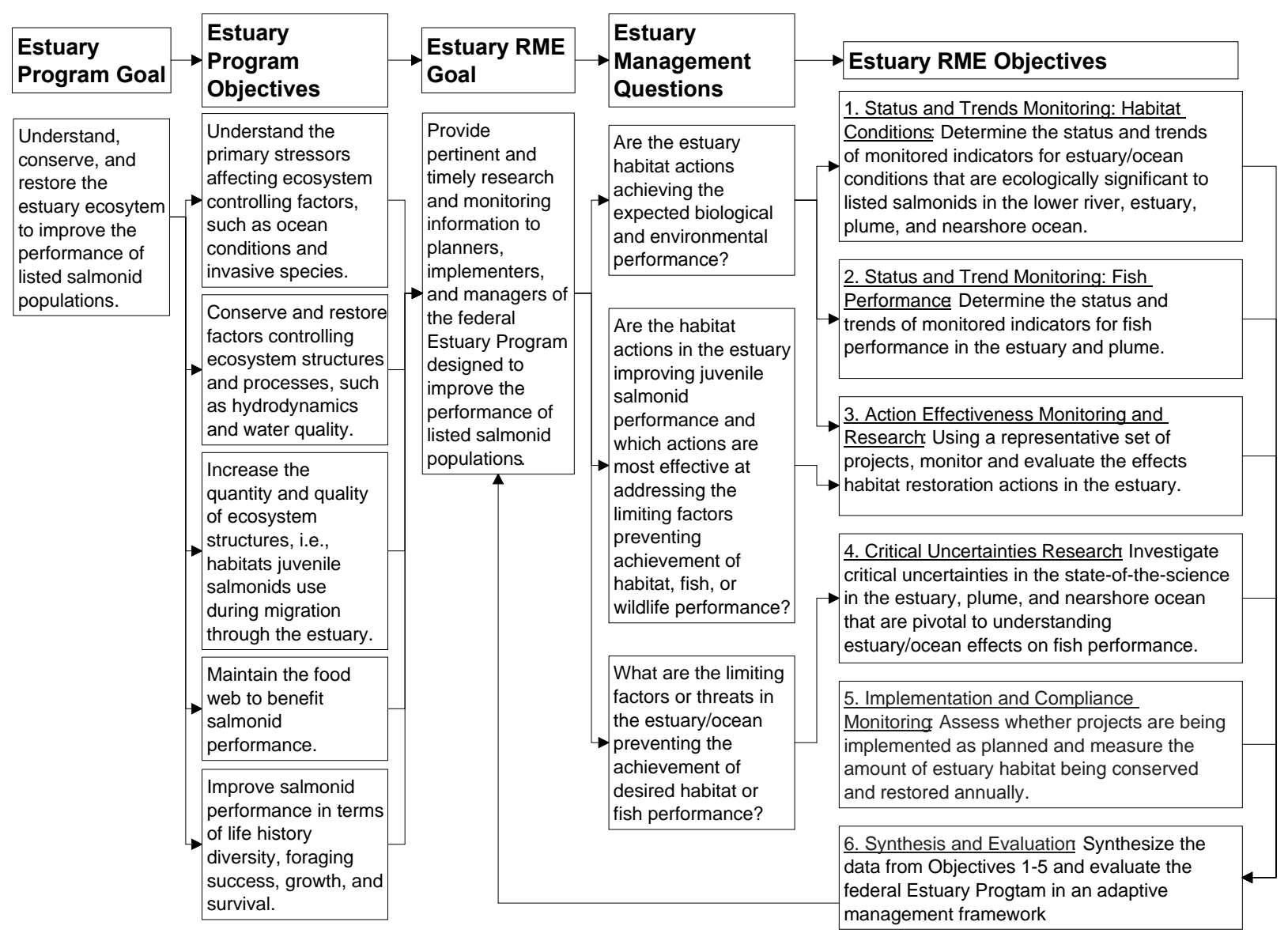

Figure 2. Estuary Program Goal and Objectives and Estuary RME Goal, Management Questions, and Objectives 


\subsection{Organization}

This document is organized as follows. Following this Introduction (Section 1), an integrated Monitoring Plan for status and trends and action effectiveness monitoring is presented in Section 2. Critical uncertainties research is described in the Research Plan in Section 3. The estuary RME effort, including implementation and compliance monitoring and synthesis and evaluation, is laid out in Section 4, the estuary RME Action Plan. Literature cited is listed in Section 5.

Detailed explanations and rationales for each estuary RME objective are presented in Sections 2, 3, and 4 as we cover each of the six estuary RME objectives -- habitat and fish performance status and trends monitoring, action effectiveness research, uncertainties research, implementation and compliance monitoring, and synthesis and evaluation. Specific information about the monitored indicators and sampling designs corresponding to the status and trends and action effectiveness objectives is also developed in Section 2; associated protocols are cited in Appendix C.

The appendices contain additional important supporting material for estuary RME. Background and the study area are described in Appendix A. Scientific frameworks for status and trends monitoring and action effectiveness research are contained in Appendix B. Monitoring methods and protocols are outlined in Appendix C. Appendix D contains a list of abbreviations and acronyms and a glossary. Johnson et al. (2004) contains an annotated bibliography of regional and national monitoring plans, strategies, protocols, and guidance documents relevant to estuary RME. 


\subsection{Monitoring Plan}

The monitoring plan presented in this chapter responds to two management questions in the Estuary Program (see Figure 2); the remaining management question concerns critical uncertainties research and is addressed in Section 3, Research Plan. This monitoring plan addresses the following management questions:

- Are aquatic, riparian, and upland estuary habitat actions achieving the expected biological and environmental performance standards?

- Are the habitat actions in the estuary improving juvenile salmonid performance and which actions are most effective at addressing the limiting factors preventing achievement of habitat, fish, or wildlife performance standards?

The monitoring plan developed herein is built on scientific research and monitoring frameworks for status and trends monitoring and action effectiveness research, which can be found in Appendix B. Each fully developed research framework described in this appendix includes objectives, a conceptual model, monitored indicators, the sampling design, and a summary. These frameworks are unified by conceptual models adapted from Thom et al. (2004).

The elements of this monitoring plan are a subset of the fully developed frameworks described in Appendix B. These elements are priorities for monitoring and are congruent with the 2007 Biological Assessment and draft Biological Opinion. For example, while understanding stressors and water quality are estuary program objectives (see Section 1.1 and Figure 2), and tracking them is a status and trends monitoring objective (Appendix B), they are not among the estuary RME objectives and actions (Section 1.2) that have been prioritized specifically to address the management questions above. The complete frameworks (Appendix B) specify what, when, where, why, and how research and monitoring would ideally be implemented for estuary RME (protocols are cited in Appendix C). These frameworks, however, include many monitored indicators that, although they would contribute knowledge to management of the system, are not the most directly applicable to these management questions and RME objectives. Therefore, the monitored indicators presented in this monitoring plan have top priority in the estuary RME effort.

\subsection{Status and Trends Monitoring: Habitat Conditions}

This section of the monitoring plan addresses the nine status and trends monitoring objectives (see Section 1.2). There are two overall categories of objectives for status and trends monitoring: habitat conditions and fish performance. Sampling designs and monitoring guidance for status and trends monitoring are described briefly; details may be found in Appendix C. 


\subsubsection{Habitat Conditions}

The overall objective of status and trends monitoring for habitat conditions is to determine the status and trends of monitored indicators for estuary/ocean conditions that are ecologically significant to listed salmonids in the lower river, estuary, plume, and nearshore ocean (compare with Reasonable and Prudent Alternative [RPA] 59 in NMFS 2007). The habitat conditions objective has four sub-objectives (STM 14).

STM 1. Map bathymetry and topography of the estuary as needed for RME.

Bathymetry is a collection of depth points that represent the gradients of elevation and depth change along a surface. Topography measures the height of a point on the surface of the sediment or soil of a location, expressed relative to a datum point. These data are essential to quantify and characterize estuary habitats available for salmonids.

STM 2. Establish a hierarchical ecosystem classification system based on hydro-geomorphology, groundtruth it with vegetation cover monitoring data, and map existing habitats.

Maps generated from surveys using aerial photos and photo points, together with application of the hierarchical classification currently being developed by the University of Washington and the U.S. Geological Survey, will allow managers to monitor trends in estuary habitats beneficial to juvenile salmonids. Ecosystem structures, i.e., habitats, within the historical floodplain of the CRE are very diverse, ranging from forested wetlands to deep river channels. It is necessary to classify these habitats for the purpose of designing a sampling program for certain categories of STM monitored indicators, for example, vegetation cover and salmonid performance. In addition to status and trends monitoring, this objective has an element of uncertainties research in development of the classification.

Hydrogeomorphic reaches in the CRE (Figure 3) within a hierarchical classification have been developed by Simenstad et al. (2005) as part of the Lower Columbia River Estuary Partnership's Ecosystem Monitoring project. The reaches are Level 3 of six levels. Research is ongoing to develop and map finer scale levels. The Level 3 reaches have been delineated preliminarily based on EPA Level IV Ecoregions and modified based on transitions in large-scale hydrogeomorphic and tidal-fluvial forcing such as maximum salinity intrusion, convergences with tributaries, the upstream extent of current reversal, and transitions in maximum flood tide level. These reaches provide one potential level of stratification for status-and-trends sampling of the estuary.

STM 3. Develop an index of habitat connectivity and apply it to each of the eight reaches of the study area.

Habitat connectivity is a landscape-scale indicator of the linkages between different habitat types in the ecosystem. This action would include an inventory of passage barriers (dikes, levees, tidegates, and culverts), which are the major stressors in the CRE because they restrict access by salmon to wetland habitats. The habitat connectivity index will provide a way to track habitat actions. This action is needed 
because of the hypothesized importance of habitat connectivity to the ecology of juvenile salmonids in the estuary. In addition to status and trends monitoring, this objective has an element of uncertainties research in development of the index.

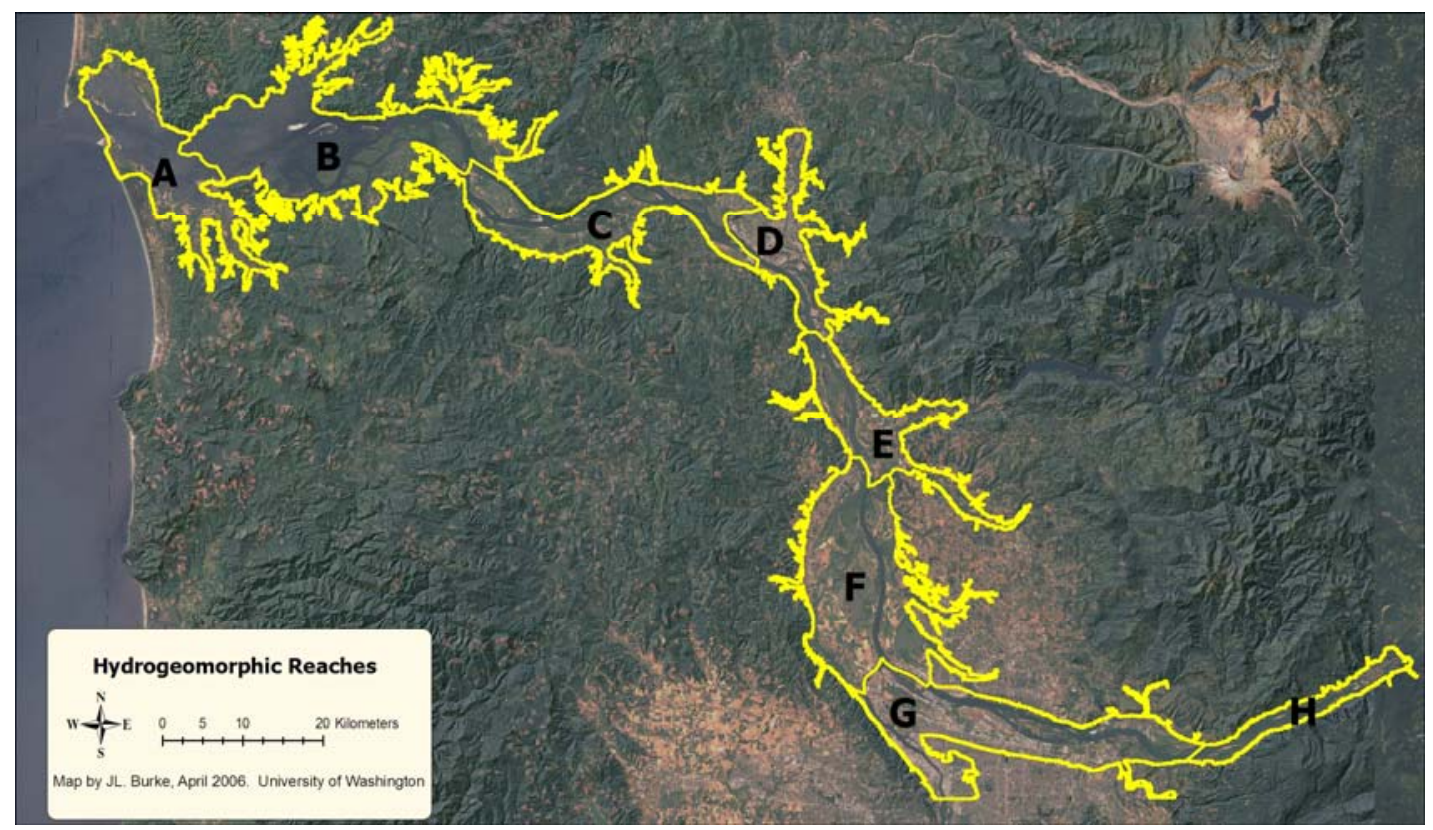

Figure 3. Map of the Lower Columbia River and Estuary Showing Hydrogeomorphic Reaches. Map provided courtesy of Jen Burke, University of Washington.

The most dominant historical change to habitat in the estuary that is not hydrosystem-related is the installation of dikes, tide gates, and other barriers to fish passage. In some cases, such barriers significantly altered habitats behind them, in addition to preventing passage (Simenstad and Feist 1996). It is expected, however, that habitat restoration actions in the estuary will improve habitat opportunity for listed salmonids. More specifically, the area of estuarine habitat currently accessible within a given geographic area is expected to increase (NMFS 2007). Furthermore, the length of tidal channel edge that is available to salmonids is expected to increase. However, these length and area values vary temporally with water level in an estuary, which in turn varies with the regulated flow of the Columbia River, sea level, and tides.

STM 4. Monitor habitat conditions periodically, including water surface elevation, vegetation cover, primary and secondary productivity, plant community structure, substrate characteristics, dissolved oxygen, temperature, and conductivity, at representative locations in the estuary and plume.

STM 4 can be addressed under a split-panel rotational sampling design. Habitat conditions reflect the quality of ecological support for juvenile salmonids. Since the Action Agencies desire to conserve and restore habitats that benefit juvenile salmonid performance, it is prudent to monitor the status and trends in the quality and quantity of these habitats. Productivity indices, such as primary and secondary production rates, reveal the capability of ecosystems to support salmonids. 


\subsubsection{Juvenile Salmonid Performance}

The overall objective here is to determine the status and trends of monitored indicators for juvenile salmonid performance in the estuary and plume (compare with RPAs 58 and 59 in NMFS 2007). The juvenile salmonid performance objective has four sub-objectives (STM 5-8).

STM 5. Evaluate migration charcateristics, including juvenile salmonid abundance, residence times, growth rates, diets, and prey resources at representative locations in the estuary and plume to understand habitat usage and relative ecological importance of various habitats to juvenile salmonids.

Indicators of migration characteristics can reflect fish performance relative to habitats in the estuary and plume. For example, residence times indicate the amount of time juvenile salmonids spend in the estuary. In conjunction, migration pathways characterize the corridors and habitats where juvenile salmonids are predominantly found migrating through the system (Schreck et al. 2005). Growth rate, which is calculated as the change in length or weight of the sampled juvenile salmon population per unit time, is a direct indicator of ecological benefits from estuarine habitats, especially when coupled with monitoring of diet and prey resources.

STM 6. Monitor and evaluate smolt survival from Bonneville Dam through the estuary into the plume.

Survival rate is a fundamental performance measure that can be estimated using tagging techniques for juveniles of selected species and life history types. Locations of interest include the CRE from Bonneville Dam to the plume, and selected areas of the estuary where predation rates may be relatively high.

STM 7. Develop an index and monitor and evaluate life history diversity of salmonid populations at representative locations in the estuary.

An index for life history diversity is needed to monitor trends in this important indicator of salmon performance. An understanding of trends in life history diversity is important to assessing the performance of restoration projects. In addition to status and trends monitoring, this objective contains an element of uncertainties research in development of the index.

STM 8. Monitor and evaluate temporal and spatial species composition, abundance, and foraging rates of juvenile salmonid predators at representative locations in the estuary and plume.

Predation on juvenile salmonids is a concern throughout the Columbia basin, as it is in the estuary and plume. Monitoring predators and their foraging rates will help determine the extent of effects of this limiting factor on salmonid performance. 


\subsubsection{Sampling Design}

Many of the status and trends monitoring objectives require assessment at the estuary-wide (or "landscape") scale. Landscape-scale status and trends monitoring must be based on relatively easy and inexpensive collection procedures for indicators associated with habitat capacity and opportunity for salmonids; expensive or difficult-to-collect indicators are unlikely to persist across decades of changing budgetary priorities. The use of remote sensing and GIS to monitor indicators such as total habitat area, connectivity, or changes in land use has the potential to canvas large areas in a cost-effective manner. Thus, this plan draws on a variety of methods targeted to address each specific objective. It incorporates a) remote sensing and GIS procedures using a census design, and b) on-the-ground monitoring using a split-panel rotational sampling design.

A census design is required for status and trends monitoring for bathymetry/topography, habitat classification and mapping, and habitat connectivity (Objectives STM 1-3). Census means complete enumeration, an approach ideally suited to remote sensing and GIS techniques. Capabilities of these technologies are increasing rapidly and are suited for an area as large as the Columba River estuary.

A rotational panel design (McDonald 2003) is the recommended sampling design for estuary RME status and trends monitoring for habitat conditions and juvenile salmonid performance (Objectives STM 4-8, except STM 6 which uses a survival estimation design). The rotational panel design provides the best features for simultaneous status and trends monitoring. There are several advantages of rotational designs over traditional fixed-location schemes, including:

1. Continual input of new locations keeps the sampling scheme refreshed, allowing the design to detect environmental events that fixed-location designs might miss.

2. Rotational designs provide opportunity for precise estimates of both status and trends.

3. The repeated measures from one year to the next also allow annual estimates of status to be updated (i.e., recalculated), taking into account the temporal correlation for improved precision.

Rotational designs optimally allocate effort over time and space to provide precise estimates of both status (e.g., $\bar{x}$ ) and trends (e.g., $\bar{x}_{2}-\bar{x}_{1}$ ). Rotational split-panel designs (Figure 4), where some sites are sampled infinitum while others are rotated in and out of the design over time, provide the opportunity to collocate status and trends sites with reference sites used in regional effectiveness monitoring (see AER 1). The merits of rotational designs are developed more fully in Appendix B. 


\begin{tabular}{|c|c|c|c|c|c|c|c|c|c|}
\hline \multirow{2}{*}{ Panel } & \multicolumn{7}{|c|}{ Sampling Occasion } \\
\hline & 1 & 2 & 3 & 4 & 5 & 6 & 7 & 8 & 9 \\
\hline 1 & & & & & & & & & \\
\hline 2 & & & & & & & & & \\
\hline 3 & & & & & & & & & \\
\hline 4 & & & & & & & & & \\
\hline 5 & & & & & & & & & \\
\hline 6 & & & & & & & & & \\
\hline 7 & & & & & & & & & \\
\hline 8 & & & & & & & & & \\
\hline 9 & & & & & & & & & \\
\hline 10 & & & & & & & & & \\
\hline 11 & & & & & & & & & \\
\hline 12 & & & & & & & & & \\
\hline
\end{tabular}

Figure 4. Rotational Split-Panel Design. Here, one panel of sites is monitored annually because of strategic, biological, or social importance. Other panels are sampled in a rotational scheme to provide additional time series data and provide greater spatial coverage (Appendix B; Figure B10).

\subsubsection{Monitoring Guidance}

Monitoring guidance includes sampling design, spatial/temporal scale, monitored indicators, monitoring protocols, derived variables, analysis, possible funding entities, and implementation and coordination (Table 1). In an effort to improve coordination and consistency basin-wide, this structure is the same as that used in the RME Plan for the Upper Columbia Domain (UCTRT 2007). The possible funding entities and implementation and coordination avenues are suggestions based on established related activities. 
Table 1. Monitoring Guidance for Status and Trends Monitoring

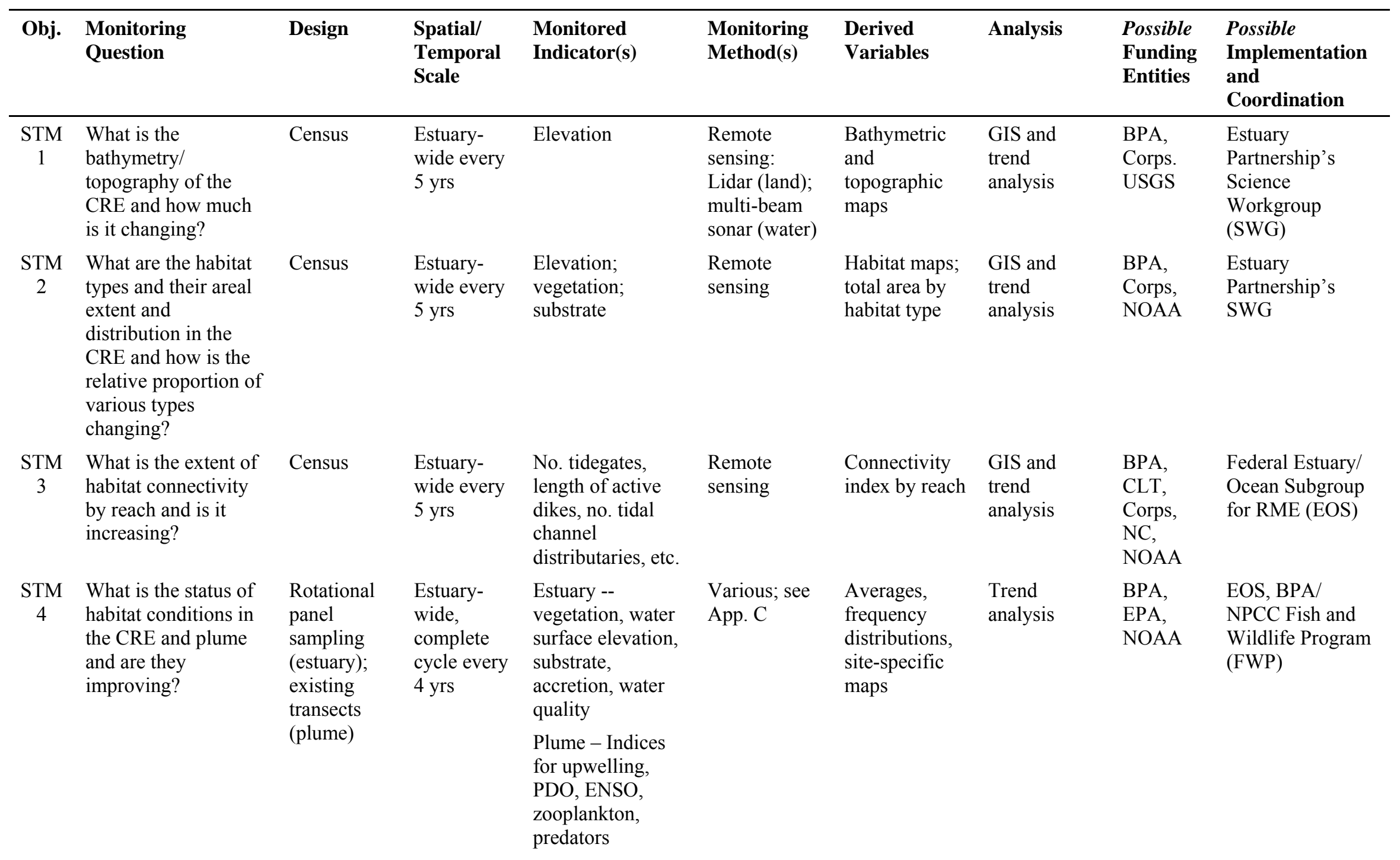




\begin{tabular}{|c|c|c|c|c|c|c|c|c|c|}
\hline Obj. & $\begin{array}{l}\text { Monitoring } \\
\text { Question }\end{array}$ & Design & $\begin{array}{l}\text { Spatial/ } \\
\text { Temporal } \\
\text { Scale }\end{array}$ & $\begin{array}{l}\text { Monitored } \\
\text { Indicator(s) }\end{array}$ & $\begin{array}{l}\text { Monitoring } \\
\text { Method(s) }\end{array}$ & $\begin{array}{l}\text { Derived } \\
\text { Variables }\end{array}$ & Analysis & $\begin{array}{l}\text { Possible } \\
\text { Funding } \\
\text { Entities }\end{array}$ & $\begin{array}{l}\text { Possible } \\
\text { Implementation } \\
\text { and } \\
\text { Coordination }\end{array}$ \\
\hline $\begin{array}{l}\text { STM } \\
5\end{array}$ & $\begin{array}{l}\text { What are migration } \\
\text { characteristics and } \\
\text { habitat use by } \\
\text { juvenile salmonids in } \\
\text { the CRE and are they } \\
\text { changing? }\end{array}$ & $\begin{array}{l}\text { Rotational } \\
\text { panel } \\
\text { sampling }\end{array}$ & $\begin{array}{l}\text { Estuary- } \\
\text { wide, } \\
\text { complete } \\
\text { cycle every } \\
4 \text { yrs }\end{array}$ & $\begin{array}{l}\text { Abundance, age- } \\
\text { size structure, } \\
\text { distribution, } \\
\text { residence and } \\
\text { travel time, } \\
\text { growth rate, } \\
\text { migration } \\
\text { pathway, species } \\
\text { composition, } \\
\text { stock identity }\end{array}$ & $\begin{array}{l}\text { Various; see } \\
\text { App. C }\end{array}$ & $\begin{array}{l}\text { Averages, } \\
\text { frequency } \\
\text { distributions, } \\
\text { correlations }\end{array}$ & $\begin{array}{l}\text { Regression } \\
\text { and trends } \\
\text { analysis }\end{array}$ & $\begin{array}{l}\text { BPA, } \\
\text { Corps }\end{array}$ & $\begin{array}{l}\text { EOS, Corps' } \\
\text { Anadromous Fish } \\
\text { Eval. Program } \\
\text { (AFEP) }\end{array}$ \\
\hline $\begin{array}{l}\text { STM } \\
6\end{array}$ & $\begin{array}{l}\text { What is reach } \\
\text { survival for juvenile } \\
\text { listed salmonids in } \\
\text { the CRE and is it } \\
\text { improving? }\end{array}$ & $\begin{array}{l}\text { Survival } \\
\text { model }\end{array}$ & $\begin{array}{l}\text { Estuary- } \\
\text { wide } \\
\text { annually }\end{array}$ & Survival rate & $\begin{array}{l}\text { Acoustic } \\
\text { telemetry }\end{array}$ & $\begin{array}{l}\text { Averages, } \\
\text { correlations } \\
\text { with env. } \\
\text { cond's }\end{array}$ & $\begin{array}{l}\text { Trend } \\
\text { analysis, } \\
\text { statistical } \\
\text { comparisons }\end{array}$ & $\begin{array}{l}\text { BPA, } \\
\text { Corps }\end{array}$ & AFEP, FWP \\
\hline $\begin{array}{l}\text { STM } \\
7\end{array}$ & $\begin{array}{l}\text { What is the level of } \\
\text { life history diversity } \\
\text { in salmonids and is it } \\
\text { increasing? }\end{array}$ & $\begin{array}{l}\text { Rotational } \\
\text { panel } \\
\text { sampling }\end{array}$ & $\begin{array}{l}\text { Estuary- } \\
\text { wide, } \\
\text { complete } \\
\text { cycle every } \\
8 \text { yrs }\end{array}$ & $\begin{array}{l}\text { Abundance, } \\
\text { distribution, } \\
\text { species comp., } \\
\text { stock id. }\end{array}$ & $\begin{array}{l}\text { Various; } \\
\text { App. C }\end{array}$ & $\begin{array}{l}\text { Life history } \\
\text { diversity } \\
\text { index }\end{array}$ & $\begin{array}{l}\text { Trend } \\
\text { analysis }\end{array}$ & $\begin{array}{l}\text { BPA, } \\
\text { NOAA }\end{array}$ & $\begin{array}{l}\text { AFEP, EOS, } \\
\text { FWP, SWG }\end{array}$ \\
\hline $\begin{array}{l}\text { STM } \\
8\end{array}$ & $\begin{array}{l}\text { How much mortality } \\
\text { of listed salmonids } \\
\text { can be attributable to } \\
\text { piscine, avian, and } \\
\text { marine mammal } \\
\text { predators? }\end{array}$ & $\begin{array}{l}\text { Rotational } \\
\text { panel } \\
\text { sampling }\end{array}$ & $\begin{array}{l}\text { Estuary- } \\
\text { wide, } \\
\text { complete } \\
\text { cycle every } \\
4 \text { yrs }\end{array}$ & $\begin{array}{l}\text { Abundance of } \\
\text { predators, } \\
\text { consumption rates }\end{array}$ & $\begin{array}{l}\text { Various; see } \\
\text { App. C }\end{array}$ & $\begin{array}{l}\text { Predation } \\
\text { index, no. } \\
\text { salmonids } \\
\text { eaten by } \\
\text { predator class }\end{array}$ & $\begin{array}{l}\text { Trend } \\
\text { analysis }\end{array}$ & $\begin{array}{l}\text { BPA, } \\
\text { Corps, } \\
\text { NOAA }\end{array}$ & AFEP, FWP \\
\hline $\begin{array}{l}\text { AFEP- } \\
\text { Wildli } \\
\text { SWG }\end{array}$ & $\begin{array}{l}\text { Anadromous Fish Eva } \\
\text { Program; ENSO=El } \\
\text { cience Work Group }\end{array}$ & $\begin{array}{l}\text { tion Progr } \\
\text { to Souther }\end{array}$ & $\begin{array}{l}\text { LT }=\text { Colum } \\
\text { illation; GPs }\end{array}$ & $\begin{array}{l}\text { ia Land Trust; CRE } \\
\text { =global positioning }\end{array}$ & $\begin{array}{l}\text { Lolumbia Riv } \\
\text { stem; PDO= }\end{array}$ & $\begin{array}{l}\text { estuary; } \mathrm{EPA}= \\
\text { ific decadal os }\end{array}$ & $\begin{array}{l}\text { vironmental } \\
\text { lation; STM= }\end{array}$ & $\begin{array}{l}\text { ection } \mathrm{Ag} \\
\text { us and tre }\end{array}$ & $\begin{array}{l}\text { cy; FWP=Fish and } \\
\text { s monitoring; }\end{array}$ \\
\hline
\end{tabular}




\subsection{Action Effectiveness Research}

In estuary RME, action effectiveness research is focused on the habitat restoration efforts that the Action Agencies are undertaking in tidally-influenced waters from Bonneville Dam to the mouth of the Columbia River. Habitat restoration, including protection, conservation, and rehabilitation, is the primary means in the estuary for "off-site mitigation" for operation of the FCRPS. The overall objective of estuary RME's action effectiveness research is to use a representative set of projects to monitor and evaluate the effects of habitat restoration actions in the estuary. This topic is addressed through three subobjectives: reference sites, effectiveness monitoring, and validation monitoring (compare with RPA 60 in NMFS 2007).

AER 1. Develop a limited number of reference sites for typical habitats, e.g., tidal swamp, marsh, island, and tributary delta, to use in action effectiveness evaluations.

A network of reference sites representing tidal marshes, tidal swamps, and other estuary habitats and having relatively undisturbed ecosystem structures and processes is required for action effectiveness monitoring of restoration projects. These sites can also serve as status and trends monitoring locations (see Section 2.1.3, Sampling Design).

Reference sites will be a crucial part of an action effectiveness sampling design (see AER 2). It is recognized that there are no undisturbed sites available because of changes to the hydrograph (a controlling factor), and various stressors. For statistical power, the number of reference sites in each habitat type should be equal to or greater than the number of restoration project sites in that category. However, it may not be possible to identify enough relatively pristine areas to fulfill this need. Following the recommendations in An Approach to Improving Decision Making in Wetland Restoration and Creation (Kentula et al. 1992), the network of reference sites in each category may be considered a population for the purpose of statistical analysis and compared against the population of project sites. The trajectories of development of restoration and reference sites may also be analyzed as pairs, where suitable paired sites exist; an example of this method is provided by the use of a similarity index to evaluate the Elk River estuarine marsh restoration in Grays Harbor, Washington (Thom et al. 2002).

The natural or reference sites also serve as a source of information from which to develop performance criteria for restoration project sites (Kentula et al. 1992). Trajectories of post-restoration ecosystem development may then be predicted, with monitoring data used as the basis for annual analyses to determine whether projects are meeting expectations or needing adjustments within an adaptive management framework (Kentula et al. 1992; Thom 1997; Thom 2000). It is hoped that some of the long-term status and trends sampling sites proposed for the estuary will overlap with suitable reference sites to provide for long-term sampling efficiency. To facilitate such multiple uses of the monitoring data, the monitoring protocols selected for status monitoring and action effectiveness sampling should be congruent to the extent possible given different primary objectives. The USACE study on cumulative effects of restoration has produced a working draft of protocols for restoration monitoring in the estuary 
(Roegner et al. 2008). The EOS recommends that this be adopted estuary-wide as part of estuary RME. The core biological and physical indicators recommended by Roegner et al. (2008) are shown in Table 2:

Table 2. Core Biological and Physical Indicators Recommended for Action Effectiveness Monitoring of Habitat Restoration Projects in the Estuary. Adapted from Roegner et al. (2008).

\begin{tabular}{llc}
\hline Attribute & Category & Monitored Indicator \\
\hline Physical & Hydrology & Surface Water Elevation \\
\cline { 2 - 3 } & Water quality & Temperature \\
& & Salinity \\
& & Dissolved oxygen \\
\cline { 2 - 3 } & Habitat & Landscape features: \\
& & Photo points \\
& & Aerial imagery \\
\cline { 2 - 2 }
\end{tabular}

Elevation:

Channel cross sections

Fixed points on vegetation transects

Fixed points at water level instrument locations

Sediment accretion stakes

\begin{tabular}{ccc}
\hline Biological & Vegetation & Vegetation cover: \\
& Species composition \\
Species percent cover \\
Elevation correlations \\
Similarity index (temporal change) \\
Planting success rate \\
\hline Fish community & Species composition \\
& Size structure \\
& Temporal presence \\
\hline
\end{tabular}

AER 2. Evaluate the effects of selected individual habitat restoration actions at project sites relative to reference sites and evaluate post-restoration trajectories based on project-specific goals and objectives. ("Effectiveness Monitoring")

This action consists of monitoring multiple restoration project sites. Trends in core monitored indicators at restoration sites and a network of corresponding reference and status monitoring sites are analyzed to meet this objective (see AER 1). Where available, paired reference and restoration sites should also be compared using similarity indexes (e.g., Thom et al. 2002). In addition, evaluation based on project-specific goals should follow methods for habitat and fish monitoring outlined in Roegner et al. (2008). 
The action effectiveness sampling design uses a control chart method to document the condition of restoration sites relative to a suite of reference sites; alternative action effectiveness sampling designs, including control-reference designs and replicate restoration-reference designs, are developed more fully in Appendix B. We take the view that control sites ${ }^{\mathrm{a}}$ are an unnecessary luxury if the difference between states $A$ and $B$ is great. In other words, if the ranges of characteristics at restoration and reference sites do not overlap, then there should be little or no risk of falsely concluding restoration (i.e., reaching state B) when the site is still within the range of the initial state A. In this case, only reference sites are needed to assess the status of recovery (Figure 5). Restoration success is still defined in this situation as the subject site merging into the range of reference conditions and tracking reference site responses over time. Using only reference sites as part of an effectiveness monitoring design is analogous in many ways to accident assessment designs (Skalski 1995). Recovery of impacted sites following some environmental accident is defined by the impacted site approaching the range of reference conditions and subsequently sharing their same temporal trajectory over time.

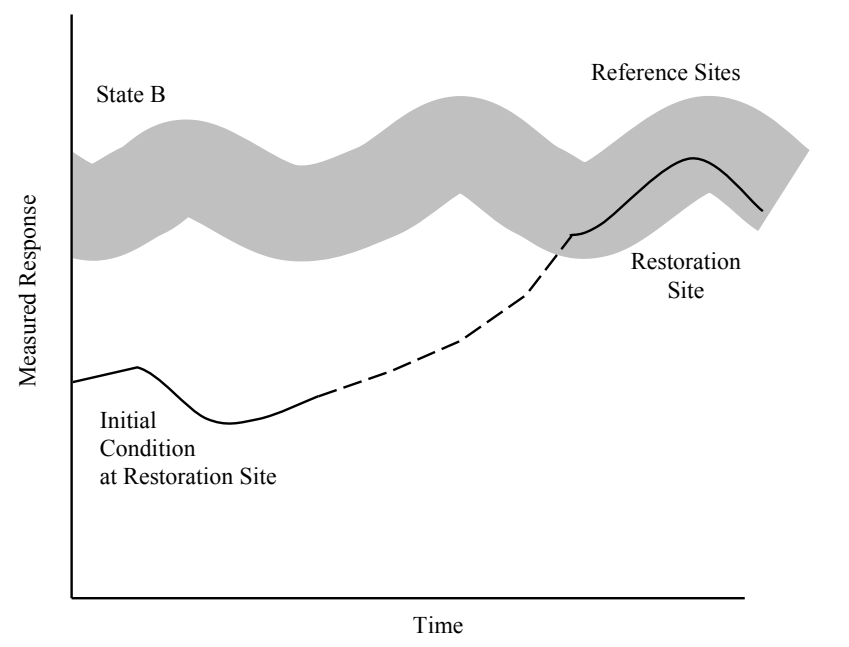

Figure 5. Conceptual Framework for Monitoring Restoration Effectiveness Using Only Reference Sites as a Target for Recovery. The initial condition at the restoration site is "State A." The gray-shaded area for the reference sites is "State B."

The control chart method mirrors accident assessment, in which typically there are multiple reference sites and multiple potentially impacted sites in the evaluation. Skalski and Robson (1992) suggested using repeated measures analysis in conjunction with a test for parallelism to assess recovery. Recovery was achieved when the reference and impact sites began tracking each other through time, i.e., parallelism (Skalski et al. 2001). However, in monitoring the restoration of a single site, standard tests of parallelism

\footnotetext{
${ }^{a}$ Control sites are replicate locations with habitat traits similar to the subject site prior to restoration, which are sampled over time to monitor any temporal shifts in baseline conditions and how the subject area might have responded over time had no restoration action taken place.
} 
cannot be performed. There is no between-site, within-treatment variance, only within-site measurement error at the restoration site.

From the repeated sampling at the reference sites, upper and lower control limits for reference responses can be constructed. Control limits describe a range of population responses, such that a prescribed proportion of the population falls within their bounds. For example, the limits

$$
\mu \pm 3 \sigma
$$

contain approximately $99.7 \%$ of a normally distributed population. Shewhart control charts (Grant and Leavenworth 1972; Duncan 1974; Burr 1976) use this principle to establish control limits to monitor production processes in manufacturing. A variation of this concept could be used to assess whether a restoration site merges into the range of reference conditions (Figure 6). Wheeler (1995; p. 205-225) provides statistical power calculations for control charts.

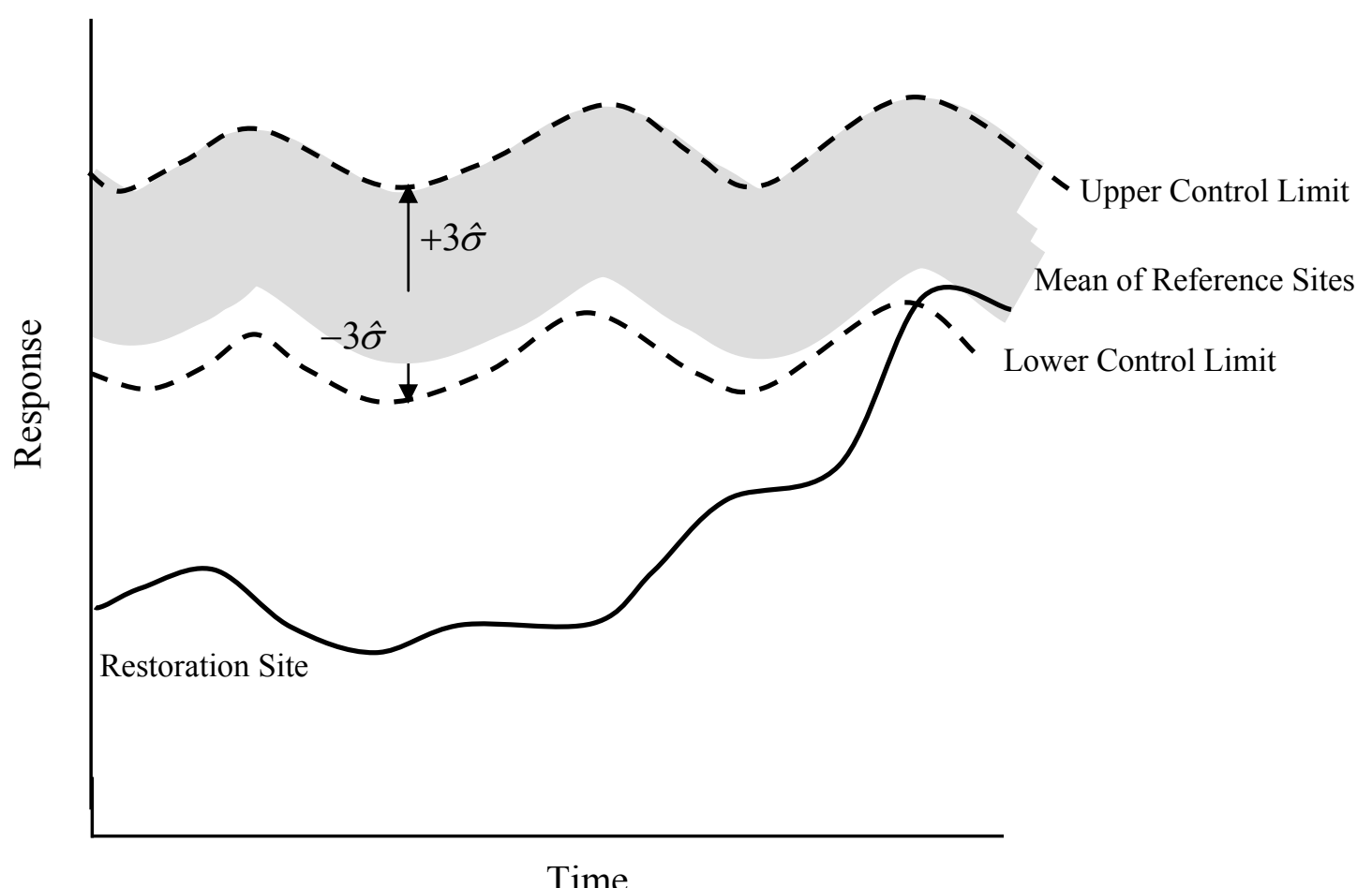

Figure 6. Illustration of Using Control Chart Methods to Monitor Recovery Success 


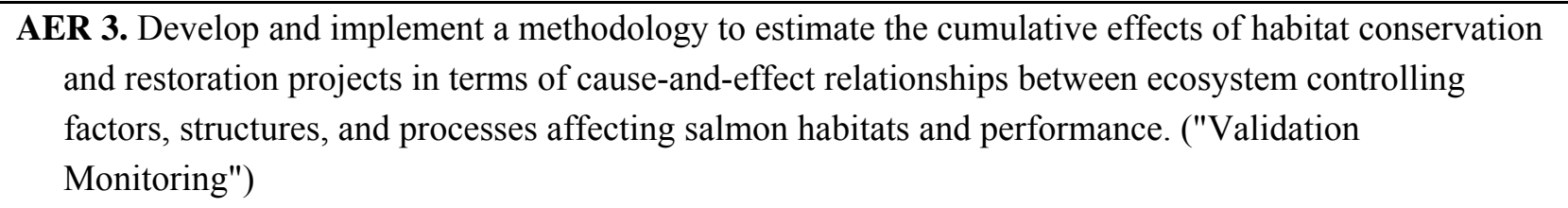

This action consists of research and monitoring at landscape, watershed, and site/project scales. The validation objective is to answer a question: "what was the cumulative effect of all habitat conservation and restoration efforts in the estuary relative to the program goal?" The answer to this question is critical to objectively determining whether habitat restoration actions in the estuary are positively affecting salmon.

Cumulative effects assessment must, by definition, include multiple restoration locations and activities. While the term "cumulative effects" typically implies that "the whole is greater than the sum of the parts," in fact effects may be additive, synergistic, or countervailing. The purpose of cumulative effects analysis in the CRE is to demonstrate whether the effects of a series of restoration activities are greater than their individual contributions taken in isolation. For example, increased habitat connectivity might be expected to have cumulative effects on salmonid performance measures, biodiversity, nutrient cycling, hydrodynamic processes, etc. Assessment of cumulative effects requires testing for synergistic effects or non-additive effects. Consequently, no single site or haphazard collection of restoration sites initiated over time would suffice for cumulative effects assessment. The restoration activities must be structured in such a manner that environmental responses can be related to the scale of restoration. Indicators of cumulative effects proposed by Diefenderfer et al. (2006) are as follows: salmonid growth, residence time, and prey; organic matter and nutrient fluxes; hydraulic geometry; swamp and marsh macrophyte productivity; species diversity and distribution (species-area curves); hydrological and flood storage modeling; sediment accretion rates; and correspondence between plant community and elevation. The latter two of these indicators are available from data developed from core action effectiveness monitoring indicators (Table 2).

The relative importance of a cumulative effect may be thought of in terms of a) the difference from the historical or current baseline, b) progress toward restoration objectives for estuary habitats and salmon, or c) its relationship to a known environmental threshold beyond which significant change in ecological processes and functions will occur. Other actions affecting the estuary subbasin, such as land conversion for suburban development, flow regulation, forestry, agriculture, and climate and ocean variability, also will continue to generate cumulative effects that may complicate the evaluation of restorative actions. Three meta-analysis approaches for cumulative effects are developed more fully in Appendix B: a) relating cumulative response to physical size of restoration sites, b) relating cumulative response to number of projects in a restoration cluster, and c) relating cumulative response to temporal trends in restoration events. AER 3 contains an element of uncertainties research in that the assessment of cumulative effects previously has been done for ecosystem degradation, not restoration. 


\subsection{Extensive vs. Intensive Monitoring}

There is usually a trade-off between spatially extensive and locally intensive sampling efforts in the allocation of scarce sampling resources. Status and trends monitoring at the estuary-wide scale requires spatially extensive sampling in order to make inferences across a broad geographic area. Precise estimates of status and the power to detect time trends are improved if numerous sites are lightly sampled, rather than a few sites heavily characterized. Consequently, effort is redistributed from the site level to more locations across the landscape. Extensive sampling can include the panel designs proposed herein for STM where individual sites are rotated in and out of the sampling frame over time. The reallocation of effort may also include measuring fewer responses and responses that better summarize or integrate overall effects of habitat restoration. This is the strategy underlying the STM monitoring guidance (Section 2.1.4).

Action effectiveness research, on the other hand, requires guidance on which restoration end points to measure and when to measure them that must be determined from intensively studied reference and treatment areas. Therefore, a few intensively sampled AER areas must be integrated within the fabric of an extensive STM effort. Based on these AER sites, sampling protocols are developed and the trajectories of physical and biological responses to restoration can be mapped (Section 2.2). These intensive sites provide a virtual model of the restoration process that guide the selection of the strategic measurements to be taken at the extensive sites. These intensively monitored reference sites effectively provide the inferential framework to help assess the success of restoration from the cursory observations taken over time at the individual restoration projects.

Thus, Estuary RME will entail a proper mix of extensive and intensively monitored sites, where individual restoration projects surveyed for AER help to provide maximum opportunities to detect estuary-wide benefits when integrated with results from STM sites.

\subsection{Summary}

The monitoring framework, fully developed in Appendix B, provides the scientific basis for status and trends monitoring (STM) in the CRE. The overall objective of STM is to measure monitored indicators that are ecologically significant to listed salmonids in the lower river, estuary, plume, and nearshore ocean. The specific STM objectives deal with ecosystem controlling factors, structures, and salmonid performance. The Columbia River Estuary Conceptual Model (Thom et al. 2004) forms a basis for the selection of monitored indicators for each objective. A rotational split panel sampling design is proposed. Data collection methods, the spatial and temporal scale of monitoring, and example protocols are provided in Appendix C.

The overall purpose of action effectiveness research (AER) is to use quantitative studies to demonstrate how habitat restoration actions affect factors controlling ecosystem structures and processes at site and landscape scales and, in turn, juvenile salmonid performance. The specific AER objectives address effectiveness and validation monitoring. (Implementation monitoring is covered in 
Section 4.1.4.) The research and monitoring framework for action effectiveness research is consistent with the monitoring recommendations under the Estuary Restoration Act (Thayer et al. 2003; 2005). A control chart method based on data from a suite of reference and restoration sites is recommended for effectiveness monitoring, and a meta-analysis method for validation monitoring. To efficiently assess the effectiveness of habitat restoration in the Columbia River estuary and to meet the AER objectives, pertinent elements of the datasets developed through status and trends monitoring, implementation and compliance monitoring, and restoration project-specific monitoring will need to be analyzed, synthesized, and evaluated. A network of reference sites will be crucial to this effort. Data collection methods for action effectiveness, as well as the spatial and temporal scale of monitoring and example protocols are provided in Appendix C.

In conclusion, status and trends monitoring in the CRE is important because it will reveal whether ecosystem features supporting salmonids are improving, staying the same, or degrading. Action effectiveness research in the CRE is important because it will show the ecological results from the primary management action in the CRE - habitat restoration - and provide feedback to managers of the next-generation restoration projects. Knowledge developed from status and trends monitoring and action effectiveness research incorporating both extensive and intensive monitoring, when integrated with scientific findings from critical uncertainties research (see Section 3.1), will help guide management actions on the estuary. 
Research, Monitoring, and Evaluation for the Federal Columbia River Estuary Program 


\subsection{Research Plan}

The overall objective of the research plan is to investigate critical uncertainties in the state-of-thescience in the estuary, plume, and nearshore ocean that are pivotal to understanding estuary/ocean effects on fish performance. The resolution of uncertainties in the existing estuary knowledge base is fundamental to implement appropriate restoration actions, status and trends monitoring, and action effectiveness research in the Estuary Program. Uncertainties are those pieces of information currently unavailable that managers require for informed decision making. Many of the uncertainties presented in this section were identified in Columbia River Estuary and the Columbia River Basin Fish and Wildlife Program (Bisson et al. 2000), Coordinated Research Plan for Estuarine and Ocean Research on Pacific Salmon (Brodeur et al. 2000), Salmon at River's End (Bottom et al. 2005), Research Needs Identification Workshop for the Columbia River Estuary (USACE and Estuary Partnership 2003), Ecosystem-Based Approach for Restoration Projects in the Columbia River Estuary (Johnson et al. 2003), Role of the Estuary in the Recovery of Columbia River Basin Salmon and Steelhead: an Evaluation of Selected Factors on Population Viability (Fresh et al. 2005), Columbia River Basin Research Plan (NPCC 2006b), and Mainstem/Systemwide Project Review Process (Mainstem Systemwide Review Team 2006). The estuary/ocean RME subgroup reviewed the uncertainties in these documents in the context of the goal and objectives of the federal Estuary Program. The uncertainties research plan does not include sampling design because these details are appropriately developed at the project level by the researchers.

\subsection{Objectives}

The resolution of the uncertainties identified below is fundamental to successful implementation of estuary RME and to the goal of restoring salmonid populations (compare RPA 61). Critical uncertainties regarding fish performance in the estuary that have potential causal mechanisms rooted in the hydrosystem (e.g., delayed mortality) are addressed under Hydrosystem RME and therefore not included here. The five uncertainties, or sub-objectives, that follow are expressed as null hypotheses to provide clarity.

CUR 1. Continue work to define the ecological importance of the tidal freshwater, estuary, plume and nearshore ocean environments to the viability and recovery of listed salmonid populations in the Columbia Basin.

$\mathrm{H}_{\mathrm{o}}$ : Tidal freshwater, estuary, plume, and nearshore ocean environments have no effect on the viability or recovery of listed salmonid populations in the Columbia Basin.

This is a major uncertainty, the resolution of which will determine the importance of estuary/ocean actions in the overall recovery effort for listed salmonids. This action includes studies to determine 1) the linkage between habitat conditions and growth and survival of juvenile salmonid fishes in the estuary and ocean, and 2) which ecosystem controlling factors, structures, and processes of the estuary and ocean are limiting for the salmon ESUs. Also, it is uncertain which ecosystem controlling factors, structures, and processes of the estuary and ocean are limiting for the salmon ESUs. The research need is to determine 
the extent of any estuary ecological functions that are limiting for juvenile salmon, because knowledge of limiting factors may lead to more effective resource allocation. This will improve the understanding of plume dynamics and their role in salmon life histories.

CUR 2. Continue work to define the causal mechanisms and migration/behavior characteristics affecting survival of juvenile salmon during their first weeks in the ocean and subsequent adult returns.

$\mathrm{H}_{\mathrm{o}}$ : Neither the timing of ocean entry, juvenile migration pattern, in-estuary growth and survival, nor ocean conditions affect a) juvenile salmonid survival during their first weeks in the ocean or b) interannual variations in sizes of runs of returning adult salmonids.

This research is interrelated with CUR 1. CUR 2 includes the effect of timing of ocean entry and whether concurrent monitoring of ocean conditions and salmonid migration patterns, growth, and survival can be used to predict inter-annual variations in sizes of runs of returning adult salmonids. The need is to collect concurrent environmental and juvenile salmonid data during the first weeks in the ocean and correlate these data with adult salmonid returns.

CUR 3. Investigate the importance of early life history of salmon populations in tidal freshwater of the lower Columbia River.

$\mathrm{H}_{\mathrm{o}}$ : Shallow water habitats in the tidal freshwater reach of the CRE are not important to the growth and survival of ocean-type salmon.

Shallow water habitats in the tidal freshwater reach of the lower Columbia River and estuary are hypothesized to be important to the growth and survival of ocean-type salmon, such as Snake River fall Chinook salmon, but scientific knowledge specifically addressing this hypothesis is sparse and current monitoring efforts are fragmented.

CUR 4. Investigate the effects of hatchery salmonids on wild (naturally produced) juvenile salmonids in the estuary.

$\mathrm{H}_{\mathrm{o}}$ : Hatchery salmonids in the estuary have no effect on the growth and survival of wild salmonids.

Every year millions of juvenile salmonids that are released from hatcheries in the Columbia basin migrate through the CRE. These hatchery fish can occur in high densities relative to their wild counterparts, potentially causing competition for food and refuge. The research need is to investigate whether there is a density-dependent effect of hatchery salmonids on the growth and survival of wild salmonids in the estuary.

CUR 5. Understand the wetting and drying of the floodplain habitats caused by complex hydrodynamic interactions of tides, mainstem and tributary flows, and the effect of the FCRPS on river conditions.

$\mathrm{H}_{\mathrm{o}}$ : The regulation of river flows by the FCRPS does not reduce available salmonid habitats through effects on wetting and drying of the floodplain in the estuary. 
Water surface elevation, i.e., wetting and drying, of floodplain habitats is fundamental to the ecological processes that are the basis for estuary habitat restoration action involving tidal reconnection, such as dike breaches, tide gate retrofits, and culvert replacements. Water surface elevation affects habitat opportunity, capacity, and functionality. Thus, there is a research need to continue development, validation, and implementation of hydrodynamic numerical models for the estuary.

\subsection{Conceptual Model}

As in status and trends monitoring and action effectiveness research frameworks, we adapted the Columbia River Estuary Conceptual Model (Thom et al. 2004) to develop monitored indicators for uncertainties research for estuary RME (Figure 7). Using the model's linkages supporting the ecosystem function for salmonid performance, we identified the model's components that address uncertainties objectives (see highlights in Figure 7). The objectives for estuary RME uncertainties research correspond to flow regulation, passage/flow barriers, and ocean conditions and the linkages of these stressors to controlling factors that include hydrodynamics, bathymetry/topography, and temperature (Figure 7). In addition, the CRE Conceptual Model applied to uncertainties research shows the prominence of ecosystem processes and their linkages with ecosystem structures and salmonid performance (Figure 7). As in status and trends monitoring and action effectiveness research frameworks (Appendix B), the model reveals important monitored indicators.

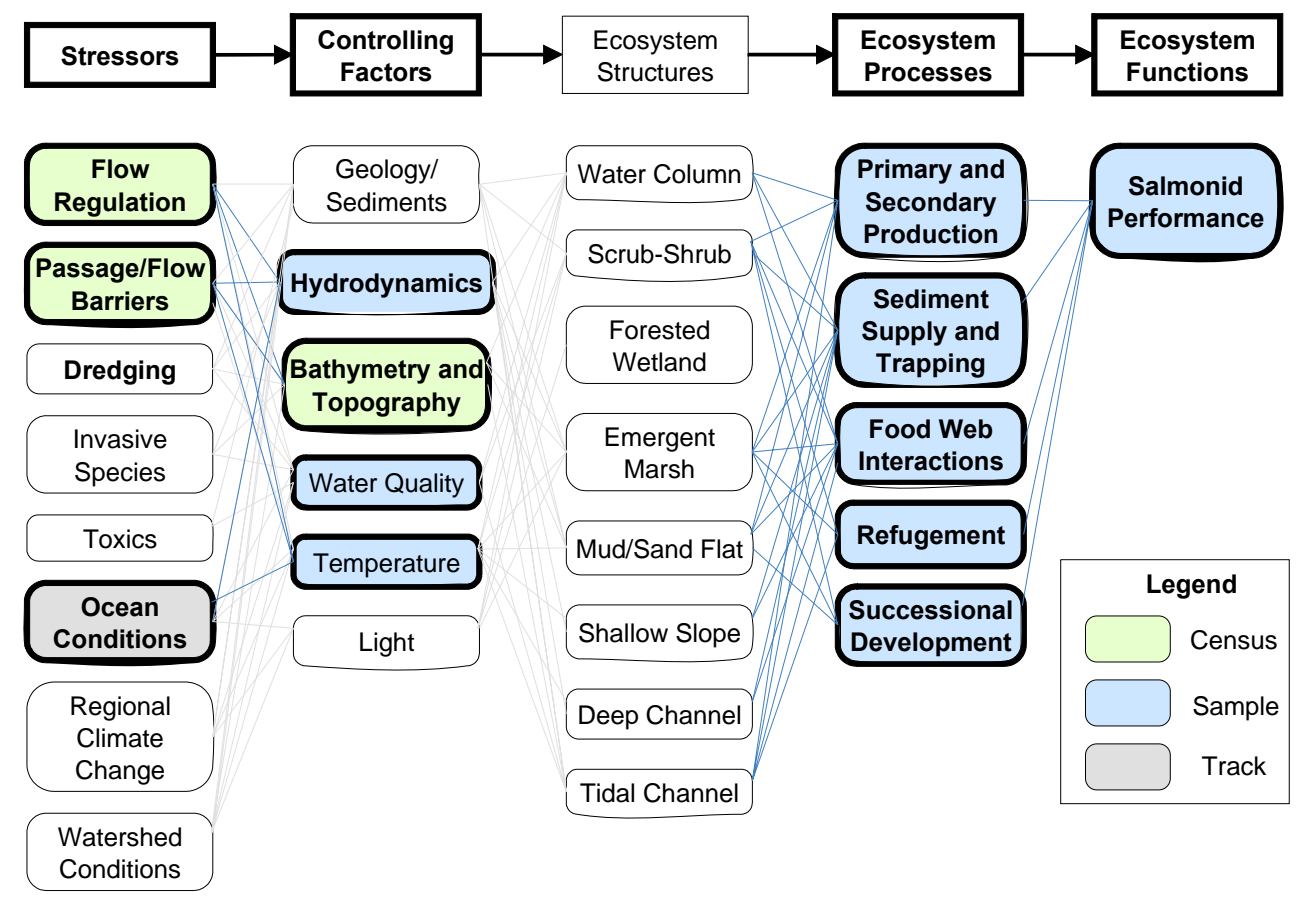

Figure 7. Columbia River Estuary Conceptual Model Applied to Estuary Uncertainties Research. The spatial scale is the CRE from Bonneville to the mouth. (Adapted from Thom et al. 2004.) 


\subsection{Monitored Indicators}

Uncertainties research necessarily involves many of the monitored indicators for status and trends monitoring and action effectiveness research, because these indicators and attributes are fundamental measures of the controlling factors, structures, processes, and functions in the CRE. Uncertainties research may directly use data produced from STM and AER efforts and, in turn, may contribute to the fundamental understanding of the nature and role of the indicator in the system. For example, STM work on the habitat connectivity index, life history diversity index, and ecosystem classification system will be pertinent to uncertainties research; while sufficient information exists to include these in status and trends monitoring, much remains unknown (Bottom et al. 2005). All four uncertainties involve multiple monitored indicators (Table 3). The monitored indicators shown here are common in research in the CRE, but will need to be supplemented for the specific needs of particular research projects.

Table 3. Monitored Indicators for Uncertainties Research in Estuary RME. Asterisk* implies core indicator: green $=$ census; blue $=$ probabilistic sample; gray $=$ track information provided by others.

\begin{tabular}{|c|c|c|c|c|c|c|}
\hline Category & Monitored Indicator(s) & $\begin{array}{c}\text { CUR } \\
1\end{array}$ & $\begin{array}{c}\text { CUR } \\
2\end{array}$ & $\begin{array}{c}\text { CUR } \\
3\end{array}$ & $\begin{array}{c}\text { CUR } \\
4\end{array}$ & $\begin{array}{c}\text { CUR } \\
5\end{array}$ \\
\hline Flow Regulation & Water Discharge & & $\bullet$ & & & $\bullet$ \\
\hline Passage/Flow Barriers & Passage Barriers & & - & - & & - \\
\hline Ocean Conditions & $\begin{array}{l}\text { Upwelling Index, PDO Index, ENSO Index, } \\
\text { Zooplankton Index, Hake Index }\end{array}$ & $\bullet$ & & & & \\
\hline \multirow[t]{3}{*}{ Hydrodynamics } & Ground Water Level & & & - & & - \\
\hline & Surface Water Elevation* & & & $\bullet$ & & $\bullet$ \\
\hline & Water Velocity (currents) & & - & - & & - \\
\hline \multirow[t]{2}{*}{ Bathymetry/Topography } & Bathymetry & & $\bullet$ & & & $\bullet$ \\
\hline & Floodplain Topography* & & $\bullet$ & & & $\bullet$ \\
\hline \multirow[t]{4}{*}{ Water Quality } & Dissolved Oxygen* & - & & & & \\
\hline & Nutrients (nitrogen, phosphorous) & - & & & & \\
\hline & $\mathrm{pH}$ & - & & & & \\
\hline & Salinity* & - & & & & \\
\hline Temperature & Temperature* & - & & - & & \\
\hline \multirow[t]{2}{*}{ Landscape Features } & Ecosystem Structures Map* & & & - & & \\
\hline & Large Woody Debris & & - & & & \\
\hline $\begin{array}{l}\text { Tidal Channel } \\
\text { Morphology }\end{array}$ & Edge/Density/Sinuosity & & - & $\bullet$ & & $\bullet$ \\
\hline Vegetation Cover & Percent Cover by Species & - & & - & & \\
\hline Primary Production & Primary Production Index & $\bullet$ & & & & \\
\hline \multirow[t]{3}{*}{ Food Web } & Foraging Success & $\bullet$ & & & - & \\
\hline & Predation Index & $\bullet$ & & & $\bullet$ & \\
\hline & Prey Availability & $\bullet$ & & & & \\
\hline \multirow[t]{10}{*}{ Salmonid Performance } & Abundance & $\bullet$ & & & - & \\
\hline & Age/Size-Structure* & - & & & - & \\
\hline & Distribution: Spatial & $\bullet$ & & & $\bullet$ & \\
\hline & Distribution: Temporal* & $\bullet$ & & & $\bullet$ & \\
\hline & Growth Rate & - & & & - & \\
\hline & Migration Pathways & $\bullet$ & & & $\bullet$ & \\
\hline & Residence Time & $\bullet$ & & & $\bullet$ & \\
\hline & Species Composition* & $\bullet$ & & & $\bullet$ & \\
\hline & Stock Identity & - & & & - & \\
\hline & Survival Rate & - & & & - & \\
\hline
\end{tabular}




\subsection{Summary}

The overall objective of the research plan is to investigate critical uncertainties in the state-of-thescience in the estuary, plume, and nearshore ocean that are pivotal to understanding estuary/ocean effects on salmonid performance. The necessary focus is on management questions and RME objectives, which thus excludes many important fundamental research questions in the CRE. Specific uncertainties pertain to the ecological importance of the CRE to salmonids, causal mechanisms affecting survival, early life history in tidal freshwater, and effects of hatchery fish on wild fish in the estuary. As shown in the Columbia River Estuary Conceptual Model, many of the monitored indicators for research are ecosystem processes and linkages between these and ecosystem structures and salmonid performance. Results from research will reduce risk during management decision making for the CRE. 
Research, Monitoring, and Evaluation for the Federal Columbia River Estuary Program 


\subsection{Action Plan}

The action plan for estuary RME includes both project-level and program-level components. By program-level, we mean over-arching activities, e.g., data management, that support estuary-wide synthesis, evaluation, and decision making, not the specific research or monitoring programs within which projects relevant to estuary RME are undertaken. To be clear, the RME effort for the Estuary Program is served by projects developed as part of other existing programs. The programs and projects that address estuary RME are compiled in Appendix D. Earlier in Sections 2 and 3, we described monitoring and research needs, respectively. The program-level estuary RME is described in Section 4.1. Specific project- and program-level actions to implement the estuary RME are presented in Section 4.2, and an assessment of coverage by current projects is made in Section 4.3.

\subsection{Program-Level Elements}

The Estuary Program is being implemented in an adaptive management framework (Figure 8). Adaptive management is a structured learning process for testing hypotheses through management experiments in natural systems, collecting and interpreting new information, and making changes based on monitoring information to improve the management of ecosystems. Adaptive management is being implemented in large programs ranging from the Mississippi River Delta (Louisiana Coastal Wetlands Conservation and Restoration Task Force 2000) to the Colorado River (Ringold et al. 2003) to the Northwest Forest Plan (Stevens and Gold 2003). In the case of the Columbia River estuary, the overarching adaptive management framework for estuary RME is derived from the goal for the Estuary Program: Understand, conserve, and restore the estuary ecosystem to improve the performance of listed salmonid populations. The estuary RME effort will make use of custom adaptive management frameworks for estuary habitat restoration work by the USACE Portland District and the Estuary Partnership, respectively, which are currently being developed (Thom et al. 2007).

Using the adaptive management process in Figure 8 as a guide, the Estuary Program has accomplished steps one and two: a set of program goals and objectives (Section 1.2) has been established, and a design for monitoring and research plans has been laid out (Sections 2 and 3). The discussion that follows assesses the current status of the remaining five steps (coordination and implementation, data management and analysis, information reporting, implementation/compliance, and synthesis, evaluation, and decision making). These elements are consistent with recommendations in the Estuary Partnership's Monitoring Strategy (Lower Columbia River Estuary Program 1998), actions for the estuary in the 2000 and 2004 FCRPS Biological Opinions (NMFS 2000, 2004), the 2007 Biological Assessment (Action Agencies 2007), and the 2007 draft FCRPS Biological Opinion (NMFS 2007).

\subsubsection{Coordination and Implementation}

To implement effective RME for an area the size of the Columbia River estuary that includes multiple entities and numerous individual projects, central coordination is absolutely critical. It is also problematic 
for the CRE because currently there is no oversight body with authority to coordinate the multiple efforts. Currently, coordination is provided de facto by the funding and implementing organizations through their respective project review and coordination processes. To ensure the successful implementation and evaluation of the estuary RME Program, we recommend that the Action Agencies consider forming a committee to ensure the continued development, coordination, and adaptive management of the estuary RME effort. It would be the committee's responsibility to integrate the results of individual monitoring and research efforts, ensure that the data are analyzed from an estuary-wide perspective, disseminate the information, and evaluate the program. The committee would also be tasked with ensuring that adaptive management is built into routine, cyclic program management.

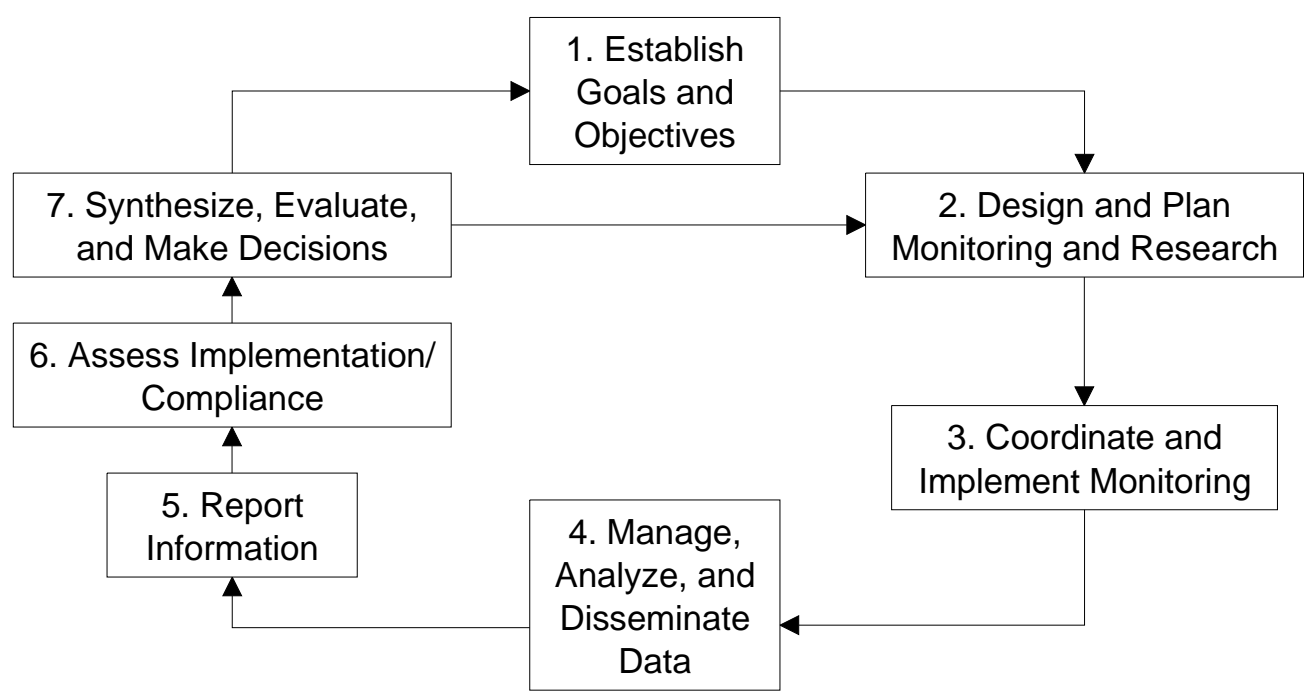

Figure 8. Schematic of an Adaptive Management Process for Estuary RME

Partnerships are often critical to the success of restoration programs (Harrington and Feather 1996). As these partnerships develop, coordination is critical to make use of all existing information, maximize efficiencies in budgets and effort, and learn from related projects. Currently, collaborations between local, state, and federal agencies, non-governmental organizations, and others working in the Columbia River estuary are rapidly developing. The coordinating committee could help these partnerships coalesce with meaningful commitments to implement portions of estuary RME.

Coordination of estuary RME with other regional monitoring efforts is also an essential element of the Estuary Program. For example, it is critical to coordinate with the Estuary Partnership's Aquatic Ecosystem Monitoring Strategy, and appropriate to coordinate with other regional research and monitoring efforts: 1) NOAA's ESA recovery planning effort; 2) the Pacific Northwest Aquatic Monitoring Partnership's (PNAMP 2004) effort to plan and coordinate monitoring in the region, in conjunction with the Collaborative Systemwide Monitoring and Evaluation Program and the Northwest Environmental Data network; 3) the Lower Columbia Fish Recovery Board's Salmon Recovery and Monitoring, Research, and Evaluation plans; 4) the Northwest Power and Conservation Council's Fish and Wildlife Program, Research and Monitoring Plan and estuary Subbasin Plan; 5) the Corps of Engineers' Water Resources and Development Act programs, General Investigations Study, and 
Anadromous Fish Evaluation Program; and 6) adaptive management efforts for estuary habitat restoration by the Estuary Partnership and the USACE.

Of special note, PNAMP is working to achieve substantive coordination among state, federal, and tribal watershed and salmon monitoring programs in the Pacific Northwest (PNAMP 2004). Its guiding principles involve resource policy and management, efficiency and effectiveness, science basis, and information sharing. It will be focused on areas where regional programs overlap, which is primarily in tributary habitats. However, its scope includes Puget Sound and Pacific Northwest and Northern California coastal estuaries; thus, there is potential for regional coordination of estuary adaptive management frameworks (Thom et al. 2007). PNAMP's scope is much broader than would be functionally efficient for the role of the CRE coordinating committee, although estuary RME will continue to inform PNAMP and vice versa.

A key aspect of coordination and implementation is sampling protocols. The use of standard methods to collect and analyze data on the monitored indicators, wherever possible, will be crucial to the success of the estuary RME effort, particularly because multiple organizations are involved in the work of restoring and conserving the lower river and estuary. A lack of common sampling protocols has created a significant barrier to data sharing, as noted in the Estuary Partnership's Monitoring Strategy (1998). To address this need for action effectiveness research, Diefenderfer et al. (2005) offered draft AER monitoring protocols. These protocols were field-tested in 2005 and a revised set of protocols were released in spring 2006 for regional review with a final version released in 2008 (Roegner et al. 2008). Many of the data collection protocols will also apply to status and trends monitoring, although the sampling designs will differ as described in Section 2.

\subsubsection{Data Management, Analysis, and Dissemination}

Estuary RME at the program level includes data management, analysis, and dissemination (subobjective SE 1, Section 1.2). Sharing data for basin-wide and estuary-wide analyses for the purposes of status and trends monitoring, action effectiveness research, uncertainties research, and implementation and compliance monitoring will be critical to the Estuary Program's success. The data function is currently performed to varying degrees at the project level, but not at the program level. Although project-level analysis is critical, the Estuary Program will require its own comprehensive synthesis of data. No single entity is presently responsible for data management and dissemination related to the Columbia River estuary. The estuary RME projects should feed data to a central, program-level data location and provide web-based reports and public access as a key mechanism for data dissemination. An estuary RME data center linked to the Northwest Environmental Data (NED) network could fill this role; however, at this time, an estuary RME data center, such as StreamNet conducted by the Pacific State Marine Fisheries Commission, does not exist either alone or as part of a larger effort.

The NED was formulated in the basin-wide data management plan for RME (RME Plan 2003) and the PNAMP data management module (PNAMP 2004). The estuary RME data center would be consistent with NED in efforts to 1) develop a RME information system architecture, 2) use existing data centers where appropriate, 3 ) develop a cost-sharing approach, 4) promote free exchange of information, 
and 5) emphasize that metadata -- e.g., purpose, method, quality assurance, proper uses, record of raw data -- are essential.

The specific requirements for estuary RME data and their management remain to be developed. Such requirements should directly address the monitored indicators for both status and trends and action effectiveness research and include specifications for data attributes, collection protocols, methods, standards, users, reporting requirements, etc. Some of these requirements are incorporated in the methods (Appendix C), but others need to be developed. For example, to form a data management system, we need to 1) decide what data will be collected, by whom, how often, where, and when; 2) define data standards; 3) define metadata needs; 4) establish access methods and policies; 5) establish how the data will be used; and 6) designate and fund staff to implement the data standards and maintain the database. A long-term funding commitment would be necessary for this effort. We recommend attention be given to this critical issue.

Data produced by existing monitoring programs, primarily operated by state and federal agencies, should be integrated by the coordinating committee into estuary RME analyses to avoid duplication of efforts. This is consistent with the Estuary Partnership's Monitoring Strategy (1998), which recommends that a coordinated framework be built on existing monitoring programs including a) ambient water quality monitoring by the Oregon Department of Environmental Quality and Washington Department of Ecology, b) the USGS National Stream Quality Accounting Network, c) USACE temperature and total dissolved gas sampling, and d) other state, federal, tribal, municipal, and university programs. Also consistent with the Estuary Partnership's recommendations for data management (1998), the estuary RME effort includes the establishment of a central, web-accessible repository for estuary data, and a homepage with links to a networked system of databases. Furthermore, this system should be linked to basin-wide RME data to facilitate basin-wide evaluations. The data management and analysis effort will feed directly into information reporting. For example, a web-based interactive GIS map with the estuary RME research and monitoring projects would be most useful; the Estuary Partnership has already made progress on this element of the program (www.lcrep.org) and may initiate a pilot project with NED. The coordinating committee should oversee the estuary RME data center.

\subsubsection{Information Reporting}

The information from status and trends monitoring, action effectiveness research, critical uncertainties research, and implementation and compliance monitoring should be summarized and integrated in a biennial estuary RME report for decision-makers, interested parties, and the annual progress and periodic comprehensive evaluation reports mandated in the Biological Opinion (subobjective SE 2, Section 1.2; compare RPA 59). The intent is to "roll up" project-specific data into program-level information. This effort was initiated in 2006 by the Estuary/Ocean RME Subgroup as they developed a detailed outline for such a report, as described by Johnson and Diefenderfer (2007). Furthermore, since not every indicator will be monitored annually or biennially, every sixth year the estuary RME report should summarize major one-time or non-annual monitoring efforts, such as bathymetry, floodplain topography, vegetation mapping, or geological coring. Whether sponsored by the 
Action Agencies or other entities, all major monitoring efforts within the estuary should be summarized to the extent that data are available. Annual reporting at the project level will be a key mechanism for data dissemination; biennial reporting at the program level will be key to estuary-wide synthesis, evaluation, and decision making. Program-level reports for estuary RME should be coordinated with reporting required under the Estuary Module of NMFS Recovery Plans in the Columbia basin. The coordinating committee would guide development of the biennial estuary RME report, while contract stipulations could ensure its production.

\subsubsection{Implementation/Compliance Monitoring}

The overall objective of implementation/compliance monitoring is to determine if projects are being implemented as planned and to determine if objectives, such as the amount of estuary habitat being conserved and restored annually, are being met (compare with RPA 73 in NMFS 2007). Implementation/ compliance monitoring includes two project-specific sub-objectives.

ICM 1. Determine whether restoration projects were carried out as planned, i.e., whether specified project criteria were met ("Implementation Monitoring").

This objective involves the assessment of projects relative to project goals, e.g., the degree of function attained in a restored area or the size of habitat restored. Assessment of the implementation of the adaptive management plan in case of failure to meet the goals is also included. This objective is referred to as "implementation monitoring." It includes monitoring during construction as well as after. This objective also compares the "as-built" project to the planned project according to project-specific criteria established before construction. The point is to ensure that engineering designs for the project were carried out correctly and to document any variances.

ICM 2. Total the amount of estuary habitat conserved and restored annually by habitat type.

This sub-objective entails routine tracking of habitat restoration and protection actions, organized by habitat type. It does not address the level of success for a given restoration action. Knowledge from the hierarchical habitat classification system as well as the definition of habitat in terms of the timing, frequency, and duration of inundation will be required. The area of habitat so defined may change as a restored site develops, particularly relative to sediment accretion rates. Thus, knowledge of water levels relative to topography is critical to this measurement.

Monitored indicators for ICM will be project-specific and will depend on the degree of risk associated with achieving a successful project. In general, the more complex the project, the more intensive the ICM will be. This is an important aspect of estuary RME because, for example, very small differences in elevation have the potential to produce different ecosystem structures. Whatever the extent of ICM, the results should be documented in a formal report. Examples of ICM monitored indicators include on-site review by project managers; verification of construction by licensed, bonded contractors; land and water 
level surveys to determine elevations relative to specifications; and engineering surveys to determine asbuilt and compare to the project's engineering plan.

\subsubsection{Synthesis, Evaluation, and Decision making}

The objective here is to synthesize data from Objectives 1-5 and to evaluate the Estuary Program within an adaptive management framework. This objective has three sub-objectives:

SE 1. Upload, compile, manage, and disseminate project-level data at the Estuary Program level.

SE 2. Synthesize the data and periodically report it to the region.

SE 3. Use the synthesized data to evaluate the Estuary Program and refine the estuary RME effort as necessary.

In an adaptive management process (Figure 8), program evaluation includes adjusting program objectives and methodologies based on new information (sub-objective SE 3, Section 1.2). As such, instituting a program evaluation as part of the coordinating committee's oversight process will bring estuary RME full-circle from the initial establishment of goals and objectives, through coordination and implementation, data management and analysis, dissemination and information reporting to synthesis and evaluation (Figure 8). As Noon (2003) stated, monitoring programs “....must be constantly revisited and revised as scientific knowledge is acquired..." Procedures should be established that link decisionmakers to estuary RME monitoring overseers and data managers in a manner consistent with basin-wide adaptive management described in the federal RME Plan (RME Plan 2003). This also applies to the annual progress and periodic comprehensive evaluation reports mandated in the Biological Opinion (subobjective SE 2, Section 1.2; compare RPA 59).

Contract stipulations by the funding agencies can be an effective way to ensure project-specific information is available during program evaluation. Such information could be the basis of biennial analyses during program evaluation to determine whether the program is meeting expectations. Contracts for restoration and monitoring projects should require that sponsors report monitoring data relative to project-specific goals and, wherever possible, reference site conditions. Furthermore, contracts for restoration projects should state that funding is contingent on review of annual reports and implementation of on-the-ground adjustments at project sites as necessary. This will strengthen the program evaluation step in the adaptive management process, helping inform management decision making.

Building on the biennial reporting cycle, a coordinating committee would review the reports relative to the goal and objectives of the program stated above. The collective monitoring data will also be reviewed against more specific questions developed based on the objectives of the status and trends monitoring, action effectiveness research, uncertainties research, and implementation and compliance components of the program (Section 1.2). The coordinating committee would be tasked to determine if the projects collectively meet program goals and, if not, what can be done about it. The coordinating 
committee would make adjustments to the program based on successes and failures. The committee would have several areas of oversight, each with the potential for adjustment through management actions: 1) the most important monitored indicators for status and trends; 2) the management of existing habitat restoration project trajectories; 3) the characteristics and funding of new restoration projects; 4) the objectives and funding of new uncertainties research; and 5) the goals and objectives of the Estuary Program and any other aspect of this estuary RME effort, which could be modified under the direction of the coordinating committee.

Program evaluation for restoration monitoring at sites throughout the estuary also presents the opportunity to use information gained to improve the conceptual model of estuary structures, processes, and functions, and in some cases to provide numerical models of components of the system. The improved models can then be used through the adaptive management process to help better design future restoration projects. An important responsibility of the coordinating committee will be to ensure that the conceptual model of the estuary is continually improved through evaluation of data collected through the status and trends monitoring, action effectiveness research, and uncertainties research components of the program.

\subsection{Coverage Assessment}

There are at least 18 ongoing programs (Table 4) that include projects addressing aspects of research and monitoring in the estuary. The largest programs in terms of numbers of projects are the NPCC's Columbia Basin Fish and Wildlife Program funded by BPA and the Anadromous Fish Evaluation Program funded by USACE. Lead entities include the BPA, NOAA, NPCC, USACE, and US Geological Survey (USGS).

There are 42 ongoing projects known to be performing monitoring or research in the estuary and plume (Table 5). These projects exist for the purposes of their respective programs, e.g., the USGS monitors discharge of the Columbia River as part of its National Stream Quality Accounting Network. Many of them, although not all, are pertinent to estuary RME status and trends monitoring, action effectiveness research, and critical uncertainties research objectives (Section 1.2).

Coverage of estuary RME objectives and sub-objectives is shown in Table 4. The sub-objectives not covered at all by existing projects are STM 3 Habitat Connectivity, STM 7 Life History Diversity Index, and CUR 4 Hatchery Fish Effects. The remaining objectives are covered to varying degrees. They remain, however, to be coalesced into a cohesive estuary RME effort. 
Table 4. Ongoing Monitoring Programs Applicable to Estuary RME (August 2007 status). Modified from Table 2 in the RME appendix in the Estuary Module; Estuary Partnership 2007.

\begin{tabular}{|c|c|c|c|c|}
\hline Id. & Program & $\begin{array}{l}\text { Lead } \\
\text { Entity }\end{array}$ & Description & More Information \\
\hline P1 & $\begin{array}{l}\text { National Stream Quality } \\
\text { Accounting Network } \\
\text { (reported in Nat'l Streamflow } \\
\text { Info' Program) }\end{array}$ & USGS & $\begin{array}{l}\text { Discharge monitoring at Beaver Terminal (RM54); } \\
\text { includes water quality and discharge measurements. }\end{array}$ & $\begin{array}{l}\text { NASQAN: http://water.usgs.gov/nasqan/ } \\
\text { Columbia River Factsheet: } \\
\text { http://water.usgs.gov/ } \\
\text { nasqan/progdocs/factsheets/ } \\
\text { clmbfact/clmbfact.html }\end{array}$ \\
\hline \multirow[t]{2}{*}{ P2 } & \multirow{2}{*}{$\begin{array}{l}\text { National Water-Quality } \\
\text { Assessment Program }\end{array}$} & \multirow[t]{2}{*}{ USGS } & \multirow{2}{*}{$\begin{array}{l}\text { Routine water quality monitoring nationwide; it } \\
\text { includes the Willamette basin, but not the estuary. }\end{array}$} & NAWQA: http://water.usgs. gov/nawqa/ \\
\hline & & & & $\begin{array}{l}\text { Willamette page: http://or.water.usgs.gov/ } \\
\text { projs_dir/pn366/ nawqa.html }\end{array}$ \\
\hline P3 & $\begin{array}{l}\text { Columbia Basin Fish and } \\
\text { Wildlife Program }\end{array}$ & $\begin{array}{l}\text { BPA/ } \\
\text { NPCC }\end{array}$ & $\begin{array}{l}\text { Contains a measure addressing the question, "Is the } \\
\text { Columbia River estuary improving or deteriorating } \\
\text { relative to desired conditions?" BPA/NPCC } \\
\text { implements estuary RME projects here. }\end{array}$ & http://www. nwcouncil.org/ library/2000/ \\
\hline P4 & $\begin{array}{l}\text { Columbia River Channel } \\
\text { Improvements Project }\end{array}$ & USACE & Monitoring occurs as required for ESA concerns. & https://www.nwp. usace.army.mil/ issues/crcip/ \\
\hline P5 & Mouth of the Columbia River & $\begin{array}{l}\text { USACE/ } \\
\text { Ports }\end{array}$ & Monitoring occurs as required for ESA concerns. & $\begin{array}{l}\text { https://www.nwp. usace.army.mil/op/n/ } \\
\text { projects/ }\end{array}$ \\
\hline P6 & $\begin{array}{l}\text { Anadromous Fish Evaluation } \\
\text { Program }\end{array}$ & USACE & $\begin{array}{l}\text { Implements the Columbia River Fish Mitigation Project } \\
\text { designed to improve survival through the hydrosystem. } \\
\text { The USACE does estuary research in AFEP. }\end{array}$ & https://www.nwd. usace.army.mil/ps/ \\
\hline P7 & $\begin{array}{l}\text { NOAA General Funds } \\
\text { Program }\end{array}$ & NOAA & $\begin{array}{l}\text { Provides funds for specific estuary/ocean research } \\
\text { projects by NOAA. }\end{array}$ & Unk. \\
\hline P8 & $\begin{array}{l}\text { Oregon Dept. Environmental } \\
\text { Quality/106/General Funds }\end{array}$ & ODEQ & $\begin{array}{l}\text { Focus is on Willamette, incl. confluence with the } \\
\text { Columbia River. }\end{array}$ & $\begin{array}{l}\text { http://www.deq.state. or.us/lab/ } \\
\text { wqm/watershed.htm }\end{array}$ \\
\hline \multirow[t]{2}{*}{ P9 } & \multirow[t]{2}{*}{$\begin{array}{l}\text { Total Dissolved Gas } \\
\text { Monitoring Program }\end{array}$} & \multirow[t]{2}{*}{$\begin{array}{l}\text { USACE/ } \\
\text { USGS }\end{array}$} & \multirow[t]{2}{*}{ Routine monitoring. } & $\begin{array}{l}\text { USGS: http://or.water.usgs.gov/ } \\
\text { projs_dir/pn307.tdg/ }\end{array}$ \\
\hline & & & & $\begin{array}{l}\text { USACE: http:// 137.161.202.92/TMT/ } \\
\text { WQ/2001/ MonitorPlan/ tdgmgt01.pdf }\end{array}$ \\
\hline P10 & $\begin{array}{l}\text { Washington Dept. Ecology } \\
\text { Ambient Monitoring Program }\end{array}$ & WDE & $\begin{array}{l}\text { Usually includes at least one mainstem site, in addition } \\
\text { to tributary water quality monitoring. }\end{array}$ & $\begin{array}{l}\text { Monitoring Home: } \mathrm{http} / / \text { www.ecy.wa.gov/ } \\
\text { programs/eap/ fw riv/rv main.html }\end{array}$ \\
\hline
\end{tabular}




\begin{tabular}{|c|c|c|c|c|}
\hline Id. & Program & $\begin{array}{l}\text { Lead } \\
\text { Entity }\end{array}$ & Description & More Information \\
\hline P11 & $\begin{array}{l}\text { Water Resources } \\
\text { Development Act - } \\
\text { Ecosystem Restoration } \\
\text { Programs }\end{array}$ & USACE & $\begin{array}{l}\text { USACE conducts monitoring of specific restoration } \\
\text { actions conducted under these authorities; monitoring } \\
\text { maximum cost is } 3 \% \text { total project cost. }\end{array}$ & https://www.nwp. usace.army.mil/pm/lcr/ \\
\hline $\mathrm{P} 12$ & $\begin{array}{l}\text { Lower Columbia River } \\
\text { Ecosystem Restoration } \\
\text { General Investigations } \\
\text { Feasibility Study (GI Study) }\end{array}$ & USACE & $\begin{array}{l}\text { The purpose of the GI Study is to "...investigate and } \\
\text { recommend appropriate solutions to accomplish } \\
\text { ecosystem restoration in the lower Columbia River and } \\
\text { estuary, including wetland/riparian habitat restoration, } \\
\text { stream and fisheries improvement, water quality, and } \\
\text { water-related infrastructure improvements..." }\end{array}$ & $\frac{\mathrm{https}: / / \text { www.nwp.usace.army.mil// }}{\mathrm{pm} / \mathrm{cr} / \mathrm{envres} . \text { asp }}$ \\
\hline P13 & $\begin{array}{l}\text { Portland Harbor Superfund } \\
\text { Assessment Program }\end{array}$ & EPA & $\begin{array}{l}\text { Implements clean-up at the superfund site in Portland } \\
\text { harbor. }\end{array}$ & $\begin{array}{l}\text { EPA: http://yosemite.epa.gov/R10/ } \\
\text { CLEANUP.NSF/sites/ptldharbor }\end{array}$ \\
\hline P14 & $\begin{array}{l}\text { Estuary Partnership } \\
\text { Monitoring Programs }\end{array}$ & $\begin{array}{l}\text { Estuary } \\
\text { Partnership }\end{array}$ & $\begin{array}{l}\text { Implements the Monitoring Strategy. Funding by } \\
\text { BPA/NPCC, EPA, and others }\end{array}$ & http://www.lcrep.org/pdfs/ ccmp_vol2.pdf \\
\hline P15 & NOAA Tides and Currents & NOAA & Geodetic monitoring & http://tidesandcurrents.noaa.gov/ \\
\hline P16 & $\begin{array}{l}\text { Surface Water Data } \\
\text { Collection Program }\end{array}$ & USGS & Water quality monitoring & \\
\hline P17 & $\begin{array}{l}\text { Volunteer Water Quality } \\
\text { Monitoring Program }\end{array}$ & $\begin{array}{l}\text { Will. River } \\
\text { Keeper }\end{array}$ & Volunteer water quality monitoring & \\
\hline P18 & $\begin{array}{l}\text { Zebra Mussel Monitoring } \\
\text { Program }\end{array}$ & PSU & Monitoring of zebra mussels, an invasive species & \\
\hline
\end{tabular}


Table 5. Ongoing Projects Addressing Estuary RME. Project numbers are from the respective program. The numbers under STM, AER, and CUR refer to the Estuary RME Sub-Objectives. A shaded bullet means the project addresses the respective objective. (Modified from Table 3 in the RME appendix in the Estuary Module; Estuary Partnership 2007).

\begin{tabular}{|c|c|c|c|c|c|c|c|c|c|c|c|c|c|c|c|c|c|c|c|}
\hline & & & & \multicolumn{8}{|c|}{ STM } & \multicolumn{3}{|c|}{ AER } & \multicolumn{5}{|c|}{ CUR } \\
\hline Id. & Title & Project No. & Entity & 1 & 2 & 3 & 4 & 5 & 6 & 7 & 8 & 1 & 2 & 3 & 1 & 2 & 3 & 4 & 5 \\
\hline $\mathrm{J} 1$ & ODEQ Ambient Water Quality Monitoring & unk. & OR Dept. Env. Quality & & & & $\bullet$ & & & & & & & & & & & & \\
\hline $\mathrm{J} 2$ & $\begin{array}{l}\text { WDOE Ambient Water Quality } \\
\text { Monitoring }\end{array}$ & unk. & WA Dept. Ecology & & & & $\bullet$ & & & & & & & & & & & & \\
\hline $\mathrm{J} 3$ & USGS Discharge and Water Quality Mon. & unk. & USGS & & & & $\bullet$ & & & & & & & & & & & & \\
\hline $\mathrm{J} 4$ & Ives Is. Chum Salmon Monitoring & $2000-012-00$ & USFWS & & & & & & & & & & & & & & & & \\
\hline J5 & LCRE Ecosystem Monitoring & 2003-007-00 & Estuary Partnership & $\bullet$ & $\bullet$ & & $\bullet$ & & & & & & & & & & & & \\
\hline $\mathrm{J} 6$ & Total Dissolved Gas Monitoring & PNAMP\#409 & USGS & & & & $\bullet$ & & & & & & & & & & & & \\
\hline $\mathrm{J} 7$ & Avian Predation on Juvenile Salmonids & $1997-024-00$ & OSU & & & & & & & & $\bullet$ & & & & & & & & \\
\hline $\mathrm{J} 8$ & Baitfish/Salmonid Relationships & unk. & NMFS & & & & & & & & & & & & $\bullet$ & & & & \\
\hline J9 & Canada-US Shelf Salmon Survival Study & 2003-009-00 & DFO & & & & & & & & & & & & $\bullet$ & & & & \\
\hline $\mathrm{J} 10$ & Habitat Usage by Juvenile Salmon & unk. & NMFS & & & & & $\bullet$ & & & & & & & $\bullet$ & & & & \\
\hline $\mathrm{J} 11$ & Estimation of Salmon Survival & EST-P-02-01 & NMFS/ PNNL & & & & & & $\bullet$ & & & & & & & & & & \\
\hline $\mathrm{J} 12$ & Current and Historical Linkages & EST-P-02-02 & NMFS & & & & & & & & & & & & $\bullet$ & & & & \\
\hline $\mathrm{J} 13$ & Sampling PIT Tagged Juvenile Salmonids & BPS-W-0-11 & NMFS & & & & & & $\bullet$ & & & & & & & & & & \\
\hline $\mathrm{J} 14$ & Juvenile Salmonids in the Plume & 1998-014-00 & NMFS & & & & & & & & $\bullet$ & & & & $\bullet$ & & & & \\
\hline $\mathrm{J} 15$ & $\begin{array}{l}\text { Cumulative Ecosys. Response to } \\
\text { Restoration }\end{array}$ & EST-P-02-04 & PNNL/ NMFS/ CREST & & & & & & & & & & $\bullet$ & & $\bullet$ & & $\bullet$ & & \\
\hline J16 & $\begin{array}{l}\text { Eval. of Juveniles following } \\
\text { Transportation }\end{array}$ & TPE-W-0-01 & OSU & & & & & & & & & & & & $\bullet$ & & & & \\
\hline $\mathrm{J} 17$ & $\begin{array}{l}\text { Habitat Opportunities \& Food-Web } \\
\text { Linkages }\end{array}$ & 2003-010-00 & NMFS/ OHSU/ PSU/ UW & & & & & & & & & & & & $\bullet$ & & $\bullet$ & & $\bullet$ \\
\hline $\mathrm{J} 18$ & Acoustic Tracking for Survival (POST) & 2003-114-00 & Kintama & & & & & & & & & & & & $\bullet$ & & & & \\
\hline $\mathrm{J} 19$ & Time of Ocean Entry Study & EST-P-02-03 & NMFS & & & & & & & & & & & & & $\bullet$ & & & \\
\hline $\mathrm{J} 20$ & Effectiveness Monitoring at Chinook R. & 2003-006-00 & Sea Resources/CREST & & & & & & & & & & $\bullet$ & & & & & & \\
\hline $\mathrm{J} 21$ & Habitat Restoration Program & 2003-011-00 & Estuary Partnership & $\bullet$ & & & & & & & & $\bullet$ & $\bullet$ & & & & & & \\
\hline
\end{tabular}




\begin{tabular}{|c|c|c|c|c|c|c|c|c|c|c|c|c|c|c|c|c|c|c|c|}
\hline & & & & \multicolumn{8}{|c|}{ STM } & \multicolumn{3}{|c|}{ AER } & \multicolumn{5}{|c|}{ CUR } \\
\hline Id. & Title & Project No. & Entity & 1 & 2 & 3 & 4 & 5 & 6 & 7 & 8 & 1 & 2 & 3 & 1 & 2 & 3 & 4 & 5 \\
\hline $\mathrm{J} 22$ & Monitoring at Smith and Bybee Lakes & unk. & Ducks Unlimited & & & & & & & & & & - & & & & & & \\
\hline $\mathrm{J} 23$ & Ramsey Lake Project Monitoring & unk. & City of Portland & & & & & & & & & & $\bullet$ & & & & & & \\
\hline $\mathrm{J} 24$ & Impact of American Shad & 2007-275-00 & USGS & & & & & & & & & & & & - & & & & \\
\hline $\mathrm{J} 25$ & Caspian Tern Management & 2006-002-00 & OSU & & & & & & & & & & & & & & & & \\
\hline $\mathrm{J} 26$ & Tidal Freshwater Mon. Juvenile Salmonids & 2005-001-00 & PNNL/ODFW/UW/NMFS & & & & & - & & & & & - & & & & - & & \\
\hline $\mathrm{J} 27$ & Effects of Total Diss. Gas on Chum Fry & SPE-P-07-01 & PNNL & & & & & & & & & & & & & & & & \\
\hline $\mathrm{J} 28$ & CORIE & unk. & Or. Health Sci. U. & & & & $\bullet$ & & & & & & & & & & & & \\
\hline $\mathrm{J} 29$ & Pile Structure Removal Study & unk. & PNNL/USGS & & & & & & & & & & & & & & & & \\
\hline $\mathrm{J} 30$ & $\begin{array}{l}\text { Julia Butler Hanson Tide Gate } \\
\text { Replacement }\end{array}$ & unk. & USFWS & & & & & & & & & & - & & & & & & \\
\hline $\mathrm{J} 31$ & Juvenile Salmonid Stranding & unk. & $\mathrm{PNNL} / \mathrm{UW}$ & & & & & - & & & & & & & & & & & \\
\hline $\mathrm{J} 32$ & Bonneville Sea Lion Exclusion Study & ADS-02-16 & USACE & & & & & & & & - & & & & & & & & \\
\hline $\mathrm{J} 33$ & Sea Lion Deterrent System & BPA & Smith Root & & & & & & & & & & & & & & & & \\
\hline $\mathrm{J} 34$ & Caspian Tern Management Measures & AVS-P-08-1 & OSU & & & & & & & & $\bullet$ & & & & & & & & \\
\hline $\mathrm{J} 35$ & $\begin{array}{l}\text { Double-Crested Cormorant Mngt } \\
\text { Measures }\end{array}$ & AVS-P-08-2 & OSU & & & & & & & & $\bullet$ & & & & & & & & \\
\hline $\mathrm{J} 36$ & Impact of Avian Predation on Smolts & AVS-W-03-1 & NMFS & & & & & & & & • & & & & & & & & \\
\hline $\mathrm{J} 37$ & Tides and Currents & unk. & NOAA & & & & $\bullet$ & & & & & & & & & & & & \\
\hline $\mathrm{J} 38$ & Northern Pikeminnow Surveys & 1990-077-00 & ODFW & & & & & & & & • & & & & & & & & \\
\hline J39 & Effectiveness Mon. in Lower Grays R. & PNAMP\#529 & CREST & & & & & & & & & & - & & & & & & \\
\hline $\mathrm{J} 40$ & Ives Is. Adult Chum Salmon Monitoring & PNAMP\#277 & ODFW & & & & & & & & & & & & & & & & \\
\hline $\mathrm{J} 41$ & Volunteer Water Quality Monitoring & PNAMP\#575 & Willamette River Keeper & & & & & & & & & & & & & & & & \\
\hline $\mathrm{J} 42$ & Zebra Mussel Monitoring & PNAMP\#425 & PSU & & & & & & & & & & & & & & & & \\
\hline
\end{tabular}




\subsection{Actions}

Estuary RME is comprised of project- and program-level actions that are driven by the estuary RME goal and objectives (Section 1.2), the resulting monitoring and research needs (Section 2 and Section 3), and a coverage assessment of those needs (Section 4.2). The action plan for estuary RME should be implemented by the responsible funding and management agencies through contract provisions addressing the specific actions outlined below.

\subsubsection{Project-Level}

In general, the ongoing projects identified in Table 5 that address estuary RME should be continued. These projects help meet estuary RME goals and objectives by providing data for status and trends monitoring, action effectiveness research, and uncertainties research. For the estuary RME objectives not currently being addressed by an existing project, the estuary/ocean subgroup recommends modifications to existing projects or formation of new projects as follows for each estuary RME sub-objective:

- STM 3. Develop an index of habitat connectivity and apply it to each of the eight reaches of the study area.

- STM 7. Develop an index and monitor and evaluate life history diversity of salmonid populations at representative locations in the estuary.

- CUR 4. Investigate the effects of hatchery fish on wild (naturally produced) fish in the estuary.

\subsubsection{Program-Level}

The estuary RME effort for the Estuary Program is underway with the research and monitoring projects currently funded, albeit as part of other ongoing monitoring programs. To further develop the estuary RME effort and meet its objectives, the following program-level recommendations are offered (compare with RPA 71, 72, 73 in NMFS 2007).

\section{Coordination and Implementation}

- Establish an estuary RME coordination committee that includes the Action Agencies, NMFS, the Estuary Partnership, and other entities charged with research and monitoring in the estuary.

- Develop a statement of roles and responsibilities of each agency and entity working on RME in the estuary. In addition, consider establishing a memorandum of understanding between the key parties regarding the roles and responsibilities, governance structure, and organization of the estuary RME effort.

- Use contractual mechanisms when possible to require that 1) performance criteria be developed in the planning phase of each habitat restoration project; 2) post-restoration monitoring of performance indicators be conducted; and 3) data resulting from action effectiveness and status 
and trends monitoring be compiled and reported to standards appropriate for estuary-wide analyses.

- Coordinate with other basin-wide RME groups, other federal monitoring programs, interested parties, and state and local monitoring efforts. Continue to integrate estuary RME with the Pacific Northwest Aquatic Monitoring Partnership with representation at PNAMP meetings to describe and report estuary RME activities and participation in the estuary group for PNAMP.

\section{Data Management, Analysis, and Dissemination}

- Develop estuary RME data specifications to support a coordinated data management system.

- Adopt standardized methods for status and trends monitoring to allow comparisons through time for given monitored attributes.

- Adopt standardized methods for action effectiveness research to allow comparisons across projects and to address the cumulative effects of projects.

- Build a database of results from status and trends monitoring and action effectiveness research.

- Establish an estuary RME data center -- a central, web-accessible repository for estuary data, and a publicly accessible homepage with links to a networked system of databases. Specifically, this system should be linked to basin-wide RME data to facilitate basin-wide evaluations.

- Maintain a project inventory database for restoration projects in the Estuary Program.

\section{Information Reporting}

- Convene biennial estuary RME workshops to present new data, evaluate the conduct of the estuary RME effort, exchange information, and provide input to the coordinating committee.

- Write a biennial estuary RME report - this estuary RME report series would summarize data and provide adaptive management recommendations at the program level for submittal to the Action Agencies, estuary restoration project leaders, and other related entities (e.g., PNAMP).

- Establish procedures that link decision makers and data managers to the coordinating committee in a manner consistent with basin-wide adaptive management.

- Develop web-based information portals.

\section{Implementation and Compliance Monitoring}

- Determine whether restoration projects were carried out as planned, i.e., whether specified project criteria were met ("Implementation Monitoring"). BPA's project management system, Pisces, and similar NMFS and USACE systems could be applied here.

- Total the amount of estuary habitat conserved and restored annually, by habitat type.

\section{$\underline{\text { Synthesis and Evaluation }}$}

- Upload, compile, manage, and disseminate project-level data at the estuary RME program-level. 
- Synthesize the data and periodically report it to the region.

- Use the synthesized data to evaluate the Estuary Program and refine estuary RME as necessary.

\subsection{Summary}

The estuary RME action plan responds to project- and program-level needs (Section 4.1). The action plan identifies what needs to be done to implement estuary RME. While it is beyond the scope of this document to designate responsible agencies, we do provide a definitive list of actions to prioritize the research and monitoring activities in the CRE. The intent is to coordinate estuary RME implementation across multiple entities. The estuary RME effort is designed to meet the research and monitoring needs of the Estuary Program using an adaptive management process. Estuary RME's success and usefulness will depend on the actual conduct of adaptive management, as embodied in the objectives, implementation, data, reporting, and synthesis, evaluation, and decision making described herein. 


\subsection{Literature Cited}

Action Agencies. 2007. Biological Assessment for Effects of Federal Columbia River Power System and Mainstem Effects of Other Tributary Actions on Anadromous Salmonid Species Listed Under the Endangered Species Act. Prepared by the U.S. Army Corps of Engineers, Bonneville Power Administration, and U.S. Bureau of Reclamation, August, 2007. Portland, Oregon.

Arkoosh, M., E. Casillas, P. Huffman, E. Clemons, U. Varanasi, J. Evered, and J. Stein. 1998. Increased susceptibility of juvenile Chinook salmon from a contaminated estuary to Vibrio anguillarum. Transactions of the American Fisheries Society 127:360-374.

Bates, C.R. and P.W. Byham. 2001. Bathymetric sidescan techniques for near shore surveying. Hydrographic Journal 100:13-18.

Batiuk R.A., R.J. Orth, K.A. Moore, W.C. Dennison, J.C. Stevenson, L.W. Staver, V. Carter, N.B. Rybicki, R.E. Hickman, S. Kollar, S. Bieber, and P. Heasley. 1992. Chesapeake Bay Submerged Aquatic Vegetation Habitat Requirements and Restoration Targets: A Technical Synthesis. Chesapeake Bay Program, Annapolis, Maryland.

Batiuk R.A., P. Bergstrom, M. Kemp, E. Koch, L. Murray, J.C. Stevenson, R. Bartleson, V. Carter, N.B. Rybicki, J.M. Landwehr, C. Gallegos, L. Karrh, M. Naylor, D. Wilcox, K.A. Moore, S. Ailstock, and M. Teichberg. 2000. Chesapeake Bay Submerged Aquatic Vegetation Water Quality and HabitatBased Requirements and Restoration Targets: A Second Technical Synthesis. Chesapeake Bay Program, Annapolis, Maryland.

Beneficial Use Reconnaissance Project Technical Advisory Committee (BURPTAC). 1999. Beneficial Use Reconnaissance Project Workplan for Wadable Streams. Idaho Division of Environmental Quality, Boise, ID. Web link: http://www.deq.state.id.us/water/surface_water/99_burp_workplan.pdf.

Berquam, T.B., B.D. Ebberts, and J. Wilcox. 2003. Action Plan to Implement the FCRPS Biological Opinion in the Columbia River Estuary. Submitted to NOAA Fisheries, Portland, Oregon. September 30, 2003.

Bickford, C.A., C.E. Mayer, and K.D. Ware. 1963. An efficient design for forest inventory: the Northeastern forest resurvey. Journal of Forestry 61:826-833.

Bickford, S. and J. Skalski. 2000. Re-analysis and interpretation of 25 years of Snake-Columbia river juvenile salmonid survival studies. North American Journal of Fisheries Management 20: 53-68.

Bisbal, G.A. and W.E. McConnaha. 1998. Consideration of ocean conditions in the management of salmon. Canadian Journal of Fisheries and Aquatic Science 55: 2178-2186.

Bisson, P. and nine co-authors. 2000. The Columbia River Estuary and the Columbia River Basin Fish and Wildlife Program. Independent Scientific Advisory Board of the Northwest Power and Conservation Council. Portland, Oregon. ISAB 2000-5. 
Blight, B.J.N. and A.J. Scott. 1973. A stochastic model for repeated surveys. Journal of the Royal Statistical Society, Series B 35:61-66.

Bollens, S.M., J.R. Cordell, S. Avent, and R. Hoof. 2002. Zooplankton invasions: a brief review, plus two case studies from the northeast Pacific Ocean. Hydrobiologia 480:67-110.

Bonneville Power Administration (BPA). 2005. Supplemental Information for Research, Monitoring and Evaluation Proposals for the FY 07-09 Fish and Wildlife Program Project Solicitation Process. Portland, OR. December 5, 2005.

Bottom, D. and K. Jones. 1990. Species composition, distribution and invertebrate prey of fish assemblages in the Columbia River estuary. Progress in Oceanography 25: 243-270.

Bottom, D.L., K.K. Jones, and J.J. Herring. 1984. Fishes of the Columbia River Estuary. Internal report, 113 pp. Available from Columbia River Data Development Program, Astoria OR. (Managed by the Columbia River Estuary Taskforce, www.columbiaestuary.org.)

Bottom, D.L., C.A. Simenstad, J. Burke, A.M. Baptista, D.A. Jay, K.K. Jones, E. Casillas, and M. Schiewe. 2005. Salmon at River's End: the Role of the Estuary in the Decline and Recovery of Columbia River Salmon. NOAA Fisheries, Northwest Fisheries Science Center, Seattle, WA. NOAA Technical Memorandum NMFS-NWFSC-68, 246 p.

Bowen, Z.H. and R.G. Waltermire. 2002. Evaluation of light detection and ranging (LIDAR) for measuring river corridor topography. Journal of American Water Resources Association 38: 33-41.

British Columbia Ministry of Environmental Lands, and Parks. 1999. Automated Water Quality Monitoring. Prepared by the Water Management Branch for the Aquatic Inventory Task Force Resource Inventory Committee. 61 pp. June 8, 1999.

Brock, J.C., C.W. Wright, A.H. Sallenger, W.B Krabill, and R.N. Swift. 2002. Basis and methods of NASA airborne topographic mapper lidar surveys for coastal studies. Journal of Coastal Research 18: $1-13$.

Brodeur, R.D., G.W. Boehlert, E. Casillas, M.B. Eldridge, J.H. Helle, W.T. Peterson, W.R. Heard, S. Lindley, and M.H. Schiewe. 2000. A coordinated research plan for estuarine and ocean research on Pacific salmon. Fisheries 25(6):7-16.

Bureau of Reclamation, Corps of Engineers, Bonneville Power Administration. 2003. ESA 2003 CheckIn Report for the FCRPS. Submitted to NOAA Fisheries, Portland, Oregon.

Burke, J.L. 2004. Life Histories of Juvenile Chinook Salmon in the Columbia River Estuary, 1916 to the Present. Masters Thesis, Oregon State University, Corvallis, OR

Burnham, K., D. Anderson, G. White, C. Brownie, and K. Pollock. 1987. Design and analysis methods for fish survival experiments based on release-recapture. American Fisheries Society Monograph 5. Bethesda, Maryland. 
Burr, I. W. 1976. Statistical Quality Control Methods. Marcel Dekker, New York.

Busch, D.E., Trexler, J.C., eds., 2003. Monitoring Ecosystems-Interdisciplinary Approaches for Evaluating Ecoregional Initiatives. Washington, D.C., Island Press, 447 p.

CALFED. 2000. Comprehensive Monitoring, Assessment, and Research Program for Chinook Salmon and Steelhead in the Central Valley Rivers. Draft report obtained from a website http://calfed.ca.gov/programs/cmarp/.

Callaway, J.C., G. Sullivan, J.S. Desmond, G.D. Williams, and J.B. Zedler. 2001. Assessment and Monitoring. In J.B. Zedler (ed.) Handbook for Restoring Tidal Wetlands, pp.271-335, CRC Press, Boca Raton, Florida.

Clarke, S.E., D. White and A.L. Schaedel. 1991. Oregon, USA, ecological regions and subregions for water quality management. Environmental Management 15(6): 847-856.

Coats, R.N., P.B. Williams, C.K. Cuffe, J.B. Zedler, D. Reed, S.M. Watry and J.S. Noller. 1995. Design Guidelines for Tidal Channels in Coastal Wetlands. Report prepared for U.S. Army Corps of Engineers Waterways Experiment Station, Catalog. No. TA7W343.D47, Vicksburg, MS.

Cochran, W.G. 1953. Sampling Techniques. First edition. Wiley, New York.

Cochran, W.G. 1977. Sampling Techniques. Third edition. John Wiley \& Sons, New York.

Cochran, W.G. 1979. Sampling theory on repeated occasions with ecological applications. Pages 315328 in R. M. Cormack, G. P. Patil, and D. S. Robson, eds. Sampling Biological Populations. International Co-op Publishing House, Fairland, MD.

Cohen, A.N. and 21 co-authors. 2001. Washington State Exotics Expedition 2000: A Rapid Survey of Exotic Species in the Shallow Waters of Elliot Bay, Totten and Eld Inlets, and Willipa Bay. Prepared for the Washington State Department of Natural Resources, Olympia, WA. 46 pp.

Columbia River Estuary Data Development Program (CREDDP). 1984a. Index to CREDDP Data. Compiled by H.T. Mercier. S. Bell, ed. Columbia River Estuary Study Taskforce, Astoria, OR.

Columbia River Estuary Data Development Program (CREDDP). 1984b. Abstracts of Major CREDDP Publications. Compiled by D. Fox. Columbia River Estuary Study Taskforce, Astoria, OR.

Craddock, D.R., T.H. Blahm, and W.D. Parente. 1976. Occurrence and utilization of zooplankton by juvenile chinook salmon in the lower Columbia River. Transactions of the American Fisheries Society 1:72-76

Dawley, E.M., R.D. Ledgerwood, and A.L. Jensen. 1985a. Beach and Purse Seine Sampling of Juvenile Salmonids in the Columbia River Estuary and Ocean Plume, 1977-1983; Volume I; Procedures, Sampling Effort and Catch Data. NOAA Fisheries, Northwest Fisheries Science Center, Seattle, WA. NOAA Tech. Memo. NMFS, F/NWC-74:1-260. 
Dawley, E.M., R.D. Ledgerwood, and A.L. Jensen. 1985b. Beach and Purse Seine Sampling of Juvenile Salmonids in the Columbia River Estuary and Ocean Plume, 1977-1983; Volume II; Data on Marked Fish Recoveries. U.S. Dep. Commerce, NOAA Tech. Memo. NMFS, F/NWC-75:1-397.

Dawley, E.M., R.D. Ledgerwood, T.H. Blahm, C.W. Sims, J.T. Durkin, R.A. Kirn, A.E. Rankis, G.E. Monan, and F.J. Ossiander. 1986. Migrational Characteristics, Biological Observations, and Relative Survival of Juvenile Salmonids Entering the Columbia River Estuary, 1966-1983. Report to Bonneville Power Admin., Portland, OR by NOAA Fisheries, Northwest Fisheries Science Center, Seattle, WA. Contract DACW57-85-F-0623, 256 p.

Desmond, J.S., J.B. Zedler and G.D. Williams. 2000. Fish use of tidal creek habitats in two southern California salt marshes. Ecological Engineering 14: 233-252.

Dias, P.C. 1996. Sources and sinks in population biology. Trends in Ecology and Evolution 11:326-330.

Diefenderfer, H.D., G.C. Roegner, R.M. Thom, E.M. Dawley, A.H. Whiting, G.E. Johnson, K.L. Sobocinski, M.G. Anderson, and B.D. Ebberts. 2005. Evaluating Cumulative Ecosystem Response to Restoration Projects in the Columbia River Estuary, Annual Report 2004. PNNL-15102. Final report to the U. S. Army Corps of Engineers, Portland District by the Pacific Northwest National Laboratory, Richland, WA. December 2005.

Diefenderfer, H.L., R.M. Thom, A.B. Borde, G.C. Roegner, A.H. Whiting, G.E. Johnson, E.M. Dawley, J.R. Skalski, J. Vavrinec, and B.D. Ebberts. 2006. Evaluating Cumulative Ecosystem Response to Restoration Projects in the Columbia River Estuary, Annual Report 2005. PNNL-15934. Final report to the U.S. Army Corps of Engineers, Portland District, by Pacific Northwest National Laboratory, Richland, WA. December 2006.

Diffendorfer, J.E. 1998. Testing models of source-sink dynamics and balanced dispersal. Oikos 81:417433.

Duncan, A.J. 1974. Quality Control and iIdustrial Statistics. Fourth edition. Irwin, Homewood, IL.

Durkin, J.T., T. Blahm, G. McCabe, T. Coley, R. McConnell, R. Emmett, and W. Muir. 1981. Columbia River Estuary Data Development Program Report: Salmonid and Non-Salmonid Fish. Study managed by Columbia River Estuary Study Taskforce for the Pacific Northwest River Basins Commission, Vancouver, WA. 146 pages.

Dyer, K.R. and R.J. Orth, eds. 1994. Changes in Fluxes in Estuaries: Implications from Science to Management. Proceedings of ECSA22/ERF Symposium, 13-18 September 1992, Institute of Marine Studies, University of Plymouth. Olsen \& Olsen, Fredensborg.

Eckler, A. R. 1955. Rotation sampling. Annals of Mathematical Statistics 26:664-685.

Emmett, R.L., R.D. Brodeur, and P.M. Orton. In Press. Depth and Diel -Related Variability in Catches of Juvenile Salmon and Associated Biota in Relation to Physical Oceanographic Features in the Columbia River Plume. 
Environmental Protection Agency (EPA). 2001. National Coastal Assessment: Quality Assurance Project Plan 2001-2004. EPA/620/R-01/002, Washington, DC.

Environmental Protection Agency (EPA). 2004. National Estuary Program. Available URL: http://www.epa.gov/owow/estuaries/

Evans, N.R., R.M. Thom, G.D. Williams, J. Vavrinec, K.L. Sobocinski, L.M. Miller, A.B. Borde, V.I. Cullinan, J.A. Ward, C.W. May, and C. Allen. 2006. Lower Columbia River Restoration Prioritization Framework. PNWD-3652 prepared by Battelle, Pacific Northwest Division for the Lower Columbia River Estuary Partnership.

Finkbeiner, M.A. 2003. High-resolution Multi-spectral Remote Sensing for Intertidal Oyster Reef Mapping and Characterization in Coastal South Carolina. Conference Abstracts, Estuarine Research Federation, 17th Biennial Conference, September 14-18, 2003, Seattle, WA.

Fleiss, J. L. 1985. The Design and Analysis of Clinical Experiments. John Wiley and Sons, New York.

Forman, R.T.T. and M. Godron. 1986. Landscape Ecology. John Wiley and Sons, New York.

Franklin, J.F. and C.T. Dyrness. 1988. Natural Vegetation of Oregon and Washington. OSU Press. Corvallis, OR.

Fresh, K. and 11 co-authors. 2003. Guidance for Protection and Restoration of the Nearshore Ecosystems of Puget Sound. Report prepared by the Nearshore Science Team in support of the Puget Sound Nearshore Ecosystem Restoration Program. NOAA Fisheries, Northwest Fisheries Science Center, Seattle, WA. May 2, 2003. URL: http://www.pugetsoundnearshore.org/science.htm.

Fresh, K., E. Casillas, L. Johnson, and D. Bottom. 2005. Role of the Estuary in the Recovery Columbia River Basin Salmon and Steelhead: an Evaluation of Selected Factors Ooopulation Viability. NOAA Fisheries, Northwest Fisheries Science Center, Seattle, WA. NOAA Technical Memorandum NMFSNWFSC-69.

Fuhrer, G.J., D.Q. Tanner, J.L. Morace, S.W. McKenzie and K.A. Skach. 1996. Water Quality of the Lower Columbia River Basin: Analysis of Current and Historical Water-Quality Data through 1994. U.S. Geological Survey Water-Resources Investigations Report 95-4294, prepared in cooperation with the Lower Columbia River Bi-State Water-Quality Program, Portland, OR. Available URL: www.lcrep.org

Garano, R., B. Anderson, R. Robinson, and C. Simenstad. 2003. Change in Land Cover along the Lower Columbia River Estuary as Determined from Landstat TM Imagery. Draft report submitted to the Lower Columbia River Estuary Partnership by Earth Design Consultants, Inc. November 2003. Portland, OR.

Garano, R.J. and R. Robinson. 2003. Estuarine Landcover along the Lower Columbia River Estuary Determined from Compact Airborne Spectrographic Imager (CASI) Imagery. Final Report submitted to Lower Columbia River Estuary Partnership, Portland, OR, October 2003. 
Garcia-Berdeal, I., B. Hickey, and M. Krause. 2002. Influence of wind stress and ambient flow on a high discharge river plume. Journal of Geophysical Research 107:3130.

Grant, E. L., and R. S. Leavenworth. 1972. Statistical Quality Control. McGraw-Hill, New York.

Hansen, M. H., W. N. Hurwitz, J. Nisselson, and J. Steinberg. 1955. The redesign of the census current population survey. Journal of the American Statistical Association 50:701-719.

Harrington, K.W. and T.D. Feather. 1996. Evaluation of Environmental Investments Procedures: Interim Overview Manual. IWR Report 96-R-18, June 1996. U.S. Army Corps of Engineers Institute for Water Resources, Alexandria, VA.

Haugerud, R.A. and D.J. Harding. 2002. Some Algorithms for Virtual Deforestation (VDF) of LIDAR Topographic Survey Data. Presented at ISPRS WGIII/3-6 Workshop Land Surface Mapping and Characterization Using Laser Altimetry, Annapolis, MD.

Hickey, B. and N. Banas. 2003. Oceanography of the U.S. Pacific Northwest coastal ocean and estuaries with application to coastal oceanography. Estuaries 26: 1010-1031.

Hillman, T.W. 2004. Monitoring Strategy for the Upper Columbia Basin. Draft report prepared for the Upper Columbia Regional Technical Team of the Upper Columbia Salmon Recovery Board, Wenatchee, WA, February 1, 2004.

Hillman, T.W. and A.E. Giorgi. 2002. Monitoring Protocols: Effectiveness Monitoring of Physical/Environmental Indicators in Tributary Habitats. Prepared for Bonneville Power Administration, Portland, OR. July 25, 2002.

Hood, W.G. 2002. Landscape allometry: from tidal channel hydraulic geometry to benthic ecology. Can. J. Fish. Aquat. Sci. 59: 1418-1427.

Horvitz, D.G., and D.J. Thompson. 1952. A generalization of sampling without replacement from a finite universe. Journal of the American Statistical Association 47:663--685.

Independent Scientific Advisory Board (ISAB) and Independent Scientific Review Panel (ISRP). 2004. A Joint ISAB and ISRP Review of the Draft Research, Monitoring, and Evaluation Plan for the NOAA-Fisheries 2000 Federal Columbia River Power System Biological Opinion. ISAB/ISRP 20041. Northwest Power and Conservation Council, Portland, OR. January 14, 2004.

Independent Scientific Review Panel (ISRP). 2005. Independent Scientific Review Panel Retrospective Report 1997-2005. ISRP 2005-14. Northwest Power and Conservation Council, Portland, OR. August 31, 2005.

Jay, D. and T. Kukulka. 2003. Revising the paradigm of tidal analysis -- the uses of non-stationary data. Ocean Dynamics 53:110-125. 
Johnson, G.J. and H.L. Diefenderfer. 2007. Facilitation of the Estuary/Ocean Subgroup for Research, Monitoring, and Evaluation - FY07 Annual Report. Final report submitted to the Bonneville Power Administration, Portland, OR. September, 2007.

Johnson G.E., R.M. Thom, A.H. Whiting, G.B. Sutherland, T. Berquam, B.D. Ebberts, N.M. Ricci, J.A. Southard, and J.D. Wilcox. 2003. An Ecosystem-Based Approach to Habitat Restoration Projects with Emphasis on Salmonids in the Columbia River Estuary. PNNL-14412, final report submitted to the Bonneville Power Administration, Portland, Oregon, November 2003, by Pacific Northwest National Laboratory, Richland, WA.

Johnson, G.E., H.D. Diefenderfer, T. Berquam, B.D. Ebberts, C. Tortorici, and J.D. Wilcox. 2004. Plan for Research, Monitoring, and Evaluation of Salmon in the Columbia River Estuary. PNNL-14632. August 10, 2004. Pacific Northwest National Laboratory, Richland, WA.

Johnson, O.W., R.S. Waples, T.C. Wainwright, K.G. Neely, F.W. Waknitz, and L.T. Parker. 1994. Status Review for Oregon's Umpqua River Sea-Run Cutthroat Trout. NOAA Fisheries, Northwest Fisheries Science Center, Seattle, WA. NOAA Technical Memorandum NMFS-VWFSC-15.

Kareiva, P., M. Marvier, and M. McClure. 2000. Recovery and management options for spring/summer Chinook salmon in the Columbia River Basin. Science 290: 977-979.

Kentula, M.E., R.P. Brooks, S. Gwin, C. Holland, A.D. Sherman, and J. Sifneos. 1992. An Approach to Improving Decision Making in Wetland Restoration and Creation. Report by the U.S. Environmental Protection Agency, Environmental Research Laboratory, EPA/600/R-92/150, August 1992, Corvallis, Oregon.

Kirn, R.A., R.D. Ledgerwood, and A.L. Jensen. 1986. Diet of subyearling chinook salmon (Oncorhynchus tshawytscha) in the Columbia River estuary and changes effected by the 1980 eruption of Mount St. Helens. Northwest Science 60: 191-196.

Kukulka, T. and D.A. Jay, 2003a. Impacts of Columbia River discharge on salmonids habitat: 1. a nonstationary fluvial tide model. Journal of Geophysical Research 108(C9):3293.

Kukulka, T. and D.A. Jay, 2003b. Impacts of Columbia River discharge on salmonids habitat: 2. changes in shallow-water habitat. Journal of Geophysical Research 108(C9):3294.

Leary, J.C., J.L. Morace, C.A. Simenstad, J.L. Burke, T.D. Counihan, J.R. Hatten, I.R. Waite, K.L. Sobocinski, J. Dietrich, F. Loge, B. Anulacion, J. Spromberg, M. Arkoosh, and L. Johnson. 2005. Lower Columbia River Ecosystem Monitoring Project Annual Report for Year 2 (September 2004 to August 2005). Prepared by the Lower Columbia River Estuary Partnership for the Bonneville Power Administration, Portland, OR.

Ledgerwood, R.D., F.P. Thrower, and E.M. Dawley. 1991. Diel sampling of migratory juvenile salmonids in the Columbia River estuary. Fisheries Bulletin 89: 69-78. 
Ledgerwood, R. D., B. A. Ryan, C. Z. Banks, E. P. Nunallee, B. P. Sandford, S. G. Smith, and J. W. Ferguson. 2003. Detection of PIT-Tagged Juvenile Salmonids in the Columbia River Estuary Using a Surface-Trawl Detection System, 1999. Report to the U.S. Army Corps of Engineers by NOAA Fisheries, Northwest Fisheries Science Center, Seattle, WA.

Los Penasquitos Lagoon and California Coastal Conservancy. 1995. Los Penasquitos Lagoon Enhancement Plan and Program. October, 1995.

Louisiana Coastal Wetlands Conservation and Restoration Task Force. 2001. The 2000 evaluation report to the U.S. Congress on the effectiveness of Louisiana coastal wetland restoration projects. Louisiana Department of Natural Resources, Baton Rouge, LA.

Lower Columbia River Estuary Partnership and Lower Columbia Fish Recovery Board. 2004. Lower Columbia Salmon and Steelhead Recovery and Subbasin Plan. Volume I and II. Draft report prepared for the Northwest Power and Conservation Council, May 28, 2004. Available URL: http://www.nwcouncil.org/fw/subbasinplanning/lowerColumbia/plan/.

Lower Columbia River Estuary Program. 1998. Lower Columbia River Estuary Plan, Aquatic Ecosystem Monitoring Strategy for the Lower Columbia River and Information Management Strategy, Volume II. Portland, OR.

Lower Columbia River Estuary Program. 1999. Lower Columbia River Estuary Plan, Comprehensive Conservation and Management Plan, Volume I. Portland, OR.

Lower Columbia River Estuary Partnership. 2007. Columbia River Estuary Recovery Plan Module. Submitted to NOAA Fisheries, Portland, OR.

MacDonald, L.H., A.W. Smart, and R.C. Wissmar. 1991. Monitoring Guidelines to Evaluate Effects of Forestry Activities on Streams in the Pacific Northwest and Alaska. U.S. Environmental Protection Agency, EPA/910/9-91-001, Seattle, WA.

Mainstem Systemwide Review Team. 2006. Mainstem/Systemwide Project Review Process. Final draft. Northwest Power and Conservation Council, Portland, OR.

Mantua, N.J., S.R. Hare, Y. Zhang, J.M. Wallace, and R.C. Francis. 1997. A Pacific interdecadal climate oscillation with impacts on salmon production. Bulletin of the American Meteorological Society 78(6):1069-1080.

McCabe, G.T. Jr., R.L. Emmett, W.D. Muir, and T.H. Blahm. 1986. Utilization of the Columbia River estuary by subyearling chinook salmon. Northwest Science 60:113-124.

McCabe, G.T. Jr., W.D. Muir, and J. T. Durkin. 1983. Interrelationships between juvenile salmonids and nonsalmonid fish in the Columbia River Estuary. Fisheries Bulletin 81:815-826.

McConnell, R., T. Blahm, G. McCabe, T. Clocksin, T. Coley, J. Durkin, R. Emmett, and W. Muir. 1983. Columbia River Estuary Data Development Program Data Report: Salmonid and Non-Salmonid Fish, 4 volumes. Columbia River Estuary Data Development Program. Managed by Columbia River 
Estuary Taskforce, Astoria, OR.

McDonald, T. L. 2003. Review of environmental monitoring methods: survey designs. Environmental Monitoring and Assessment 85:277-292.

McRoberts, R. E., and M. Hansen. 1999. Annual forest inventories for the North Central Region of the United States. Journal of Agricultural Biology and Environmental Statistics 4:361-371.

Meffe, G. K., C. R. Carroll, and contributors. 1994. Principles of Conservation Biology. Sinauer Assoc., Inc., Sunderland, MA.

Monitoring Oversight Committee (MOC). 2002a. The Washington Comprehensive Monitoring Strategy and Action Plan for Watershed Health and Salmon Recovery. Executive Report, Volume 1 of 3. December 2002, Olympia, WA.

Monitoring Oversight Committee (MOC). 2002b. The Washington Comprehensive Monitoring Strategy and Action Plan for Watershed Health and Salmon Recovery. December 2002, Olympia, WA.

Monitoring Oversight Committee (MOC). 2002c. The Washington Comprehensive Monitoring Strategy and Action Plan for Watershed Health and Salmon Recovery. Action Plan, Volume 3 of 3. December 2002, Olympia, WA.

Murphy, B.R. and D.W. Willis (eds). 1996. Fisheries Techniques. $2^{\text {nd }}$ Edition. American Fisheries Society, Bethesda, MD.

National Estuarine Research Reserve System. 2004. Systemwide Monitoring Program. Available URL: http://cdmo.baruch.sc.edu/overview.html

National Oceanic and Atmospheric Administration. 2004. Monitoring Requirements Under the Estuary Restoration Act. Available URL: http://era.noaa.gov/htmls/era/era_monitoring.html.

National Research Council (NRC). 1992. Restoration of Aquatic Ecosystems. National Academy Press, Washington, D.C.

National Research Council (NRC). 1995. Review of EPA's Environmental Monitoring and Assessment Program: Overall Evaluation. National Academy Press, Washington, D.C.

National Research Council (NRC). 2003. Adaptive Monitoring and Assessment for the Comprehensive Everglades Restoration Plan. National Academy Press, Washington, D.C.

Neal, V.T. 1972. Physical Aspects of the Columbia River and Its Estuary. In Pruter, A.T. and D.L. Alverson, (eds). The Columbia River Estuary and Adjacent Ocean Waters: Bioenvironmental Studies. University of Washington Press, Seattle, WA.

Neckles, H. and M. Dionne (eds.). 2000. Regional Standards to Identify and Evaluate Tidal Wetland Restoration in the Gulf of Maine. A report by the Global Programme of Action Coalition (GPAC) for the Gulf of Maine, workshop June 2-3, 1999, at the Wells National Estuarine Research Reserve, Wells, ME. 
NMFS (National Marine Fisheries Service). 2000. Biological Opinion: Reinitiation of Consultation on Operation of the Federal Columbia River Power System, Including the Juvenile Fish Transportation Program, and 19 Bureau of Reclamation Projects in the Columbia Basin. National Marine Fisheries Service - Northwest Region, Seattle, WA. December 2000. Available at http://www.salmonrecovery.gov/implementation.

NMFS. 2004. Biological Opinion: Operation of the Federal Columbia River Power System (FCRPS) including 19 Bureau of Reclamation Projects in the Columbia Basin (Revised and reissued pursuant to court order, NWF v. NMFS, Civ. No. CV 01-640-RE (D. Oregon)). National Marine Fisheries Service (NOAA Fisheries) - Northwest Region, Seattle, WA. November 2004. Available at http://www.salmonrecovery.gov/implementation.

NMFS. 2007. Biological Opinion - Remand Draft. Consultation on Remand for Operation of the Federal Columbia River Power System, 11 Bureau of Reclamation Projects in the Columbia Basin and ESA Section 10(a)(1)(A) Permit for Juvenile Fish Transportation Program (Revised and reissued pursuant to court order, NWF v. NMFS, Civ. No. CV 01-640-RE (D. Oregon)). National Marine Fisheries Service (NOAA Fisheries) - Northwest Region, Seattle, WA. October 2007. Available at http://www.salmonrecovery.gov/implementation.

NOAA Coastal Services Center. 1997. Coastal Change Analysis Program (C-CAP): Changes in Land Cover in the Columbia River Estuary: 1989-1992. NOAA CSC/1-97/001. NOAA Coastal Services Center, Charleston, SC. http://csc.noaa.gov.

Noon, B.R. 2003. Conceptual Issues in Monitoring Ecological Resources. In: Busch and Trexler (ed.) Monitoring Ecosystems. Island Press, Washington, D.C.

NPCC (Northwest Power and Conservation Council). 2000. Columbia River Basin Fish and Wildlife Program: A Multi-Species Approach for Decision Making. Document 2000-19. Northwest Power and Conservation Council, Portland, OR.

NPCC (Northwest Power and Conservation Council). 2006a. Guidance for developing monitoring and evaluation as a program element of the Fish and Wildlife Program. March 2006. Portland, OR.

NPCC. 2006b. Columbia River Basin Research Plan. Document 2006-3. Northwest Power and Conservation Council, February 2006, Portland, OR.

Omernik, J.M. and A.L. Gallant. 1986. Ecoregions of the Pacific Northwest States. EPA/600/3-86/033, U.S. Environmental Protection Agency Environmental Research Laboratory, Corvallis, OR, July 1986.

Oregon Watershed Enhancement Board (OWEB). 2004. Monitoring Strategy for the Oregon Plan for Salmon and Watersheds. Available at http://www.oweb.state.or.us/monitoring/index.shtml. 
Osprey Environmental Services. 1996. A Guide to Photo-Documentation for Aquatic Inventory. Prepared for the Aquatic Ecosystems Task Force, Resources Inventory Committee on Behalf of the B.C. Ministry of Environment, Lands and Parks, Fisheries Branch. British Columbia, Canada. Available URL: http://www.publications.gov.bc.ca, 1-800-663-6105.

Pacific Northwest Aquatic Monitoring Partnership (PNAMP). 2004. Recommendations for Coordinating State, Federal, and Tribal Watershed and Salmon Monitoring Programs in the Pacific Northwest. Draft report, January 6, 2004.

Pacific Northwest Aquatic Monitoring Partnership (PNAMP). 2007. Management Question Survey Summary Report. April 2007.

Patterson, H. D. 1950. Sampling on successive occasions with partial replacement of units. Journal of the Royal Statistical Society, Series B 12:241-255.

Peterson, W.T. and D.L. Mackas. 2001. Shifts in zooplankton abundance and species composition off central Oregon and southwestern British Columbia. PICES Press 9(2):28-31.

Peterson, W.T., J. Keister, and L. Feinberg. 2002. The effects of the 1997-98 el Niño event on hydrography and zooplankton off the central Oregon coast. Progress in Oceanography 54:381-398.

Philander, S.G.H.. 1990. El Niño, La Niña and the Southern Oscillation. Academic Press, San Diego, CA, $289 \mathrm{pp}$.

Pruter, A.T. and D.L. Alverson (eds.). 1972. The Columbia River Estuary and Adjacent Ocean Waters: Bioenvironmental Studies. University of Washington Press, Seattle, WA.

Pulliam, H.R. 1988. Sources, sinks and population regulations. American Naturalist 132:652-661.

Rao, J.N.K., and J.E. Graham. 1964. Rotation designs for sampling on repeated occasions. Journal of the American Statistical Association 59:492-509.

Reams, G.A., and P.V. Deusen. 1999. The southern annual forest inventory system. Journal of Agricultural Biology and Environmental Statistics 4:346-360.

Reimers, P.E., and R.E. Loeffel. 1967. The length of residence of juvenile fall chinook salmon in selected Columbia River tributaries. Res. Briefs, Fish Comm. Oreg. 13(1): 5-19

Rice, C.A., W.G. Hood, L.M. Tear, C.A. Simenstad, G.D. Williams, L.L. Johnson, B.E. Feist, and P. Roni. 2005. Monitoring Rehabilitation in Temperate North American Estuaries. In P. Roni (ed.) Monitoring Stream and Watershed Restoration. American Fisheries Society, Bethesda, MD.

Rich, W.H. 1920. Early history and seaward migration of Chinook salmon in the Columbia and Sacramento rivers. U.S. Bur. Fish. Bull. 37: 2-73. 
Ringold, P.L., B. Mulder, J. Alegria, R.L. Czaplewski, T. Tolle and K. Burnett. 2003. Design of an Ecological Monitoring Strategy for the Forest Plan in the Pacific Northwest. In Busch, E.E. and J.C. Trexler, (eds.), Monitoring Ecosystems: Interdisciplinary Approaches for Evaluating Ecoregional Initiatives, pp. 73-99. Island Press, Washington, D.C.

RME Plan. 2003. Research, Monitoring \& Evaluation Plan for the NOAA-Fisheries 2000 Federal Columbia River Power System Biological Opinion. Draft dated September 11, 2003. NOAA Fisheries, Bonneville Power Administration, U.S. Army Corps of Engineers, and Bureau of Reclamation. Portland, OR.

Roby, D.D., D.E. Lyons, D.P. Craig, K. Collis, and G.H. Visser. 2003. Quantifying the effect of predators on endangered species using a bioenergetics approach: Caspian terns and juvenile salmonids in the Columbia River estuary. Canadian Journal of Zoology 81:250-265.

Roegner, G.C., D.L. Bottom, A. Baptista, S. Hinton, C.A. Simenstad, E. Casillas and K. Jones. 2005. Estuarine Habitat and Juvenile Salmon - Current and Historical Linkages in the Lower Columbia River and Estuary, 2003. Draft report prepared for the U.S. Army Corps of Engineers, Portland District.

Roegner, G.C., H.L. Diefenderfer, A.B. Borde, R.M. Thom, E.M. Dawley, and A.H. Whiting. 2008. Monitoring Protocols for Salmon Habitat Restoration Projects in the Lower Columbia River and Estuary. Prepared by NOAA Fisheries and Pacific Northwest National Laboratory for the U.S. Army Corps of Engineers, Portland District.

Sallenger, A.H. Jr. and 13 others. 2003. Evaluation of airborne topographic lidar for quantifying beach changes. Journal of Coastal Research 19: 125-133.

Schabetsberger, R., C.A. Morgan, R.D. Brodeur, C.L. Potts, W.T. Peterson and R.L. Emmett. In Press. Prey selectivity and diel feeding chronology of juvenile chinook (Oncorhynchus tshawytscha) and coho (O. kisutch) salmon in the Columbia River plume. Fish. Oceanogr.

Schreck, C.B., M.D. Karnowski, and B.J. Clemens. 2005. Evaluation of Post-Release Losses and Barging Strategies that Minimize Post Release Mortality. Final report by the Oregon Cooperative Fish and Wildlife Unit, Oregon State University submitted to the Walla Walla District, U.S. Army Corps of Engineers. Contract DACW68-00-C-0028.

Schreck, C. and T. Stahl. 2000. Evaluation of Migration and Survival of Juvenile Salmonids Following Transportation. Annual report 1998 submitted to Walla Walla District, U.S. Army Corps of Engineers. December 2000.

Schuett-Hames, D., A.E. Pleus, E. Rashin, and J. Mathews. 1999. TFW Monitoring Program Method Manual for The Stream Temperature Survey. Prepared for the Washington State Dept. of Natural Resources under the Timber, Fish, and Wildlife Agreement. TFW-AM9-99-005. DNR \#107. June 1999. 35 pp. Available URL: www.nwifc.wa.gov. 
Schwing, F.B., T. Murphree, and P. Green. In Press. A Climate Index for the Northeast Pacific. Progress in Oceanography.

Scott, A. J., and T. M. F. Smith. 1974. Analysis of repeated surveys using time series methods. Journal of the American Statistical Association 69:674-678.

Sen, A. R. 1971. Increased precision in Canadian waterfowl harvest survey through successive sampling. Journal of Wildlife Management 35:664-668. . 1979. Sampling theory on repeated occasions with ecological applications. Pages $315-328$ in R. M. Cormack, G. P. Patil, and D. S. Robson, eds. Sampling Biological Populations. International Coop Publishing House, Fairland, MD.

Sewell, A. T., J. G. Norris, S. Wyllie-Echeverria, and J. Skalski. 2001. Eelgrass Monitoring in Puget Sound: Overview of the Submerged Vegetation Monitoring Project. Report to Washington State Department of Natural Resources, Olympia, WA.

Sherwood, C.R. and J.S. Creager. 1990. Sedimentary geology of the Columbia River estuary. Progress in Oceanography 25:15-79.

Sherwood, C.R., D.A. Jay, R.B. Harvey, P. Hamilton and C.A. Simenstad. 1990. Historical changes in the Columbia River estuary. Progress in Oceanography 25:299-352.

Simenstad, C.A. and B.E. Feist. 1996. Restoration Potential of Diked Estuarine Wetlands: Inferring Fate and Recovery Rate of Historically-Breached Sites. U.S. Environmental Protection Agency Office of Ecosystems \& Communities, EPA 910/R-96-005, July 1996, Seattle, WA.

Simenstad, C.A., J.L. Burke, I.R. Waite, T.D. Counihan and J.R. Hatten. 2005. Lower Columbia River and Estuary Ecosystem Classification: Phase II. Wetland Ecosystem Team, School Aquat. Fish. Sci., Univ. Wash., and U.S. Geol. Surv., Water Res. Div., Ore. Dist. Off., rep. to Lower Columbia River Estuary Partnership, Portland, OR.

Simenstad, C.A. and J.R. Cordell. 2000. Ecological assessment criteria for restoring anadromous salmonid habitat in Pacific Northwest estuaries. Ecological Engineering 15:283-302.

Simenstad, C.A., C.D. Tanner, R.M. Thom and L.L. Conquest. 1991. Estuarine Habitat Assessment Protocol. EPA 910/9-91-037. Prepared for U.S. EPA, Region 10, Office of Puget Sound, Seattle, WA.

Simenstad, C.A., L.F. Small, C.D. McIntire, D.A. Jay and C Sherwood. 1990a. Consumption process and food web structure in the Columbia River estuary. Progress in Oceanography 25: 271-297.

Simenstad, C.A., L.F. Small, C.D. McIntire, D.A. Jay and C Sherwood. 1990b. Columbia River estuary studies: An introduction to the estuary, a brief history, and prior studies. Progress in Oceanography 25:1-13. 
Skalski, J. and six co-authors. 2001. Estimating in-river survival of migrating salmonid smolts using radiotelemetry. Can. J. Fish. Aquat. Sci. 58:1987-1997.

Skalski, J.R. 1995. Statistical considerations in the design and analysis of environmental damage assessment studies. Journal of Environmental Management 43:67-85.

Skalski, J.R., and D.S. Robson. 1992. Techniques for Wildlife Investigations: Design and Analysis of Capture Data. Academic Press, San Diego, CA.

Skalski, J.R., D.A. Coats, and A.K. Fukuyama. 2001. Criteria for oil spill recovery: a case study of the intertidal community of Prince William Sound, Alaska, following the Exxon Valdez oil spill. Environmental Management 28:9-18.

Small, L.F. (ed.). 1990. Columbia River: Estuarine System. Progress in Oceanography. Vol. 25, no. 14.

Sobocinski, K.L., A.B. Borde, L.M. Miller, R.M. Thom, and L.M. Tear. 2006. Columbia River Estuary Habitat Monitoring Pilot Field Study and Remote Sensing Analysis. PNWD-3475-C. Final report submitted to the Lower Columbia River Estuary Partnership, Portland, OR.

Stevens, L.E. and B.D. Gold. 2003. Monitoring for Adaptive Management of the Colorado River Ecosystem in Glen and Grand Canyons. In Busch, E.E. and J.C. Trexler, eds., Monitoring Ecosystems: Interdisciplinary Approaches for Evaluating Ecoregional Initiatives, pp. 101-134. Island Press, Washington, D.C.

Sukhatme, P.V. 1954. Sampling Theory of Surveys with Applications. Iowa State College Press, Ames, IW.

Systema, M.D., J.R. Cordell, J.W. Chapman, and R.C. Draheim. 2004. Lower Columbia River Aquatic Nonindigenous Species Survey 2001-2004. Final technical report submitted to the U.S. Coast Guard and the U.S. Fish and Wildlife Service. Portland State University, Portland, OR.

Taylor, W.J., J. Cordell, B.W. Rummel, B. Berkompas, and J. Gilbert. 2003. Sampling Tidal Flux of Invertebrate Prey Organisms from a Constructed Estuarine Habitat Restoration Site to Assess Design Performance. Conference Abstracts, Estuarine Research Federation, 17th Biennial Conference, September 14-18, 2003, Seattle, WA.

Tegler, B., M. Sharp, and M.A. Johnson. 2001. Ecological monitoring and assessment network's proposed core monitoring variables: an early warning of environmental change. Environmental Monitoring and Assessment 67:29-56.

Teel, D.J., G.B. Milner, G.A. Winans, and W.S. Grant. 2000. Genetic population structure and origin of life history types in Chinook salmon in British Columbia, Canada. Transactions of the American Fisheries Society 129: 194-209. 
TetraTech. 1996. The Health of the River 1990-1996: Integrated Technical Report. Report TC 0253-01, prepared by Tetra Tech for the Lower Columbia River Bi-State Program, May 20, 1996. Available URL: www.lcrep.org.

Thayer, G.W., T.A. McTigue, R.J. Bellmer, F.M. Burrows, D.H. Merkey, A.D. Nickens, S.J. Lozano, P.F. Gayaldo, P.J. Polmateer, and P.T. Pinit. 2003. Volume One: Science-Based Restoration Monitoring of Coastal Habitats. NOAA Coastal Ocean Program Decision Analysis Series No. 23. Center for Sponsored Coastal Ocean Research, Silver Spring, MD. Available URL: www.cop.noaa.gov.

Thayer, G.W., T.A. McTigue, R.J. Salz, D.H. Merkey, F.M. Burrows, and P.F. Gayaldo, (eds.). 2005. Science-Based Restoration Monitoring of Coastal Habitats, Volume Two: Tools for Monitoring Coastal Habitats. NOAA Coastal Ocean Program Decision Analysis Series No. 23. NOAA National Centers for Coastal Ocean Science, Silver Spring, MD. Available URL: www.cop.noaa.gov.

Thom R.M. 2000. Adaptive management of coastal ecosystem restoration projects. Ecological Engineering 15:365-372.

Thom R.M. 1997. System-development matrix for adaptive management of coastal ecosystem restoration projects. Ecological Engineering 8: 219-232.

Thom, R.M. and K.F. Wellman. 1996. Planning Aquatic Ecosystem Restoration Monitoring Programs. Report No. 96-R-23, U.S. Army Corps of Engineers Institute for Water Resources and Waterways Experiment Station, Vicksburg, MS.

Thom, R., M. Anderson, and H. Diefenderfer. 2007. Adaptive Management Plan for the Ecosystem Restoration Program of the Lower Columbia River Estuary Partnership. Draft report submitted to the Lower Columbia River Estuary Partnership, Portland, OR.

Thom, R.M., H.L. Diefenderfer, and K.D. Hofseth. 2006. A Framework for Risk Analysis in Ecological Restoration Projects. Chapter 4 in Economics and Ecological Risk Assessment: Applications to Watershed Management, Randy Bruins and Matt Heberling, eds., CRC Press, Boca Raton, FL.

Thom, R.M., A.B. Borde, N.R. Evans, C.W. May, G.E. Johnson, and J.A. Ward. 2004. A Conceptual Model for the Lower Columbia River Estuary. Final report to the U. S. Army Corps of Engineers by Pacific Northwest National Laboratory, Richland, WA.

Thom, R.M., R. Zeigler, and A.B. Borde. 2002. Floristic development patterns in a restored Elk rRiver estuarine marsh, Grays Harbor, Washington. Restoration Ecology 10(3):487-496.

Thomas, D.W. 1983. Changes in Columbia River Estuary Habitat Types Over the Past Century. Columbia River Estuary Data Development Program, Columbia River Estuary Study Taskforce, Astoria, OR, July 1983.

Thorpe, J.E., L Ross, G. Struthers, and W. Watts. 1981. Tracking Atlantic salmon smolts, Salmo salar L., through Loch Voil, Scotland. Journal of Fish Biology 19: 519-537. 
Tranter, D. and J. Fraser (ed.). 1974. Zooplankton sampling. Monographs in Oceanographic Methodology 2. Unesco Press, Paris, France.

Upper Columbia Technical Recovery Team (UCTRT). 2007. Upper Columbia Monitoring and Evaluation Plan. Appendix P under development for the Upper Columbia salmon and steelhead recovery plan. Prepared for the NOAA Fisheries Salmon Recovery Division, Portland, OR.

USACE. 2001. Biological Assessment Columbia River Channel Improvements Project. Submitted to NMFS and USFWS. December 28, 2001. Portland, OR.

USACE and Estuary Partnership. 2003. Research Needs Identification Workshop for the Columbia River Estuary. March 24-25, 2003. Portland, OR.

Urquhart, N. S., and T. M. Kincaid. 1999. Designs for detecting trend from repeated surveys of ecological resources. Journal of Agricultural Biology and Environmental Statistics 4:404-414.

USACE \& SFWMD. 1999. Central and Southern Florida Project Comprehensive Review Study Final Integrated Feasibility Report and Programmatic Environmental Impact Statement. U.S. Army Corps of Engineers, Jacksonville District and South Florida Water Management District. Available URL: http://www.evergladesplan.org/pub/pubrequest/requestfrm.cfm

USGS (United States Geological Survey). 1990. Largest Rivers in the United States, in Discharge, Drainage Area, or Length. Open-File Report 87-242, Reston, Virginia.

Waldeck, R., J. Chapman, J. Cordell, and M. Systma. 2003. Lower Columbia River Aquatic Nonindigenous Species Survey 2001-2003. Interim report submitted to the U.S. Coast Guard. May 2003.

Walters, C. J., J. S. Collie, and T. Webb. 1988. Experimental design for estimating transient responses to management disturbances. Canadian Journal of Fisheries and Aquatic Sciences 45:530-538.

Ware, K. D., and T. Cunia. 1962. Continuous forest inventory with partial replacement of samples. Forest Science Monographs 3.

Washington Salmon Recovery Funding Board (WSRFB). 2003a. Monitoring and Evaluation Strategy for Habitat Restoration and Acquisition Projects. Draft report, Olympia, WA, May 23, 2003. MP-0.

Washington Salmon Recovery Funding Board (WSRFB). 2003b. Sampling Procedures, Designs, and Expected Costs -- Fish Passage Projects Effectiveness Monitoring (Culverts, Bridges, Fishways, Logjams, Dam Removal). MP-1. Draft report, Olympia, WA, May 23, 2003.

Washington Salmon Recovery Funding Board (WSRFB). 2003c. Sampling Procedures, Designs, and Projected Costs -- In-Stream Habitat Projects Effectiveness Monitoring (Channel Connectivity, Off Channel Habitat, Wetland Restoration). MP-6. Draft report, Olympia, WA, May 23, 2003. 
Washington Salmon Recovery Funding Board (WSRFB). 2003d. Sampling Protocols -- Effectiveness Monitoring Habitat Restoration Projects Requirements. MP-X. Draft report, Olympia, WA, May 23, 2003.

Wheeler, D. J. 1995. Advanced Topics In Statistical Process Control. SPC Press, Knoxville, TN.

Williams, G.L. 1989. Coastal/Marine Fish Habitat Description and Assessment Manual. Part II. Habitat Description Procedures. G.L. Williams \& Associates Ltd., Coquitlam, B.C. 38 pp + appendices. Available: Department of Fisheries and Oceans and Pacific Region Habitat Enhancement Branch, Vancouver, B.C.

Williams, P.B. and M.K. Orr. 2002. Physical evolution of restored breached levee salt marshes in the San Francisco Bay estuary. Restoration Ecology 10(3):527-542.

Williams, P.B., M.K. Orr and N.J. Garrity. 2002. Hydraulic geometry: a geomorphic design tool for tidal marsh channel evolution in wetland restoration projects. Restoration Ecology 10(3):577-590.

Woodruff, D.L. 2004. Personal Communication. Pacific Northwest National Laboratory, Battelle Marine Sciences Laboratory, Sequim, WA.

Zedler J.B. (ed.). 2001. Handbook for Restoring Tidal Wetlands. CRC Press, Boca Raton, Florida.

Zimmerman, M. and D. Ward. 1999. Index of predation on juvenile salmonids by northern pikeminnow in the Lower Columbia River basin, 1994-1996. Transactions of the American Fisheries Society 128: 995-1007. 
Research, Monitoring, and Evaluation for the Federal Columbia River Estuary Program 


\section{Appendix A: Background and Study Area}

The Columbia River estuary plays an important ecological role in the performance of threatened and endangered salmonid populations in the Columbia basin (Bottom et al. 2005). More than simply serving as a corridor for passage between the tributaries and the Pacific Ocean, the estuary provides rearing and refuge habitats for various life history stages of salmon and steelhead (Bottom et al. 2005). Although use of estuary habitats by juvenile salmonids varies by species and life history stage (Rich 1920), all Columbia basin salmonids migrating to and from the ocean use the estuary in some fashion. Information on salmon biology and ecology in the Columbia River estuary can be found in Bottom et al. $(1984,2005)$, Bottom and Jones (1990), Dawley et al. (1985a,b, 1986), Durkin et al. (1981), Fresh et al. (2005), Kirn et al. (1986), Ledgerwood et al. (1991), McCabe et al. (1983, 1986), and McConnell et al. (1983).

In recognition of the Columbia River estuary's importance to salmonid populations in the Columbia basin, the 2000 and 2004 Biological Opinions on operation of the Federal Columbia River Power System (FCRPS), and the 2007 Remand Draft Biological Opinion, called for the restoration ${ }^{\text {a }}$ of estuarine habitat, estuarine research, and monitoring as important actions to avoid jeopardizing the continued existence of the listed salmonids shown in Table A.1 (NMFS 2000, 2004, 2007). The Action Agencies ${ }^{\mathrm{b}}$ are coordinating and implementing their Estuary Program and other estuary-related actions called for in the FCRPS Biological Opinions.

Table A.1. Technical Recovery Team, Evolutionarily Significant Unit, and Endangered Species Act (ESA) Status of Listed Salmonids.

\begin{tabular}{|c|c|c|}
\hline Technical Recovery Team & Evolutionarily Significant Unit & ESA Status \\
\hline \multirow[t]{5}{*}{ Willamette and Lower Columbia River } & Lower Columbia R. Chinook (Oncorhynchus tshawytscha) & threatened \\
\hline & Lower Columbia R. Steelhead (O. mykiss) & threatened \\
\hline & Upper Willamette R. Chinook (O. tshawytscha) & threatened \\
\hline & Upper Willamette R. Steelhead (O. mykiss) & threatened \\
\hline & Columbia R. Chum (O. keta) & threatened \\
\hline \multirow[t]{7}{*}{ Interior Columbia River Basin } & Upper Columbia R. Spring Chinook (O. tshawytscha) & endangered \\
\hline & Upper Columbia R. Steelhead (O. mykiss) & threatened \\
\hline & Mid Columbia R. Steelhead (O. mykiss) & threatened \\
\hline & Snake R. Spring/Summer Chinook (O. tshawytscha) & threatened \\
\hline & Snake R. Fall Chinook (O. tshawytscha) & threatened \\
\hline & Snake R. Steelhead (O. mykiss) & threatened \\
\hline & Snake R. Sockeye (O. nerka) & endangered \\
\hline
\end{tabular}

a In this document, the term "restoration" generally includes other fundamental restoration approaches commonly reported in the literature, such as creation, enhancement, and protection (defined in the glossary).

${ }^{\mathrm{b}}$ The Action Agencies for the Estuary/Ocean Research, Monitoring and Evaluation are the Bonneville Power Administration (BPA) and U.S. Army Corps of Engineers (USACE). 


\section{A.1 Estuary Research, Monitoring, and Evaluation Development}

Development of estuary RME involves a sequential process (Figure A.1). We use the goals and objectives of the Estuary Program to establish RME goals and objectives in the context of the study area and relationships with other programs, as described in this Appendix. Then we apply a conceptual ecosystem model to determine linkages between objectives and monitored indicators (e.g., Batiuk et al. 1992), as described in Appendix B. The next step involves selection of monitored indicators ${ }^{\text {a }}$ for estuary RME based on a review of existing literature and conditions in the estuary. With the monitored indicators in place, we identify methods, including example protocols and sampling design considerations (Appendix C). This process - from objectives to conceptual model to monitored indicators to methods describes a research and monitoring framework. Such frameworks are detailed for status and trend monitoring and action effectiveness research in Appendix B. Project-level and program-level assessments of the coverage of the estuary RME objectives were used to identify gaps (Section 4, Table 4). To fill the gaps and implement estuary RME, we specified an action plan (Section 4.3).

In the sense that estuary RME functions as an "umbrella" document for monitoring in the estuary, it should be periodically revised to cover new monitoring efforts and respond to changing program goals in an adaptive management framework (Thom 2000). The adaptive management process is fundamentally iterative, as shown by the box in Figure A.1. As the Action Plan is implemented over time, the monitoring data is evaluated periodically and resulting changes in understandings are applied to reevaluate and, if necessary, revise the Estuary Program goals and objectives and estuary RME goals and objectives (Thom 2000). Evaluation of the monitoring data is also used to update the Conceptual Model, which informs the remainder of the process (Figure A.1).

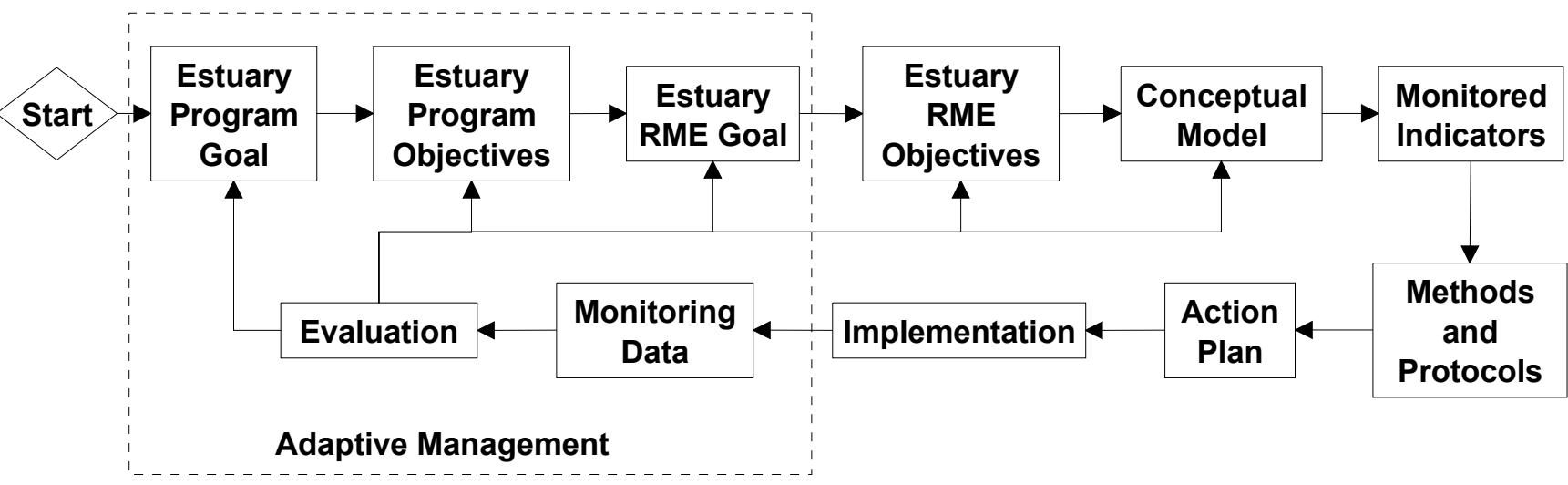

Figure A.1. Schematic of RME Development for the Estuary Program

\footnotetext{
${ }^{a}$ A monitored indicator is a measurable parameter that characterizes an important aspect of the ecosystem and is sensitive to changes in the system.
} 
The approach for estuary RME in the CRE relies heavily on conceptual ecosystem models. It is generally accepted that a conceptual model is central to the development of scientific research, monitoring, and evaluation programs in ecological systems (cf. Busch and Trexler 2003). For the purpose of this program, the Columbia River Estuary Conceptual Model (Thom et al. 2004) serves to represent the state-of-the-science in regard to ecosystem stressors, controlling factors, structures, processes, and functions (Figure A.2; see the Glossary for definitions). This model guided the development of status and trends monitoring and action effectiveness monitoring as described in Appendix B. In addition, the previous version of this document (August 2004) proposed a framework for action effectiveness research based in part on work describing essential features of salmon habitats by Simenstad and Cordell (2000). This is appropriate because much of the conservation and restoration work in the estuary is directed at salmonids. Therefore, the estuary RME effort has adopted the current state-of-the-science in regard to factors affecting salmon habitats (e.g., Bottom et al. 2005), which was also built in part on Simenstad and Cordell (2000). In this way, the document remains both consistent and current.

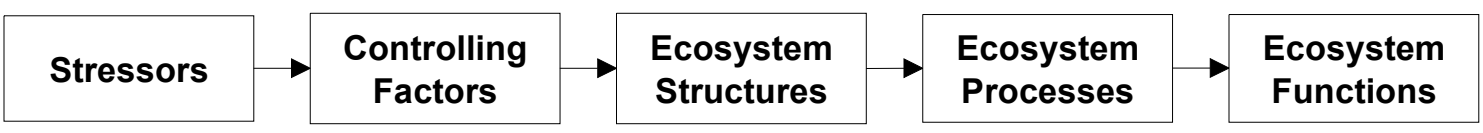

Figure A.2. Basic Elements of the Columbia River Estuary Conceptual Model (from Thom et al. 2004)

Estuary RME includes research and monitoring activities in the historical floodplain of the Columbia River from Bonneville Dam to the river's mouth. Lower river tributaries are not considered in estuary RME because salmon-related monitoring and research in these areas are covered under state and local programs. Also, it does not cover research for the juvenile fish transportation (barging) program on effects that have been hypothesized to manifest themselves in the estuary, such as delayed mortality (NMFS 2004). Fish transportation research is addressed in the hydrosystem component of the basin-wide RME plan (RME Plan 2003). Nor does the program include sediment dynamics, channel deepening, or dredge material disposal in the nearshore ocean. Information on these topics is provided at www.nwp.usace.army.mil. Estuary RME, however, does incorporate research on Columbia Basin juvenile salmon in the plume and eastern Pacific Ocean.

Since the last version of this estuary RME document was released (August 2004), a large number of scientific studies and planning processes have released documents of importance to estuary RME. The material herein reflects the current status of planning as it pertains to the CRE and incorporates the stateof-the-science regarding CRE ecosystem structures and processes and salmon performance as represented by the following documents and events:

- Bottom et al. (2005) Salmon at River's End: The Role of the Estuary in the Decline and Recovery of Columbia River Salmon

- Diefenderfer et al. (2005; 2006) Evaluating Cumulative Ecosystem Response to Restoration Projects in the Columbia River Estuary, Annual Reports for 2004 and 2005, respectively

- Evans et al. (2006) Lower Columbia River and Estuary Habitat Restoration Prioritization Framework 
- Fresh et al. (2005) Role of the Estuary in the Recovery of Columbia River Basin Salmon and Steelhead: an Evaluation of Selected Factors on Population Viability

- Johnson and Sutherland (ed.) (2006) Proceedings of the 2006 Conference on Research, Monitoring, and Restoration in the Lower Columbia River, Estuary, and Nearshore Ocean

- Leary et al. (2005) Ecosystem Monitoring Program, Annual Report 2005

- LCREP (2006) Columbia River Estuary Recovery Plan Module

- $\quad$ NOAA Workshop on Columbia River Estuary Research and Monitoring (February 2006)

- NOAA Workshop on Columbia River Management Scenarios Modeling (March 2006)

- NPCC (2006a) Guidance for Developing Monitoring and Evaluation as a Program Element of the Fish and Wildlife Program

- $\quad$ NPCC (2006b) Columbia River Basin Research Plan

- Roegner et al. (2005) Estuarine Habitat and Juvenile Salmon - Current and Historical Linkages in the Lower Columbia River and Estuary, 2002-2004

- Roegner et al. (2008) Monitoring Protocols for Salmon Habitat Restoration Projects in the Lower Columbia River and Estuary

- Sobocinski et al. (2006) Columbia River Estuary Habitat Monitoring Pilot Field Study and Remote Sensing Analysis.

Although RME mandates in the 2000, 2004, and 2007 Biological Opinions were the impetus for this estuary RME effort by the Action Agencies, this program has broader applications. It is pertinent to regional and national programs in the estuary because its ecosystem approach furthers the ongoing effort by various agencies and organizations to develop the science basis for long-term management of the Columbia River estuary and its resources. Thus, the intended outcome of estuary RME is three-fold. First, it will provide data on the performance of the Estuary Program to allow decision-makers to assess whether program goals and objectives are being met. Second, program-level coordination will help allocate research, monitoring, conservation, and restoration funding effectively. Third, the knowledge developed will improve the state-of-the-science represented by the conceptual model, which in turn is applied in planning and management decisions designed to increase estuary habitats used by listed salmonids and other focal species.

\section{A.2 Study Area Description}

For the purpose of the federal estuary RME effort, the Columbia River estuary includes the plume (see glossary for definition), the estuary proper, and the tidally influenced part of the river upstream to Bonneville Dam, except for the Willamette River (Figure A.3). While definitions of estuaries typically use the maximum extent of seawater intrusion, all tidally influenced areas are included in the definition under the Clean Water Act. The semidiurnal tidal range in the estuary is relatively large at $3.6 \mathrm{~m}$ and oceanic tides affect water levels throughout the entire lower reach to Bonneville Dam (rkm 235) (Sherwood and Creager 1990; Neal 1972). Maximum seawater intrusion during low river flow is variable but less than $37 \mathrm{~km}$ upstream (Neal 1972). The study area includes the floodplain of the Columbia River from Bonneville Dam to the mouth. 


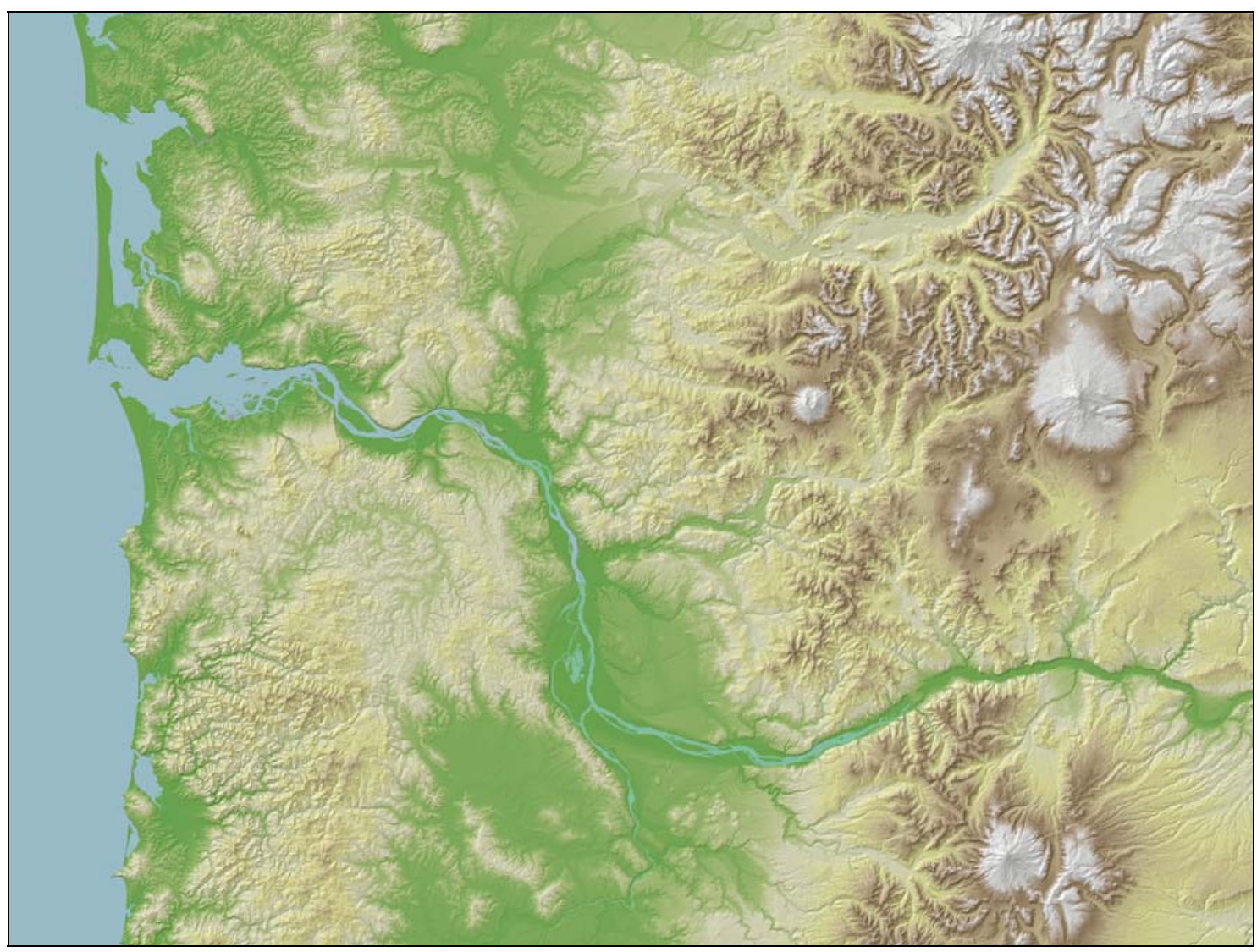

Figure A.3. Image of the Lower Columbia River and Estuary. (Provided by Evans et al. 2006.)

A number of publications provide descriptive information about the estuary study area: Salmon at River's End (Bottom et al. 2005); Role of the Estuary in the Recovery of Columbia River Basin Salmon and Steelhead (Fresh et al. 2005); Biological Assessment for the Columbia River Channel Improvements Project (USACE 2001); Programmatic Action Plan (Berquam et al. 2003); An Ecosystem-Based Approach to Habitat Restoration Projects (Johnson et al. 2003); and Estuarine Habitat and Juvenile Salmon - Current and Historical Linkages in the Lower Columbia River and Estuary, 2002-2004 (Roegner et al. 2005). Important earlier compendiums include: The Columbia River Estuary and Adjacent Ocean Waters (Pruter and Alverson 1972); "Columbia River Estuary" in Changes in Fluxes in Estuaries: Implications from Science to Management (Dyer and Orth 1994); and Columbia River:

Estuarine System (Small 1990), which contains reviews of earlier work supported by the Columbia River Estuary Data Development Program (CREDDP) on physical and biological processes (CREDDP 1984a, 1984b). Another comprehensive environmental study of the lower Columbia River was the Bi-State Water Quality Study (TetraTech 1996; Fuhrer et al. 1996), completed as part of the process to include the Columbia River estuary in the U.S. Environmental Protection Agency's National Estuary Program.

The Columbia River, with a drainage basin area of $660,480 \mathrm{~km}^{2}$ (Simenstad et al. 1990b), has the fourth highest average discharge at mouth and the sixth largest watershed in the United States according to the U.S. Geological Survey (1990) (this analysis includes the Great Lakes/St. Lawrence and Yukon 
rivers and separates the Mississippi, Missouri, and Ohio rivers). The width of the Columbia River is less than $2 \mathrm{~km}$ at Rkm 84, nearly $15 \mathrm{~km}$ at Rkm 32, and approximately $3 \mathrm{~km}$ at the jetties at the river mouth (Neal 1972). The river bottom is below sea level at Bonneville Dam and the estuary contains scattered deep areas, for example near $30 \mathrm{~m}$ at Grays Point (Neal 1972).

Historically, unregulated flows were estimated to range from a minimum of $2,237 \mathrm{~m}^{3} / \mathrm{s}(79,000 \mathrm{cubic}$ feet per second (cfs)) in the fall to maximum flood flows of over $28,317 \mathrm{~m}^{3} / \mathrm{s}$ ( 1 million $\mathrm{cfs}$ ) during spring freshets (Sherwood et al. 1990). Since the 1930s, however, the timing of the Columbia River's discharge has been progressively regulated due to construction and operation of 28 major dams and approximately 100 minor dams that reduce spring freshet flows and increase fall/winter flows on the river's main stem and tributaries. Modeling studies have estimated that the spring freshet (May-July) flow reduction attributable to flow regulation, irrigation withdrawal, and climate change is equal to $45 \%$ (Jay and Kukulka 2003). Another modeling study showed that diking has reduced shallow water habitat area during the spring freshet by $52 \%$ while flow cycle alteration reduced it by $29 \%$ (Kukulka and Jay $2003 \mathrm{a}, \mathrm{b})$. Alterations in the physical processes of the estuary that are attributable to human intervention include decreased freshwater discharge rates, tidal prism, and mixing; and increased flushing time and fine sediment deposition, resulting in a net accumulation of sediment (Sherwood et al. 1990).

Despite alterations to river discharge patterns by the FCRPS and other factors, the estuary is still river-dominated because of relatively high flow volumes. As an extension of the estuary, the Columbia River plume is a dominant factor affecting the hydrography of Pacific Northwest coastal waters (GarciaBerdeal et al. 2002; Hickey and Banas 2003). Flushing time has been calculated using several methods; calculations using a river flow of $549 \times 10^{7} \mathrm{cu} \mathrm{ft/tidal} \mathrm{cycle} \mathrm{and} \mathrm{maximum} \mathrm{salinity} \mathrm{intrusion} \mathrm{of} 19$ nautical miles, for example, predict total flushing time ranging from 4.97 tidal cycles using the fraction-offreshwater method to 9.0 tidal cycles using the modified tidal-prism method (Neal 1972). The Columbia River estuary, which occupies a drowned river valley, has been classified as a meso-tidal estuary according to Sherwood and Creager (1990). According to Neal (1972), the Columbia River estuary resists classification by approaches based on mixing characteristics because of temporal and regional variability between three of the classes: vertically stratified, partially mixed, and well mixed.

According to the U.S. Environmental Protection Agency (EPA) classification (Omernik and Gallant 1986), the ecoregions containing the Columbia River estuary are Coast Range, Puget Lowland, Willamette Valley, and Cascades. The classification on the Oregon side has been refined for the purpose of water quality management to include Coastal Mountains, Coastal Lowlands, Willamette Valley Plains, and Western Cascades (Clarke et al. 1991). For the Lower Columbia River Estuary Partnership's ecosystem classification (Simenstad et al. 2005), Level III ecoregions are used (Available URL: http://www.gis.state.or.us/data/alphalist.html). The study area contains five physiographic provinces: Southern Washington Cascades, Western Cascades, Puget Trough, Willamette Valley, and Coast Ranges (Franklin and Dyrness 1988). Urbanization and land conversion for agriculture and other uses has altered the natural vegetation and hydrologic processes of portions of these ecoregions.

Estuarine landcover mapped using LandSat and compact airborne spectrographic imaging includes several categories of herbaceous wetlands, shrub-scrub wetlands, and coniferous and deciduous forest 
wetlands (Garano and Robinson 2003). For the purpose of a change analysis from 1870 to present, Thomas (1983) found that only five habitat types could be delineated. In order by elevation from highest to lowest, these are tidal swamps, tidal marshes, shallows and flats, medium depth water, and deep water. He assessed the change in these habitat types in seven subareas: the river mouth, mixing zone, Youngs Bay, Baker Bay, Grays Bay, Cathlamet Bay and the upper estuary. Not only habitat loss but habitat conversion is documented in Thomas' maps (1983). Perhaps the most critical findings for salmon are that below Puget Island the area of tidal swamps has been reduced by $77 \%$, and that $65 \%$ of the 1870 tidal marshes have been lost while new marshes totaling about $22 \%$ of the original area have been formed (a net loss of 43\%) (Thomas 1983). The study also showed net losses of medium and deep water habitats (35\% and $7 \%$, respectively), and a gain of shallows and flats caused mostly by shoaling in formerly deeper water areas $(10 \%)$.

Thus, the Columbia River estuary has seen significant changes in the past 150 years; in particular, the significant conversion of vegetated habitats to agriculture and urbanization, together with loss of access to habitats through passage barriers and changes to the hydrograph. These have had unmeasured but presumably important impacts on the once abundant salmon populations that migrated through on their way up and downstream (Bottom et al. 2005). Estuary RME provides the basis to measure these impacts and implement research that will support the goal of conserving and restoring estuary habitats to improve the performance of endangered and threatened salmonid populations.

Downstream of RM 46 in the lower Columbia River and estuary, the migration characteristics of juvenile salmon have been studied. Researchers have used nets, seines, traps, and trawls to examine migration timing, spatial distribution, abundance, relative survival, and feeding habits for various populations of salmon. Important research efforts included the U.S. Bureau of Fisheries (Rich 1920), the Fish Commission of Oregon in 1963 (Reimers and Loeffel 1967), the National Marine Fisheries Service in 1966-1972 (Craddock et al. 1976; Dawley et al. 1986; Durkin 1981), the Northwest Regional Council and the Bonneville Power Administration in 1977-1983 (Dawley et al. 1986; Kirn et al. 1986; Ledgerwood et al. 1991), the Columbia River Estuary Data Development Program in 1978-1984 (Bottom et al. 1984; McCabe et al. 1983; Small 1990), the Corps of Engineers Anadromous Fish Evaluation Program in 1995-present (Ledgerwood et al. 2003; Roegner et al. 2005; Schreck et al. 2005); and the Northwest Power and Conservation Council's Fish and Wildlife Program in 2001-present (Bottom et al. 2005b; Fresh et al. 2005; Burke 2004). There are, however, few studies of migration characteristics between RM46 and Bonneville Dam (Shreck et al. 2005).

\section{A.3 Programmatic Relationships}

The estuary RME effort is a function of particular drivers, regional funding sources, technical guidance from other regional salmon-related programs and monitoring efforts, regional planning processes, and estuary RME projects (Figure A.4). In these relationships, estuary RME is affected by a process or program and, usually, vice versa. The fundamental driver for estuary RME is the Endangered Species Act and the resulting FCRPS Biological Opinions, as explained in the introduction. The primary regional funding sources to implement estuary RME include BPA, EPA, NOAA, USACE, USGS, and the 
States of Oregon and Washington. Johnson et al. (2004) in the most recent estuary RME document provided an annotated bibliography of monitoring plans, strategies, protocols, and guidance documents relevant to estuary RME.

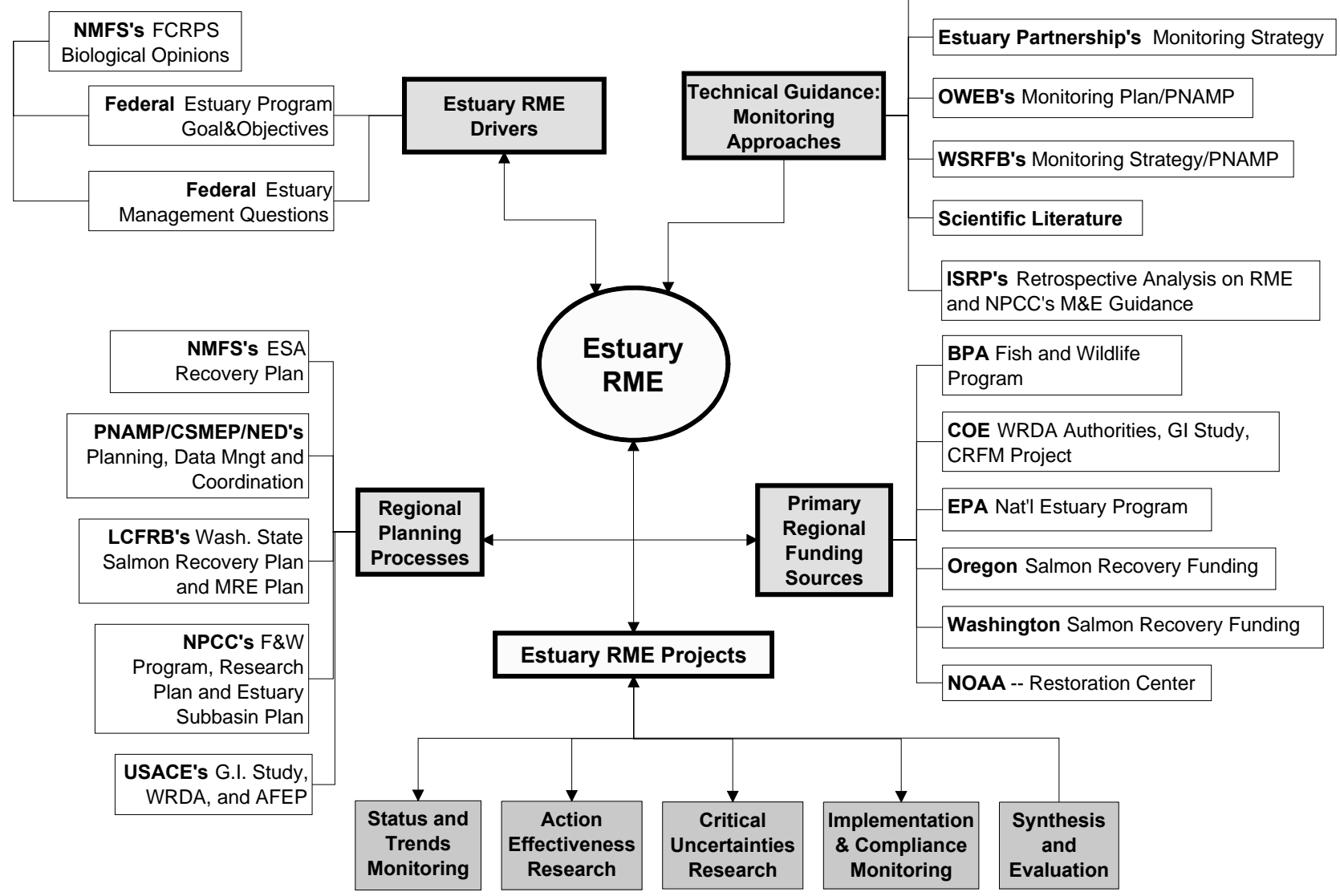

Figure A.4. Relationship of Estuary RME to Drivers, Technical Guidance, Regional Planning Processes, Primary Funding Sources, and Estuary RME Project Areas. This figure represents primary relevant relationships and is not exhaustive.

Estuary RME affects and is affected by ongoing regional planning processes by NOAA Fisheries, the Northwest Power and Conservation Council (NPCC), the Pacific Northwest Aquatic Monitoring Partnership (PNAMP), the Lower Columbia Fish Recovery Board (LCFRB), and the USACE (Figure A4). The NOAA Fisheries Recovery Plan for listed salmonids in the lower Columbia River will incorporate elements of estuary RME. The PNAMP process is occurring in coordination with the Collaborative Systemwide Monitoring and Evaluation Program (CSMEP) by the Columbia Basin Fish and Wildlife Authority. Much of the content regarding the estuary that was discussed at a PNAMP/CSMEP workshop in Portland, OR, in March 2006 derives from this estuary RME effort. On another front, the LCFRB is developing a Monitoring, Research, and Evaluation Plan for tributary watersheds in Southwest Washington. Finally, the USACE is undertaking a General Investigations Study for Lower Columbia River Ecosystem Restoration. The purpose of the General Investigations Study is to 
provide a comprehensive, long-range approach to investigate and recommend appropriate solutions to accomplish ecosystem restoration in the estuary, encompassing wetland/riparian habitat restoration, stream and fisheries improvement, water quality, and water-related infrastructure improvements.

Estuary RME incorporates technical guidance on monitoring approaches from other regional and national monitoring programs (Figure A4). This is important to avoid duplication of effort and to learn from other experiences. Six monitoring resources are especially influential to estuary RME.

First, we coordinated estuary RME with the basin-wide RME plan by NOAA Fisheries and the Action Agencies (RME Plan 2003) and the RME Guidance Document (BPA 2005). Our terminology and monitoring approaches are consistent with these (see Section 1).

Second, the Estuary Partnership's Aquatic Ecosystem Monitoring Strategy (Lower Columbia River Estuary Program 1998) provides a broad underpinning for estuary RME. The Monitoring Strategy makes specific recommendations for monitoring oversight, data management, and monitoring and research on pollutants, toxics, habitat, exotic species, and primary production, many of which are embedded in the estuary RME effort. Estuary RME includes many of the Estuary Partnership's monitoring and research efforts to implement its Monitoring Strategy.

Third, the Oregon Watershed Enhancement Board (2004, http://www.oweb.state.or.us/) role in monitoring is described in their program statement, "Recent legislation, Senate Bill 945, directs the Oregon Watershed Enhancement Board (OWEB) to develop and implement a statewide Monitoring Program ... improve water quality, restore salmon runs, and strengthen ecosystems that are critical to healthy watersheds and sustainable communities. OWEB is responsible for three interrelated monitoring functions: strategic guidance and support for cooperative monitoring activities; accountability for restoration investments; and reporting on the progress of the Oregon Plan." Estuary RME will be coordinated with OWEB through the Pacific Northwest Aquatic Monitoring Partnership (PNAMP).

Fourth, the Washington Salmon Recovery Funding Board (Monitoring Oversight Committee 2002a,b,c and WSRFB 2003a,b,c,d) developed a comprehensive monitoring strategy (Volume 2), including the necessary technical information, and provided an action plan (Volume 3), including costs, priorities, and timelines, in order to fulfill State Senate Bill 5637, on monitoring of watershed health and salmon recovery. Many of the elements of the broad Washington Monitoring Strategy are consistent with the estuary RME design. For example, the distinction between status/trend and effectiveness monitoring is the same. The WSRFB documents (2003a-d) serve as planning documents to implement the monitoring strategy. Estuary RME will be coordinated with the Washington Monitoring Strategy, largely through PNAMP.

Fifth, we reviewed scientific literature relevant to estuary RME. (See Johnson et al. 2004, Appendix A for an annotated bibliography of 36 documents that relate to estuary RME.) Monitoring Ecosystems by Busch and Trexler (2003) was especially useful. In addition, we reviewed monitoring plans and reports from major coastal restoration efforts across the country: Chesapeake Bay (Batiuk et al. 1992, 2000), Florida Everglades (USACE \& SFWMD 1999), Louisiana coastal wetlands (Louisiana Coastal Wetlands 
Conservation and Restoration Task Force 2001), Tijuana Estuary (Zedler 2001), San Francisco Bay Delta (CALFED 2000; Williams and Orr 2002), and the more recent Puget Sound nearshore ecosystem (Fresh et al. 2003), which is still in the planning stages. Our intent was to learn from these efforts and apply relevant elements from them to estuary RME.

Sixth, the Independent Scientific Review Panel's Retrospective Analysis on RME (ISRP 2005) and the Northwest Power and Conservation Council's Monitoring and Research Guidance document were especially pertinent to estuary RME. The retrospective analysis provided recommendations for a common RME terminology and considerations for statistical designs for various types of monitoring. The research plan provided guidance from a regional perspective.

In summary, the technical basis for the estuary RME effort is different from the basis of other basinwide RME elements, such as Tributary Habitat RME and other plans that are primarily focused on monitoring freshwater environments. Fundamental information about important attributes of salmon biology related to the estuary such as life history diversity and spatial distribution is not well-known, and less monitoring has occurred in the estuary to date. Monitoring in the estuary also is different from tributary monitoring on many counts, from the appropriate objectives of restoration projects, to the appropriate indicators and protocols for data collection and analysis. Thus, while the estuary RME described herein has drawn from existing programs to the extent possible for the purpose of ultimately providing efficiencies in basin-wide analyses and coordination, the RME effort also will be able to provide new valuable information to existing programs about the appropriate RME for the complicated and highly impacted estuarine environment of one of the largest rivers in the nation. This RME document will also guide projects for status and trend monitoring, action effectiveness research, uncertainties research, and implementation and compliance monitoring. Research and monitoring frameworks for status and trend monitoring and action effectiveness research are described in Appendix B. 


\section{Appendix B: Monitoring Frameworks}

This appendix contains separate research and monitoring frameworks for 1) status and trends monitoring, and 2) action effectiveness research. These frameworks are unified by conceptual models adapted from Thom et al. (2004). Each framework includes objectives, a conceptual model, monitored indicators, the sampling design, and a summary. The frameworks specify what, when, where, why, and how research and monitoring needs to be done for estuary RME (protocols are cited in Appendix C).

\section{B.1 Status and Trends Monitoring}

The overall objective of status and trends monitoring (STM) is to measure the status and trends of monitored indicators that are ecologically significant to listed salmonids in the lower river, estuary, plume, and nearshore ocean.

Status monitoring is the "measurement of environmental characteristics over an extended period of time to determine status or trends in some aspect of environmental quality" (from Suter 1993, cited in Noon 2003). Status monitoring can describe differences in values of given monitored indicators among locations at a given moment in time (snap-shot) or changes in their values across time at a given location (trend). The estuary RME effort includes both status and trends monitoring.

\section{B.1.1 Objectives}

The objectives for status and trends monitoring in estuary RME are as follows (recall Section 1.2):

STM 1. Map bathymetry and topography of the estuary as needed for RME.

STM 2. Establish a hierarchical ecosystem classification system based on hydro-geomorphology, groundtruth it with vegetation cover monitoring data, and map existing habitats.

STM 3. Develop an index of habitat connectivity and apply it to each of the eight reaches of the study area.

STM 4. Monitor habitat conditions periodically, including water surface elevation, vegetation cover, primary and secondary productivity, plant community structure, substrate characteristics, dissolved oxygen, temperature, and conductivity, at representative locations in the estuary and plume.

STM 5. Evaluate migration charcateristics, including juvenile salmonid abundance, residence times, growth rates, diets, and prey resources at representative locations in the estuary and plume to understand habitat usage and relative ecological importance of various habitats to juvenile salmonids.

STM 6. Monitor and evaluate smolt survival from Bonneville Dam through the estuary into the plume.

\section{Cont'}

STM 7. Develop an index and monitor and evaluate life history diversity of salmonid populations at representative locations in the estuary. 
STM 8. Monitor and evaluate temporal and spatial species composition, abundance, and foraging rates of juvenile salmonid predators at representative locations in the estuary and plume.

\section{B.1.2 Conceptual Model}

Development of a monitoring program benefits significantly from a conceptual model of the ecosystem (Busch and Trexler 2003). According to the National Research Council's (1992) conclusions and recommendations on monitoring ecosystems, "Indicators should be chosen based on a conceptual model that clearly links stressors (e.g., pollutants, management practices) and indicators with pathways that lead to effects on the structure and function of ecological systems." The "indicators" referred to by the National Research Council are comparable to the "monitored indicators" identified in this estuary RME document. Indicators must be representative of the project or program objectives and be tightly linked, as demonstrated in a conceptual model, to structures, functions or processes expected to change as a result of management actions. Noon (2003) states, "In most cases it will be sufficient to model a restricted, but relevant, component of the system. Thus, a complete model of an ecological system is seldom necessary to proceed with a reliable monitoring program."

Thom et al. (2004) revamped the conceptual model by USACE (2001) using new knowledge of stressors, controlling factors, structures, processes, and functions in the CRE. The Thom et al. (2004) model, called the Columbia River Estuary Conceptual Model, brings together existing models of subcomponents of the estuary into one easily navigated electronic tool

(www.nwp.usace.army.mil/pm/lcr/science.asp ). The model was built in HTML in order to allow the user to navigate the numerous connections represented only schematically in Figure B.1. This schematic, adapted from the conceptual model, represents myriad stressors and controls on the development of ecosystem structures, with fewer direct links with ecosystem processes and finally five direct links to salmon performance. The website permits the user to "drill down" from any node in the model, that is, to explore the relationships via hyperlinks between pages representing each controlling factor, ecosystem structure, process, and function. All conceptual models contain uncertainty and many elements may be viewed as belonging to more than one of the components: stressor, controlling factor, structure, process, function.

We adapted the Columbia River Estuary Conceptual Model (Thom et al. 2004) with current state-ofthe-science and applied it to develop monitored indicators for status and trends monitoring for the estuary RME effort (Figure B.1). Specifically, we used the model's linkages supporting the ecosystem function for salmonid production. We substituted performance for production because the federal Estuary Program's goal is related to salmonid performance. This adaptation does not include all features of the original, e.g., ecosystem functions other than salmon performance. The objectives for estuary RME status and trends monitoring correspond to some of the main components of the CRE Conceptual Model, namely stressors, controlling factors, ecosystem structures, and salmonid performance (Figure B.1). The 
indicators to monitor for status and trends in the estuary RME effort are stressors, controlling factors, and ecosystem structures that are connected to the Salmonid Performance function.

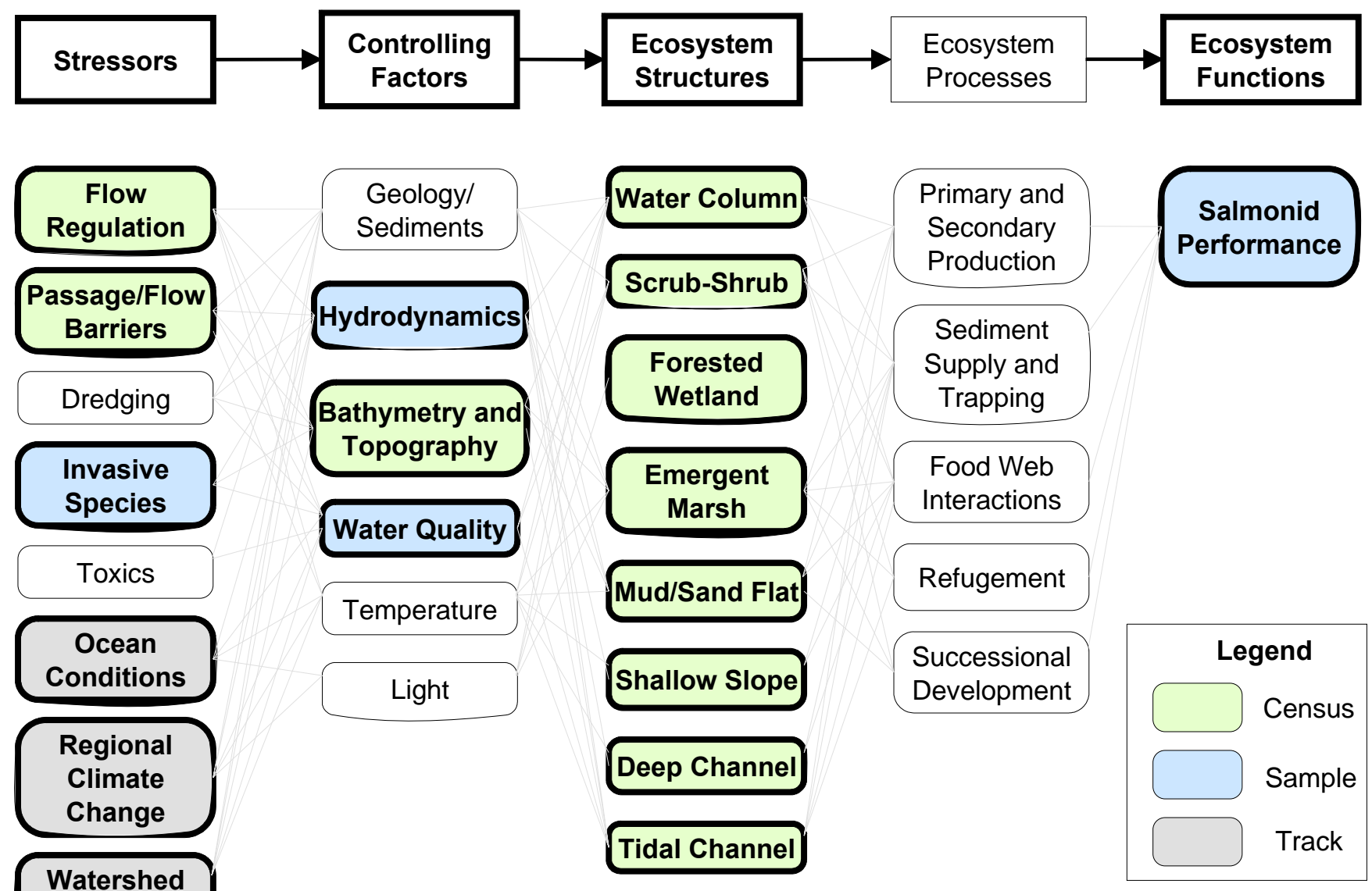

Figure B.1. Columbia River Estuary Conceptual Model Applied to Estuary RME Status and Trends Monitoring. (Adapted from Thom et al. 2004.) The spatial scale is estuary-wide. Census=a complete and thorough collection of data on the population of interest. Track=to access, assess, and summarize information made available by others. Sample=to collect field data under a sampling design.

\section{B.1.3 Monitored Indicators}

This section develops monitored indicators for status and trends monitoring by applying the Columbia River Estuary Conceptual Model (adapted from Thom et al. 2004). The monitored indicators evolved directly from the estuary RME objectives identified above and the state-of the-science regarding estuarine ecosystem structures and processes for the salmonid performance function, as defined in the conceptual model. Monitored indicators were selected for measurability and clear linkage with the objectives. The monitored indicators for status and trends monitoring (Table B.1) are ecosystem characteristics that are relevant to the objectives, measurable, and sensitive to changes in the system. 
The estuary/ocean RME subgroup developed the monitored indicators listed in Table B.1. In addition to applying a conceptual model, we consulted with researchers (e.g., E. Casillas, NOAA Fisheries, and C. Peterson, Portland State University), reviewed existing regional monitoring plans and strategies (e.g., Lower Columbia River Estuary Program 1998; Hillman 2004; RME Plan 2003; BPA 2005; NPCC 2000), and examined monitoring plans for other estuaries (e.g., San Francisco Bay-Delta by CALFED 2000; Gulf of Maine by Neckles and Dionne 2000) and coastal ecosystems (e.g. the Everglades by NRC 2003; Louisiana by the Louisiana Coastal Wetlands Conservation and Restoration Task Force 2001); and nation-wide by Thayer et al. (2003). Monitored indicators for the estuary are consistent with efforts elsewhere in the Columbia basin and estuaries nationally.

The monitored indicators for estuary RME status and trends address all eight STM objectives (Table B.1). They range from ecosystem stressors, such as flow regulation and passage barriers, to salmonid performance indicators, such as age/size structure and spatial distribution (Table B1). Sampling for the STM monitored indicators is at both the landscape and site-scales, and over hourly, daily, weekly, monthly, yearly, and five-yearly time scales depending on the monitored indicator (Table B.1).

Table B.1. Monitored Indicators for Status and Trends Monitoring in Estuary RME. Shading implies core indicator: green $=$ census; blue $=$ probabilistic sample; gray=track information provided by others See also Table 1.

\begin{tabular}{|c|c|c|c|c|c|c|c|c|c|c|}
\hline & & & \multicolumn{8}{|c|}{ STM Objectives } \\
\hline Category & $\begin{array}{l}\text { Monitored } \\
\text { Indicator(s) } \\
\end{array}$ & Description & 1 & 2 & 3 & 4 & 5 & 6 & 7 & 8 \\
\hline $\begin{array}{l}\text { Flow } \\
\text { Regulation }\end{array}$ & Water Discharge & Water volume per unit time. & & & & $\bullet$ & & & & \\
\hline $\begin{array}{l}\text { Passage/ } \\
\text { Flow } \\
\text { Barriers }\end{array}$ & Passage Barriers & $\begin{array}{l}\text { Restrict access by salmon to } \\
\text { wetland habitats. Barriers } \\
\text { include dikes, levees, } \\
\text { tidegates, culverts. }\end{array}$ & & $\bullet$ & $\bullet$ & $\bullet$ & & & & \\
\hline $\begin{array}{l}\text { Invasive } \\
\text { Species }\end{array}$ & $\begin{array}{l}\text { Species Composition, } \\
\text { Abundance, Spatial } \\
\text { Distribution }\end{array}$ & $\begin{array}{l}\text { Invasive species can inhibit } \\
\text { or prevent the restoration of } \\
\text { habitat quality and quantity } \\
\text { for native species by preying } \\
\text { on juvenile salmonids, } \\
\text { competing for prey, } \\
\text { decreasing diversity, and } \\
\text { limiting habitat availability. }\end{array}$ & & & & - & & & & \\
\hline $\begin{array}{l}\text { Ocean } \\
\text { Conditions }\end{array}$ & $\begin{array}{l}\text { Upwelling Index, PDO } \\
\text { Index, ENSO Index, } \\
\text { Zooplankton Index, Hake } \\
\text { Index }\end{array}$ & $\begin{array}{l}\text { These indicators } \\
\text { characterize conditions in } \\
\text { the nearshore ocean, a key } \\
\text { habitat because of ecological } \\
\text { interconnections between } \\
\text { estuary and ocean due to } \\
\text { ocean currents, tides, and } \\
\text { river discharge. }\end{array}$ & & & & $\bullet$ & & & & \\
\hline $\begin{array}{l}\text { Regional } \\
\text { Climate } \\
\text { Change }\end{array}$ & Snowpack, Sea Level & $\begin{array}{l}\text { Estuarine effects of global } \\
\text { climate change via Cascade } \\
\text { Mountains and Pacific } \\
\text { Ocean. }\end{array}$ & & & & $\bullet$ & & & & \\
\hline $\begin{array}{l}\text { Watershed } \\
\text { Conditions }\end{array}$ & $\begin{array}{l}\text { Discharge, Water } \\
\text { Velocity/Temp, Sediment }\end{array}$ & $\begin{array}{l}\text { Effects of estuary tributary } \\
\text { watersheds on floodplain }\end{array}$ & & & • & $\bullet$ & & & & \\
\hline
\end{tabular}




\begin{tabular}{|c|c|c|c|c|c|c|c|c|c|c|}
\hline & \multirow[b]{2}{*}{$\begin{array}{l}\text { Monitored } \\
\text { Indicator(s) }\end{array}$} & \multirow[b]{2}{*}{ Description } & \multicolumn{8}{|c|}{ STM Objectives } \\
\hline Category & & & 1 & 2 & 3 & 4 & 5 & 6 & 7 & 8 \\
\hline & $\begin{array}{l}\text { Budget, Large Woody } \\
\text { Debris }\end{array}$ & habitats. & & & & & & & & \\
\hline \multirow[t]{4}{*}{$\begin{array}{l}\text { Geology } \\
\text { Sediments }\end{array}$} & Accretion Rates & $\begin{array}{l}\text { Reveals sedimentation rates } \\
\text { from measurements of } \\
\text { prehistoric, early historic, } \\
\text { pre-diking, post-diking, and } \\
\text { post restoration. }\end{array}$ & & & & & & & & \\
\hline & Contaminants & $\begin{array}{l}\text { Need to select indicator } \\
\text { toxins, and assess fish tissue } \\
\text { and body burden. } \\
\text { Possibilities include PCBs. }\end{array}$ & & & & & & & & \\
\hline & Redox Potential & $\begin{array}{l}\text { Measured from pore water at } \\
\text { selected sites and used to } \\
\text { evaluate organic } \\
\text { accumulation. }\end{array}$ & & & & & & & & \\
\hline & Soil Composition & $\begin{array}{l}\text { Grain size, organic matter, } \\
\text { etc. }\end{array}$ & & & & & & & & \\
\hline \multirow{3}{*}{$\begin{array}{l}\text { Hydro- } \\
\text { dynamics }\end{array}$} & Ground Water Level & Self explanatory & & & & & & & & \\
\hline & Surface Water Elevation & Self explanatory & & - & - & - & & & & \\
\hline & Water Velocity (currents) & $\begin{array}{l}\text { Currents are the rates and } \\
\text { patterns of water movement. }\end{array}$ & & $\bullet$ & & & & & & \\
\hline \multirow[t]{2}{*}{$\begin{array}{l}\text { Bathymetry/ } \\
\text { Topography }\end{array}$} & Bathymetry & $\begin{array}{l}\text { Bathymetry is a collection of } \\
\text { depth points that represent } \\
\text { the gradients of elevation } \\
\text { and depth change along a } \\
\text { surface. }\end{array}$ & $\bullet$ & & $\bullet$ & & & & & \\
\hline & Floodplain Topography & $\begin{array}{l}\text { Topography measures of the } \\
\text { height of a point on the } \\
\text { surface of the sediment or } \\
\text { soil of a location, expressed } \\
\text { relative to a datum point }\end{array}$ & $\bullet$ & & $\bullet$ & & & & & \\
\hline \multirow[t]{4}{*}{$\begin{array}{l}\text { Water } \\
\text { Quality }\end{array}$} & Dissolved Oxygen & $\begin{array}{l}\text { The amount of oxygen in } \\
\text { solution in the water. }\end{array}$ & & & & - & & & & \\
\hline & $\begin{array}{l}\text { Nutrients (nitrogen, } \\
\text { phosphorous) }\end{array}$ & $\begin{array}{l}\text { Nutrients are inorganic } \\
\text { chemical constituents } \\
\text { needed for plant and animal } \\
\text { growth. }\end{array}$ & & & & & & & & \\
\hline & $\mathrm{pH}$ & The acidity of the water. & & & & & & & & \\
\hline & Salinity & $\begin{array}{l}\text { The concentration of salts in } \\
\text { the water. }\end{array}$ & & & & $\bullet$ & & & & \\
\hline Temperature & Temperature & $\begin{array}{l}\text { A measure that expresses the } \\
\text { temporal and spatial } \\
\text { dynamics of the thermal } \\
\text { energy content of the water. }\end{array}$ & & & & $\bullet$ & & & & \\
\hline \multirow[t]{2}{*}{$\begin{array}{l}\text { Landscape } \\
\text { Features }\end{array}$} & Ecosystem Structures Map & $\begin{array}{l}\text { Aerial Photos and Photo } \\
\text { Points. }\end{array}$ & & $\bullet$ & $\bullet$ & • & & & & \\
\hline & Area (Size) Restored & $\begin{array}{l}\text { Provides a way to track } \\
\text { habitat actions. }\end{array}$ & & & & • & & & & \\
\hline $\begin{array}{l}\text { Tidal } \\
\text { Channel } \\
\text { Morphology }\end{array}$ & Edge/Density/Sinuosity & $\begin{array}{l}\text { Provides an interface for } \\
\text { transfer of energy between } \\
\text { wetlands and the main }\end{array}$ & & $\bullet$ & $\bullet$ & $\bullet$ & & & & \\
\hline
\end{tabular}




\begin{tabular}{|c|c|c|c|c|c|c|c|c|c|c|}
\hline & & & \multicolumn{8}{|c|}{ STM Objectives } \\
\hline \multirow[t]{2}{*}{ Category } & $\begin{array}{l}\text { Monitored } \\
\text { Indicator(s) }\end{array}$ & Description & 1 & 2 & 3 & 4 & 5 & 6 & 7 & 8 \\
\hline & & channel; salmon forage. & & & & & & & & \\
\hline $\begin{array}{l}\text { Vegetation } \\
\text { Cover }\end{array}$ & Percent Cover by Species & $\begin{array}{l}\text { Provides classification of } \\
\text { native and non-native } \\
\text { vegetation. }\end{array}$ & & $\bullet$ & & $\bullet$ & & & & \\
\hline \multirow[t]{10}{*}{$\begin{array}{l}\text { Salmonid } \\
\text { Performance }\end{array}$} & Age/Size-Structure & $\begin{array}{l}\text { Reveals the life history } \\
\text { strategy by species. }\end{array}$ & & & & & $\bullet$ & & & \\
\hline & Distribution: Spatial & $\begin{array}{l}\text { Describes where the juvenile } \\
\text { salmon are, i.e., which } \\
\text { habitats they are using. }\end{array}$ & & & & & $\bullet$ & & $\bullet$ & \\
\hline & Distribution: Temporal & $\begin{array}{l}\text { Provides data on when the } \\
\text { fish are present in the } \\
\text { estuary. } \\
\text { The combination of species } \\
\text { composition, age-structure, } \\
\text { and temporal distribution } \\
\text { characterizes life history } \\
\text { diversity. }\end{array}$ & & & & & - & & $\bullet$ & \\
\hline & Growth Rate & $\begin{array}{l}\text { Calculated as the change in } \\
\text { length or weight of the } \\
\text { sampled juvenile salmon } \\
\text { population per unit time. }\end{array}$ & & & & & $\bullet$ & & & \\
\hline & Migration Pathways & $\begin{array}{l}\text { Characterizes the corridors } \\
\text { where juvenile salmon } \\
\text { predominately are found } \\
\text { migrating downstream. }\end{array}$ & & & & & - & & & \\
\hline & Predation Index & $\begin{array}{l}\text { Estimates predation } \\
\text { pressure, including who, } \\
\text { when, where }\end{array}$ & & & & & & & & \\
\hline & Residence Time & $\begin{array}{l}\text { Shows the amount of time } \\
\text { juvenile salmon spend in the } \\
\text { estuary. }\end{array}$ & & & & & - & & & \\
\hline & Species Composition & $\begin{array}{l}\text { Data on which salmon are } \\
\text { present. }\end{array}$ & & & & & - & & - & \\
\hline & Stock Identity & $\begin{array}{l}\text { Genetic analyses to } \\
\text { determine ESU. }\end{array}$ & & & & & - & & & \\
\hline & Survival Rate & $\begin{array}{l}\text { Estimated for juveniles of } \\
\text { selected species and life } \\
\text { history types for the reach } \\
\text { from Bonneville Dam to the } \\
\text { CR mouth, and also for } \\
\text { selected areas of the estuary. }\end{array}$ & & & & & & $\bullet$ & & \\
\hline
\end{tabular}

\section{B.1.4 CRE Ecosystem Classification - Hydrogeomorphic Reaches}

Ecosystem structures, i.e., habitats, within the historical floodplain of the CRE are very diverse, ranging from forested wetlands to deep river channels. It is necessary to classify these habitats for the purpose of designing a probabilistic sampling program for certain categories of STM monitored indicators - invasive species, hydrodynamics, bathymetry/topography, water quality, temperature, tidal morphology, 
vegetation cover, and salmonid performance (Table B1). Hydrogeomorphic reaches in the CRE (Section 2.1.1, Figure 3) within a hierarchical classification have been developed by Simenstad et al. (2005) as part of the Lower Columbia River Estuary Partnership's habitat monitoring project. The reaches are Level 3 of six levels. Research is ongoing to develop and map finer scale levels. The Level 3 reaches have been delineated preliminarily based on EPA Level IV Ecoregions and modified based on transitions in largescale hydrogeomorphic and tidal-fluvial forcing such as maximum salinity intrusion, convergences with tributaries, the upstream extent of current reversal, and transitions in maximum flood tide level. These reaches provide one potential level of stratification for status-and-trends sampling of the estuary.

\section{B.1.5 Sampling Design}

The recommended sampling design for estuary RME status and trends monitoring is a rotational panel design (McDonald 2003), which provides the best features for simultaneous status and trends monitoring. Rotational designs have several advantages of over more traditional fixed-location sampling schemes, including:

1. Continual input of new locations keeps the sampling scheme refreshed, allowing the design to detect environmental events that fixed-location designs might miss.

2. It provides opportunity for precise estimates of both status and trends.

3. The repeated measures from one year to the next also allow annual estimates of status to be updated (i.e., recalculated), taking into account the temporal correlation for improved precision.

The subsections that follow describe the utility of the Environmental Monitoring and Assessment Program (EMAP) sampling design and alternative STM sampling designs.

\section{EMAP}

The U.S. Environmental Protection Agency's EMAP has been widely recommended for monitoring designs in the Pacific Northwest and the Columbia River Basin (e.g., ISRP 2005; PNAMP 2004). Nationally, it has been recommended by the Coastal Research and Monitoring Strategy Workgroup in its 2000 Clean Water Action Plan. EMAP uses a probability-based sampling design to spatially sample geographic areas. As with all probability-based designs that are properly implemented and analyzed, EMAP provides unbiased estimates and variance calculations. This design is well suited to assessing the status of environmental conditions. The EMAP approach also accommodates stratification to help reduce the overall variance of measured responses across the landscape.

The Coastal Research and Monitoring Strategy Workgroup - composed of EPA, NOAA, U.S. Department of Agriculture, and USGS - considers EMAP effective for its "Tier 1" monitoring, which can be summarized as "status and trends." This group clearly recognizes two key characteristics of EMAP that were previously identified by the National Research Council (NRC 1995): 1) it is suitable for coarse spatial and temporal scales, and 2) it is responsive, not predictive, monitoring, designed to characterize problems once they have already occurred. On that basis, this group does not recommend EMAP for its 
“Tier 2" sampling - Diagnosis of Large-Scale Causes - or its “Tier 3" sampling - Diagnosis of Interactions and Forecasting.

Rarely, however, does any one sampling design successfully accommodate multiple sampling objectives. The estuary RME effort finds that EMAP is not well suited for the task of action effectiveness monitoring, for example. Here, the restoration of a specific location is compared to neighboring reference sites. A probabilistic sample of potential reference sites in the region may not be the best choice of sites. Proximity, hydrology, topography, etc., all may play relevant roles in finding the most suitable sites as targets for a particular restoration project.

Another consideration in the use of EMAP is the way sample locations are drawn and the associated inference. In many applications, EMAP uses sampling with probability proportional to geographic size (i.e., "ps sampling". Large geographic units will have a proportionally higher probability of entering the sample than smaller geographic units. Variations on the Horvitz-Thompson (1952) estimator (Cochran 1977, p. 259-261) are then used to provide unbiased estimates and variances. However, the resulting estimate of the population mean is not, for example, average mercury concentration in a lake but, rather, average concentration in lake water (i.e., all water pooled). If mean response across locations is sought, then sampling with equal probability of selection is required.

The applicability of EMAP to status and trends monitoring in the Columbia River estuary is thus limited by the fine scale of spatial and temporal variability of the ecological structures and processes occurring in this estuary. The sampling intensity required to apply EMAP designs to a finely structured environment such as this estuary would be prohibitively expensive because of the number of strata and the number of samples required to characterize the variability in each. For example, an exercise in applying the tessellated design to the estuary in a draft habitat monitoring plan for the Estuary Partnership in 2004 resulted in 100 randomly selected data points from 1000 hexagons bounded by a depth contour; this was before stratifying by the seven appropriate ecosystem structures and did not account for stratifying by reach. To date, eight reaches of the estuary have been identified (Section 2.1.1, Figure 3) (Simenstad et al. 2005).

The estuary is composed of interwoven ecosystem structures including water column, scrub-shrub, forested wetland, emergent marsh, mud/sand flat, shallow slope, and deep tidal channel. The shapes that these land cover types present have a high fractal dimension. To stratify according to land cover type would produce strata with complex shapes similar to channel networks because typically the vegetation communities are governed by elevation, which changes along linear gradients away from both channels and the mainstem. In addition to these elevation gradients, the mainstem estuary poses longitudinal gradients from the mouth to Bonneville Dam based on salinity and the relative influence of ocean and river conditions (Kukulka and Jay 2003a, 2003b). Thus, the strata from one reach are not comparable to and cannot be compared to those from other reaches in the $235-\mathrm{km}$ estuary. The EMAP program has been critiqued for using the simplest ecological units (e.g., lakes) in its examples (NRC 1995). Likewise, averaging across the fine spatial and tidal and flow-driven temporal scales that occur even within strata in the estuary would produce information of little value, whether it is data from physically homogeneous 
sources such as water, or physically disconnected sources such as the soils and vegetation of multiple plant communities.

Monitoring for trends is also not the primary utility of EMAP. Certainly, an initial selection of sites by EMAP can be repeatedly sampled through time to monitor for trends. However, this sampling scheme is then suboptimal for the dual objective of status and trends monitoring. For status monitoring, a new annual selection of sites provides the smallest variance; for trends monitoring, repeated sampling of the same sites provides the smallest variance. Rotational designs provide an ideal compromise where some sites are retained and others are replaced on an annual rotational basis (see Section 2.1.3). Sampling with equal probability of selection makes rotational designs much easier to implement and analyze. In rotational designs, all sites enter and leave the sampling scheme with equal probabilities of selection. Combining sampling with probability proportional to size (pps) for site entry and equal probability of selection for site removal makes valid data analysis difficult or impossible. Data analyses become increasingly complex as the different sampling components in the overall design become more diverse. Valid methods of analyses may not currently exist for some combinations and would require new estimators and variances to be developed on a case-by-case basis. It is important that valid methods for analyzing the monitoring data collected exist before a monitoring design is chosen.

\section{$\underline{\text { STM Sampling Design Alternatives }}$}

A landscape-wide monitoring program is more than simply a collection of site-specific efforts. Foremost, the site selection in a landscape-wide monitoring program must be a probabilistic sample in order to make inferences back to the whole. A haphazard collection of site-specific monitoring studies is incapable of valid inferences at the regional scale. Secondly, the extensive, long-term sampling of a landscape-wide status and trends monitoring program must be cost efficient if it is to persist. Laborintensive and expensive sampling schemes and indicators are unlikely to survive decades of changing budgetary priorities. Intensive, short-term sampling of both physical and biological responses may be justifiable for effectiveness monitoring at a site-specific restoration project. Finally, performance measures at the landscape scale need to be integrated measures that are sensitive to both environmental and anthropogenic effects. At the site level, the reoccurrence of salmonids or the restoration of a marsh may be a sign of success. However, at the landscape level, success is better measured by an overall increase in smolt abundance or survival and an increase in total marsh habitat. For these reasons, geographic scale is important in the design, analysis, and interpretation of a monitoring program.

At the landscape level, the number of indicators that can be monitored will be relatively small compared to site-specific investigations (Figure B.2). Although small in number, their selection is crucial. These measures need to provide general information on habitat capacity and opportunity at a relatively low cost. Physical and geographic traits will generally be easier and less costly to sample and maintain as a time series than biological response. Examples include total amount of marshland, degree of wetland connectivity, and amount of area still diked which can be obtained from remote sensing (aerial and satellite photos) and GIS analysis (Figure B.2). 
Ecosystem function and salmonid performance will nevertheless be the ultimate measures of salmonid recovery. Increased fish usage may be a reasonable metric for monitoring restoration effectiveness but may not be sufficient to infer regional benefits. Increased fish usage can occur either because an area acts as a sink that draws fish from other locations or because of new production. Sitespecific studies cannot differentiate between source and sink phenomenon (Pulliam 1988; Dias 1996; Diffendorfer 1998). Indicators such as smolt survival or total abundance are therefore better metrics at the landscape scale for measuring the benefits of estuary-wide improvements.

The siting of restoration projects is going to be driven by need, not probabilistic selection. It is therefore unlikely that restoration sites and regional monitoring sites are going to be frequently colocated. However, part of the restoration monitoring and assessment will be a comparison of restored areas to reference areas. Some of these reference areas could be co-located with the status and trends sites if opportunities arise. In many situations, however, carefully paired reference sites in the vicinity of the restoration activities will be preferable to widely scattered and blindly selected monitoring sites.

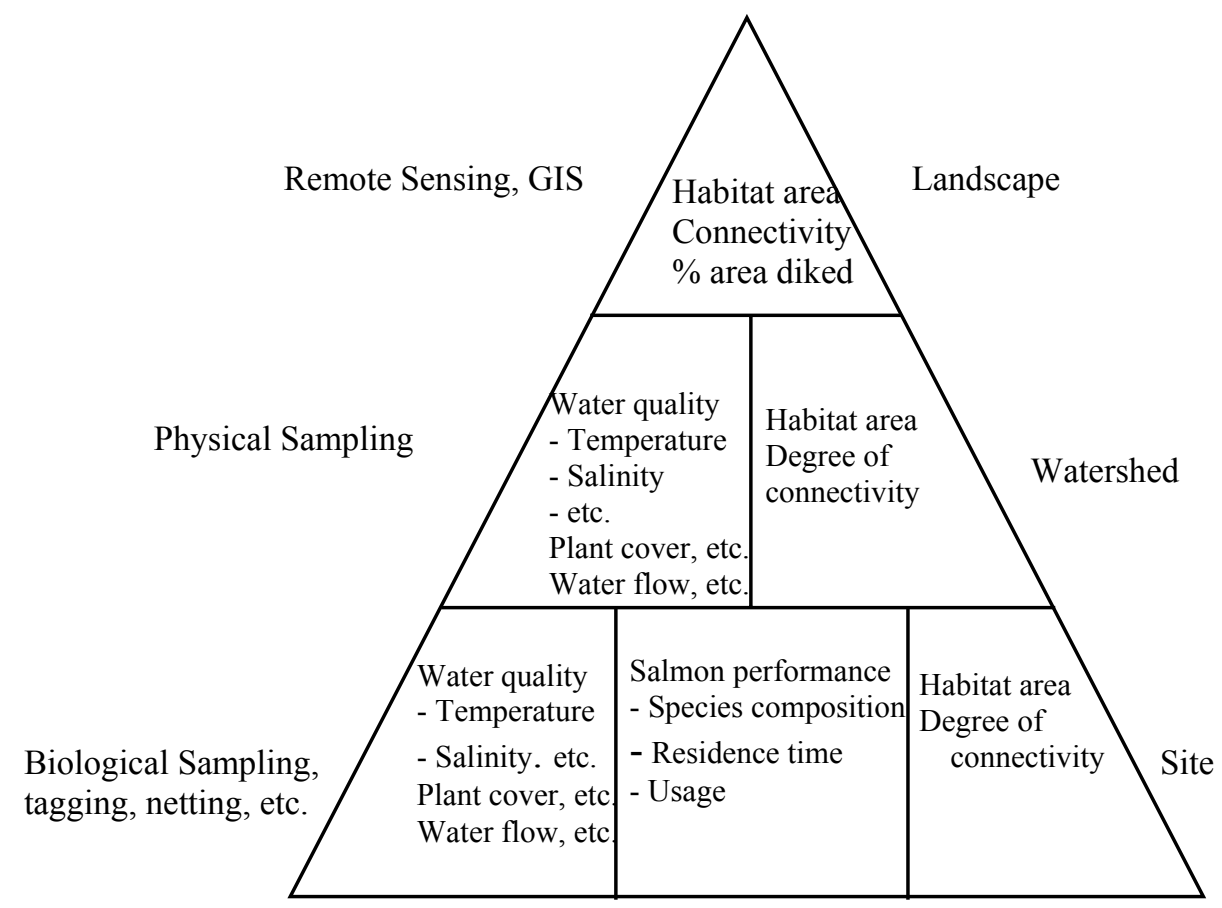

Figure B.2. Relationship between Geographic Scale of the Monitoring Program, the Indicators Measured, and Associated Sampling Techniques.

No single sample event in time can measure the rate of environmental change. By necessity, repeated observations over time are needed to document a change in status, i.e., trends. In regional monitoring, the situation is further complicated by the fact that the location and timing of a potential insult is indeterminate. As such, the sampling design must encompass broad spatial and temporal bounds, which can strain sampling resources. Furthermore, the concept of reference stations (i.e., controls) is no longer completely applicable in regional monitoring, as any site could eventually become impacted in the future. 
An optimal sampling design for one objective is rarely optimal for another sampling objective. This includes the objectives of estuary RME status and trends monitoring. In a sense, status and trends are diametrically opposed. Consider the simple case of comparing a sample mean over two time periods. A trend over time (i.e., $\Delta x / \Delta t$ ) in this case can be expressed as the difference in means where

$$
\text { Trend }=\bar{x}_{2}-\bar{x}_{1}
$$

with variance

$$
\operatorname{Var}\left(\bar{x}_{2}-\bar{x}_{1}\right)=\operatorname{Var}\left(\bar{x}_{1}\right)+\operatorname{Var}\left(\bar{x}_{2}\right)-2 \rho \sqrt{\operatorname{Var}\left(\bar{x}_{1}\right) \cdot \operatorname{Var}\left(\bar{x}_{2}\right)}
$$

if the sample locations are revisited, or

$$
\operatorname{Var}\left(\bar{x}_{2}-\bar{x}_{1}\right)=\operatorname{Var}\left(\bar{x}_{1}\right)+\operatorname{Var}\left(\bar{x}_{2}\right)
$$

if new sites are sampled each period. A positive correlation $(\rho)$ over time suggests precision is best when the same sites are revisited [Eq. (1)] time after time.

Alternatively, status over the two sampling periods can be characterized as the average performance over time where

$$
\text { Status }=\frac{\bar{x}_{1}+\bar{x}_{2}}{2}
$$

with variance

$$
\operatorname{Var}\left(\frac{\bar{x}_{1}+\bar{x}_{2}}{2}\right)=\frac{\operatorname{Var}\left(\bar{x}_{1}\right)+\operatorname{Var}\left(\bar{x}_{2}\right)+2 \rho \sqrt{\operatorname{Var}\left(\bar{x}_{1}\right) \cdot \operatorname{Var}\left(\bar{x}_{2}\right)}}{4}
$$

if the same sites are revisited, or

$$
\operatorname{Var}\left(\frac{\bar{x}_{1}+\bar{x}_{2}}{2}\right)=\frac{\operatorname{Var}\left(\bar{x}_{1}\right)+\operatorname{Var}\left(\bar{x}_{2}\right)}{4}
$$

if new sites are sampled each period. In the case of status monitoring, the sampling variance is smallest [Eq. (4) vs. Eq. (3)] when new sites are sampled each year because of the typically positive $\rho$ over time. Hence, repeated visits to the same sampling locations over time are best for trend analysis, while independent annual samples are best for status monitoring.

A sampling approach that combines the best of status and trends monitoring is sampling with partial replacement or rotational designs. Sampling with partial replacement represents a survey method with an extensive theoretical (Patterson 1950, Cochran 1953; Sukhatme 1954; Eckler 1955) and practical (Hansen et al. 1955) background. Other names for this survey design include "rotational sampling" (Eckler 1955; Rao and Graham 1964), "sampling for time series" (Hansen et al. 1955; Scott and Smith 1974) and 
"repeated surveys" (Blight and Scott 1973; Cochran 1977), "paired designs" (Urquhart and Kincaid 1999; McDonald 2003), and "revisit designs" (McDonald 2003). These study design have been used in wildlife investigations (Sen 1971, 1979) and to inventory forest resources in the U.S. and Canada (Ware and Cunia 1962; Bickford et al. 1963; McRoberts and Hansen 1999; Reams and Deusen 1999), and to monitor eelgrass in Puget Sound (Sewell et al. 2001). Figure B.3a-f schematically illustrates design options.

a. Never Revisit

\begin{tabular}{|c|c|c|c|c|c|c|c|c|c|c|c|c|}
\hline \multirow{2}{*}{ Panel } & \multicolumn{10}{|c|}{ Sampling Occasion } \\
\hline & 1 & 2 & 3 & 4 & 5 & 6 & 7 & 8 & 9 & 10 & 11 & 12 \\
\hline 1 & & & & & & & & & & & & \\
\hline 2 & & & & & & & & & & & & \\
\hline 3 & & & & & & & & & & & & \\
\hline 4 & & & & & & & & & & & & \\
\hline 5 & & & & & & & & & & & & \\
\hline 6 & & & & & & & & & & & & \\
\hline 7 & & & & & & & & & & & & \\
\hline 8 & & & & & & & & & & & & \\
\hline 9 & & & & & & & & & & & & \\
\hline 10 & & & & & & & & & & & & \\
\hline
\end{tabular}

c. Repeating Panel

\begin{tabular}{|c|c|c|c|c|c|c|c|c|c|c|c|c|}
\hline Panel & \multicolumn{10}{|c|}{ Sampling Occasion } \\
\hline & 1 & 2 & 3 & 4 & 5 & 6 & 7 & 8 & 9 & 10 & 11 & 12 \\
\hline 1 & & & & & & & & & & & & \\
\hline 2 & & & & & & & & & & & & \\
\hline 3 & & & & & & & & & & & & \\
\hline 4 & & & & & & & & & & & & \\
\hline 5 & & & & & & & & & & & & \\
\hline 6 & & & & & & & & & & & & \\
\hline 7 & & & & & & & & & & & & \\
\hline 8 & & & & & & & & & & & & \\
\hline 9 & & & & & & & & & & & & \\
\hline 10 & & & & & & & & & & & & \\
\hline
\end{tabular}

e. Rotational Design

\begin{tabular}{|c|c|c|c|c|c|c|c|c|c|c|}
\hline \multirow{2}{*}{ Panel } & \multicolumn{7}{|c|}{ Sampling Occasion } \\
\hline & 1 & 2 & 3 & 4 & 5 & 6 & 7 & 8 & 9 & 10 \\
\hline 1 & & & & & & & & & & \\
\hline 2 & & & & & & & & & & \\
\hline 3 & & & & & & & & & & \\
\hline 4 & & & & & & & & & & \\
\hline 5 & & & & & & & & & & \\
\hline 6 & & & & & & & & & & \\
\hline 7 & & & & & & & & & & \\
\hline 8 & & & & & & & & & & \\
\hline 9 & & & & & & & & & & \\
\hline 10 & & & & & & & & & & \\
\hline 11 & & & & & & & & & & \\
\hline 12 & & & & & & & & & & \\
\hline
\end{tabular}

b. Complete Revisit

\begin{tabular}{|c|c|c|c|c|c|c|c|c|c|c|c|c|}
\hline \multirow{2}{*}{ Panel } & \multicolumn{10}{|c|}{ Sampling Occasion } \\
\hline & 1 & 2 & 3 & 4 & 5 & 6 & 7 & 8 & 9 & 10 & 11 & 12 \\
\hline 1 & & & & & & & & & & & & \\
\hline 2 & & & & & & & & & & & & \\
\hline 3 & & & & & & & & & & & & \\
\hline 4 & & & & & & & & & & & & \\
\hline 5 & & & & & & & & & & & & \\
\hline 6 & & & & & & & & & & & & \\
\hline 7 & & & & & & & & & & & & \\
\hline 8 & & & & & & & & & & & & \\
\hline 9 & & & & & & & & & & & & \\
\hline 10 & & & & & & & & & & & & \\
\hline
\end{tabular}

d. Split Panel

\begin{tabular}{|c|c|c|c|c|c|c|c|c|c|c|c|c|}
\hline \multirow{2}{*}{ Panel } & \multicolumn{10}{|c|}{ Sampling Occasion } \\
\hline & 1 & 2 & 3 & 4 & 5 & 6 & 7 & 8 & 9 & 10 & 11 & 12 \\
\hline 1 & & & & & & & & & & & & \\
\hline 2 & & & & & & & & & & & & \\
\hline 3 & & & & & & & & & & & & \\
\hline 4 & & & & & & & & & & & & \\
\hline 5 & & & & & & & & & & & & \\
\hline 6 & & & & & & & & & & & & \\
\hline 7 & & & & & & & & & & & & \\
\hline 8 & & & & & & & & & & & & \\
\hline 9 & & & & & & & & & & & & \\
\hline 10 & & & & & & & & & & & & \\
\hline 11 & & & & & & & & & & & & \\
\hline
\end{tabular}

f. Rotational Split-Panel Design

\begin{tabular}{|c|c|c|c|c|c|c|c|c|c|}
\hline \multirow{2}{*}{ Panel } & \multicolumn{7}{|c|}{ Sampling Occasion } \\
\hline & 1 & 2 & 3 & 4 & 5 & 6 & 7 & 8 & 9 \\
\hline 1 & & & & & & & & & \\
\hline 2 & & & & & & & & & \\
\hline 3 & & & & & & & & & \\
\hline 4 & & & & & & & & & \\
\hline 5 & & & & & & & & & \\
\hline 6 & & & & & & & & & \\
\hline 7 & & & & & & & & & \\
\hline 8 & & & & & & & & & \\
\hline 9 & & & & & & & & & \\
\hline 10 & & & & & & & & & \\
\hline 11 & & & & & & & & & \\
\hline 12 & & & & & & & & & \\
\hline
\end{tabular}

Figure B.3.a-f. Six Alternative Sampling Designs

Rotational designs are a special case of a much broader class of the sampling designs called "panel designs" (McDonald 2003). These panel designs have both spatial and temporal elements. The "revisit design" refers to how the sampling units are visited and sampled over time (McDonald 2003). The "membership design" (McDonald 2003) defines the way the sampling units over space were selected. 
The group of all sites that will be visited on the same occasion is called a panel. There are an almost unlimited number of combinations of membership and revisit designs.

- Never Revisit Design. In this sampling scheme, a different set of sampling units is visited on each occasion (Figure B.3a). These designs are, in fact, a degenerative case of a rotational design, suited only for status monitoring.

- $\quad$ Completely Revisited Design. In this sampling scheme, the same set of sampling units (i.e., panel 1) is revisited on all occasions (Figure B.3b). These designs are, again, a degenerative case of a rotational design, best suited only for trends monitoring.

- $\quad$ Repeated Panel Design. In this sampling scheme, for instance, panels are periodically repeated over time (Figure B.3c). In this example, panels 1 and 6 are sampled together, with a revisit every five years. Other panels are also revisited on a five-year rotational schedule. The benefit of this design is that sampling effort is distributed eventually over a wide geographic area to better characterize spatial variability and patterns. The benefits to trends monitoring are limited by the infrequent revisit schedule.

- $\quad$ Split Panel Design. In this design, different sets of panels are revisited at different schedules (Figure B.3d). The design depicted in Figure 10d illustrates a case where one panel is monitored yearly for trends analysis while other panels provide additional spatial coverage for status monitoring.

- $\quad$ Rotational Design. Each year, some fraction of the sample location is revisited from the previous year while new sites enter the sample (Figure B.3e). In the case of Figure B.3e, there is a $2 / 3$ retention rate from one year to the next. This design, by retaining some sample locations from one year to the next, while at the same time refreshing the design with new locations each year provides desirable properties for both status and trends monitoring.

- Rotational Split-Panel Design. Here, one panel of sites is monitoring annually because of strategic, biological, or social importance (Figure B.3f). Other panels are sampled in a rotational scheme to provide additional time series data and provide greater spatial coverage (Figure B.3f).

\section{Merits of Rotational Designs}

Of the various panel designs, the rotational designs of Figure B.3 provide the best features of both status and trends monitoring. The observations in year $i$ are used in a rotational design to provide an initial estimate of the status in year ${ }^{i}$ (e.g., population mean, ${ }^{\hat{X}_{i}}$ ). However, from the locations sampled in both year $i$ and $i+1$, an alternative estimate of the population mean in year $i$ can also be calculated as

$$
\tilde{\bar{X}}_{i}=\hat{\alpha}+\hat{\beta}\left(\hat{\bar{X}}_{i+1}\right)
$$


where, alpha and beta are regression coefficients assuming a linear relationship. Then the updated estimate of status in year $i$ is the weighted average,

$$
\hat{\bar{X}}_{i}^{\prime}=Q\left(\hat{\bar{X}}_{i}\right)+(1-Q)\left(\tilde{\bar{X}}_{i}\right)
$$

where $\mathrm{Q}$ is a weighting constant $(0<\mathrm{Q}<1)$ dependent on the variance of the two estimates. The update estimate of status in year $i$ (i.e., $\hat{\bar{X}}_{i}^{\prime}$ ) will have a smaller variance than the initial estimate $\hat{\bar{X}}_{i}$; the precision gain dependent on the degree of temporal correlation.

Cochran (1977, p. 347) indicates the optimal fraction of sampling locations to retain from one year to the next in a rotational design is

$$
\frac{\sqrt{1-\rho^{2}}}{1+\sqrt{1-\rho^{2}}}
$$

where, $\rho=$ temporal correlation from one year to the next. Table B-2 illustrates the optimal retention fraction as a function of $\rho$. For moderate to low correlations (i.e., $\rho<0.5$ ), 50\% of the site should be retained and the other $50 \%$ replaced with new locations each year. Only at higher levels of temporal correlation $(0.5<\rho<0.9)$ would a $2 / 3$ or larger rotational scheme be advisable. These recommendations of Cochran (1977) are for the case of no measurement error. In the situation where site characterization has additional measurement error, then the proportion of sites that should be retained from one year to the next should be greater than that reported in Table B.2. Measurement error has the effect of diminishing the perceived temporal correlation. Consequently, more sites need to be revisited to better characterize the correlation in rotational designs. It is therefore not uncommon to have retention rates of $75 \%$ to $80 \%$ from one year to the next. These high retention rates also mean fewer new sites need to be established each year, thereby reducing the overall cost of the monitoring project.

Table B.2. Optimal fraction of monitoring sites to retain from one year to the next in a rotational sampling design for status and trends monitoring as a function of interannual correlation $(\rho)$.

\begin{tabular}{|cc|}
\hline$\rho$ & $\begin{array}{c}\text { Optimal Fraction of } \\
\text { Sites to Retain from } \\
\text { One Year to the Next }\end{array}$ \\
\hline 0 & 0.5 \\
0.1 & 0.499 \\
0.2 & 0.495 \\
0.3 & 0.488 \\
0.4 & 0.478 \\
0.5 & 0.464 \\
0.6 & 0.444 \\
\hline
\end{tabular}




\begin{tabular}{|cc|}
\hline 0.7 & 0.417 \\
0.8 & 0.375 \\
0.89 & 0.304 \\
0.95 & 0.238 \\
0.98 & 0.166 \\
\hline
\end{tabular}

\section{Allocation of Spatial Sampling Effort}

The monitoring program will have replicate sites which are, in turn, subsampled. At each site, multiple stations will typically be sampled and, within each of these locations, often multiple measurements will be taken. This configuration of sites, stations within sites, and samples within stations, constitutes a hierarchical or nested design (Cochran 1977; p. 285-288). In the case where the overall response is the population mean $(\overline{\bar{X}})$, it has a variance of

$$
\operatorname{Var}(\overline{\bar{x}})=\frac{1-f_{1}}{n} S_{1}^{2}+\frac{1-f_{2}}{n m} S_{2}^{2}+\frac{1-f_{3}}{n m k} S_{3}^{2}
$$

where

$$
\begin{aligned}
& f_{i}=\text { sampling fraction at the } i \text { th sampling stage, } \\
& S_{1}^{2}=\text { between-site variance, } \\
& S_{2}^{2}=\text { between-sampling-stations-within-site variance, } \\
& S_{3}^{2}=\text { between samples-within-station variance, } \\
& n=\text { number of sites sampled, } \\
& m=\text { number of sampling stations within a site, } \\
& k=\text { number of samples drawn within a station. }
\end{aligned}
$$

Optimal allocation at the different stages of sampling depends on the relative magnitude of the different variance components and sampling costs at each stage (Cochran 1977; p. 288). However, the general form of $\operatorname{Var}(\overline{\bar{X}})$ indicates that for even moderate values of $n, m$, and $k$, the third term in Eq. 5 will contribute little to the overall sampling variance. To a lesser degree, the same can be said for the between-station, within-site contribution. Hence, for precise estimates of status, sampling effort should be "extensive" rather than "intensive." In other words, more sites with less in-site characterization will provide better overall precision than fewer sites intensely sampled. 
The variance of $\overline{\bar{X}}$ can also be reduced by stratifying the monitoring sites by habitat type, topography, salinity, etc. Stratification in sampling is analogous to blocking in experimental design. The between-strata (e.g., block) variance is eliminated by blocking, thereby reducing the value of $S_{1}^{2}$ [Eq. 5] within each strata. Stratification need not be perfect to achieve precision benefits. The reduction in variance depends on how correlated the response variable of interest $(x)$ is to the criteria $(y)$ used in strata construction. The variance of stratified random sampling $\left(\operatorname{Var}\left(\bar{x}_{S T}\right)\right)$, as a function of the number of strata $(L)$, has the approximate relationship:

$$
\operatorname{Var}\left(\bar{x}_{S T}\right) \geq \frac{S^{2}}{n}\left[\frac{\rho^{2}}{L}+\left(1-\rho^{2}\right)\right],
$$

where

$$
\begin{aligned}
& \rho=\text { the correlation between } x \text { and } y, \\
& S^{2}=\text { variance among sampling units, } \\
& n=\text { number of samples within a stratum, } \\
& L=\text { number of strata. }
\end{aligned}
$$

Cochran (1977; p. 133) shows that unless $\rho>0.95$, there is little precision gained by using more than $L$ $=6$ strata.

\section{B.1.6 Summary - Status and Trends Monitoring}

The overall objective of status and trends monitoring is to measure the status and trends of monitored indicators that are ecologically significant to listed salmonids in the lower river, estuary, plume, and nearshore ocean. The specific STM objectives deal with ecosystem stressors, controlling factors, structures, and salmonid performance. The Columbia River Estuary Conceptual Model (Thom et al. 2004) forms a basis to choose monitored indicators for each STM objective. A rotational split panel sampling design is proposed. Data collection methods for STM, the spatial and temporal scale of monitoring, and example protocols are provided in Appendix C. Status and trends monitoring in the CRE is important because it will reveal whether ecosystem features supporting salmonids are improving, staying the same, or degrading. This knowledge, when integrated with scientific findings from action effectiveness and uncertainties research, will help guide management actions. The STM research and monitoring framework provides the scientific basis for status and trends monitoring in the CRE, as follows:

- Landscape-wide status and trends monitoring must be based on relatively easy and inexpensive collection procedures of indicators associated with habitat capacity and opportunity for salmonids. Expensive and difficult-to-collect indicators are unlikely to persist across decades of changing 
budgetary priorities. Use of remote sensing and GIS to monitor indicators such as total habitat area, connectivity, or changes in land use have the potential to canvas large areas cost effectively.

- For indicators that must be directly measured, sampling schemes will be based on rotational sampling designs. These rotational designs optimally allocate effort over time and space to provide precise

estimates of both status (e.g., $\bar{x}$ ) and trends (e.g., $\bar{x}_{2}-\bar{x}_{1}$ ). Rotational split-panel designs (Figure B3f), where some sites are sampled infinitum while others are rotated in and out of the design over time, provide the opportunity to collocate status and trends sites with reference sites used in regional effectiveness monitoring.

- Spatial sampling will be "extensive" rather than "intensive." Precise estimates of status and the power to detect time trends are improved if numerous sites are lightly sampled, rather than a few sites heavily characterized. The measurements taken at these status and trends sites will typically be the nature of water quality and habitat variables.

- Salmonid performance can be assessed by estimating survival through the estuary. Improvements in estuary survival should promote improved adult returns. Residence time and salmonid usage (e.g., smolt-days) may provide additional information on salmon performance. However, unless these indicators are measured at the landscape level, site-specific improvements may be difficult to correctly interpret. Differentiating between habitat improvements serving as a source or sink can be difficult. In the mainstem Columbia, releases of tagged smolts to monitor survival trends have been more opportunistic than thoughtfully planned. Monitoring survival through the estuary will require coordinated support.

\section{B.2 Action Effectiveness Research}

The overall objective of estuary RME's action effectiveness research is to use a representative set of projects to monitor and evaluate the effects of habitat restoration actions in the estuary.

\section{B.2.1 Objectives}

Action effectiveness research determines the biological and ecological effects of management actions relative to project and program objectives. The three-phased approach to evaluation described by Busch and Trexler (2003) is used in this RME Plan: implementation monitoring, or "how the initiative is being implemented;" effectiveness monitoring, or "effects of implementing the initiative;" and validation monitoring, which is "an ongoing program to validate the assumptions linking implementation (causes) and effects." This is consistent with classifications by MacDonald et al. (1991) used in Columbia tributary monitoring protocols by Hillman and Giorgi (2002), and with a major concurrent restoration planning effort in the Pacific Northwest - the Puget Sound nearshore ecosystem (Fresh et al. 2003). Taylor et al. (2003) surveyed 143 of 260 projects funded under the Washington State Salmon Recovery Funding Board, finding fault in that most performed "implementation" and "effectiveness" monitoring, 
while little "validation" monitoring occurred. As applied to the Columbia River estuary", the primary management actions that require monitoring involve habitat restoration through hydrological reconnection (Diefenderfer et al. 2005). Flow management by FCRPS operators for the purpose of affecting estuary habitat is not currently being undertaken as a management action.

Fundamental elements of monitoring aquatic habitat restoration projects can be found in Thom and Wellman (1996), Zedler (2001) and Rice et al. (2005). Restoration projects ongoing in the estuary are currently being monitored to varying degrees. The intensity of project-specific monitoring in the estuary is expected to increase with the number of projects implemented. Evaluation of the cumulative effects of multiple restoration projects in the estuary relative to the objectives of various programs sponsoring restoration projects will describe effectiveness at the landscape scale. The conclusions generated from action effectiveness research and monitoring will inform decision making in the adaptive management process for the NOAA Fisheries/Action Agencies' estuary program as a whole. The three objectives for action effectiveness research in the estuary are designed to assess the effects of habitat restoration actions at multiple spatial and temporal scales.

AER 1. Develop a limited number of reference sites for typical habitats, e.g., tidal swamp, marsh, island, and tributary delta, to use in action effectiveness evaluations.

\section{Cont'}

AER 2. Evaluate the effects of selected individual habitat restoration actions at project sites relative to reference sites and evaluate post-restoration trajectories based on project-specific goals and objectives. ("Effectiveness Monitoring")

AER 3. Develop and implement a methodology to estimate the cumulative effects of habitat conservation and restoration projects in terms of cause-and-effect relationships between ecosystem controlling factors, structures, and processes affecting salmon habitats and performance. ("Validation Monitoring")

\section{B.2.2 Conceptual Model}

The framework organizing action effectiveness research (Johnson et al. 2003) is built on the Columbia River estuary conceptual model (Thom et al. 2004) as well as the estuary habitat "capacity," "opportunity," and "realized function" model developed for salmonids by Simenstad and Cordell (2000) (Table B.3). The latter model has been elaborated with respect to listed stocks of Columbia Basin salmon by Bottom et al. (2005). Habitat capacity, opportunity, and realized function are categories of assessment

\footnotetext{
${ }^{a}$ Currently, there are no "actions" being undertaken in the plume. Therefore, action effectiveness research in the estuary pertains only to the reach RM 0-146.
} 
metrics (Table B.3). Realized Function corresponds well to the viability concept as defined by Fresh et al. (2005) for the estuary, which includes four performance criteria: abundance, productivity, spatial structure, and life history diversity. Based on this framework and the Estuary Program Goal, a unifying action effectiveness research question emerges: Is the estuarine habitat opportunity and capacity adequate to support necessary realized functions throughout Columbia River estuary-associated salmonid life histories?

Table B.3. Definitions of habitat capacity, habitat opportunity, and realized function (from Simenstad and Cordell 2000).

\begin{tabular}{|l|l|}
\hline $\begin{array}{l}\text { Habitat } \\
\text { Capacity }\end{array}$ & $\begin{array}{l}\text { A category of habitat assessment metrics including "habitat attributes that promote } \\
\text { juvenile salmon production through conditions that promote foraging, growth, and } \\
\text { growth efficiency, and/or decreased mortality," for example, invertebrate prey } \\
\text { productivity, salinity, temperature, and structural characteristics. }\end{array}$ \\
\hline $\begin{array}{l}\text { Habitat } \\
\text { Opportunity }\end{array}$ & $\begin{array}{l}\text { A category of habitat assessment metrics that "appraise the capability of juvenile } \\
\text { salmon to access and benefit from the habitat's capacity," for example, tidal elevation } \\
\text { and geomorphic features. }\end{array}$ \\
\hline $\begin{array}{l}\text { Realized } \\
\text { Function }\end{array}$ & $\begin{array}{l}\text { A category of assessment metrics that "include any direct measures of physiological or } \\
\text { behavioral responses that can be attributable to fish occupation of the habitat and that } \\
\text { promote fitness and survival," for example, survival, habitat-specific residence time, } \\
\text { foraging success and growth. }\end{array}$ \\
\hline
\end{tabular}

Action effectiveness research in this RME Plan is governed by the Thom et al. (2004) conceptual model adapted in Figure B.4. This model details ecosystem structures of the estuary (e.g., emergent marsh and deep channel), some elements which must be measured for action effectiveness monitoring (e.g., vegetation cover). It identifies stressors (i.e., anthropogenic, and external factors) to the Columbia River estuary. The Bottom et al. (2005) model of stressors and controlling factors on salmon habitat opportunity, capacity, and population structure/life history is not inconsistent with this model. Monitoring the effects of the reduction or elimination of stressors to the system - such as land use, passage barriers, and changes to the hydrograph - is important for validation monitoring. The model also treats factors controlling the development of ecosystem structures and processes significant to salmon habitat capacity. Monitoring controlling factors is important for effectiveness monitoring as described in Section 2.2.

The core elements required for assessing salmonid performance - habitat capacity, habitat opportunity, and population structure/life history - are highlighted in Figure B.5. The scale of the conceptual model is estuary-wide, not site-specific. 


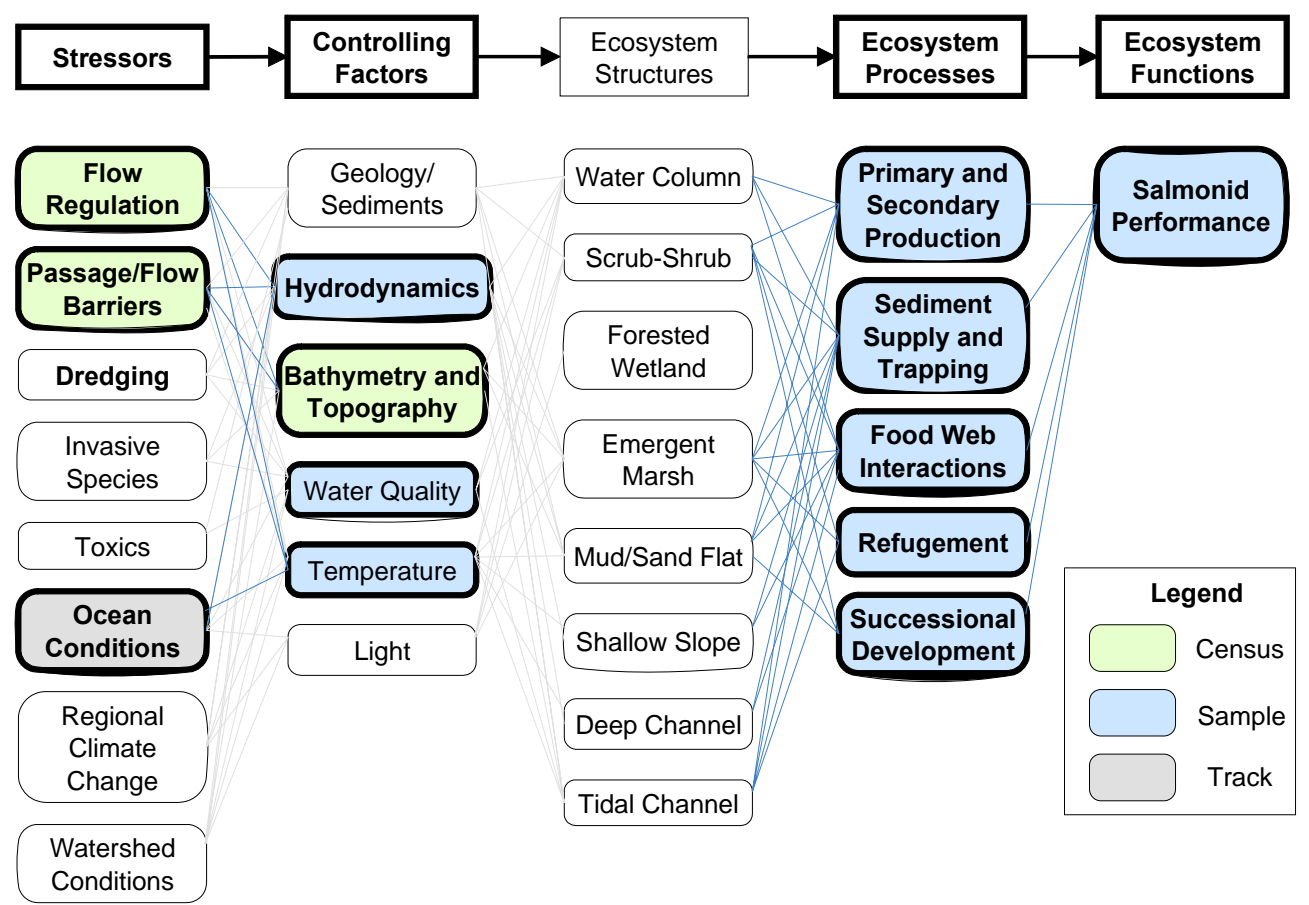

Figure B.4. Columbia River Estuary Conceptual Model Applied to Estuary RME Action Effectiveness Research. (Adapted from Thom et al. 2004). The spatial scale is estuary-wide.

\section{ERME Habitat Capacity, Opportunity, and Function}

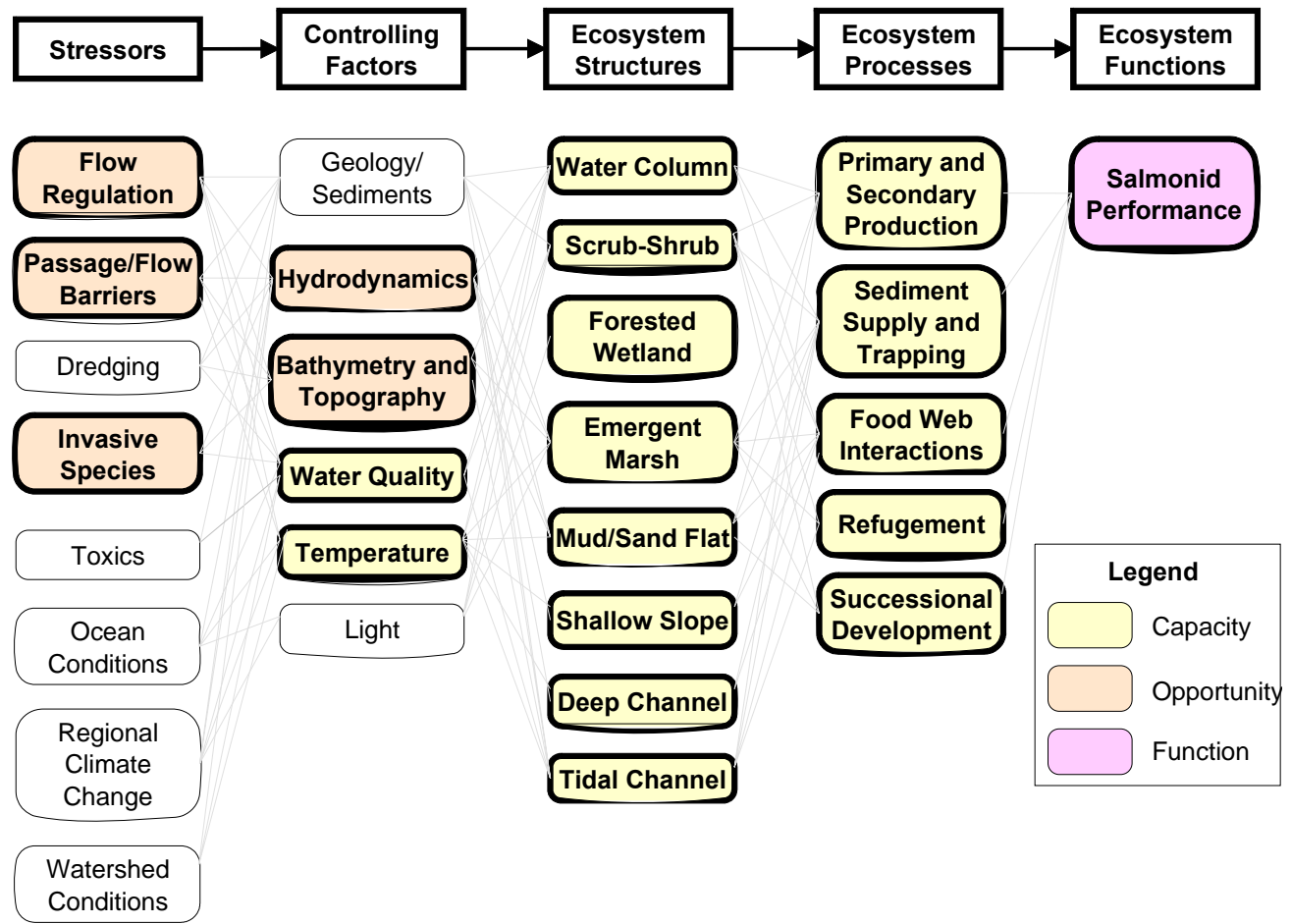

Figure B.5. Habitat Capacity, Opportunity, and Realized Function as Depicted in the Columbia River Estuary Conceptual Model. (Adapted from Thom et al. 2004.) 


\section{B.2.3 Monitored Indicators}

Three levels of monitoring data will be required to meet the objectives for action effectiveness: project-specific "implementation and compliance monitoring" (Section 4.1.4), project-related ecosystem structure and process "effectiveness monitoring," and regional cumulative effects "validation monitoring." To assess action effectiveness, indicators associated with habitat capacity, opportunity, and realized function must be analyzed. Furthermore, restoration projects within the tidally influenced portion of a tributary watershed may be influenced by processes occurring at a watershed scale, such as sediment transport. Therefore, tracking any research in the watershed is important to restoration project management. To facilitate judgments about action effectiveness, the relevant indicators are categorized in Table B-4 with respect to the most applicable of the AER objectives. However, many attributes will contribute to more than one objective.

If monitoring shows that a) through habitat restoration actions, habitat opportunity and capacity improve relative to present levels, and b) that salmon exhibit improved realized functions associated with their use of restored habitats, then this information may serve as a basis for inferences regarding the benefits of estuary habitat restoration actions to salmonids. Direct measurement of the effects of estuarine habitat on salmon populations remains extremely challenging because of 1) the lack of knowledge about the life histories of genetic stocks from the range of natal areas in the basin, and 2) the fact that salmon use tributary, mainstem, and oceanic habitats in addition to the estuary.

A USACE Anadromous Fish Evaluation Program project to evaluate the cumulative effects of multiple restoration projects in the estuary has proposed a set of "core indicators" for monitoring restoration sites and issued a working draft of corresponding protocols (Diefenderfer et al. 2005; Roegner et al. 2008; See Section 2.2). The selection of these core metrics was based on the following interrelated criteria:

- Diagnostic of relevant ecosystem function and direct correspondence to common goals (i.e. hydrological reconnection) of CRE restoration projects (Thom and Wellman 1996)

- Three classes must be tracked: controlling factors (e.g., tidal regimes), structural factors (e.g., plant communities), and functional factors (e.g., salmonids age/size) (NRC 1992)

- Metrics applicable to all sites with measurements that result in comparable datasets relevant to present and future investigations (Tegler et al. 2001)

- Measurements and data analysis practical in terms of funding, manpower, and processing requirements (Callaway et al. 2001).

Monitoring the same core indicators using the same protocols at all CRE restoration sites is part of the foundation for validation monitoring at the landscape scale. These metrics were specifically designed to be feasible and economical for all projects. Other metrics in Table B.4, which may require greater 
technical resources or costs to measure, are appropriate for directed research to reduce uncertainties in the state-of-the-science regarding the estuary and salmonid performance, for elucidating cause-and-effect relationships, and for assessing the cumulative effects of restoration projects on fundamental estuarine processes (e.g., flux). The sampling design, monitored indicators, and protocols (Appendix C) are expected to be further refined in the concurrent USACE cumulative effects research project. Starred attributes in Table B.4 have been recommended as suggested core monitoring attributes for hydrological reconnection projects (Diefenderfer et al. 2005; Roegner et al. 2008).

Table B.4. Monitored Indicators and the Action Effectiveness Research Component of Estuary RME by Category. Shading implies priority indicator: green $=$ census; blue=probabilistic sample; gray=track information provided by others. Indicators with asterisks and bolding have been recommended as core project (AER 1) monitoring indicators for hydrological reconnection projects (Roegner et al. 2008).

\begin{tabular}{|c|c|c|c|c|c|c|c|}
\hline Category & Monitored Indicator(s) & $\begin{array}{l}\text { AER } \\
1 \\
\text { Ref. } \\
\text { Sites } \\
\end{array}$ & $\begin{array}{c}\text { AER } 2 \\
\text { Effectiveness } \\
\text { Monitoring }\end{array}$ & $\begin{array}{c}\text { AER 3 } \\
\text { Validation } \\
\text { Mon.itoring }\end{array}$ & Cap. & Opp. & Fun. \\
\hline Flow Regulation & Water Discharge & & & - & & - & \\
\hline Passage/Flow Barriers & Passage Barriers & - & - & & - & & \\
\hline Invasive Species & $\begin{array}{l}\text { Species Composition, } \\
\text { Abundance, Spatial } \\
\text { Distribution }\end{array}$ & $\bullet$ & $\bullet$ & $\bullet$ & & $\bullet$ & \\
\hline Watershed Conditions & $\begin{array}{l}\text { Discharge, Water } \\
\text { Velocity/Temp., } \\
\text { Sediment Budget, Large } \\
\text { Woody Debris }\end{array}$ & & & $\bullet$ & & & \\
\hline \multirow[t]{4}{*}{ GeologySediments } & Accretion Rates & - & - & & - & - & \\
\hline & Contaminants & & $\bullet$ & & $\bullet$ & $\bullet$ & \\
\hline & Redox Potential & & $\bullet$ & & & $\bullet$ & \\
\hline & $\begin{array}{l}\text { Soil Composition (grain } \\
\text { size, organic matter) }\end{array}$ & & - & & $\bullet$ & - & \\
\hline \multirow[t]{3}{*}{ Hydrodynamics } & Ground Water Level & & $\bullet$ & & $\bullet$ & - & \\
\hline & $\begin{array}{l}\text { Surface Water } \\
\text { Elevation* }\end{array}$ & $\bullet$ & $\bullet$ & & - & - & \\
\hline & $\begin{array}{l}\text { Water Velocity } \\
\text { (currents) }\end{array}$ & & $\bullet$ & & $\bullet$ & $\bullet$ & \\
\hline \multirow[t]{2}{*}{ Bathymetry/Topography } & Bathymetry* & - & - & & - & - & \\
\hline & $\begin{array}{l}\text { Floodplain } \\
\text { Topography* }\end{array}$ & - & $\bullet$ & & $\bullet$ & - & \\
\hline \multirow[t]{4}{*}{ Water Quality } & Dissolved Oxygen* & $\bullet$ & $\bullet$ & & & $\bullet$ & \\
\hline & $\begin{array}{l}\text { Nutrients (nitrogen, } \\
\text { phosphorous) }\end{array}$ & & $\bullet$ & & & - & \\
\hline & $\mathrm{pH}$ & & - & & & $\bullet$ & \\
\hline & Salinity* & - & $\bullet$ & & & $\bullet$ & \\
\hline Temperature & Temperature* & $\bullet$ & $\bullet$ & & & $\bullet$ & \\
\hline \multirow[t]{3}{*}{ Landscape Features } & $\begin{array}{l}\text { Ecosystem Structures } \\
\text { Map* }\end{array}$ & $\bullet$ & & $\bullet$ & $\bullet$ & $\bullet$ & $\bullet$ \\
\hline & Area (Size) Restored & & $\bullet$ & & $\bullet$ & $\bullet$ & \\
\hline & Large Woody Debris & & $\bullet$ & & $\bullet$ & $\bullet$ & \\
\hline $\begin{array}{l}\text { Tidal Channel } \\
\text { Morphology }\end{array}$ & Edge/Density/Sinuosity & - & • & & - & • & \\
\hline
\end{tabular}




\begin{tabular}{|l|l|c|c|c|c|c|c|}
\hline Category & Monitored Indicator(s) & $\begin{array}{c}\text { AER } \\
\mathbf{1} \\
\text { Ref. } \\
\text { Sites }\end{array}$ & $\begin{array}{c}\text { AER 2 } \\
\text { Effectiveness } \\
\text { Monitoring }\end{array}$ & $\begin{array}{c}\text { AER 3 } \\
\text { Validation } \\
\text { Mon.itoring }\end{array}$ & Cap. & Opp. & Fun. \\
\hline Vegetation Cover & $\begin{array}{l}\text { Percent Cover by } \\
\text { Species* }\end{array}$ & $\bullet$ & $\bullet$ & & $\bullet$ & $\bullet$ & \\
\hline \multirow{5}{*}{ Food Web } & Foraging Success & $\bullet$ & & $\bullet$ & & & $\bullet$ \\
\hline & Predation Index & & $\bullet$ & & & $\bullet$ & \\
\hline & Prey Availability & & & $\bullet$ & & $\bullet$ & $\bullet$ \\
\hline \multirow{5}{*}{ Salmonid Performance } & Abundance & $\bullet$ & $\bullet$ & & $\bullet$ & $\bullet$ & \\
\hline & Age/Size-Structure* & & $\bullet$ & & & & $\bullet$ \\
\hline & Distribution: Spatial & & $\bullet$ & & & & $\bullet$ \\
\hline & $\begin{array}{l}\text { Distribution: } \\
\text { Temporal* }\end{array}$ & $\bullet$ & $\bullet$ & & & & $\bullet$ \\
\hline & Growth Rate & & & & & & $\bullet$ \\
\hline & Migration Pathways & & $\bullet$ & & & & $\bullet$ \\
\hline & Residence Time & & $\bullet$ & & & & $\bullet$ \\
\hline & Species Composition* & $\bullet$ & $\bullet$ & & & & $\bullet$ \\
\hline & Stock Identity & & $\bullet$ & & & & $\bullet$ \\
\hline
\end{tabular}

\section{B.2.4 AER 1 Effectiveness Monitoring Design}

This section prefaces the sampling design with a discussion of the unique nature of evaluating the effectiveness of habitat restoration actions in estuarine environments and some of the relationships between recommended methods in the estuary and the tributaries. One important feature of this environment, the continuously changing connectivity between estuarine habitats and associated fluctuating habitat opportunity for salmonids, is given special attention. The purpose of the sampling design for effectiveness monitoring is to assess whether restoration measures achieve project and program goals and objectives. Testing for a simple change in ecosystem structures or processes is superfluous because a physical change was intentionally performed. Instead, the purpose is to assess whether the restoration activity produced the desired shift from some state A to state B. Auxiliary questions may include how rapidly the shift occurred and the relative costs of alternative restoration activities. The sampling designs described here are appropriate for testing these questions in the complex environment of the CRE. No one design is recommended, however, because the monitoring design will depend on the project's objectives.

\section{$\underline{\text { Relationship to Columbia Basin Tributaries }}$}

Action effectiveness research efforts in the estuary and the Columbia Basin tributaries (see basinwide RME plan) have some differences and similarities. In terms of differences, the diversity of habitats and variability at multiple spatial scales are greater in the estuary than in tributary areas, thereby affecting experimental designs and the applicability of EMAP as discussed above. The aquatic environment in the estuary is more dynamic than it is in the tributaries, with water surface elevations, water currents, and salinities, among other variables changing on semi-diurnal tidal scales as well as due to the mainstem hydrograph. In terms of similarities, the Tributary Habitat RME subgroup confronted some of the same 
issues that are inherent to action effectiveness research in the estuary. For example, control or reference sites will be difficult to identify and maintain through time, and adequate replication and isolation of individual action effects will be difficult to accomplish. In the estuary, data from restoration project sites may be compared with data from comparable trends monitoring reference sites to evaluate the trajectory of restoration progress, for efficiency. This melding of status and trends monitoring with action effectiveness research is analogous to that prescribed for Tributary Habitat RME. Furthermore, the estuary/ocean subgroup will continue to coordinate with Tributary Habitat and Hydrosystem RME planners in order to make estuary RME as consistent as possible with RME efforts upstream.

\section{Habitat Opportunity Methods for AER}

While habitat capacity and realized function monitoring comprise commonly measured indicators such as water quality, vegetation, and fish populations (Table 5), the methods for indicators used in habitat opportunity assessment are less well known and deserve further discussion because they often pertain directly to AER.. The most dominant historical change to habitat in the estuary that is not hydrosystem-related is the installation of dikes, tide gates, and other barriers to fish passage. In some cases, such barriers significantly altered habitats behind them, in addition to preventing passage (Simenstad and Feist 1996). It is expected, however, that habitat restoration actions in the estuary will improve habitat opportunity for listed salmonids. More specifically, the area of estuarine habitat currently accessible within a given geographic area is expected to increase toward the area of estuarine habitat that was historically accessible. Furthermore, the length of tidal channel edge that is available to listed salmonids is expected to increase toward pre-settlement levels. However, these length and area values vary temporally with water level in an estuary, which in turn varies with the regulated flow of the Columbia River.

Although only passage barriers and tidal channel edge, density, and sinuosity are shown for the tidal channel morphology indicator in Table B-4, habitat opportunity in fact integrates several variables. For example, the area of restored habitat metric includes temporal scale, or the period of the year and portions of the tidal cycle during which habitat is available based on hydrodynamics and topography. Habitat availability is associated with the topography and inundation regime, which in turn are associated with geomorphic features such as the total edge and penetration of tidal channels. Coats et al. (1995) and Williams et al. (2002) identified bifurcation ratios, channel order, and other variables that can also be used to evaluate tidal channels. These physical parameters have been correlated with ecological processes in studies of allometry (Hood 2002). The calculation of a habitat connectivity index has similar importance in tributary restoration (Hillman and Giorgi 2002).

Several variables that correspond to habitat opportunity for listed salmonids can be calculated using geographic information systems (GIS) and data sources including diking district records and remote sensing imagery. These tools are recommended in Appendix $\mathrm{C}$ for monitoring habitat opportunity indicators. For example, a "diked area" class can be calculated and subjected to a change analysis (Evans et al. 2006). Although resolution previously limited the width of tidal channels that could be visualized with remote sensing (e.g., NOAA Coastal Services Center 1997), recent research in the estuary has revealed tidal channels using digital aerial photography at $0.25-\mathrm{m}^{2}$ spatial resolution. For these channels, 
variables such as density, sinuosity, and total edge length can be calculated using GIS (e.g., Desmond et al. 2000), though these methods are still being developed for the variable vegetation cover types in CRE environments.

\section{AER Sampling Design Alternatives}

\section{Control-Reference Designs}

The assessment of restoration effectiveness is based on evaluating whether a shift from a site's current state (A) to a desired state (B) in a natural system subject to spatial and temporal variability has occurred (Figure B6). Control sites are replicate locations with habitat traits similar to the subject site prior to restoration. These sites are sampled over time to monitor any temporal shifts in baseline conditions and how the subject area might have responded over time had no restoration action taken place. Reference sites are replicate areas considered representative of the desired outcome of the restoration action. These replicate areas are used to characterize the spatial heterogeneity of the target habitat and any temporal shift in the target over time due to climate shift, maturation, etc. Hence, the goal of the restoration may be best viewed as a range of ecosystem conditions, itself subject to natural change over time. A fully restored site might therefore be expected to be within this reference range and mimic any temporal pattern displayed by these reference sites (Figure B.6).

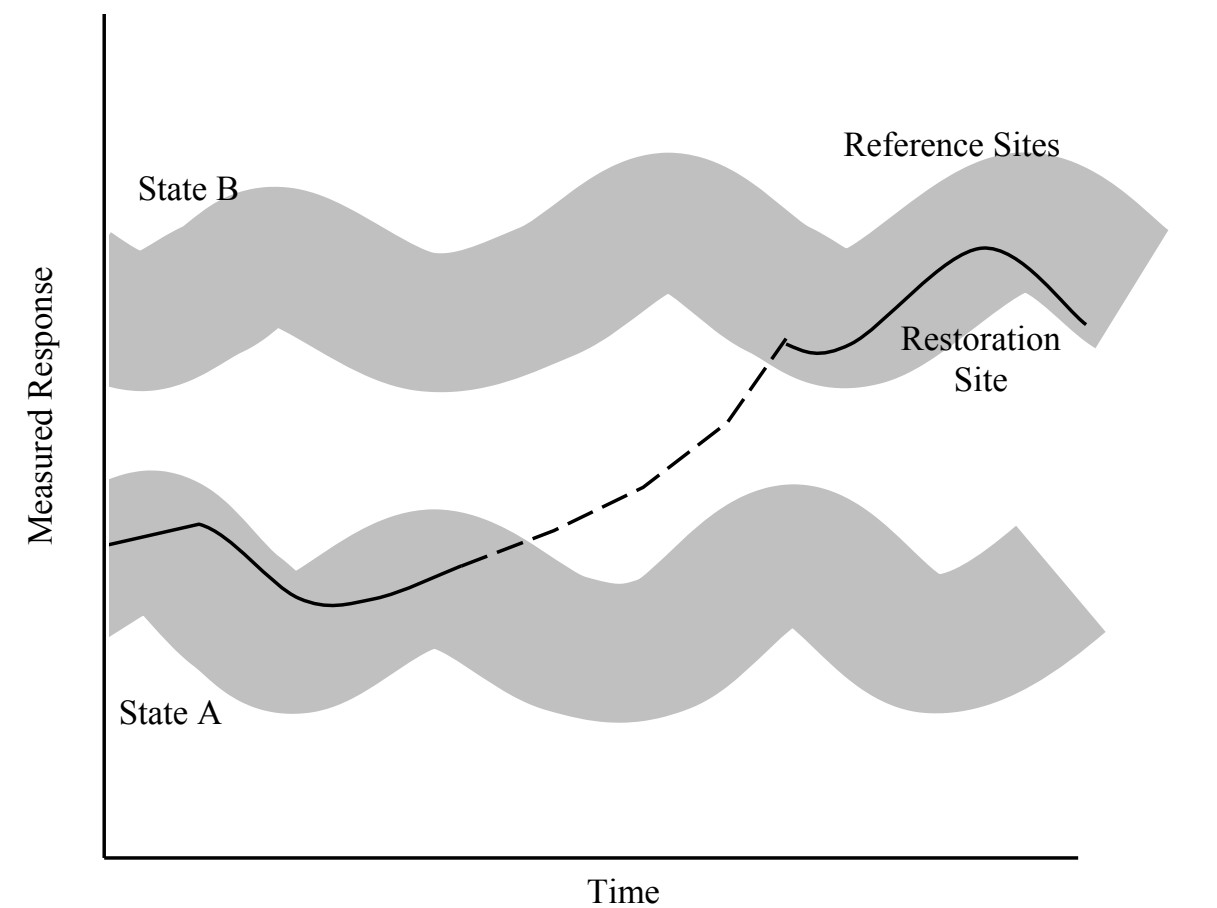

Figure B.6. Conceptual Framework for Evaluating Restoration Effectiveness. The restoration site should shift from its initial state (A) to a desired state B over time. The successfully restored site should have response values within the range of reference sites and track their temporal pattern. 


\section{Reference Only Designs}

Control sites might be an unnecessary luxury if the difference between states A and B is great. In other words, if the ranges of characteristics at restoration and reference sites do not overlap, then there should be little or no risk of falsely concluding restoration (i.e., reaching state B) when the site is still within the range of the initial state A. In this case, only reference sites are needed to assess the status of recovery (Figure B.7). Restoration success is still defined in this situation as the subject site merging into the range of reference conditions and tracking their responses over time. Using only reference sites as part of an effectiveness monitoring design is analogous in many ways to accident assessment designs (Skalski 1995). Recovery of impacted sites following some environmental accident is defined by the impacted site approaching the range of reference conditions and subsequently sharing their same temporal trajectory over time.

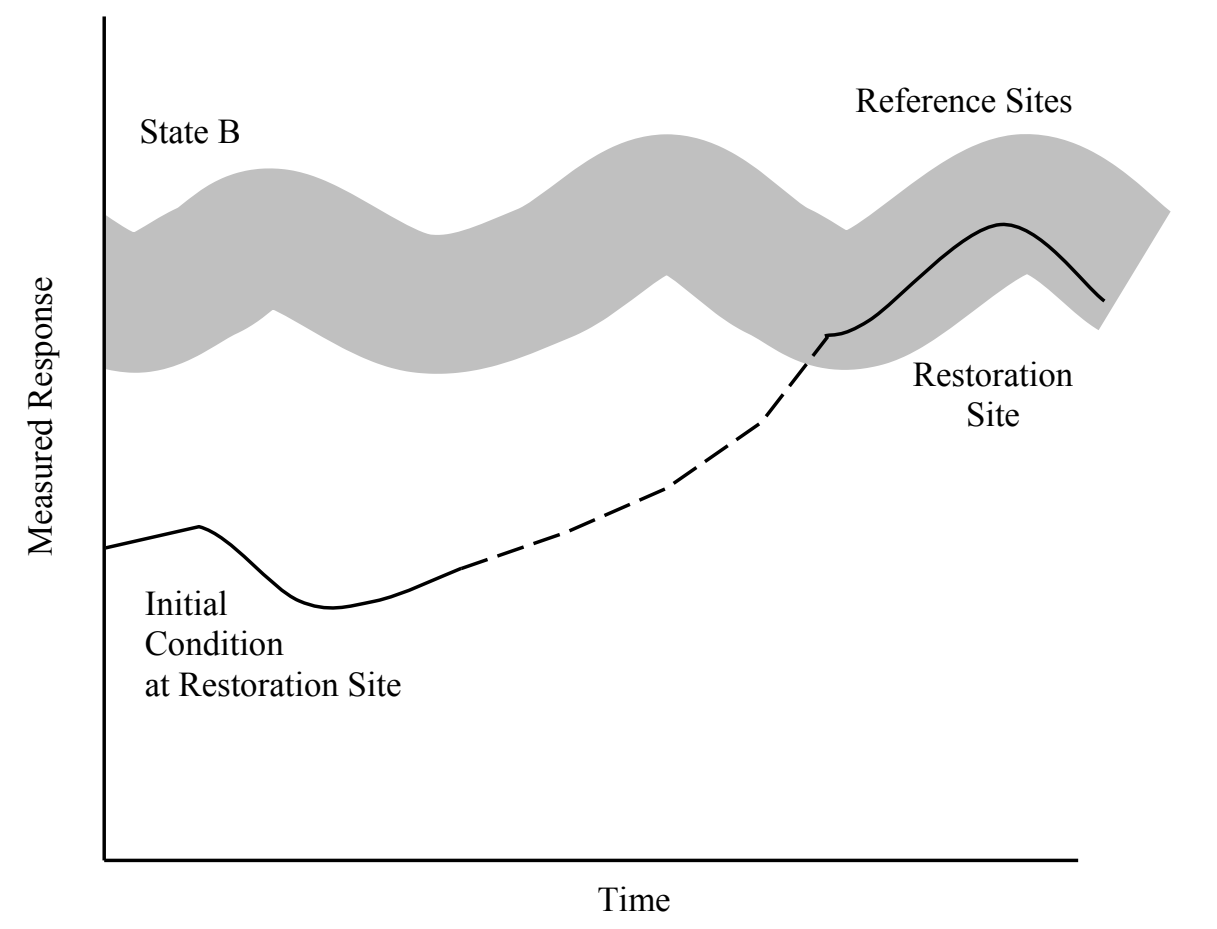

Figure B.7. Conceptual Framework for Monitoring Restoration Effectiveness Using Only Reference Sites as a Target For Recovery

\section{Control Chart Method}

In accident assessment, typically there are multiple reference sites and multiple potentially impacted sites in the evaluation. Skalski and Robson (1992) suggested using repeated measures analysis in conjunction with a test for parallelism to assess recovery. Recovery was achieved when the reference and impact sites began tracking each other through time, i.e., parallelism (Skalski et al. 2001). However, in 
monitoring the restoration of a single site, standard tests of parallelism cannot be performed. There is no between-site, within-treatment variance, only within-site measurement error at the restoration site.

From the repeated sampling at the reference sites, upper and lower control limits for reference responses can be constructed (Figure B8). Control limits describe a range of population responses, such that a prescribed proportion of the population falls within their bounds. For example, the limits

$$
\mu \pm 3 \sigma
$$

contain approximately $99.7 \%$ of a normally distributed population. Shewhart control charts (Grant and Leavenworth 1972; Duncan 1974; Burr 1976) use this principle to establish control limits to monitor production processes in manufacturing. A variation of this concept could be used to assess whether a restoration site merges into the range of reference conditions (Figure B.8). Wheeler (1995; p. 205-225) provides statistical power calculations for control charts.

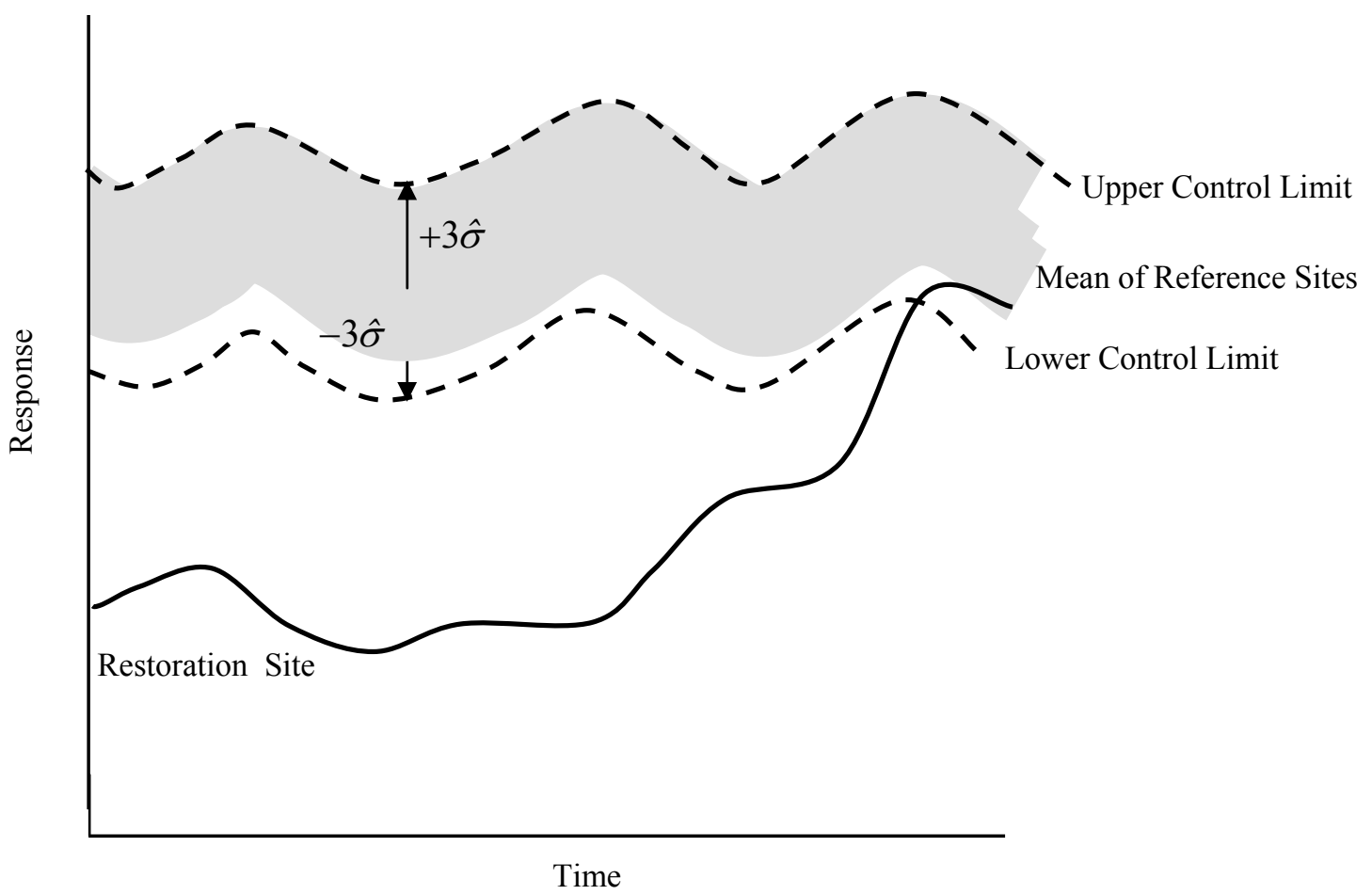

Figure B.8. Illustration of Using Control Chart Methods to Monitor Recovery Success 


\section{Replicate Restoration-Reference Design}

In many cases, focused effectiveness monitoring at the site level will be cost prohibitive. Therefore, the majority of restoration activities will go largely unmonitored. However, a regional effectiveness monitoring approach substituting extensive sampling for intensive, site-specific sampling may be used. A random sample (or stratified random sample) of restoration sites could be selected according to habitat type and restoration activity (e.g., rechannelization, dike removal, etc.). Each site would be paired with a nearby reference site, similar to matched pairs in biometrical studies (Fleiss 1985).

Indicators will be measured prior to restoration and periodically in subsequent years at each site within a pair (Figure B.9). The replicated investigations would test whether there is an interaction between time (i.e., before-after) and treatment (restoration vs. reference site) as well as a convergence of response over time. Site-specific covariates could also be used to determine which conditions are correlated with restoration success. This replicated trial would provide a region-wide assessment of restoration success. By blocking on different habitat or restoration practices, the analysis could also provide insight into which habitats or practices are best suited for restoration. In conclusion, the recommended action effectiveness sampling design (Section 2.2) uses a control chart method to document the condition of restoration sites relative to a suite of reference sites. All monitoring designs for effectiveness monitoring (AER 1) described here would require a network of reference sites (AER 1).

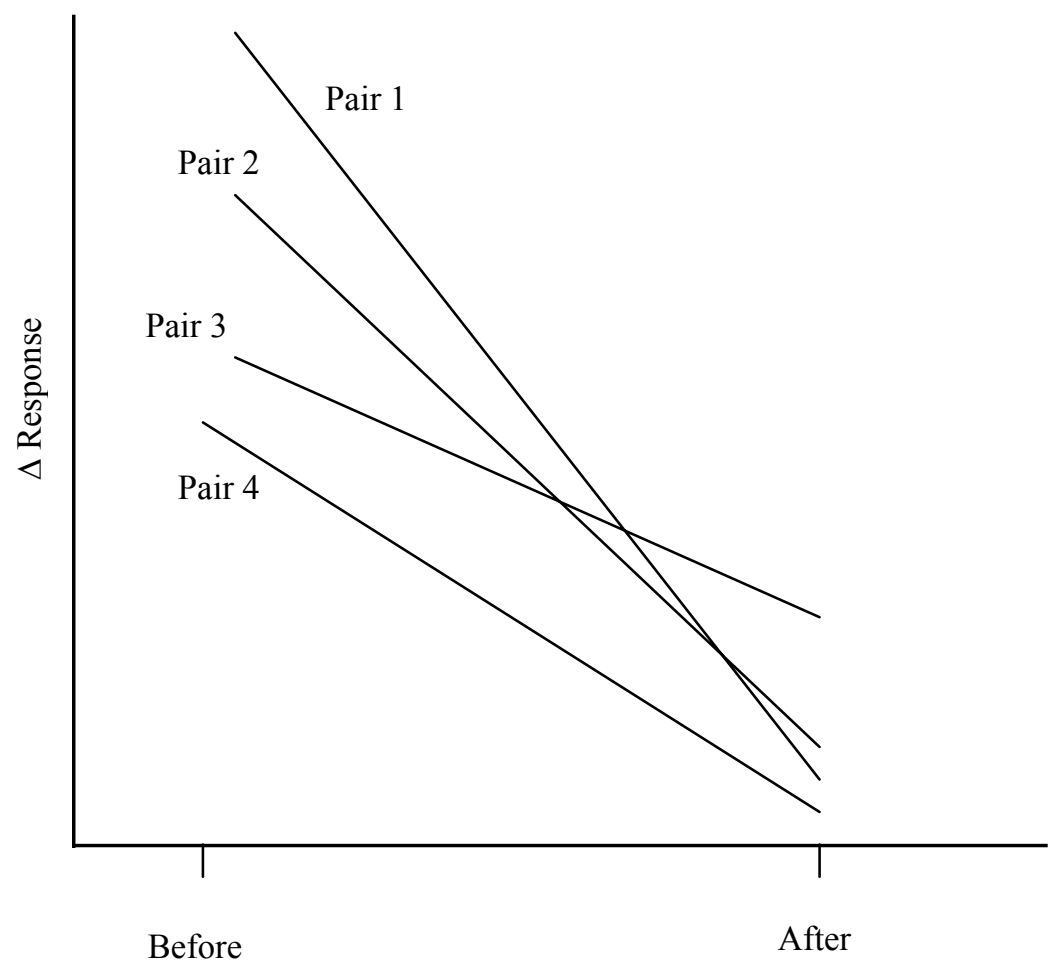

Figure B.9. Graphical Representation of Before-After Response to Restoration at Replicate RestorationReference Sites used in Regional Assessment. Measured response is the difference $(\Delta)$ between reference and restoration sites. 


\section{B.2.5 AER 2 Validation Monitoring Design}

The relative importance of a cumulative effect may be thought of in terms of a) the difference from the historical or current baseline, b) progress toward restoration objectives for estuary habitats and salmon, or c) its relationship to a known environmental threshold beyond which significant change in ecological processes and functions will occur. Three meta-analysis approaches for cumulative effects are applicable: a) relating cumulative response to physical size of restoration sites, b) relating cumulative response to number of projects in a restoration cluster, and c) relating cumulative response to temporal trend in restoration events.

\section{Alternative Meta-Analysis Approaches}

\section{$\underline{\text { Relating Cumulative Response to Physical Size of Restoration Sites }}$}

In the absence of cumulative effects, the magnitude of physical, chemical, or biological responses to restoration should be proportional to the size of the area. Should cumulative effects exist, the size of the response should be disproportionately larger at larger restoration sites (Figure B10). A proportional relationship between environmental responses $\left(y_{i}\right)$ and restoration area $\left(A_{i}\right)$ can be written as

$$
E\left(y_{i}\right)=\alpha A_{i}
$$

versus

$$
E\left(y_{i}\right)=\alpha A_{i}^{\beta}
$$

for an exponential response. In this case, a test of cumulative effects is equivalent to the one-tailed test

$$
\begin{aligned}
& \mathrm{H}_{\mathrm{o}}: \beta \leq 1 \\
& \mathrm{H}_{\mathrm{a}}: \beta>1 .
\end{aligned}
$$

The study design would consist of multiple restoration sites of different sizes restored at the same time and monitored over time. Log-linear regression of response versus size could then be used to test the significance of the slope term (i.e., $\beta$ ) some years post-restoration. 


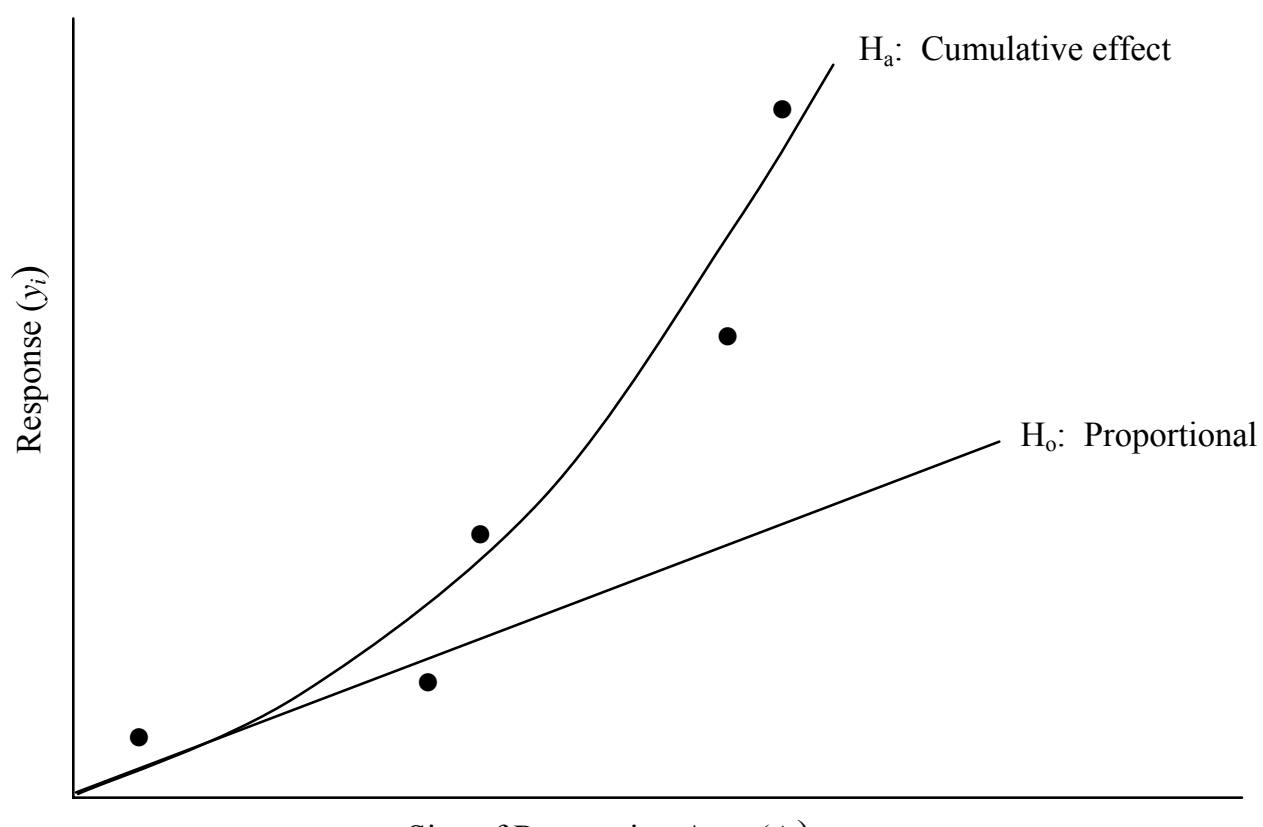

Size of Restoration Area $\left(A_{i}\right)$

Figure B.10. Hypothetical Relationships between the Magnitude of Environmental Response and Size of the Restoration Area Under the Null $\left(\mathrm{H}_{\mathrm{o}}\right.$ : Proportionality) and Alternative $\left(\mathrm{H}_{\mathrm{a}}\right)$ Hypotheses of Cumulative Effects

\section{$\underline{\text { Relating Cumulative Response to Clusters of Restorations }}$}

Analogous to project size, cumulative effects may occur as restoration events become more and more spatially clustered together. A single restoration event has little or no opportunity to benefit from mutual interactions with neighboring sites. On the other hand, neighboring restoration activities may benefit from interaction and mutual feedback to produce cumulative effects greater than the sum of the individual projects. If true, the average response per restoration project should increase as the cluster size of the projects increases (Figure B11).

In this scenario, the experimental design would consist of restoration clusters of size 1, 2, 3, and more together. Ideally, these different project clusters would be initiated concurrently to eliminate confounding size with duration or time. The clusters of projects of different sizes would be replicated and randomized within the estuary. The test of cumulative effects would be based on the null hypotheses

$$
\mathrm{H}_{\mathrm{o}}: \beta \leq 0 \text {, versus } \quad \mathrm{H}_{\mathrm{a}}: \beta>0,
$$

where $\beta$ is the slope of the relationship, $\bar{y}_{i}=\alpha+\beta n_{i}$, and where

$$
\begin{aligned}
& \bar{y}_{i}=\text { mean response per project within the } i \text { th cluster, } \\
& n_{i}=\text { number of restoration projects in the } i \text { th cluster. }
\end{aligned}
$$

A significant positive slope would be evidence of cumulative effects. 


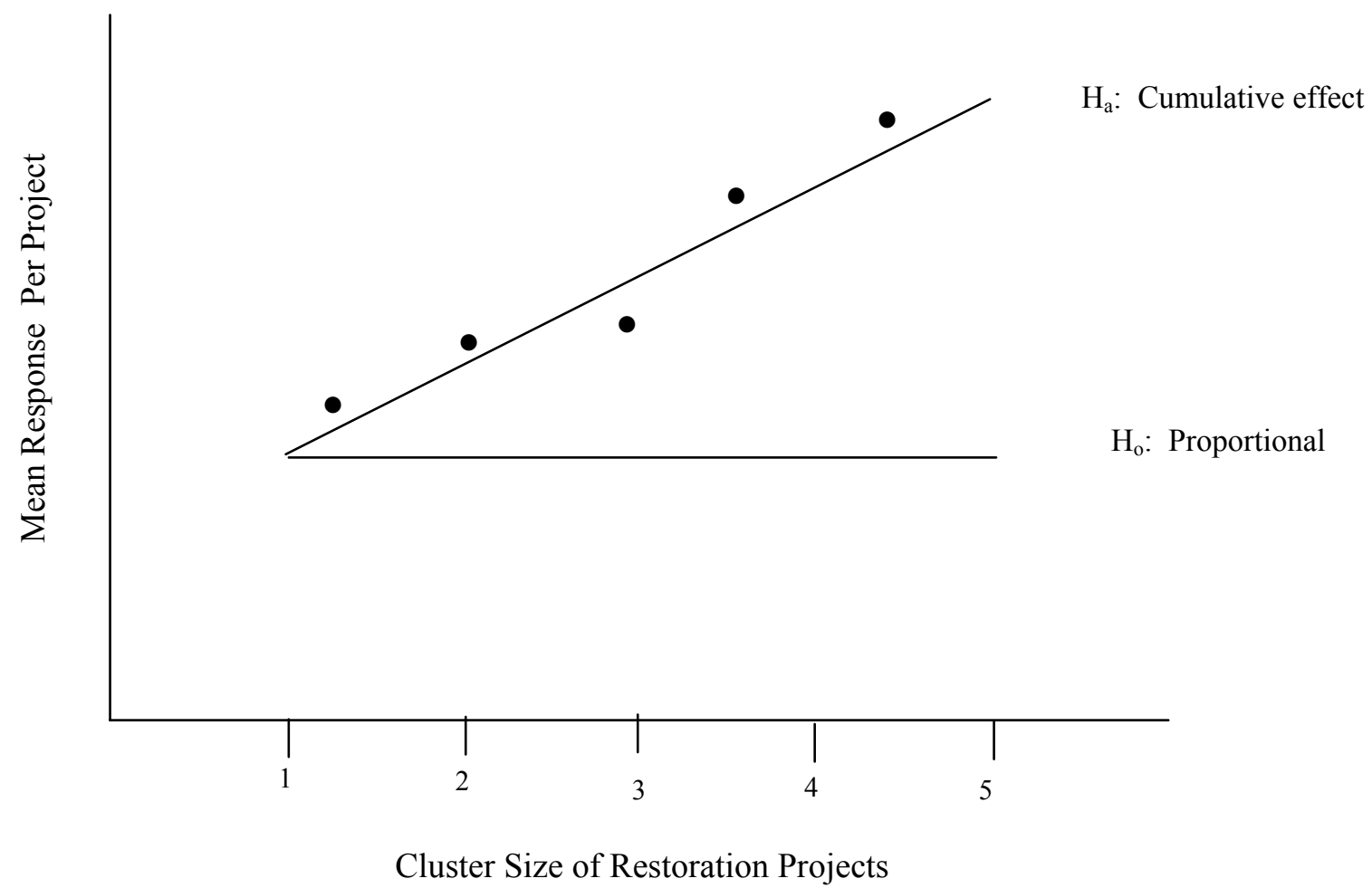

Figure B11. Hypothetical relationship between numbers of restoration projects in a cluster and mean responses per project under the null $\left(\mathrm{H}_{\mathrm{o}}\right.$ : no relationship) and alternative $\left(\mathrm{H}_{\mathrm{a}}\right)$ hypotheses of cumulative effects.

\section{$\underline{\text { Relating Cumulative Responses to Temporal Trend in Restoration Events }}$}

As time progresses, an isolated restoration site may be joined by new sites in the vicinity that are also restored. The temporal pattern of site response may therefore be altered by these neighboring events. Cumulative effects may be evident if the equilibrium state of a site increases with such subsequent neighboring restoration events (Figure B12a). The experimental design would consist of a series of replicate restoration events in isolation. Restoration processes would be allowed to reach a new level of equilibrium response before another restoration event in the near vicinity was allowed to occur. A random sample of these sites would then be selected for nearby intervention; the rest would remain in isolation. The working hypothesis is that response output from the sites with a nearby restoration would increase compared to sites in isolation. The statistical test of cumulative effects would be based on a time-by-treatment interaction. The design could be augmented with additional restoration activities over the course of time and the expectations of additive shifts in site productivity (Figure B12b). A staircase design (Walters et al. 1988) is illustrated in Figure B12b. Intervention could be coincidentally confounded by other environmental perturbations leading to false conclusions. Walters et al. (1988) suggest using a staircase design where the treatment is staggered over time at different experimental units. The idea is that if the treatment response is observed repeatedly over time, regardless of onset, it is unlikely that extraneous factors are responsible. Since the staging of restoration activities may be outside of experimental control, a staircase design may occur by default if not design. 


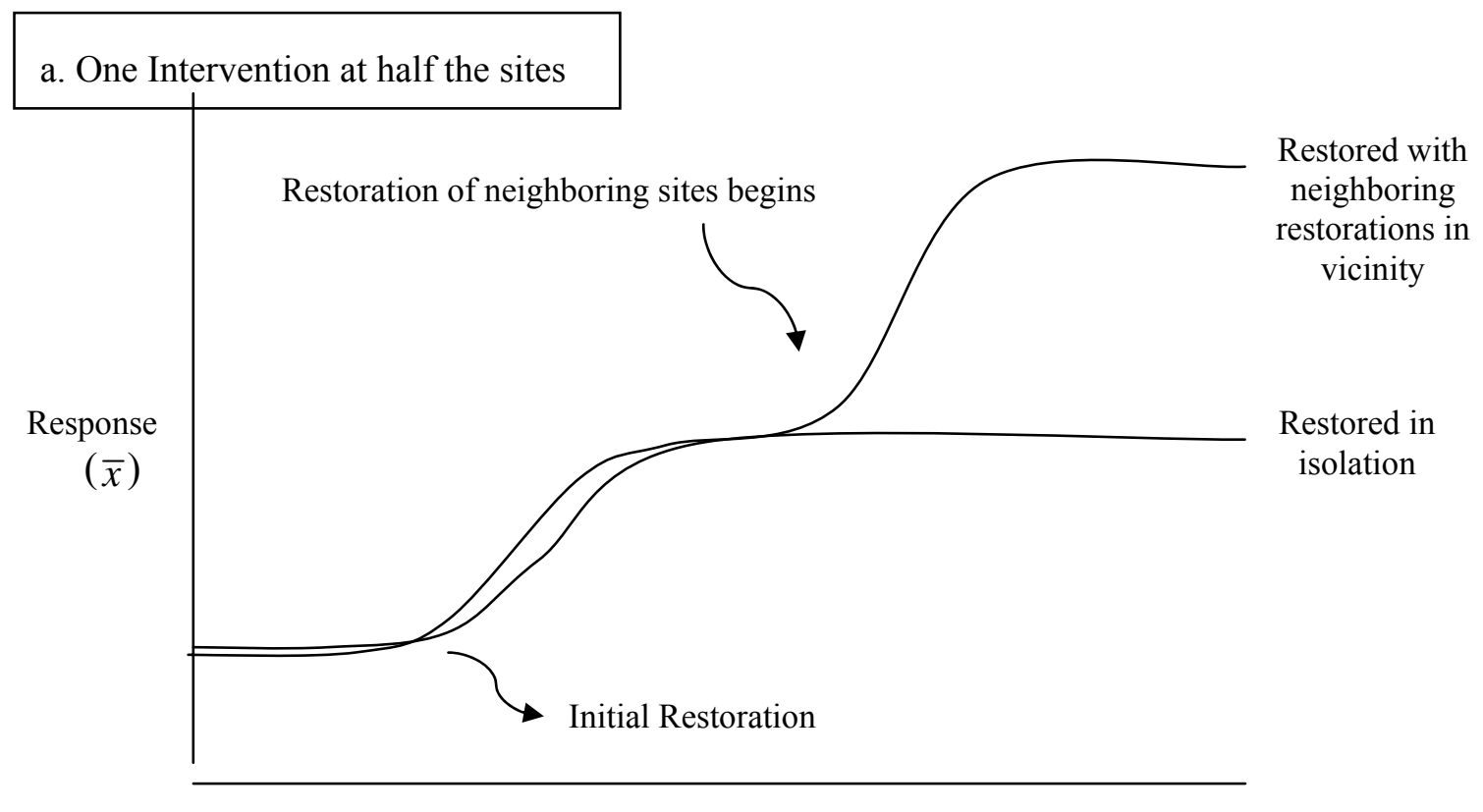

Time

\section{b. Two Interventions}

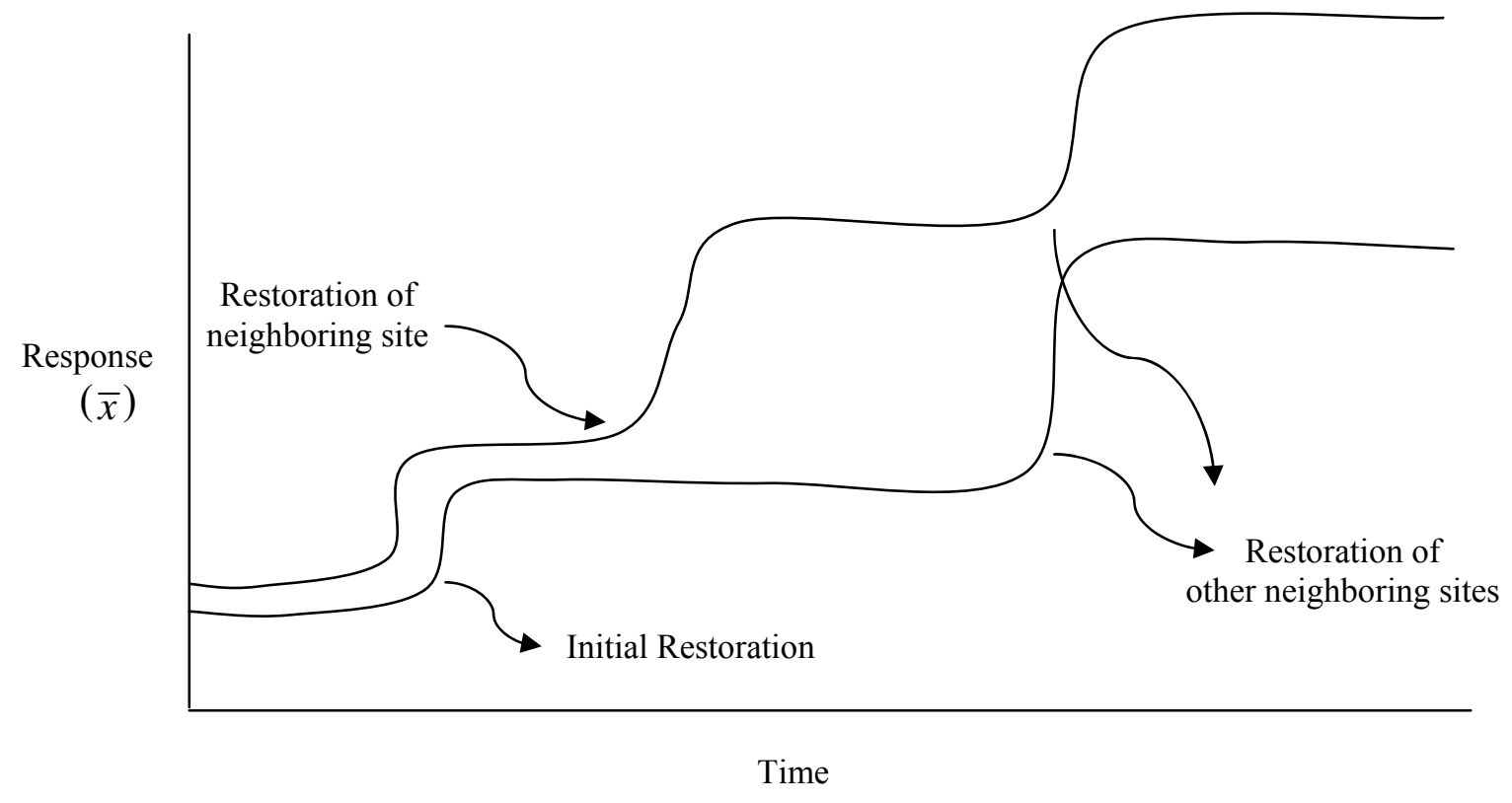

Figure B 12a-b. Hypothetical relationship between temporal patterns of site response to one (a) and more (b) interventions at nearby restoration sites.

\section{B.2.6 Regional Perspective}

In practice, there will be a myriad of restoration projects. Some of these projects may receive formal and structured site-specific effectiveness evaluations. However, the cost of such studies is relatively high, 
so the number of such studies may be small. Meta-analysis will therefore be used to determine the consistency of effectiveness across studies as a whole. If enough individual assessment studies exist, it may be possible to identify those factors shared by successful restoration and those traits common to failed attempts. Results of the meta-analysis would provide an overall assessment of the effectiveness of restoration projects and provide guidance on which proposed sites and methods have the greatest chance of succeeding.

The replicate restoration-reference design is another option for regional assessment of the effectiveness of restoration projects. The replicate approach requires more deliberate action to implement than the meta-analysis of historical restorations but may benefit from less heterogeneity and greater sample sizes. There would be a direct cost in performing an intentional replicated restoration-reference investigation. Neither the opportunistic or planned replicated investigation, however, will provide direct information on synergistic effects. These meta-analyses will instead determine on average whether restoration activities are beneficial or not.

\section{B.2.7 Summary - Action Effectiveness Research}

The overall objective of action effectiveness research (AER) is to use a representative set of projects to monitor and evaluate the effects of habitat restoration actions in the estuary. The specific AER objectives address effectiveness and validation monitoring utilizing a suite of reference sites. (Implementation monitoring is covered in Section 4.1.4.) To efficiently assess the effectiveness of habitat restoration actions on the Columbia River estuary and to meet the AER objectives, pertinent elements of the datasets developed through status and trends monitoring, implementation and compliance monitoring, and restoration project-specific monitoring will be subjected to analysis, synthesis, and evaluation. A network of reference sites will be crucial to this effort. Data collection methods for action effectiveness, the spatial and temporal scale of monitoring, and example protocols are provided in Appendix C. Action effectiveness research in the CRE is important because it will show the ecological results from the primary management action in the CRE -- habitat restoration. This knowledge, when integrated with results from status and trends monitoring and uncertainties research, will help guide future management actions. The research and monitoring framework for action effectiveness research in the estuary RME is consistent with the monitoring recommendations under the Estuary Restoration Act (Thayer et al. 2003; 2005). 
Research, Monitoring, and Evaluation for the Federal Columbia River Estuary Program 


\section{Appendix C: Methods and Protocols}

Four guiding principles were applied in the selection of methods for the monitored attributes in the estuary. First, methods that have been developed for or applied in the Columbia River estuary were sought because of the importance of regional specificity and the significance of existing baseline data collected in accordance with these methods. Second, consistency with Hillman and Giorgi (2002) and Hillman (2004) was valued because of the importance of basin-wide evaluations synthesizing indicators in both tributary habitat and the estuary, although Hillman (2004) does not categorize uncertainties research in a separate research plan. Third, to establish the credibility of the planned monitoring program, published peer-reviewed methods were favored, as were those currently in use and accepted in the scientific community. Fourth, in the absence of a comprehensive set of protocols developed specifically for the estuary ${ }^{\mathrm{a}}$, existing protocols developed and tested through long-term monitoring programs on the West Coast were relied on heavily. Cost constraints are the final consideration which must be addressed through a balanced combination of extensive and intensive sampling (Section 2.3).

Projects to standardize monitoring protocols for the estuary are occurring concurrent with development of this RME plan. In particular, a protocols manual by the USACE (Roegner et al. 2008) describes specific sampling methods for the core recommended AER metrics (Section 2.2, Table 2). These methods are also applicable to status and trends monitoring. The Columbia River estuary protocols (Roegner et al. 2008) are tailored to monitoring the unique characteristics of the estuary and are intended to become standard in the estuary and their use wherever possible is recommended to assist in the development of a consistent estuary-wide data set.

Certain key sources were especially useful for the monitoring methods referenced in Table C-1. They include the Estuarine Habitat Assessment Protocol developed for the Puget Sound Estuary Program (Simenstad et al. 1991), which is used extensively in the Pacific Northwest. Rice et al. (2005) provided details on methods for sampling estuarine habitats in the Pacific Northwest useful for further reference in conjunction with Table C.1. For water quality parameters, the EPA and other standard methods utilized by the U.S. Geological Survey are recommended for consistency with historical data and other regional monitoring. Action effectiveness research protocols developed through a well-known long-term restoration monitoring research program in California and recently published in the Handbook for Restoring Tidal Wetlands (Zedler 2001) were also utilized (Callaway et al. 2001). In addition, the Monitoring Oversight Committee (2002b. p. 76) of the Washington State Salmon Recovery Funding Board recommended standardized protocols for action effectiveness research. Thayer et al. (2004) provided 12 steps to develop a project-specific monitoring plan.

\footnotetext{
${ }^{a}$ Monitoring and evaluation protocols for the estuary (Roegner wet al. 2008) are currently being developed via a project funded by USACE (EST-P-04-001).
} 
A major multi-agency effort to synthesize existing protocols for the inventory and monitoring of salmon habitat in the Pacific Northwest was also consulted for the recommendation of protocols in Table C1 (Johnson et al. 2001). Johnson et al. (2001) relies heavily on Simenstad et al. (1991) for estuary and nearshore marine monitoring protocols, and the majority of methods recommended by Johnson et al. (2001) are for tributaries. However, Johnson et al (2001) do recommend several protocols applicable to estuarine monitoring in the estuary, and the use of these protocols for estuary research would help to contribute to consistency in data throughout the region: Automated Water Quality Monitoring (British Columbia Ministry of Environmental Lands and Parks 1999) as well as the Oregon Plan for Salmon and Watersheds: Water Quality Monitoring Technical Guidebook (OPSW 1999); protocols for subtidal benthic macroinvertebrate assemblages in Puget Sound, which may require modification for the Columbia River estuary (Puget Sound Estuary Program 1987); the timber-fish-wildlife method for stream temperature surveys, which may be applicable in temperature studies of tidal channels (Schuett-Hames 1999); a guide to photographic documentation for aquatic inventory (Osprey Environmental Services 1996); and a fish habitat description and assessment manual (Williams 1989). The EPA's EMAP study has also developed a Quality Assurance Project Plan, although modifications for application on the West Coast have not been published. And, the Washington State Salmon Recovery Funding Board is planning to develop estuary monitoring protocols.

Methods for measuring the monitored attributes at the ecosystem and habitat/population levels are listed in Table C.1. As a rule of thumb, to the extent possible, data on the monitored attributes involving salmonid populations should be differentiated with respect to life history, origin (hatchery or wild), and ESU. Both the monitored attributes and the methods developed for the estuary will require additional research establishing their suitability before final selection for estuary RME. The appropriate spatial scale for applying each method is also suggested in Table C-1. For example, "site specific" refers to project implementation and effectiveness sampling at restoration and reference sites, while "CRE" refers to general estuarine sampling not linked to a specific project. While project performance criteria will of necessity be developed on a project-by-project basis to appropriately reflect each unique site, the methods and attributes labeled "site specific" in Table C-1 are recommended for post-restoration monitoring. The terminology in the methods table (Table $\mathrm{C}-1$ ) has the following working definitions:

- Geographic (Spatial) Scale - The spatial extent over which sampling or analysis will occur. CRE is only the Columbia River estuary, including the plume.

- Temporal Scale-Frequency - How often the sampling or analysis will be performed.

- Data Collection Method - The primary technique used to collect the data.

- Example Protocol/Data Source - Reference where the data collection method was described.

- Use in Status Monitoring - How the data applies to status monitoring.

- Use in Action Effectiveness Research - How the data applies to action effectiveness research.

- Site Specific - Means "restoration" sites and includes both restoration and reference sites. 
Table C.1. Methods to Measure the Monitored Indicators. The terminology is defined in the text above.

\begin{tabular}{|c|c|c|c|c|c|c|c|}
\hline Category & $\begin{array}{l}\text { Monitored } \\
\text { Indicator(s) }\end{array}$ & Description & Description 2 & $\begin{array}{l}\text { Data Collection } \\
\text { Method }\end{array}$ & Example Protocol & $\begin{array}{l}\text { Use in Status } \\
\text { Monitoring }\end{array}$ & $\begin{array}{l}\text { Use in Action } \\
\text { Effectiveness } \\
\text { Research }\end{array}$ \\
\hline Flow Regulation & Water Discharge & $\begin{array}{l}\text { Water volume } \\
\text { per unit time }\end{array}$ & $\begin{array}{l}\text { Daily mean } \\
\text { streamflow at } \\
\text { Beaver for the } \\
\text { CRE }\end{array}$ & Stream gauge & $\begin{array}{l}\text { DART } \\
\text { (www.cqs.washingt } \\
\text { on.edu/dart/) }\end{array}$ & $\begin{array}{l}\text { Provide } \\
\text { context } \\
\text { regarding } \\
\text { environmental } \\
\text { conditions }\end{array}$ & $\begin{array}{l}\text { Provide context } \\
\text { regarding } \\
\text { environmental } \\
\text { conditions }\end{array}$ \\
\hline Diking & Passage Barriers & $\begin{array}{l}\text { Restrict access } \\
\text { by salmon to } \\
\text { wetland } \\
\text { habitats. } \\
\text { Barriers } \\
\text { include dikes, } \\
\text { levees, } \\
\text { tidegates, } \\
\text { culverts. }\end{array}$ & $\begin{array}{l}\text { Number and } \\
\text { location of tide } \\
\text { gates, culverts, } \\
\text { plugs, and other } \\
\text { barriers or } \\
\text { constrictions }\end{array}$ & $\begin{array}{l}\text { Use GIS to record } \\
\text { number removed/ } \\
\text { length of new area } \\
\text { available }\end{array}$ & $\begin{array}{l}\text { Osprey } \\
\text { Environmental } \\
\text { Services } 1996\end{array}$ & $\begin{array}{l}\text { Show trends in } \\
\text { the number of } \\
\text { barriers }\end{array}$ & $\begin{array}{l}\text { Barrier removal or } \\
\text { modification is a } \\
\text { common action }\end{array}$ \\
\hline Invasive Species & $\begin{array}{l}\text { Species Composition, } \\
\text { Abundance, Spatial } \\
\text { Distribution }\end{array}$ & $\begin{array}{l}\text { Invasive } \\
\text { species can } \\
\text { inhibit or } \\
\text { prevent the } \\
\text { restoration of } \\
\text { habitat quality } \\
\text { and quantity } \\
\text { for native } \\
\text { species by } \\
\text { preying on } \\
\text { juvenile } \\
\text { salmonids, } \\
\text { competing for } \\
\text { prey, } \\
\text { decreasing } \\
\text { diversity, and } \\
\text { limiting habitat } \\
\text { availability. }\end{array}$ & $\begin{array}{l}\text { Presence/absenc } \\
\text { e, Location and } \\
\text { timing, } \\
\text { Population size }\end{array}$ & Site surveys & $\begin{array}{l}\text { Waldeck et al. } \\
\text { 2003; Cohen et al. } \\
\text { 2001: Systema et al. } \\
2004\end{array}$ & Trends & $\begin{array}{l}\text { Restoration actions } \\
\text { could effect plant } \\
\text { communities - } \\
\text { hopefully driving } \\
\text { out things like reed } \\
\text { canary grass for } \\
\text { native plants more } \\
\text { beneficial to the } \\
\text { food web and } \\
\text { salmonids }\end{array}$ \\
\hline $\begin{array}{l}\text { Ocean } \\
\text { Conditions }\end{array}$ & $\begin{array}{l}\text { Upwelling Index, PDO } \\
\text { Index, ENSO Index, }\end{array}$ & $\begin{array}{l}\text { These } \\
\text { indicators }\end{array}$ & $\begin{array}{l}\text { Temporal and } \\
\text { spatial }\end{array}$ & $\begin{array}{l}\text { Track work of } \\
\text { others }\end{array}$ & $\begin{array}{l}\text { Schabetsberger, et } \\
\text { al. In Press }\end{array}$ & $\begin{array}{l}\text { Provide } \\
\text { context }\end{array}$ & $\begin{array}{l}\text { Provide context } \\
\text { regarding }\end{array}$ \\
\hline
\end{tabular}




\begin{tabular}{|c|c|c|c|c|c|c|c|}
\hline Category & $\begin{array}{l}\text { Monitored } \\
\text { Indicator(s) }\end{array}$ & Description & Description 2 & $\begin{array}{l}\text { Data Collection } \\
\text { Method }\end{array}$ & Example Protocol & $\begin{array}{l}\text { Use in Status } \\
\text { Monitoring }\end{array}$ & $\begin{array}{l}\text { Use in Action } \\
\text { Effectiveness } \\
\text { Research }\end{array}$ \\
\hline & \multirow[t]{6}{*}{$\begin{array}{l}\text { Zooplankton Index, } \\
\text { Hake Index }\end{array}$} & \multirow{6}{*}{$\begin{array}{l}\text { characterize } \\
\text { conditions in } \\
\text { the nearshore } \\
\text { ocean, a key } \\
\text { habitat because } \\
\text { of ecological } \\
\text { interconnectio } \\
\text { ns between } \\
\text { estuary and } \\
\text { ocean due to } \\
\text { ocean currents, } \\
\text { tides, and river } \\
\text { discharge. }\end{array}$} & $\begin{array}{l}\text { distributions and } \\
\text { abundance }\end{array}$ & & & \multirow{6}{*}{$\begin{array}{l}\text { regarding } \\
\text { environmental } \\
\text { conditions }\end{array}$} & \multirow[t]{6}{*}{$\begin{array}{l}\text { environmental } \\
\text { conditions }\end{array}$} \\
\hline & & & $\begin{array}{l}\text { Species } \\
\text { composition and } \\
\text { density }\end{array}$ & & $\begin{array}{l}\text { Dawley et al. } \\
\text { 1985ab; Emmett et } \\
\text { al. In Press }\end{array}$ & & \\
\hline & & & $\begin{array}{l}\text { Species } \\
\text { composition and } \\
\text { density }\end{array}$ & & Peterson et al. 2002 & & \\
\hline & & & $\begin{array}{l}\text { Water } \\
\text { temperature in } \\
\text { surface layer }\end{array}$ & & $\begin{array}{l}\text { www.pmel.noass.g } \\
\text { ov/t tao/elnino }\end{array}$ & & \\
\hline & & & $\begin{array}{l}\text { Stage of the } \\
\text { Pacific decadal } \\
\text { oscillation }\end{array}$ & & $\begin{array}{l}\text { Mantua et al. 1997; } \\
\text { Schwing et al. In } \\
\text { Press } \\
\text { http://www.pfeg.no } \\
\text { aa.gov/ } \\
\text { products/PFEL/mo } \\
\text { deled/indices/ } \\
\text { NOIx/noix.html }\end{array}$ & & \\
\hline & & & $\begin{array}{l}\text { Index of } \\
\text { upwelling }\end{array}$ & & $\begin{array}{l}\text { http://www.pfeg.no } \\
\text { aa.gov/ } \\
\text { products/PFEL/mo } \\
\text { deled/indices/ } \\
\text { upwelling/upwellin } \\
\text { g.html }\end{array}$ & & \\
\hline $\begin{array}{l}\text { Regional Climate } \\
\text { Change }\end{array}$ & Sea Level, Snowpack & $\begin{array}{l}\text { Estuarine } \\
\text { effects of } \\
\text { global climate } \\
\text { change via } \\
\text { Cascade } \\
\text { Mountains and } \\
\text { Pacific Ocean } \\
\end{array}$ & & $\begin{array}{l}\text { Track work of } \\
\text { others }\end{array}$ & & & \\
\hline $\begin{array}{l}\text { Watershed } \\
\text { Conditions }\end{array}$ & $\begin{array}{l}\text { Discharge, Water } \\
\text { Velocity/Temperature, } \\
\text { Sediment Budget, } \\
\text { Large Woody Debris }\end{array}$ & $\begin{array}{l}\text { Effects of } \\
\text { estuary } \\
\text { tributary } \\
\text { watersheds on } \\
\text { floodplain } \\
\end{array}$ & & $\begin{array}{l}\text { Track work of } \\
\text { others }\end{array}$ & & & \\
\hline
\end{tabular}




\begin{tabular}{|c|c|c|c|c|c|c|c|}
\hline Category & $\begin{array}{l}\text { Monitored } \\
\text { Indicator(s) }\end{array}$ & Description & Description 2 & $\begin{array}{l}\text { Data Collection } \\
\text { Method }\end{array}$ & Example Protocol & $\begin{array}{l}\text { Use in Status } \\
\text { Monitoring }\end{array}$ & $\begin{array}{l}\text { Use in Action } \\
\text { Effectiveness } \\
\text { Research }\end{array}$ \\
\hline & & habitats. & & & & & \\
\hline $\begin{array}{l}\text { Geology/ } \\
\text { Sediments }\end{array}$ & Accretion Rates & $\begin{array}{l}\text { Reveals } \\
\text { sedimentation } \\
\text { rates from } \\
\text { measurements } \\
\text { of prehistoric, } \\
\text { early historic, } \\
\text { pre-diking, } \\
\text { post-diking, } \\
\text { and post } \\
\text { restoration. }\end{array}$ & $\mathrm{mm} / \mathrm{yr}$ & $\begin{array}{l}\text { Sediment } \\
\text { elevation table or } \\
\text { Marker horizon }\end{array}$ & $\begin{array}{l}\text { Callaway et al. } \\
2001\end{array}$ & $\mathrm{~N} / \mathrm{A}$ & $\begin{array}{l}\text { Monitor to assess } \\
\text { effects of actions, } \\
\text { depending on } \\
\text { project objectives }\end{array}$ \\
\hline $\begin{array}{l}\text { Geology/ } \\
\text { Sediments }\end{array}$ & Contaminants & $\begin{array}{l}\text { Need to select } \\
\text { indicator } \\
\text { toxins, and } \\
\text { assess fish } \\
\text { tissue and } \\
\text { body burden. } \\
\text { Possibilities } \\
\text { include } \\
\text { mercury and } \\
\text { PCBs. }\end{array}$ & $\begin{array}{l}\text { Contaminants, } \\
\text { trace elements, } \\
\text { pesticides }\end{array}$ & Various & $\begin{array}{l}\text { Standard EPA } \\
\text { Methods (EPA } \\
\text { 1991, Fuhrer 1996) }\end{array}$ & $\begin{array}{l}\text { Routine } \\
\text { monitoring for } \\
\text { trends }\end{array}$ & $\begin{array}{l}\text { Restoration work } \\
\text { could release toxics } \\
\text { from the sediments } \\
\text { or held behind } \\
\text { dikes and thus } \\
\text { impact salmonids. }\end{array}$ \\
\hline $\begin{array}{l}\text { Geology/ } \\
\text { Sediments }\end{array}$ & Redox Potential & $\begin{array}{l}\text { Measured from } \\
\text { pore water at } \\
\text { selected sites } \\
\text { and used to } \\
\text { evaluate } \\
\text { organic } \\
\text { accumulation. }\end{array}$ & $\begin{array}{l}\text { Ability to } \\
\text { support } \\
\text { vegetation }\end{array}$ & Redox Electrode & $\begin{array}{l}\text { Callaway et al. } \\
2001\end{array}$ & $\mathrm{~N} / \mathrm{A}$ & $\begin{array}{l}\text { Monitor to assess } \\
\text { effects of actions, } \\
\text { depending on } \\
\text { project objectives }\end{array}$ \\
\hline $\begin{array}{l}\text { Geology/ } \\
\text { Sediments }\end{array}$ & $\begin{array}{l}\text { Soil Composition } \\
\text { (grain size, organic } \\
\text { matter) }\end{array}$ & & $\begin{array}{l}\text { Dominant soil } \\
\text { type and } \\
\text { composition } \\
\text { (grain size, } \\
\text { percent organic } \\
\text { matter) }\end{array}$ & Core samples & $\begin{array}{l}\text { Standard EPA } \\
\text { Methods (EPA } \\
\text { 1991); Rice et al. In } \\
\text { Preparation }\end{array}$ & $\mathrm{N} / \mathrm{A}$ & $\begin{array}{l}\text { Monitor to assess } \\
\text { effects of actions, } \\
\text { depending on } \\
\text { project objectives }\end{array}$ \\
\hline Hydrodynamics & Ground Water Level & & $\begin{array}{l}\text { Plant } \\
\text { community } \\
\text { potential; fish }\end{array}$ & $\begin{array}{l}\text { Piezometer or } \\
\text { water level } \\
\text { recorder; pressure }\end{array}$ & $\begin{array}{l}\text { Callaway et al. } \\
2001\end{array}$ & $\mathrm{~N} / \mathrm{A}$ & $\begin{array}{l}\text { Monitor to assess } \\
\text { effects of actions, } \\
\text { depending on }\end{array}$ \\
\hline
\end{tabular}




\begin{tabular}{|c|c|c|c|c|c|c|c|}
\hline Category & $\begin{array}{l}\text { Monitored } \\
\text { Indicator(s) }\end{array}$ & Description & Description 2 & $\begin{array}{l}\text { Data Collection } \\
\text { Method }\end{array}$ & Example Protocol & $\begin{array}{l}\text { Use in Status } \\
\text { Monitoring }\end{array}$ & $\begin{array}{l}\text { Use in Action } \\
\text { Effectiveness } \\
\text { Research }\end{array}$ \\
\hline & & & habitat potential & transducer & & & project objectives \\
\hline Hydrodynamics & $\begin{array}{l}\text { Surface Water } \\
\text { Elevation }\end{array}$ & & $\begin{array}{l}\text { Percentage of } \\
\text { time and } \\
\text { frequency a site } \\
\text { is covered with } \\
\text { water }\end{array}$ & $\begin{array}{l}\text { Data logger or } \\
\text { water collector }\end{array}$ & $\begin{array}{l}\text { Callaway et al. } \\
2001\end{array}$ & $\mathrm{~N} / \mathrm{A}$ & $\begin{array}{l}\text { Monitor to assess } \\
\text { effects of actions, } \\
\text { depending on } \\
\text { project objectives }\end{array}$ \\
\hline Hydrodynamics & $\begin{array}{l}\text { Water Velocity } \\
\text { (currents) }\end{array}$ & $\begin{array}{l}\text { Currents are } \\
\text { the rates and } \\
\text { patterns of } \\
\text { water } \\
\text { movement. }\end{array}$ & $\mathrm{cm} / \mathrm{sec}$ & $\begin{array}{l}\text { Flow Meter; } \\
\text { Timed float }\end{array}$ & $\begin{array}{l}\text { Callaway et al. } \\
2001\end{array}$ & $\mathrm{~N} / \mathrm{A}$ & $\begin{array}{l}\text { Monitor to assess } \\
\text { effects of actions, } \\
\text { depending on } \\
\text { project objectives }\end{array}$ \\
\hline $\begin{array}{l}\text { Bathymetry/ } \\
\text { Topography }\end{array}$ & Bathymetry & $\begin{array}{l}\text { Bathymetry is } \\
\text { a collection of } \\
\text { depth points } \\
\text { that represent } \\
\text { the gradients } \\
\text { of elevation } \\
\text { and depth } \\
\text { change along a } \\
\text { surface. }\end{array}$ & $\begin{array}{l}\text { Bottom } \\
\text { elevations }\end{array}$ & $\begin{array}{l}\text { Multibeam sonar } \\
\text { bottom mapping; } \\
\text { LIDAR (shallow } \\
\text { waters if feasible) }\end{array}$ & $\begin{array}{l}\text { Multibeam - Bates } \\
\text { and Byham 2001; } \\
\text { LIDAR - Brock et } \\
\text { al. 2002; Sallenger } \\
\text { et al. } 2003\end{array}$ & $\begin{array}{l}\text { Trends in } \\
\text { bathymetry } \\
\text { over time }\end{array}$ & $\begin{array}{l}\text { Characterize } \\
\text { changes in } \\
\text { bathymetry before } \\
\text { and after action at a } \\
\text { specific site }\end{array}$ \\
\hline $\begin{array}{l}\text { Bathymetry/ } \\
\text { Topography }\end{array}$ & $\begin{array}{l}\text { Floodplain } \\
\text { Topography }\end{array}$ & $\begin{array}{l}\text { Topography } \\
\text { measures of } \\
\text { the height of a } \\
\text { point on the } \\
\text { surface of the } \\
\text { sediment or } \\
\text { soil of a } \\
\text { location, } \\
\text { expressed } \\
\text { relative to a } \\
\text { datum point }\end{array}$ & $\begin{array}{l}\text { Surface } \\
\text { elevations; } \\
\text { accretion; } \\
\text { channel } \\
\text { hydraulic } \\
\text { geometry; tidal } \\
\text { prism }\end{array}$ & LIDAR survey & $\begin{array}{l}\text { Haugarud and } \\
\text { Harding } 2002 ; \\
\text { Bowen and } \\
\text { Waltermire } 2002 ; \\
\text { Williams et al. } \\
\text { 2002; Callaway et } \\
\text { al. } 2001\end{array}$ & $\begin{array}{l}\text { Trends in } \\
\text { topography } \\
\text { over time }\end{array}$ & $\begin{array}{l}\text { Characterize } \\
\text { changes in } \\
\text { topography before } \\
\text { and after action at a } \\
\text { specific site }\end{array}$ \\
\hline Water Quality & Dissolved Oxygen & $\begin{array}{l}\text { The amount of } \\
\text { oxygen in } \\
\text { solution in the } \\
\text { water }\end{array}$ & $\begin{array}{l}\text { Maximum daily } \\
\text { maximum and } \\
\text { maximum } \\
\text { weekly } \\
\text { maximum }\end{array}$ & $\begin{array}{l}\text { Data logging } \\
\text { equipment }\end{array}$ & $\begin{array}{l}\text { Callaway et al } \\
\text { 2001; YSI } \\
\text { (http://www.ysi.co } \\
\text { m/index.html); } \\
\text { OPSW 1999; } \\
\text { British Columbia }\end{array}$ & $\begin{array}{l}\text { Routine } \\
\text { monitoring for } \\
\text { trends; } \\
\text { benchmark } \\
\text { indicators for } \\
\text { estuaries TBD }\end{array}$ & $\begin{array}{l}\text { Monitor to assess } \\
\text { effects of actions, } \\
\text { depending on } \\
\text { project objectives }\end{array}$ \\
\hline
\end{tabular}




\begin{tabular}{|c|c|c|c|c|c|c|c|}
\hline Category & $\begin{array}{l}\text { Monitored } \\
\text { Indicator(s) }\end{array}$ & Description & Description 2 & $\begin{array}{l}\text { Data Collection } \\
\text { Method }\end{array}$ & Example Protocol & $\begin{array}{l}\text { Use in Status } \\
\text { Monitoring }\end{array}$ & $\begin{array}{l}\text { Use in Action } \\
\text { Effectiveness } \\
\text { Research }\end{array}$ \\
\hline & & & & & $\begin{array}{l}\text { Ministry of } \\
\text { Environmental } \\
\text { Lands and Parks } \\
\text { 1999; Schuett- } \\
\text { Hames 1999; } \\
\text { National Estuarine } \\
\text { Research Reserve } \\
\text { System 2004 }\end{array}$ & $\begin{array}{l}\text { under MOC } \\
2002 \mathrm{~b}\end{array}$ & \\
\hline Water Quality & $\begin{array}{l}\text { Nutrients (nitrogen, } \\
\text { phosphorous) }\end{array}$ & $\begin{array}{l}\text { Nutrients are } \\
\text { inorganic } \\
\text { chemical } \\
\text { constituents } \\
\text { needed for } \\
\text { plant and } \\
\text { animal growth. }\end{array}$ & $\begin{array}{l}\text { Total nitrogen, } \\
\text { total suspended } \\
\text { nitrogen, } \\
\text { ammonia, } \\
\text { nitrite, nitrite + } \\
\text { nitrate, total } \\
\text { phosphorus, } \\
\text { orthophosphate, } \\
\text { dissolved } \\
\text { organic carbon, } \\
\text { suspended } \\
\text { organic carbon, } \\
\text { and inorganic } \\
\text { suspended } \\
\text { carbon. }\end{array}$ & $\begin{array}{l}\text { Spectropho- } \\
\text { tometer or } \\
\text { autoanalyzer }\end{array}$ & $\begin{array}{l}\text { Callaway et al. } \\
\text { 2001; OPSW 1999; } \\
\text { Standard EPA } \\
\text { Methods (EPA } \\
\text { 1991, Fuhrer 1996) }\end{array}$ & $\begin{array}{l}\text { Routine } \\
\text { monitoring for } \\
\text { trends }\end{array}$ & $\begin{array}{l}\text { Restoration work } \\
\text { may effect nutrient } \\
\text { availability and thus } \\
\text { primary } \\
\text { productivity - this } \\
\text { could have either } \\
\text { positive or negative } \\
\text { impacts on the food } \\
\text { web and thus affect } \\
\text { salmonid feeding. }\end{array}$ \\
\hline Water Quality & $\mathrm{pH}$ & $\begin{array}{l}\text { The acidity of } \\
\text { the water. }\end{array}$ & $\begin{array}{l}\text { Maximum daily } \\
\text { maximum and } \\
\text { maximum } \\
\text { weekly } \\
\text { maximum }\end{array}$ & $\begin{array}{l}\text { Data logging } \\
\text { equipment }\end{array}$ & $\begin{array}{l}\text { Callaway et al } \\
\text { 2001; YSI } \\
\text { (http://www.ysi.co } \\
\text { m/index.html); } \\
\text { OPSW 1999; } \\
\text { British Columbia } \\
\text { Ministry of } \\
\text { Environmental } \\
\text { Lands and Parks } \\
\text { 1999; Schuett- } \\
\text { Hames 1999; } \\
\text { National Estuarine } \\
\text { Research Reserve } \\
\text { System 2004 }\end{array}$ & $\begin{array}{l}\text { Routine } \\
\text { monitoring for } \\
\text { trends; } \\
\text { benchmark } \\
\text { indicators for } \\
\text { estuaries TBD } \\
\text { under MOC } \\
\text { 2002b }\end{array}$ & $\begin{array}{l}\text { Monitor to assess } \\
\text { effects of actions, } \\
\text { depending on } \\
\text { project objectives }\end{array}$ \\
\hline
\end{tabular}




\begin{tabular}{|c|c|c|c|c|c|c|c|}
\hline Category & $\begin{array}{l}\text { Monitored } \\
\text { Indicator(s) }\end{array}$ & Description & Description 2 & $\begin{array}{l}\text { Data Collection } \\
\text { Method }\end{array}$ & Example Protocol & $\begin{array}{l}\text { Use in Status } \\
\text { Monitoring }\end{array}$ & $\begin{array}{l}\text { Use in Action } \\
\text { Effectiveness } \\
\text { Research }\end{array}$ \\
\hline Water Quality & Salinity & $\begin{array}{l}\text { The } \\
\text { concentration } \\
\text { of salts in the } \\
\text { water }\end{array}$ & $\begin{array}{l}\text { Maximum daily } \\
\text { maximum and } \\
\text { maximum } \\
\text { weekly } \\
\text { maximum }\end{array}$ & $\begin{array}{l}\text { Data logging } \\
\text { equipment }\end{array}$ & $\begin{array}{l}\text { Callaway et al } \\
\text { 2001; YSI } \\
\text { (http://www.ysi.co } \\
\text { m/index.html); } \\
\text { OPSW 1999; } \\
\text { British Columbia } \\
\text { Ministry of } \\
\text { Environmental } \\
\text { Lands and Parks } \\
\text { 1999; Schuett- } \\
\text { Hames 1999; } \\
\text { National Estuarine } \\
\text { Research Reserve } \\
\text { System 2004 }\end{array}$ & $\begin{array}{l}\text { Routine } \\
\text { monitoring for } \\
\text { trends; } \\
\text { benchmark } \\
\text { indicators for } \\
\text { estuaries TBD } \\
\text { under MOC } \\
\text { 2002b }\end{array}$ & $\begin{array}{l}\text { Monitor to assess } \\
\text { effects of actions, } \\
\text { depending on } \\
\text { project objectives }\end{array}$ \\
\hline Temperature & Temperature & $\begin{array}{l}\text { A measure that } \\
\text { expresses the } \\
\text { temporal and } \\
\text { spatial } \\
\text { dynamics of } \\
\text { the thermal } \\
\text { energy content } \\
\text { of the air and } \\
\text { water. }\end{array}$ & $\begin{array}{l}\text { Maximum daily } \\
\text { maximum and } \\
\text { maximum } \\
\text { weekly } \\
\text { maximum }\end{array}$ & $\begin{array}{l}\text { Data logging } \\
\text { equipment }\end{array}$ & $\begin{array}{l}\text { Callaway et al } \\
\text { 2001; YSI } \\
\text { (http://www.ysi.co } \\
\text { m/index.html); } \\
\text { OPSW 1999; } \\
\text { British Columbia } \\
\text { Ministry of } \\
\text { Environmental } \\
\text { Lands and Parks } \\
\text { 1999; Schuett- } \\
\text { Hames 1999; } \\
\text { National Estuarine } \\
\text { Research Reserve } \\
\text { System 2004 }\end{array}$ & $\begin{array}{l}\text { Routine } \\
\text { monitoring for } \\
\text { trends; } \\
\text { benchmark } \\
\text { indicators for } \\
\text { estuaries TBD } \\
\text { under MOC } \\
\text { 2002b }\end{array}$ & $\begin{array}{l}\text { Monitor to assess } \\
\text { effects of actions, } \\
\text { depending on } \\
\text { project objectives }\end{array}$ \\
\hline Light & Light & $\begin{array}{l}\text { Light refers to } \\
\text { the solar } \\
\text { energy utilized } \\
\text { by plants in } \\
\text { photosynthesis. }\end{array}$ & & & & & \\
\hline $\begin{array}{l}\text { Landscape } \\
\text { Features }\end{array}$ & $\begin{array}{l}\text { Ecosystem Structures } \\
\text { Map }\end{array}$ & $\begin{array}{l}\text { Aerial Photos } \\
\text { and Photo } \\
\text { Points }\end{array}$ & & & & & \\
\hline Landscape & Area (Size) Restored & Provides a way & Tally of acres & Summary of & $\mathrm{N} / \mathrm{A}$ & N/A & Show cumulative \\
\hline
\end{tabular}




\begin{tabular}{|c|c|c|c|c|c|c|c|}
\hline Category & $\begin{array}{l}\text { Monitored } \\
\text { Indicator(s) }\end{array}$ & Description & Description 2 & $\begin{array}{l}\text { Data Collection } \\
\text { Method }\end{array}$ & Example Protocol & $\begin{array}{l}\text { Use in Status } \\
\text { Monitoring }\end{array}$ & $\begin{array}{l}\text { Use in Action } \\
\text { Effectiveness } \\
\text { Research }\end{array}$ \\
\hline Features & & $\begin{array}{l}\text { to track habitat } \\
\text { actions. }\end{array}$ & $\begin{array}{l}\text { protected, } \\
\text { conserved, } \\
\text { restored, } \\
\text { enhanced, or } \\
\text { created }\end{array}$ & $\begin{array}{l}\text { project records } \\
\text { and GIS analysis }\end{array}$ & & & $\begin{array}{l}\text { area affected by } \\
\text { restoration actions }\end{array}$ \\
\hline $\begin{array}{l}\text { Landscape } \\
\text { Features }\end{array}$ & Large Woody Debris & $\begin{array}{l}\text { Density by } \\
\text { diameter class }\end{array}$ & Pieces $/ \mathrm{km}$ & $\begin{array}{l}\text { Digital aerial } \\
\text { photo/hyperspectr } \\
\text { al imagery }\end{array}$ & $\begin{array}{l}\text { Finkbeiner 2003; } \\
\text { BURPTAC } 1999\end{array}$ & $\begin{array}{l}\text { Map and } \\
\text { trends in LWD }\end{array}$ & $\begin{array}{l}\text { Site characteri- } \\
\text { zation; impacts on } \\
\text { salmonids and other } \\
\text { fauna }\end{array}$ \\
\hline $\begin{array}{l}\text { Tidal Channel } \\
\text { Morphology }\end{array}$ & $\begin{array}{l}\text { Edge/Density/ } \\
\text { Sinuosity }\end{array}$ & $\begin{array}{l}\text { Provides an } \\
\text { interface for } \\
\text { transfer of } \\
\text { energy } \\
\text { between } \\
\text { wetlands and } \\
\text { the main } \\
\text { channel; } \\
\text { salmon forage. }\end{array}$ & $\begin{array}{l}\text { Total edge, } \\
\text { density, and } \\
\text { sinuousity of } \\
\text { floodplain and } \\
\text { tidal channels/ } \\
\text { organized by } \\
\text { subarea and } \\
\text { habitat type }\end{array}$ & $\begin{array}{l}\text { Digital aerial } \\
\text { photo/spectral } \\
\text { data/GIS }\end{array}$ & $\begin{array}{l}\text { Coats 1995; } \\
\text { Williams and Orr } \\
\text { 2002; Williams et } \\
\text { al. 2002; Finkbeiner } \\
\text { 2003; Hood 2002; } \\
\text { Desmond et al. } \\
2000\end{array}$ & $\begin{array}{l}\text { Trends in the } \\
\text { amount of } \\
\text { wetland } \\
\text { channel edge }\end{array}$ & $\begin{array}{l}\text { Characterize } \\
\text { changes before and } \\
\text { after restoration } \\
\text { action; allometry: } \\
\text { relationships } \\
\text { between scale of } \\
\text { tidal channels and } \\
\text { ecological } \\
\text { patterns/processes, } \\
\text { e.g. Salmonid prey } \\
\text { production/foraging } \\
\text { associated with size } \\
\text { of restored tidal } \\
\text { channel }\end{array}$ \\
\hline Vegetation Cover & $\begin{array}{l}\text { Percent Cover by } \\
\text { Species }\end{array}$ & $\begin{array}{l}\text { Provides } \\
\text { classification } \\
\text { of native and } \\
\text { non-native } \\
\text { vegetation }\end{array}$ & $\begin{array}{l}\text { Presence/ } \\
\text { absence of } \\
\text { rooted vascular } \\
\text { plant species; } \\
\text { percent cover; } \\
\text { species } \\
\text { composition }\end{array}$ & $\begin{array}{l}\text { Hyperspectral } \\
\text { imagery and/or } \\
\text { digital aerial } \\
\text { photography; field } \\
\text { survey }\end{array}$ & $\begin{array}{l}\text { Garano et al. 2003; } \\
\text { Thom et al. 2002; } \\
\text { Finkbeiner et al. } \\
\text { 2003; Dr. Dana } \\
\text { Woodruff, personal } \\
\text { communication; } \\
\text { Osprey } \\
\text { Environmental } \\
\text { Services 1996; } \\
\text { Williams 1989 }\end{array}$ & $\begin{array}{l}\text { Trends in } \\
\text { percent cover } \\
\text { by plant type } \\
\text { over time }\end{array}$ & $\begin{array}{l}\text { Compare plant } \\
\text { cover before and } \\
\text { after action at a } \\
\text { specific site }\end{array}$ \\
\hline Food Web & Foraging Success & & $\begin{array}{l}\text { Index of food } \\
\text { habits of } \\
\text { juvenile salmon }\end{array}$ & $\begin{array}{l}\text { Stomach contents } \\
\text { analysis }\end{array}$ & $\begin{array}{l}\text { Murphy and Willis } \\
\text { 1996; Roegner et al. } \\
\text { In Preparation; } \\
\text { Bottom et al. } 1984\end{array}$ & $\begin{array}{l}\text { Trends in } \\
\text { foraging } \\
\text { success over } \\
\text { time } \\
\end{array}$ & $\begin{array}{l}\text { Identify fish prey } \\
\text { and success at a } \\
\text { restored site }\end{array}$ \\
\hline
\end{tabular}




\begin{tabular}{|c|c|c|c|c|c|c|c|}
\hline Category & $\begin{array}{l}\text { Monitored } \\
\text { Indicator(s) }\end{array}$ & Description & Description 2 & $\begin{array}{l}\text { Data Collection } \\
\text { Method }\end{array}$ & Example Protocol & $\begin{array}{l}\text { Use in Status } \\
\text { Monitoring }\end{array}$ & $\begin{array}{l}\text { Use in Action } \\
\text { Effectiveness } \\
\text { Research }\end{array}$ \\
\hline Food Web & Predation Index & & $\begin{array}{l}\text { Relative } \\
\text { approximation } \\
\text { of the amount of } \\
\text { predation on } \\
\text { juvenile salmon }\end{array}$ & $\begin{array}{l}\text { Sampling of } \\
\text { distribution and } \\
\text { abundance and } \\
\text { analysis of gut } \\
\text { contents of } \\
\text { predators }\end{array}$ & $\begin{array}{l}\text { Zimmerman and } \\
\text { Ward } 1999\end{array}$ & $\begin{array}{l}\text { Trends in } \\
\text { predation } \\
\text { indices over } \\
\text { time }\end{array}$ & $\begin{array}{l}\text { Monitor to assess } \\
\text { effects of actions, } \\
\text { depending on } \\
\text { project objectives }\end{array}$ \\
\hline Food Web & Prey Availability & & $\begin{array}{l}\text { Type and energy } \\
\text { content of prey } \\
\text { items }\end{array}$ & $\begin{array}{l}\text { Prey samplers } \\
\text { such as } \\
\text { zooplankton nets, } \\
\text { bottom corers, } \\
\text { neuston nets. }\end{array}$ & $\begin{array}{l}\text { Simenstad et al. } \\
\text { 1991; Taylor et al. } \\
\text { 2003; Tranter and } \\
\text { Fraser } 1974\end{array}$ & $\begin{array}{l}\text { Trends in prey } \\
\text { availability } \\
\text { over time }\end{array}$ & $\begin{array}{l}\text { Identify prey } \\
\text { production/presence } \\
\text { at a restored site }\end{array}$ \\
\hline $\begin{array}{l}\text { Primary } \\
\text { Production }\end{array}$ & $\begin{array}{l}\text { Primary Production } \\
\text { Index }\end{array}$ & $\begin{array}{l}\text { A measure of } \\
\text { the rate of } \\
\text { organic matter } \\
\text { production } \\
\text { from } \\
\text { photosynthesis }\end{array}$ & & & & & \\
\hline $\begin{array}{l}\text { Salmonid } \\
\text { Performance }\end{array}$ & Abundance & & & & & & \\
\hline $\begin{array}{l}\text { Salmonid } \\
\text { Performance }\end{array}$ & Age/Size-Structure & $\begin{array}{l}\text { Reveals the } \\
\text { life history } \\
\text { strategy by } \\
\text { species. }\end{array}$ & $\begin{array}{l}\text { Age of juvenile } \\
\text { salmon present. } \\
\text { Expressed as life } \\
\text { stage (fry, } \\
\text { fingerling, } \\
\text { subyearling, } \\
\text { yearling) }\end{array}$ & $\begin{array}{l}\text { Scale and otolith } \\
\text { analysis of fish } \\
\text { captured in beach } \\
\text { and purse seines, } \\
\text { trap nets }\end{array}$ & $\begin{array}{l}\text { Murphy and Willis } \\
\text { 1996; Roegner et al. } \\
\text { In Preparation; Rice } \\
\text { et al. In Preparation }\end{array}$ & $\begin{array}{l}\text { Trends in age } \\
\text { structure over } \\
\text { time }\end{array}$ & $\begin{array}{l}\text { Identify age } \\
\text { structure of juvenile } \\
\text { salmon using a } \\
\text { restored site }\end{array}$ \\
\hline $\begin{array}{l}\text { Salmonid } \\
\text { Performance }\end{array}$ & Distribution: Spatial & $\begin{array}{l}\text { Describes } \\
\text { where the } \\
\text { juvenile } \\
\text { salmon are, } \\
\text { i.e., which } \\
\text { habitats they } \\
\text { are using }\end{array}$ & $\begin{array}{l}\text { Where juvenile } \\
\text { salmon are } \\
\text { located in the } \\
\text { estuary }\end{array}$ & $\begin{array}{l}\text { Telemetry, nets, } \\
\text { seines }\end{array}$ & $\begin{array}{l}\text { Murphy and Willis } \\
\text { 1996; Roegner et al. } \\
\text { In Preparation; } \\
\text { Thorpe et al. 1981; } \\
\text { Skalski et al. 2001 }\end{array}$ & $\begin{array}{l}\text { Trends in } \\
\text { spatial } \\
\text { distribution } \\
\text { over time }\end{array}$ & $\begin{array}{l}\text { Determine where } \\
\text { salmon are located } \\
\text { at a restored site }\end{array}$ \\
\hline $\begin{array}{l}\text { Salmonid } \\
\text { Performance }\end{array}$ & Distribution: Temporal & $\begin{array}{l}\text { Provides data } \\
\text { on when the } \\
\text { fish are present } \\
\text { in the estuary. }\end{array}$ & $\begin{array}{l}\text { When juvenile } \\
\text { fish are present } \\
\text { and abundance } \\
\text { peaks }\end{array}$ & $\begin{array}{l}\text { Periodic sampling } \\
\text { w/ beach and } \\
\text { purse seines, trap } \\
\text { nets; tagging and }\end{array}$ & $\begin{array}{l}\text { Murphy and Willis } \\
\text { 1996; Skalski et al. } \\
\text { 2001; Rice et al. In } \\
\text { Press }\end{array}$ & $\begin{array}{l}\text { Trends in } \\
\text { temporal } \\
\text { distribution } \\
\text { over time }\end{array}$ & $\begin{array}{l}\text { Identify when } \\
\text { juvenile salmon are } \\
\text { using a restored site }\end{array}$ \\
\hline
\end{tabular}




\begin{tabular}{|c|c|c|c|c|c|c|c|}
\hline Category & $\begin{array}{l}\text { Monitored } \\
\text { Indicator(s) }\end{array}$ & Description & Description 2 & $\begin{array}{l}\text { Data Collection } \\
\text { Method }\end{array}$ & Example Protocol & $\begin{array}{l}\text { Use in Status } \\
\text { Monitoring }\end{array}$ & $\begin{array}{l}\text { Use in Action } \\
\text { Effectiveness } \\
\text { Research }\end{array}$ \\
\hline & & $\begin{array}{l}\text { The } \\
\text { combination of } \\
\text { species } \\
\text { composition, } \\
\text { age-structure, } \\
\text { and temporal } \\
\text { distribution } \\
\text { characterizes } \\
\text { life history } \\
\text { diversity. }\end{array}$ & & tracking & & & \\
\hline $\begin{array}{l}\text { Salmonid } \\
\text { Performance }\end{array}$ & Growth Rate & $\begin{array}{l}\text { Calculated as } \\
\text { the change in } \\
\text { length or } \\
\text { weight of the } \\
\text { sampled } \\
\text { juvenile } \\
\text { salmon } \\
\text { population per } \\
\text { unit time }\end{array}$ & $\begin{array}{l}\text { Amount of } \\
\text { weight gained } \\
\text { (lost) on average } \\
\text { by juvenile } \\
\text { salmon per unit } \\
\text { time }\end{array}$ & $\begin{array}{l}\text { Weighing fish } \\
\text { captured in } \\
\text { periodic sampling } \\
\text { w/ beach and } \\
\text { purse seines, trap } \\
\text { nets }\end{array}$ & $\begin{array}{l}\text { Murphy and Willis } \\
\text { 1996; Roegner et al. } \\
\text { In Preparation }\end{array}$ & $\begin{array}{l}\text { Trends in } \\
\text { growth rates } \\
\text { over time by } \\
\text { habitat type }\end{array}$ & $\begin{array}{l}\text { Determine } \\
\text { biological benefit } \\
\text { from a restored site }\end{array}$ \\
\hline $\begin{array}{l}\text { Salmonid } \\
\text { Performance }\end{array}$ & Migration Pathways & $\begin{array}{l}\text { Characterizes } \\
\text { the corridors } \\
\text { where juvenile } \\
\text { salmon } \\
\text { predominately } \\
\text { are found } \\
\text { migrating } \\
\text { downstream } \\
\end{array}$ & $\begin{array}{l}\text { Primary routes } \\
\text { of passage } \\
\text { during } \\
\text { outmigration } \\
\text { through the } \\
\text { estuary }\end{array}$ & Telemetry & $\begin{array}{l}\text { Murphy and Willis } \\
\text { 1996; Thorpe et al. } \\
\text { 1981; Skalski et al. } \\
2001\end{array}$ & $\begin{array}{l}\text { Trends in } \\
\text { migration } \\
\text { pathways over } \\
\text { time }\end{array}$ & $\begin{array}{l}\text { Determine if a } \\
\text { restored site is part } \\
\text { of a migration } \\
\text { pathway }\end{array}$ \\
\hline $\begin{array}{l}\text { Salmonid } \\
\text { Performance }\end{array}$ & Residence Time & $\begin{array}{l}\text { Shows the } \\
\text { amount of time } \\
\text { juvenile } \\
\text { salmon spend } \\
\text { in the estuary }\end{array}$ & $\begin{array}{l}\text { Amount of time } \\
\text { juvenile salmon } \\
\text { inhabit } \\
\text { particular areas }\end{array}$ & Telemetry & $\begin{array}{l}\text { Murphy and Willis } \\
\text { 1996; Thorpe et al. } \\
\text { 1981; Skalski et al. } \\
2001\end{array}$ & $\begin{array}{l}\text { Trends } \\
\text { residence time } \\
\text { over time by } \\
\text { habitat type }\end{array}$ & $\begin{array}{l}\text { Determine } \\
\text { biological benefit } \\
\text { from a restored site }\end{array}$ \\
\hline $\begin{array}{l}\text { Salmonid } \\
\text { Performance }\end{array}$ & Species Composition & $\begin{array}{l}\text { Data on which } \\
\text { salmon are } \\
\text { present. }\end{array}$ & $\begin{array}{l}\text { Which salmon } \\
\text { species are } \\
\text { present }\end{array}$ & $\begin{array}{l}\text { Examination of } \\
\text { fish captured in } \\
\text { beach and purse } \\
\text { seines, trap nets }\end{array}$ & $\begin{array}{l}\text { Murphy and Willis } \\
\text { 1996; Roegner et al. } \\
\text { In Preparation; Rice } \\
\text { et al. In Preparation }\end{array}$ & $\begin{array}{l}\text { Trends in } \\
\text { species } \\
\text { composition } \\
\text { over time }\end{array}$ & $\begin{array}{l}\text { Identify species } \\
\text { present at a restored } \\
\text { site }\end{array}$ \\
\hline Salmonid & Stock Identity & Genetic & Composition of & Genetic analysis & Murphy and Willis & Trends over & Identify the ESUs \\
\hline
\end{tabular}




\begin{tabular}{|c|c|c|c|c|c|c|c|}
\hline Category & $\begin{array}{l}\text { Monitored } \\
\text { Indicator(s) }\end{array}$ & Description & Description 2 & $\begin{array}{l}\text { Data Collection } \\
\text { Method }\end{array}$ & Example Protocol & $\begin{array}{l}\text { Use in Status } \\
\text { Monitoring }\end{array}$ & $\begin{array}{l}\text { Use in Action } \\
\text { Effectiveness } \\
\text { Research }\end{array}$ \\
\hline Performance & & $\begin{array}{l}\text { analyses to } \\
\text { determine } \\
\text { ESU. }\end{array}$ & $\begin{array}{l}\text { juvenile salmon } \\
\text { pop. classified } \\
\text { by ESU }\end{array}$ & $\begin{array}{l}\text { of fish captured } \\
\text { for sp. comp. }\end{array}$ & $\begin{array}{l}\text { 1996; Teel et al. } \\
2000\end{array}$ & $\begin{array}{l}\text { time in the } \\
\text { ESUs } \\
\text { inhabiting the } \\
\text { study area }\end{array}$ & $\begin{array}{l}\text { for juvenile salmon } \\
\text { using a restored site }\end{array}$ \\
\hline $\begin{array}{l}\text { Salmonid } \\
\text { Performance }\end{array}$ & Survival Rate & $\begin{array}{l}\text { Estimated for } \\
\text { juveniles of } \\
\text { selected } \\
\text { species and life } \\
\text { history types } \\
\text { for the reach } \\
\text { from } \\
\text { Bonneville } \\
\text { Dam to the CR } \\
\text { mouth, and } \\
\text { also for } \\
\text { selected areas } \\
\text { of the estuary }\end{array}$ & $\begin{array}{l}\text { Proportion of } \\
\text { total population } \\
\text { entering an area } \\
\text { that are alive } \\
\text { when they leave }\end{array}$ & $\begin{array}{l}\text { Acoustic tag fish } \\
\text { and survival } \\
\text { estimation using a } \\
\text { single release- } \\
\text { recapture model }\end{array}$ & $\begin{array}{l}\text { Acoustic tagging in } \\
\text { Thorpe et al. 1981; } \\
\text { survival estimation } \\
\text { in Burnham et al. } \\
\text { 1987; Skalski et al. } \\
2001\end{array}$ & $\begin{array}{l}\text { Trends in } \\
\text { survival rates } \\
\text { over time }\end{array}$ & $\begin{array}{l}\text { Monitor to assess } \\
\text { effects of actions, } \\
\text { depending on } \\
\text { project objectives }\end{array}$ \\
\hline
\end{tabular}




\section{Appendix D: Abbreviations, Acronyms, and Glossary}

\section{Abbreviations and Acronyms}

AA - action agencies

AER - action effectiveness research

AFEP - Anadromous Fish Evaluation Program

BPA - Bonneville Power Administration

cfs - cubic feet per second

CRCIP - Columbia River Channel

Improvement Project

CRE -Columbia River Estuary (RM 0-146)

CREDDP - Columbia River Estuary Data

Development Program

CREST - Columbia River Estuary Study

Taskforce

CSMEP - Collaborative Systemwide

Monitoring and Evaluation Program

CUR - critical uncertainties research

DFO - Department of Fisheries and Oceans

EMAP -Environmental Monitoring and

Assessment Program

ENSO - El Nino Southern Oscillation

EOS - Estuary/Ocean Subgroup (for RME)

EPA - Environmental Protection Agency

ESA - Endangered Species Act

ESU - evolutionarily significant unit

FCRPS - Federal Columbia River Power

System

GIS - geographic information system

ICM - implementation and compliance monitoring

ISAB - Independent Scientific Advisory Board

ISRP -- Independent Scientific Review Panel

LCFRB - Lower Columbia River Fish Recovery Board

LCREP - Lower Columbia River Estuary Program

MCR - Mouth of the Columbia River

NED - Northwest Environmental Data network

NWFSC - Northwest Fisheries Science Center

NMFS - National Marine Fisheries Service (now called NOAA Fisheries)

NOAA - National Oceanic and Atmospheric Administration
NPCC - Northwest Power and Conservation Council (formerly Northwest Power Planning Council)

NRC - National Research Council

ODEQ - Oregon Department of Environmental Quality

ODFW - Oregon Dept. Fish and Wildlife

ORD - EPA Office of Research and

Development

OSU - Oregon State University

OWEB - Oregon Watershed Enhancement

Board

PDO - Pacific Decadal Oscillation

PIT - passive integrated transponder

PNAMP - Pacific Northwest Aquatic

Monitoring Partnership

PNNL - Pacific Northwest National Laboratory

PSU - Portland State University

$\mathbf{R M}$ - river mile

RME - research, monitoring, and evaluation

SE - synthesis and evaluation

STM - status and trends monitoring

UI - University of Idaho

UCTRT - Upper Columbia Technical Recovery Team

USACE - U.S. Army Corps of Engineers

USFWS - U.S. Fish and Wildlife Service

USGS - U.S. Geological Survey

UW - University of Washington

WDE - Wash. Dept. Ecology

WDFW - Wash. Dept. Fish and Wildlife

WRDA - Water Resources Development Act

WSRFB - Washington Salmon Recovery

Funding Board 


\section{Glossary}

action effectiveness research - Research to determine the effects of an action or suite of actions on fish survival, productivity and/or habitat conditions (referred to as Tier 3 monitoring). This is a manipulative experiment that statistically assesses the effect of a treatment (action) condition relative to a control or reference condition (BPA 2005).

adaptive management - A structured learning process for testing hypotheses through management experiments in natural systems, collecting and interpreting new information, and making changes based on monitoring information to improve the management of ecosystems; i.e., "learning by doing" (Busch and Trexler 2003).

allometry - A system is allometric when the relative rate of change of one part of a system is proportional to the relative rate of change of another part of the system, or of the whole system (Hood 2002).

attribute - Frequently called "metric" or "parameter," this is the specific variable that is measured to assess the response of the system, e.g. "percent cover" or "survival."

census - A complete and thorough collection of data on the population at hand.

Columbia River estuary - the tidally influenced portion of the river and its tributaries from Bonneville Dam to and including the plume. Lower Columbia River tributary watersheds, such as the Cowlitz and Lewis rivers, and the Willamette River upstream of the Multnomah Channel are not part of the Estuary Program's study area.

conceptual ecosystem model - A graphical representation or a simple set of diagrams that illustrate a set of relationships among factors important to the function of an ecosystem or its subsystems (Busch and Trexler 2003).

connectivity - See "habitat connectivity."

conservation -- Maintenance of biodiversity (Meffe et al. 1994).

controlling factors - The basic physical and chemical conditions that construct and influence the structure of the ecosystem.

control site - Locations with traits similar to the subject site prior to restoration. These sites are sampled over time to monitor any temporal shifts in baseline conditions and how the subject area might have responded over time had no restoration taken place.

core indicators - A standard subset of the suite of possible indicators that is always measured at sample locations (Busch and Trexler 2003). They must be relevant to the objective.

creation -- Bringing into being a new ecosystem that previously did not exist on the site (NRC 1992). critical uncertainties research - Research to resolve scientific uncertainties regarding the relationships between fish or wildlife health, population performance (abundance, survival, productivity, distribution, diversity), habitat conditions, life history, and/or genetic conditions (e.g., the existence and causes of delayed mortality, hatchery spawner reproductive success relative to wild populations, etc.). This is a manipulative experiment where variables are manipulated to infer or demonstrate cause and effect relationships using statistically designed hypothesis testing. Uncertainties research does not include 
experimental research and monitoring specifically targeting the effect of a mitigation or restoration action (this is Action Effectiveness Research). It also does not include monitoring (observational studies) of fish or habitat conditions with inferences from statistical correlation assessments (this is Status and trends Monitoring) (from BPA 2005).

disturbance - Any relatively discrete event in time that disrupts or alters some portion or portions of an ecosystem.

ecosystem - A community of organisms in a given area together with their physical environment and its characteristic climate.

ecosystem function - Ecosystem function is defined as the role the plant and animal species play in the ecosystem. It includes primary production, prey production, refuge, water storage, nutrient cycling, etc.

ecosystem process - Ecosystem processes are any interaction among physicochemical and biological elements of an ecosystem that involve changes in character or state.

ecosystem structure - Ecosystem structure is defined as the types, distribution, abundances, and physical attributes of the plant and animal species comprising the ecosystem.

effectiveness monitoring - Activities designed and undertaken to assess how well a particular restoration project performs relative to the reference site(s).

enhancement -- Any improvement of a structural or functional ecosystem attribute (NRC 1992).

estuary turbidity maxima - Circulation phenomena in an estuary that traps particles and promotes biogeochemical, microbial and ecological processes that sustain a dominant pathway in the estuary's food web (from http://depts.washington.edu/cretmweb/).

evolutionarily significant unit - A population that 1) is substantially reproductively isolated from conspecific populations and 2) represents an important component in the evolutionary legacy of the species (Johnson et al. 1994). Seventeen ESUs have been designated and mapped in the Pacific salmon range in California, Washington, Oregon, and Idaho. Each unit generally includes a major river basin such as the Snake or Sacramento Rivers or a section of coastline that may include several river basins as in the California Central Coast ESU.

extensive monitoring - monitoring of a few selected core indicators over a large spatial scale.

habitat - The physical, biological, and chemical characteristics of a specific unit of the environment occupied by a specific plant or animal.

habitat capacity - A category of habitat assessment metrics including "habitat attributes that promote juvenile salmon production through conditions that promote foraging, growth, and growth efficiency, and/or decreased mortality," for example, invertebrate prey productivity, salinity, temperature, and structural characteristics (cf. Simenstad and Cordell 2000).

habitat connectivity - A measure of how connected or spatially continuous a corridor between habitats or among habitats in a matrix is.

habitat opportunity - A category of habitat assessment metrics that "appraise the capability of juvenile salmon to access and benefit from the habitat's capacity," for example, tidal elevation and geomorphic features (cf. Simenstad and Cordell 2000). 
habitat usage - Measures of juvenile salmonid/habitat relationships in the estuary such as residence time, growth, and diet.

hydrogeomorphic reach - The third of six hierarchical levels comprising the Columbia River estuarine Ecosystem Classification System. This level partitions the Columbia River estuary into eight segments based on the EPA Ecoregion level IV, modified to incorporate positions of maximum (historic) salinity intrusion, transitions in maximum flood (pre-regulation) tide level, upstream extent of current reversal (predicted current tables), and convergence with major tributaries and slough systems. (Definition provided by C. Simenstad, UW.)

implementation and compliance monitoring - Monitoring the execution and outcomes of projects. This type of monitoring does not require environmental response data directly linking restoration actions to physical, chemical, or biological responses.

indicator - A measurable parameter that characterizes an important aspect of the ecosystem and is sensitive to changes in the system.

intensive monitoring - monitoring of many core and higher order indicators locally, i.e., over a small spatial scale.

life history diversity - Different spatial and temporal patterns of migration, habitat use, spawning, and rearing displayed within a population of Pacific salmon.

limiting factor - Physical, chemical, or biological features that impede species and their independent populations from reaching viability status.

meso-tidal estuary - Where tides have a strong, but not necessarily dominant, influence on the estuarine environment (typical range $2-4 \mathrm{~m}$ ).

monitoring - The systematic process of sampling design, collection, storage, and analysis of data related to a particular system at specific locations and times (Busch and Trexler 2003).

monitored indicator-See "indicator."

ocean-type life history - General life history pattern for salmon in which juveniles migrate to sea during their first year after emergence.

oligohaline - Water having low salinity.

performance -- An indicator of the state of anadromous salmonid populations and their habitats. Performance can be defined by growth, foraging success, spatial structure, life history diversity, and habitat conditions.

performance standard - Also called "performance criteria," a specified numerical objective deemed necessary to improve ecosystem function, improve salmon survival, and ultimately result in recovery for listed fish. A performance standard can be expressed as an absolute quantitative target, a range, or a change in condition from some baseline. The Estuary Program does not have performance standards at this time, except that progress toward the survival benefits from estuary habitat actions defined in the 2007 Biological Opinion will be assessed.

plume - The surface layer of Columbia River water in the Pacific Ocean. By definition in estuary RME, the plume is part of the Columbia River estuary. 
population viability - Measure of the status of anadromous salmonids used by NOAA Fisheries and defined using four performance criteria: abundance, productivity, spatial structure, and life historydiversity. The latter two criteria are an "especially critical portion of the role of the estuary" (Fresh et al. 2004).

protection - Ensuring that existing ecosystem structures, processes, and functions including salmonid habitat relationships are not degraded.

protocol - The standardized methodology to collect data for a monitoring indicator (Busch and Trexler 2003).

realized function - A category of habitat assessment metrics that includes any direct measures of physiological or behavioral responses that can be attributable to fish occupation of the habitat and that promote fitness and survival; for example, survival, habitat-specific residence time, foraging success, and growth (cf. Simenstad and Cordell 2000).

reference site - Locations considered to be representative of the desired outcome of the restoration action. Reference sites are used to characterize the spatial heterogeneity of the target condition and any temporal shift in the target condition over time due to climate change, maturation, etc.

restoration -- Return of an ecosystem to a close approximation of its previously existing condition (NRC 1992).

sample -- To collect data under a prescribed sampling design.

status and trends monitoring - Census or statistically designed monitoring of fish or wildlife population and/or environmental conditions (i.e. watershed conditions) to assess the current status (at a particular time) or trend (over time) (BPA 2005).

stream-type life history - General life history pattern for salmon in which juveniles migrate to sea after one year of rearing in their natal stream system.

stressor - An entity or process that is external to the estuary or anthropogenic and that affects controlling factors on estuarine ecosystem structures or processes. A component of a conceptual model.

subarea - A portion of a larger area that has unique characteristics.

track -- To access, assess, and summarize information made available by others.

validation monitoring - Monitoring directed at testing cause-and-effect relationsips between management activities and monitoring indicators (Busch and Trexler 2003).

vibracores - Systems using vibration technology to collect sediment core samples in deepwater and shallow-water environments, which range from hand-held devices to commercial systems powered by hydraulics and pneumatics operated from a lifting tower on a vessel. 
Research, Monitoring, and Evaluation for the Federal Columbia River Estuary Program 